Golo Föllmer, Alexander Badenoch (eds.)

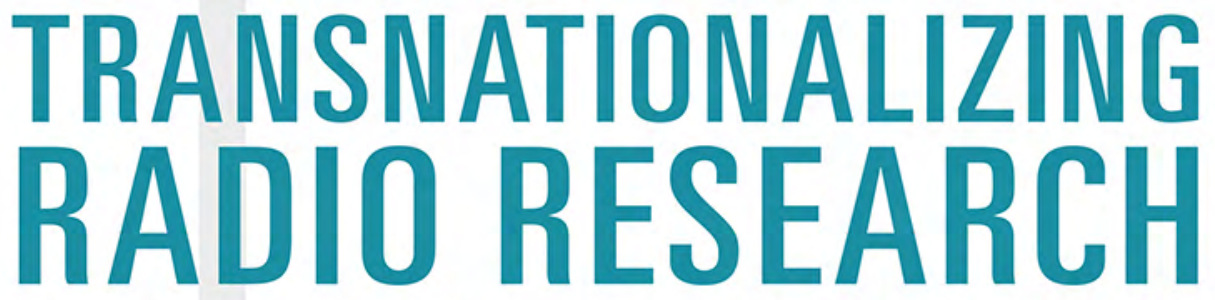
NEW APPROACHES TO AN OLD MEDIUM

[transcript] Media Studies 
Golo Föllmer, Alexander Badenoch (eds.)

Transnationalizing Radio Research

Media Studies | Volume 42 

Golo Föllmer, Alexander Badenoch (eds.)

\section{Transnationalizing Radio Research}

New Approaches to an Old Medium

[transcript] 
Bibliographic information published by the Deutsche Nationalbibliothek

The Deutsche Nationalbibliothek lists this publication in the Deutsche Nationalbibliografie; detailed bibliographic data are available in the Internet at http://dnb.d-nb.de

\section{(c) $(1)(\Theta)$}

This work is licensed under the Creative Commons Attribution-NonCommercial-NoDerivatives 4.0 (BY-NC-ND) which means that the text may be used for non-commercial purposes, provided credit is given to the author. For details go to http://creativecommons.org/licenses/by-nc-nd/4.0/

To create an adaptation, translation, or derivative of the original work and for commercial use, further permission is required and can be obtained by contacting rights@ transcript-verlag.de

Creative Commons license terms for re-use do not apply to any content (such as graphs, figures, photos, excerpts, etc.) not original to the Open Access publication and further permission may be required from the rights holder. The obligation to research and clear permission lies solely with the party re-using the material.

\section{(C) 2018 transcript Verlag, Bielefeld}

Cover layout: Maria Arndt, Bielefeld

Typeset: Anja Richter

Printed by Majuskel Medienproduktion $\mathrm{GmbH}$, Wetzlar

Print-ISBN 978-3-8376-3913-1

PDF-ISBN 978-3-8394-3913-5 


\section{Contents}

\section{INTRODUCTION}

Transnationalizing Radio Research:

New Encounters with an Old Medium

Alexander Badenoch and Golo Föllmer | 11

\section{Section 1:}

Asserting identity: Minorities' Use of Community Radio

Community Radio and Transnational Identities

Caroline Mitchell and Peter M. Lewis | 33

Accented Radio in Miami and New Orleans

Katie Moylan $\mid 47$

Radio, Refugees and Migrants Workshop:

TRE Conference, Utrecht, 2016 | 57

You Can't Tell My Story for Me!

Community Media as a Means of Expression in Multilingual Local and Globalized Contexts

Judith Purkarthofer $\mid 59$

Desi Radio by and for the Panjabi Community: Citizens' Media, Gender, and Participation

Nazan Haydari $\mid 65$

Gaywaves: Transcending Boundaries - the Rise and Demise of Britain's First Gay Radio Program

Paul Wilson and Matthew Linfoot | 73 


\section{SECTION 2:}

Transnational Communities of Aesthetic Practice

Transnational Encounters and Peregrinations of the Radio Documentary Imagination

Virginia Madsen $\mid 83$

Production and Use of Packaging Elements in Radio:

Concepts, Functions and Styles in Transnational Comparison

Golo Föllmer | 101

Makrolab as an Apparatus for Global Observation

Heather Contant | 117

Transcultural Audio Storytelling: When

German, Australian and African Voices Meet

Siobhán McHugh | 125

\section{SECTION 3:}

Staging Encounters: Translating Places and Identities

A Transnational Approach to Radio Amateurism in the 1910s Maria Rikitianskaia | 133

Radiophonic Cities

The City Portrait in Transnational Radio Collaborations

Jacob Kreutzfeldt | 143

European Music?

The International Broadcasting Union's 1930s Concert Series Concerts Européens

Morten Michelsen | 155

From Enzensberger to Clausen: An Auditive Transformation Ib Poulsen $\mid 163$ 


\section{SECTION 4:}

Doing Transnational Radio Research and the Digital Archive

Transnational Radio Research and the Digital Archive:

Promises and Pitfalls

Sonja de Leeuw $\mid 171$

Cultural Memory in the Digital Age

Nanna Bonde Thylstrup | 183

Worlding the Archive:

Radio Collections, Heritage Frameworks, and Selection Principles

Carolyn Birdsall | 197

Radio Diffusion: Re-collecting International Broadcasting in the Archive of Radio Netherlands Worldwide

Alexander Badenoch | 209

Promising Prospects, and the Hurdles Along the Way:

Sharing and Archiving Community Media Content Online Joost van Beek | 223

\section{SECTION 5:}

Digital Radio Landscapes - Transnational Challenges, National SOLUTIONS?

Making DAB Work: New Opportunities for Digital Radio in Europe Lawrie Hallett | 233

Opening up the Debate: Irish Radio, Facebook, and the Creation of Transnational Cultural Public Spheres

Daithí McMahon | 247

New Radio and Social Media:

Public Service Radio Forms of User Participation and Inclusion

Per Jauert | 257

The Role of Boundary Objects in Collaborative Radio Production Bruce Berryman | 271 
Researching Podcast Production - an Australian Podcast Study About Women and Work in Are We There Yet?

Mia Lindgren $\mid 283$

Surveying International Public Radio: Some Practical Insights

David Fernández-Quijada | 293

\section{OUtro}

The Future of Radio Studies

Michele Hilmes and Mia Lindgren | 301 


\section{INTRODUCTION}





\title{
Transnationalizing Radio Research
}

\author{
New Encounters with an Old Medium
}

\section{Alexander Badenoch and Golo Föllmer}

Over the course of the last decade, radio scholars have increasingly demonstrated that radio has long been entwined in networks and relationships beyond those framed by nations - and that even the national structures of radio were formed in transnational processes (Hilmes 2004, 2012; Fickers 2012b; Lommers 2012; Cronqvist and Hilgert 2017; Vaillant 2017). Building on these insights, as well as results of current state-of-the-art research, Transnationalizing Radio Research presents a theoretical, methodological and historical guide to 'going transnational' (Saunier 2006) in radio research. It explores various key transnational arenas, issues, and encounters that structure, and are structured by, radio. For radio scholars, it aims to provide both inspiration and concrete tools for breaking through the methodological nationalism that in many ways still structures our research. For scholars and students in related disciplines, this book provides insights and tools that will allow them to incorporate radio's vital voices into their broader investigations of transnational institutions, communities, histories and identities.

There were, and are, of course good reasons for framing radio research nationally, especially in Europe. National institutions have remained important players in media industries, and nations have provided important frameworks. When it comes to methods, it was also a question of relative ease. Before the digital revolution, most sources could only be accessed on site: transnational research often meant international travel; knowing your way around the relevant archives was not an easy task for a foreigner; and in certain cases access is still today only granted to locally employed scholars, at least on a manageable and affordable basis. Even more importantly, it often proved so much easier to approach a question if you had a natural understanding of the radio landscape in which your subject was located, that is: if you had grown up in the midst of its structural conditions, listening to it and thus acquiring an intuitive understanding of its workings and specificities. After all, as Michele Hilmes pointed out, since radio's original conditions were defined in an era of nationalism, "state/public broadcasters defined their mission as promoting, protecting, and 
producing their own distinct national identities through the means of radio programming, carefully addressing their own national publics and screening out unwelcome, foreign influences." (Hilmes 2004: iv) Above all, of course you had to speak the local language at a high level in order not to run into misunderstandings.

Given such difficulties, why take a transnational approach all? The simplest answer to this is that we live - and have lived - in a transnational world, and radio is intricately interwoven within the various transnational flows that structure it. Our communities and experiences, our mediated and material surroundings, not to mention many of the major issues filling our newspapers and public debates, all reflect connections that span across national borders. Nearly two decades ago, David Hendy (2000) spoke of "Radio in the Global Age" - but of course radio has been implicated in many globalizing arenas since its earliest years.

The transnational historian Pierre-Yves Saunier (2013) highlights three characteristic uses of transnational approaches, each of which has specific counterparts in the study of radio. First, it asks specific questions about the rise, change and occasional demise in connections between different communities, polities and societies - to which we could fruitfully add 'audiences' - to start to give "an empirical answer to what is, and when was, globalization". (Saunier 2013: 3) Translating this concern to radio studies, it means developing and maintaining a view of radio as a rich ecology entwined on multiple scales, through which a number of relationships can be traced. What things actually travel on a global scale? Who does 'the global' really reach and in what form? Second, because transnational approaches focus on exchanges, flows and projections across the boundaries of the entities often considered 'natural' units of analysis (the city, the nation, the continent, the globe), they help us to gain a much subtler view of what actually makes up these entities as structures, processes or experiences. What does it mean, at any given point in time and space, to be 'national' in the first place? Quite apart from the study of nations, this also helps us to come to grips with the medium of radio as well. As scholars have pointed out increasingly during the last decade, a transnational approach to radio research helps identify more precisely the medium-specific qualities of radio, since only the greater picture of different local, regional, national or continental radio cultures in comparison enables researchers to evaluate whether their observed standard is specific to the medium, and not primarily for instance to a specific social or political sphere. A transnational perspective also helps identify peculiarities which would not catch one's eye (or ear) without a comparative approach. Taking a transnational perspective can also alert us to the ways practitioners themselves come to cross-cultural understandings of what the medium is and does, as in the interactions between the BBC and US broadcasters (Hilmes 2012) the European Broadcasting Union's (EBU) radio 
program committee (Badenoch 2010). Zeroing in on such discussions raises a third aspect: transnational research opens up our analytical eye to patterns, organizations and people who have moved beyond and between those entities we normally take for granted and renders them visible. We are able to "recover the history of projects, individuals, groups, concepts, activities, processes and institutions that have often been invisible [...] because they have thrived in between, across and through polities and societies." (Saunier 2013: 3) Such actors and stories often take place beyond the margins of what often appears as 'mainstream' or hegemonic stories of broadcasting, and are especially prone to 'disappear' when they belong to ethnic or linguistic minorities, but also groups often under-represented in broadcasting, such as women. (Mitchell 2015; Skoog and Badenoch 2016; Birdsall 2017) There are a vast number of phenomena in radio which are transnational by nature, whether broadcasting and listening to international services via shortwave programming and listening (not to mention international broadcasters sharing audience research methods and data, eg. Zöllner 2005, and Quijada in this volume), community radio stations for diasporic or refugee communities, online radio distribution via stream and podcasting, the travel of program content and aesthetic practices, or peculiarities like collaborative productions across borders.

\section{Always Already Transnational}

In talking about radio as an 'old' medium, as we do in the title, we run both the risk of speaking of it as irrelevant or old-fashioned, or instead of harkening back to a specific, essential era of its existence when its form and meanings were fixed. (Lacey 2009) This 'essential' era tends to be the 'classical' era of radio, between its full social embedding as a point-to-mass medium, mostly received through loudspeakers (as opposed to headphones) in the home, and the advent of television. In Europe, this is roughly 1930-1960. Radio in this era is then often seen as serving the purpose revitalizing senses of the nation as an "imagined community" in Benedict Anderson's (1991) famous idea of a group of people imagining each other stepping forward together in time, and indeed strongly synchronizing the boundaries of the home with the boundaries of the nation, though in complicated ways (cf. Lacey 1996; Morley 2000). In other words, the very idea of the medium is bound up with the nation. Making radio 'old' by looking at it in longue durée through a transnational lens can quickly alter that idea. When radio first came into being - which it did in multiple forms, times and places (Ernst 2012; Balbi/Natale 2015; see also Rikitianskaia in this volume) - it was a technically obvious, but nevertheless a culturally baffling observation how effortlessly it crossed national borders, and how easily it covered and linked remote parts of the globe. The idea of radiogenic (or radiophonic) 
communication across geographical and cultural borders developed into utopian visions, into experimental wireless settings and into regular broadcasts, initiated to enable encounters of unusual qualities and to allow access to formerly unreachable sources of information and auditive experience. Utopian visions of radio uniting the world beyond borders have never been far away.

The BBC's international guide World Radio speculated that after the First Word War international broadcasting had "broken down countless decrepid [sic] and dangerous barriers" and looked to the medium to create a new, peaceful generation of world citizens, particularly through children's broadcasts.

By means of Continental relays the Children's Hour could become an hour of preparation for world citizenship. First-hand knowledge is the best means of promoting interest, and the child mind is so receptive when it is interested. Radio can bring this interest to the children, and with it the thought that the spirit of world friendship is growing stronger. ("World Citizenship and Radio" 1926)

Rudolf Arnheim famously emphasized the invigorating aesthetic experience and immediacy of vocal encounters, bringing foreign sounds and voices unusually close, allowing the listener to approach the source's intimate personal sphere: "This is the great miracle of wireless. The omnipresence of what people are singing or saying anywhere, the overlapping of frontiers, the conquest of spatial isolation, the importation of culture on the waves of the ether [...]" (Arnheim 1936: 14). Arnheim found great pleasure in the wireless world of transnational culture, where one could listen to pure sound and tune in to foreign national cultures: "If one listens in to an Italian station, one can still experience how speech sings." (Arnheim 1936: 31). This transnational promise of radio was materialized - if not always realized (Falkenberg 2005: 186) - during radio's 'classical' era in the form of tuning dials featuring foreign cities (Fickers 2012a). In his 1995 Nobel Prize acceptance speech, for example, the poet Seamus Heaney credited such a dial, along "those first encounters with the gutturals and sibilants of European speech," he discovered from turning it, "even though I did not understand what was being said," with starting him on "a journey into the wideness of the world beyond." (Heaney 1995) Radio, then has come with the promise of listening in to intended voices from over borders, but also to do what Kate Lacey called listening out: "an attentive and anticipatory communicative disposition" toward the broader unknown world. (Lacey 2013: 8)

Still decades later, the world of shortwave listening was still deeply rooted in this optimistic longing. As Grundig's 'shortwave primer', designed to market the firm's models at the beginning of the 1980 s, remarked, 
We have to learn to understand each other better by communicating better. Listening to radio internationally: that builds bridges between peoples and continents. That means: news and commentary the way foreign countries perceive them. Or language lessons directly from the Motherland. (Grundig Kurzwellenfibel, 1980: 3, translated by the authors)

Even while these grand visions of a connected, mutually attentive globe were being articulated, radio itself was increasingly taking on a material form (point to mass) and institutional structure (broadcasters and regulatory frameworks) that allied broadcasting closely with nations and nationalisms. Nevertheless, transnational aspects of radio continued in parallel, interwoven with national aspects, even as the medium evolved. As national broadcasting was being reestablished after the Second World War, cross-border reception was simultaneously re-formulated as a human right rather than a diplomatic provocation (cf. Hamelink 1994; Spohrer 2013). UNESCO's first director-general Julian Huxley insisted (somewhat in vain) in an urgent telegram to the powers discussing use of the shortwave band in 1948 that it was "uniquely adapted to free flow of ideas across borders [...] Universally accepted high frequency broadcasting plan is prerequisite to right of listeners everywhere to be informed about each other." (Huxley 1948, emphasis added) Beyond such explicitly transnational spheres, even the national systems of broadcasting were constantly shaped, challenged and contested by various transnational forces. When faced with commercial challenges, public service broadcasters in bodies like the European Broadcasting Union (EBU) and its pre-war predecessor the International Broadcasting Union (IBU) have turned constantly to transnational exchange and major simultaneous events to improve the quality of their offerings. (cf. Fickers and Lommers 2010; Badenoch 2013; Kreutzfeldt and Michelsen in this volume) As Caroline Mitchell and Peter Lewis outline here, transnational migrant and diasporic communities not served by either public service or commercial institutions have fruitfully turned to local community radio to foster new forms of participation and give voice to transnational communities and cultures. (cf. Lewis 2008)

This admittedly very Euro-centric historical sketch of some of radio's recurring transnationalisms highlights the fact that radio's transnational dimensions tend to be even more 'invisible' (Lewis/Booth 1990) than then 'regular' radio. As Jacob Kreutzfeld points out in this volume, drawing on the work of Arjun Appadurai (1996), radio has thus always been key in not just in imagined communities, but helping to form imagined worlds within various global mediascapes. Thus, as we will see, exploring the transnational aspects of radio requires a certain degree of 'un-learning' what we take for granted about radio and rethinking some of how we study it. With this book, we want to offer a conceptual and methodological toolkit for doing just that. Though broad in its focus, it neither intends to present a single global history, nor a single theoreti- 
cal framework, nor a complete cross-section of the diverse and incredibly fluid global radio landscape today. We would argue that the need to carefully situate radio demanded by a transnational approach would actually militate against such a single frame. Instead, it identifies a number of vital phenomena and questions touching upon the parallel national and transnational development of radio in its history and in its different facets and explores them through a number of conceptual overviews and an empirical case studies.

\section{TRANSNATIONAL/RADIO/ENCOUNTERS}

Even two decades ago, the term 'transnational' was already seen to be booming in academic scholarship - and indeed proliferating into a range of meanings and phenomena (Vertovec 1999) and indeed, as Kiran Patel (2015) has stated, historians who picked up the term were late to the discussion. Aimed at grasping the implications of transborder, globalizing flows, the term aimed to describe, variously, spatially dispersed diasporic communities, new forms of hybrid cultural belonging, the transborder reach and flow of capital and commodities, not to mention media content and a broad range of phenomena. Radio intersects with each one of these 'transnational' things in different ways: as a medium capable of quickly transcending national borders that can address geographically dispersed communities simultaneously; as a mode of cultural production based on both sound and language that can strengthen local bonds within transnational communities; as transnational institution (even when rooted in a nation or local community) generating transnational communities of practice and standardizing transnational sounds.

So in 'transnationalizing' our view of radio, we are explicitly broadening the horizons of what can be studied with radio, but also of the radio itself. Already a decade ago, reflecting on what was then a decade of radio studies, Kate Lacey insisted that the importance of studying radio lies not in placing it at the center of the inquiry, but in radically de-centering the radio. This means above all

the refusal to treat 'radio' as a discrete object, but to accommodate its porous and shifting boundaries, be that in terms of its technologies, its institutions, its texts, or its listeners. It is also an argument about contextualizing 'radio' in the broadest terms, understanding how the discourses of broadcasting have been interwoven with - produced by and reproducing - discourses of technology, class, gender, nation, public and private, sense perceptions and so on. (Lacey 2009: 22)

Relating this to the idea of transnational radio, rather than taking an a priori view of an 'essence' of radio, a transnational approach follows the way that transnational flows move through, shape, and are shaped by radio. To put this 
another way, just as our perceptions of 'nation' and 'culture' are observed to open up under a transnational lens, so does the concept of 'radio' itself. Once it was largely defined through its specifics of signal distribution via electromagnetic oscillations emitted and received terrestrially via antennas, through its one-to-many communication principles and through the use of a dedicated device for reception. The historians and media archaeologists mentioned above - not to mention contemporary observers (Brecht 1979) - have pointed out that none of these forms were either technological necessary, entirely exclusive of other forms, or uncontested in their becoming. Meanwhile, large market- and usage-related advantages of online distribution via audio streams and podcasting as well as new technical possibilities to realize participative, many-to-many approaches in radio production widen what once was radio to a larger set of media products, data formats and receptive uses. To put this another way: access to the means of sound production and distribution, and arenas of participation has never been greater. Software on literally any digital communication device can form a receiver, thus multiplying, mobilizing and modifying radio uses, for instance through options to personalize programming and radio listening time schedules individually.

The occasional breadth, bordering on to vagueness, of the term 'transnational' can be fruitful for exploding taken-for-granted categories as outlined above, but it does not always do more precise conceptual work in helping us to conceive of what is at stake in the encounters of radio. The authors assembled here offer many more precise tools, but here we want to briefly outline the concept of 'transculturality' in capturing and understanding these encounters. In the course of extending Benedict Anderson's challenge of the concept of nationality into the sphere of radio, 'transculturality' serves as a helpful concept to differentiate many encounters staged by radio. Wolfgang Welsch (1999) sketches the term as an answer to modernity's concepts of a) 'interculturality', which, in his eyes, acknowledged cultural differences, but failed to offer any solutions for integrating them, and b) 'multiculturality', which objects to the desire to delimit national cultures from each other, but holds tight to the ideas of detached cultural spheres and an ethnic foundation of culture, which cannot be overcome from within itself. As it has been shown, historical radio structures built around the idea of unique national identities did indeed tend to deny the tremendous degree of horizontal and vertical cultural differentiation within nation states as well as the strength of transcultural connections through the many traces of migration, social or generational bonds and communities of interest and style. A transcultural approach, in contrast, regards open-ended interaction with foreignness to be at core of a constructive approach to cultural encounters, following Wittgenstein's dictum of culture as a shared way of life (Welsch 1999). Describing processes that produce what has been termed 'soups' - synthetic conjunctions - as opposed to 'stews' - additive mixtures - 
(Antweiler 1999), many cases of radio culture observed in this volume turn out to represent elements of a 'lingua franca radiophonica', mediating in varied ways between different nations and cultures.

But, where, precisely, do we find such moments and processes? Decades of transnational research not necessarily focused on radio has generated fruitful debates on ways in which the study of the transnational can be localized and studied in its interwoven complexity, either by following transnational flows to multi-sited research, or by pinpointing vital points of contact and exchange. (Vertovec 1999) In that sense, a transnational approach can also imply a narrower empirical focus on points of contact in single buildings, such as the BBC World Service's Bush House (cf. Gillespie and Webb 2013), the microphone and phone-in interface of a single community station (cf. Moylan 2013 and in this volume), or the behind-the-scenes work of broadcasting archive, as outlined in the work of Carolyn Birdsall (2017 and in this volume). It is precisely this situatedness of transnational flows that we seek to capture in the idea of a transnational radio encounter.

This book grows out of the collaborative - and itself transnational - research project Transnational Radio Encounters (TRE), funded under the Humanities in the European Research Area (HERA) joint research program (transnationalradio.org). This exploratory project examined radio's transnationality across various technological and institutional forms of broadcasting (public service, community, and international services, among others) in a range of times. The common ground of these projects involved exploring transnational radio encounters across three realms of inquiry. Aesthetics and territoriality involves the intersections between auditory expression and feelings of belonging evoked by radio. It is concerned with auditory performance of radio is constructed to express territorial belonging or otherness, how culturally specific auditive styles are developed and maintained. Infrastructures and public spheres concerns how both technical and institutional aspects (ownership, access, training) of infrastructures shape spaces of participation. How and where do transnational spaces emerge? How do ideas of public service operate at local, national and transnational levels, and among diverse populations within increasingly globalized mediascapes? What kinds of infrastructures support or constrain the emergence of minority communities in radio? Finally, considering radio in its aspect as archive and cultural memory, means asking how archival practices preserve or erase transnational radio encounters, and how might archival knowledge be networked to restore such aspects? How can the increased availability of archival material be used to generate new transnational spaces of dialogue? As scholars begin to think increasingly in terms of transnational memory (De Cesari and Rigney 2014), broadcasting archives have nevertheless been central to practices of national cultural memory. The chapters here assembled draw both on the research of the project members as well as participants in its 
three workshops, as well as the Radio Conference Transnational Forum held in Utrecht in July of 2016 .

\section{The Book Sections}

Developing on the basic questions from the TRE project outlined above, the book is structured a number of areas of enquiry that emerged over the course of research and transnational dialogues over the course of the project.

\section{Section1:}

\section{Asserting Identity: Minorities' Use of Community Radio}

Since the birth of the Italian free radio movement in the 1970s, which spread in various forms throughout Europe and beyond, community (sometimes pirate) radio has offered an alternative voice to groups not always well-served in the public service or commercial radio sector. This section highlights the ways in which often-marginalized transnational communities use community radio to create on-air and local spaces where their experiences are given central meaning.

Peter Lewis and Caroline Mitchell give an overview of their participatory action research (PAR) with a number of radio stations serving black, minority and ethnic communities in Britain and other parts of Europe. They engaged communities directly with the issues outlined above: how certain forms of aesthetic practice, including language, helped to carve out spaces apart from mainstream media, what barriers to access and participation presented themselves, and how such communities or stations archive the stories and experiences of communities they articulate in daily practice.

Katie Moylan shows how Hamid Naficy's notion of 'accented' cultural production can be specifically adapted to critically examine "accented radio" practices of marginalized and minority groups on community radio. Presenting case studies from community radio in the USA, she shows how aspects of community radio such as spoken accent and fluid flow between two languages serve to give voice in real time to the experience of the transnational community.

Judith Purkarthofer reports on a workshop looking specifically at the use of community radio in addressing recent migrants and refugees. The workshop itself gave voice to migrant practitioners from a number of countries who through their stories and experiences gave a rich sense of the work that radio can do for welcoming migrants, in ways ranging from practical knowledge of host country institutions to giving migrants themselves a voice and a 'visibility' within society that can be vital at what can be a "key moment of doubt" in their place in society. 
Nazan Haydari explores the entanglements of gender and Panjabi identities in her study of Desi radio, a community radio station in London. Drawing on the citizen's participation framework, her study focuses less on the media products themselves as the participatory practices, and here explores the various ways in which women use the radio to bridge the divisions of caste, religion, and gender among Panjabi speakers, and shape new identities as a community within them.

Paul Wilson and Matthew Linfoot take up a different set of transnational entanglements of marginalized communities in their case study of Gaywaves, a short-lived but seminal program on pirate radio in the UK in the early 1980 s. They situate the program richly within the international experiences both of the pirate radio movement, as well as the gay activist movements, over against a local and national media landscape that was essentially closed to gay representation beyond stereotypical characters They show how the program provided a window onto a transnational community in the localized setting of London.

\section{Section 2:}

\section{Transnational Communities of Aesthetic Practice}

Increasingly, scholars have turned to teaming up transnationally when it comes to researching aesthetic practices in radio, be it original radio art focusing on the inner workings and sensual appearance of radio itself, or forms of factual or fictional storytelling in radio feature, or radio drama and podcasting, or everyday radio's aesthetics as incarnated in jingles, the radio hour's build-up and the technical design of voices or the broadcast signal.

Regarding the radio documentary as a genre with large influences on radio in general, Virginia Madsen explores how the documentary imagination in radio developed historically across, and within, a range of broadcasting cultures, highlighting narrative and aesthetic strategies in 'feature' and audio documentary productions from the 1940 s to the 1970 s with a focus on the significant influence of the BBC. Madsen tracks central figures, institutions and conceptual influences, foremostly from documentary film, and characterizes the feature as a central field of experiment in radio and a form especially close to the outer world.

By questioning 21 experts from five countries about their terminology, concepts and work procedures in 'packaging' (or 'imaging', that is the use of 'jingles' etc.) individual radio programs, Golo Föllmer discusses in how far radio stations design their sound aesthetics along national traditions, or whether they are more likely to follow transnational fashions. He goes on to identify three central functions of packaging and concludes that this omnipresent practice is much more than self-promotion or branding of a radio program, since it offers a range of crucial elements for the orientation of listeners in the program. 
Heather Contant reflects on the nature of radio waves surrounding us from all corners of the world, indeed transnationally and in fact even transplanetarily. She analyses the unique example of Marko Peljhan's Makrolab, a mobile art project travelling around the globe from 1997 to 2007 in order to collect all sorts of radio waves, atmospheric events and psychic moments. Contant shows how artistic investigations into the nature of electromagnetic waves, including aesthetic outputs like a music CD based on the recordings from Makrolab, offer opportunities to reflect on the cultural and political uses and impacts of transnational radio transmission and reception.

Turning to today's most vital developments in radio storytelling, Siobhan McHugh discusses influential traits of present day radio feature, bearing in mind the success of its youngest offspring, the podcast. She describes how an originally German feature by Jens Jarisch underwent changes when adapted to the new cultural surrounding of the Australian feature tradition, for instance by replacing narrators typical for the German style by alternative formal elements. McHugh shows how the process of translation, bearing elements of transculturation, implies a transformation which contains the potential for aesthetic development and growth and encourages transnational exchange.

\section{Section 3: Staging Encounters: Translating Places and Identities}

From the earliest years of radio broadcasting, international collaboration, particularly in programming, has been a staple of the landscape. This immediately raises the questions of how - and as what - to make radio, and radio programs, intelligible to a transnational audience. As noted above, broadcasting federations such as the IBU before the Second World War, and its successor, the EBU, developed a number of program exchanges. This is only one level of exchange, however - sometimes individual programs have traveled, sometimes bilateral exchanges dominated, and sometimes, it was notions of radio itself that traveled. This section explores on various levels how identities and affiliations were worked out on sonic and discursive levels as radio traveled over borders.

The section begins before the First World War, and thus before the establishment of what we now know as radio, with Maria Rikitianskaia's study of radio amateurs. Developing a transnational perspective built out of scholarship in the history of technology, she arrives at a re-definition both of radio and radio amateurs, thus also rethinking our periodization of radio. She shows in particular how three individuals translated radically different forms of expertise into radio enthusiasm and expertise in correspondence with the International Telecommunication Union (ITU), but also translated their expertise back to address various broader publics in their home nations. 
Jacob Kreutzfeldt analyzes the genre of the city portrait as point of international sonic and spatial exchange, drawing on two case studies involving Copenhagen: exchanges in the Nordic realm in the 1930s, and the Metropolis city portraits, initiated by Klaus Schöning and produced for Studio Akustische Kunst at the WDR Cologne in the 1980s, where various artists created radiophonic pictures of cities from San Francisco to Calcutta. He shows in each case how these city portraits establish acoustic territories, foreground technology, and make aesthetic choices that let then hang in an ambivalent space between local and global imaginaries.

Morten Michelsen turns attention to a grander-scale set of radio exchanges, the IBU's European Concerts: a series of pan-European interconnected broadcasts in the 1930s, staged as a celebration of the new medium's power to connect, but also to project individual nations into a European radio space. Michelsen analyzes the role of the music programs within these major productions, showing how these choices reflected the tensions between projections of universal European modernity and nation-states as having unique character.

Ib Poulsen takes a close look at an outstanding example of a transnational adaptation in the history of the Danish radio feature. Viggo Clausen's version of Hans Magnus Enzensberger's feature Politik und Verbrechen (English: Politics and Crime) from 1964 made crucial formal changes to the source material, i.e. reducing the dominance of critical-analytical reflections found in the German original as well as raising the psychological profiles of the characters by using a consistent voice for each person. Poulson can show how an adaptation as part of a transnational transplantation can involve critical improvements to the mediation of subject matter.

\section{Section 4:}

\section{Doing Transnational Radio Research and the Digital Archive}

Radio broadcasting, with its deep implications in the weave of everyday life, and its synchronization of 'my time' and everybody's time (Scannell 1996) has long had a publicly archival function, doubly so to the extent that radio is preserved and archived to be accessed by future generations. The digitization of archives has had tremendous impact on their inner structuring, on demands expressed by their users and also on the content itself and options for accessing and using it. Changes $\mathrm{n}$ accessibility are fundamentally changing methodological conditions for doing radio research today, for tracing transnational entanglements of the past, as well as engaging and even creating transnational publics in the present.

Sonja de Leeuw gives an overview of the "promises and pitfalls" of digital archives for doing new forms of transnational research. She begins with the grand promise of digital heritage put forth by the European Commission to grant access to heritage to all 'at the click of a mouse', and seeks to locate the 
place and of radio heritage within this landscape. She explores how the new digital archives structure knowledge in various ways and argues that these need to be made explicit. Vitally, at every turn, she points to the important role to be played by academic researchers from various disciplines in giving meaning to digital archive material as it emerges.

Nanna Bonde Thylstrup explores the politics of cultural memory and specifically what form sound and radio archives might take as sites of cultural memory. She looks both to the ways in which various forms of electronic infrastructure relate to memory, but also in particular to the specific ways that sound relates to memory. Relating these to the politics of territory, she demonstrates ways in which the electronic dissolution of some territorial heritage boundaries serves to erect new territorial boundaries in other places.

Carolyn Birdsall turns attention away from digital landscapes to the very origins of institutional radio archives and the transnational flows through them, by exploring the origins of the $\mathrm{BBC}$ archives. To begin with, she demonstrates the entanglements of radio and sound recording collections in global and imperial concerns. She further shows how these have evolved with ideas of what 'sound heritage' might be, and how this is reflected in collections. and how the collections reflect multiple and changing concepts of 'heritage.' Ultimately, she shows how her particular focus on sound archives should demand an even broader transnational framework than is outlined in this volume, but also, she argues, paradoxically, that the history of sound archives demands more sustained attention to the role of paper and written archives in making this history accessible.

Alexander Badenoch tracks the process of archiving the remainders of Radio Nederland Wereldomroep (RNW) after its closing in 2012. He shows how this closure sets in motion a new process of 'archivalization' where the preservation value of the collection is called once more into question. The remains of RNW prove a telling example for this process because different parts of its assets have gone to different locations, from recognized archival institutions to amateur archives and non-archival organizations - each with its own purpose and practices of preserving, cataloging and publishing.

Joost van Beek zooms in finally on the particular issues of archiving low power and community radio. Based on a broad survey of community stations' archival practices undertaken in the framework of EU-funded project CAPTCHA - Creative Approaches to Living Cultural Archives (2013-2015, http://livingarchives.eu/), he highlights a number of examples of good practice that show the promise of community radio archives as preservers of vital cultural heritage, as well as demonstrating barriers to their implementation. 


\section{Section 5:}

\section{Digital Radio Landscapes - Transnational Challenges, National Solutions?}

This section observes digitization's effects on the role of public service radio, currently evolving into "public service media" which follow a crossmedia approach. Important questions revolve around technical infrastructures, foremost the question whether the terrestrial broadcasting technologies DAB and $\mathrm{DAB}+$ will be able to cope with the competition from online stream distribution. Lawrie Hallett reports about new technical developments that are capable of overcoming a major drawback of the Digital Audio Broadcasting (DAB) standard: its inability to deliver smaller-scale services for commercial and community-based digital radio distribution.

The use of Facebook as a central part of radio stations' audience recruitment and retention strategies is discussed by Daithi McMahon in the case of the Irish radio industry, exploring its social, economic and cultural implications, such as the political benefit of debates involving listeners. In an analysis of a small, regional radio station's online activities, McMahon exemplarily shows the transnational impact of radio content via use of Facebook or other social media. As McMahon explains, the Irish Radio Kerry manages to establish close bonds with its listenership, including expatriates 'following' the station via Facebook and streams even from distant locations on other continents. Through contact on occasions like sporting events, show hosts manage to present themselves on eye-level, open to individual communication, thus encouraging listeners to engage online. With that strategy, Radio Kerry establishes a practice and the image of an accessible, locally-rooted but transnationally present radio station.

Per Jauert also discusses the way that public service media make use of the digital platforms available for expanding their remit into participatory programming. After a brief overview of the laws and situation regarding digital expansion and public service media providers, he develops a case study of how use of social media intensifies participation in one of Denmark's most popular radio programs.

David Fernández Quijada of the European Broadcasting Union offers a practical, institutional-based look at the way an international body like the European Broadcasting Union monitors developments in the radio sector among its partners. While pointing to the ways in which these developments are surveyed, he also highlights the difficulties that arise in defining the role and purpose of international broadcasting.

Mia Lindgren looks at podcasting from a practical academic perspective. Taking the case of the podcast Are We There Yet? (AWTY), using participative observation and focus groups, she observes the high impact of a personal storytelling approach like that of AWTY and concludes that, due to its emotional dis- 
position, it is capable of appealing to transnational audiences and helping build communities of interest and engagement around specific topics, thus fostering processes of global learning.

Since networked environments appear to change production processes in radio from the ground up, Bruce Berryman takes a look at the role of 'boundary objects' as enablers in the radio production process. He examines the use of digital editing systems in an example of cross-border radio production between radio students from Australia and the UK and how boundary objects can be used to develop the common ground and trust within groups to facilitate meaningful dialogues and production processes between geographically and/ or culturally dispersed teams. Using a participatory action research approach, the cross-fertilization of practical improvements and theoretical insight brings valuable experience of how to enhance the physically detached processes that are becoming increasingly common in globalized media production environments.

\section{The Future of Radio Studies}

Mia Lindgren and Michelle Hilmes round the book out by taking a general look at radio studies as a discipline and scholarly practice. With tongue in cheek, they state that radio studies have always shared "something of the medium's invisibility" in the research and teaching landscapes while, quite in contrast to broader perceptions of it, radio appears to flourish in forms and spin-offs, including streaming radio and podcasting. On the basis of an exemplary audit of scholarship published in the Radio Journal, as well as examples of practice-led research frameworks, Lindgren and Hilmes argue that radio challenges scholars to use transnational, transmedia, transdisciplinary and cross-institutional approaches in order to live up to radio's agile and versatile nature.

\section{Radio Garden}

The promise and challenge of transnational radio has further been brought to life by another phenomenon that initially grew out of the TRE project. Together with project partner the Netherlands Institute for Sound and Vision, the project commissioned an online interactive platform from Amsterdam-based designers Studio Moniker that would highlight key aspects of transnational radio experiences, as well as incorporating digital materials. Jonathan Puckey, who carried on the project with Studio Puckey, produced a brand new radio listening platform, http://radio.garden, in the form of a sleekly-designed, interactive globe without national borders, which invites listeners to tune into sounds from places all over. This includes samples of many historical materials mentioned in the chapter here (radio.garden/history), as well as close analysis of the anatomy of radio jingles (radio.garden/jingles), which we would invite 
the reader to explore. In addition - and most obviously and vitally- the platform allows the user to browse over 33,000 live radio streams, zooming in instantly on radio from almost anywhere on almost any device.

It is in this guise that radio.garden itself has become a new form of transnational radio listening encounter. Upon its launch in December of 2016, radio. garden went viral, generating 7.5 million hits in its first week and 28 million unique visitors in its first three months. Its numbers have seen occasional spikes as new countries discover it, but use has remained strong: four million in May 2018. After launch, radio stations from around the world clamored to get on the map, and Puckey had added 15,000 new radio stations by September of 2017, mostly via an automated self-submission form that he developed in the face of such high demand. For Studio Puckey, who have been maintaining the platform, and researchers observing the process, it remains a form of rediscovery of transnational radio - and indeed a quest to figure out what radio. garden actually is. To address a high percentage of mobile users, there is now also an official mobile app.

It is still not entirely clear what these encounters entail, but it is not hard to miss the sense of utopian curiosity and wonder in reactions that echo the sentiments we mentioned at the start of this chapter. Even though the design itself is not nostalgic for old radio dials (though they did indeed provide inspiration) for many older users the link is clear. Videos on YouTube show euphoric reactions to "the ability to just spin the planet and hear some place that's been in the news recently." While in some ways evoking old analogue radio, however, it actually disposes of the hierarchies of station power: every station is equally accessible from anywhere. This can also have downsides: while making it easier than ever for community radio stations to be present, and potentially even network, it can also be difficult to stand out and find each other, as Peter Lewis and Caroline Mitchell have discovered in their work (see their chapter in this volume).

Even in the era of podcasting and other time-shifting practices, radio.garden seems to have demonstrated the vital draw of live, transnational radio. For example, listeners used the platform to track Hurricane Irma in the Caribbean in September of 2017 (Agterberg 2017). The fact that every station on the globe has a unique URL allows stations to use radio.garden links to promote current content, making it an easy tool to promote links and other stations in real time. On World Radio Day 2017 and 2018, Caroline Mitchell reports how students at University of Sunderland's community station Spark used, promoted and indulged in radio garden on air. In one program, radio.garden's virtual globe was 'spun' and the found stations were listened in to and discussed live on air.

1 | "Radio.garden" https://www.youtube.com/watch?v=0H1Uuue-5HM\&t=99s 
Interviews with fellow community radio broadcasters about the significance of radio in reaching across borders for their listeners and their volunteers - so young listeners in Sunderland were able to hear from a station that broadcasts by and to migrant communities in Malaga and there was also a live link up with a college station in the USA. Especially as radio.garden grows, it demonstrates amply, along with the research assembled in this volume, that transnational research on radio will remain on the agenda for some time to come.

\section{REFERENCES}

Agterberg, Bas (2017): “Radio Garden raast met orkaan Irma mee” (https://www. beeldengeluid.nl/verhalen/radio-garden-raast-met-orkaan-irma-mee)

Anderson, Benedict (1991): Imagined Communities: Reflections on the Origin and Spread of Nationalism, London: Verso.

Antweiler, Christoph (1999): "Interkulturalität in der Theorie und ein Beispiel aus Indonesien,” In: Alois Hahn/Norbert H. Platz (eds.), Interkulturalität als neues Paradigma (= Trierer Beiträge aus Forschung und Lehre an der Universität Trier XXVII), Trier, pp. 35-42.

Appadurai, Arjun (1996): Modernity at Large: Cultural Dimensions of Globalization, Minneapolis: U of Minnesota Press.

Badenoch, Alexander (2010): "Die europäische Wiedergeburt des Radios? Die Entwicklung und Arbeit des EBU-Radioprogrammkomitees.” In: Rundfunk und Geschichte 36/1-2, pp. 4-18.

Badenoch, Alexander (2013): “'In What Language Do You like to Sing Best?' Placing Popular Music in Broadcasting in Post-War Europe.” In: European Review of History: Revue Europeenne d'histoire 20/5, pp. 837-57.

Balbi, Gabriele/Natale, Simone (2015): “The Double Birth of Wireless: Italian Radio Amateurs and the Interpretive Flexibility of New Media." In: Journal of Radio and Audio Media 22/1, pp. 26-41.

Birdsall, Carolyn (2017): "Divisions of Labour: Radio Archiving as Gendered Work in

Wartime Britain and Germany.” In: Special Issue on Gender and Archiving: Past, Present and Future. Jaarboek voor Vrouwengeschiedenis 37, pp. 107-133.

Brecht, Berthold (1979 [1932]): "Radio as a Means of Communication: A Talk on the Function of Radio.” In: Screen 20 /3-4, pp. 24-28.

Cronqvist, Marie, and Christoph Hilgert (2017): "Entangled Media Histories: The Value of Transnational and Transmedial Approaches in Media Historiography." Media History 23/1, pp. 130-41.

Ernst, Wolfgang (2012): "Distory: 100 Years of Electron Tubes, Media-Archaeologically Interpreted vis-à-vis 100 Years of Radio." In: Jussi Parikka and Wolfgang Ernst (eds.) Digital Memory and the Archive, Minneapolis: University of Minnesota Press, pp. 158-171. 
Falkenberg, Karin (2005): Radiohören: Zu Einer Bewusstseinsgeschichte 1933 Bis 1950, Haßfurth: Institut für Alltagskultur.

Fickers, Andreas (2012a): "Visibly Audible: The Radio Dial as Mediating Interface." In: Trevor Pinch/Karin Bijsterveld (eds.), The Oxford Handbook of Sound Studies, Oxford: Oxford University Press, pp. 411-39.

Fickers, Andreas (2012b): “The Emergence of Television as a Conservative Media Revolution: Historicising a Process of Remediation in the Post-War Western European Mass Media Ensemble.” In: Journal of Modern European History 10/1, pp. 49-74.

Fickers, Andreas, and Suzanne Lommers (2010): "Eventing Europe: Broadcasting and the Mediated Performances of Europe.” In: Alexander Badenoch/Andreas Fickers (eds.), Materializing Europe: Transnational Infrastructures and the Project of Europe, Basingstoke: Palgrave, pp. 225-51

Gillespie, Marie/Webb, Alban (2013): Diasporas and Diplomacy: Cosmopolitan Contact Zones at the BBC World Service (1932-2012). London: Routledge.

Grundig Kurzwellenfibel (1980): Fürth: Grundig AG.

Hamelink, Cees J. (1994): The Politics of World Communication. London: Sage.

Heaney, Seamus (1995): “Crediting Poetry”. Nobel Prize Lecture, Stockholm, July 12. (http://www.nobelprize.org/nobel_prizes/literature/laureates/1995/heaney-lecture.html).

Hendy, David (2000): Radio in the Global Age. Cambridge: Polity.

Hilmes, Michele (2004): “Transnational Radio in the Global Age.” Journal of Radio Studies $11 / 1$, iii

Hilmes, Michele (2012): Network Nations: A Transnational History of British and American Broadcasting, London and New York: Routledge.

Huxley, Julian (1948): Telegram. To President International High Frequency Broadcasting Conference, 22.10.1948. UNESCO Archives, 307.200.526.063

Lacey, Kate (1996): Feminine Frequencies: Gender, German Radio, and the Public Sphere, 1923-1945, Ann Arbor: University of Michigan Press.

Lacey, Kate (2009): “Ten Years of Radio Studies: The Very Idea.” In: Radio Journal: International Studies in Broadcast \& Audio Media 6/1, pp. 21-32.

Lacey, Kate (2013): Listening Publics: The Politics and Experience of Listening in the Media Age, Cambridge: Polity Press.

Lewis, Peter M. (2008) Promoting Social Cohesion: The Role of Community Media, Strasbourg: Council of Europe.

Lewis, Peter M./Booth, Jerry (1990): The Invisible Medium: Public, Commercial, and Community Radio. Howard University Press.

Lommers, Suzanne (2012): Europe - On Air: Interwar Projects for Radio Broadcasting. Amsterdam: Amsterdam University Press.

Mitchell, Caroline (2015): “Re-Sounding Feminist Radio: A Journey Through Women's Community Radio Archives" In: Feminist Media Histories 1/4, pp. 126-142.

Morley, David (2000): Home Territories: Media, Mobility and Identity. London: Routledge. 
Moylan, Katie (2013): Broadcasting Diversity: Migrant Representation in Irish Radio, Bristol: Intellect.

Patel, Kiran Klaus (2015): "An Emperor without Clothes? The Debate about Transnational History Twenty-Five Years On.” Histoire@Politique 26/2 5, www.histoirepolitique.fr

Skoog, Kristin/Alexander Badenoch (2016): "Networking Women: The International Association of Women in Radio and Television.” In: Jamie Medhurst/Sîan Nicolas/ Tom O'Malley, (eds.) Broadcasting in the UK and US in the 1950s: Historical Perspectives, Newcastle upon Tyne: Cambridge Scholars Press, pp. 189-218.

Spohrer, Jennifer (2013): "Threat or Beacon? Recasting International Broadcasting in Europe after World War II." In: Alexander Badenoch,/Andreas Fickers/Christian Henrich-Franke (eds.) Airy Curtains in the European Ether: Broadcasting and the Cold War, Baden-Baden: Nomos, pp. 29-50.

Saunier, Pierre-Yves (2006): “Going Transnational? News from down Under.” In: Geschichte.Transnational, January. http://geschichte-transnational.clio-online.net/ transnat.asp?type=artikel\&id=680\&view=pdf\&pn=forum.

Saunier, Pierre-Yves (2013): Transnational History. Basingstoke: Palgrave Macmillan. Scannell, Paddy (1996): Radio, Television, and Modern Life, London: Blackwell.

Skoog, Kristin/Alexander Badenoch (2016): "Networking Women: The International Association of Women in Radio and Television.” In: Jamie Medhurst/Sîan Nicolas/ Tom O'Malley, (eds.) Broadcasting in the UK and US in the 1950s: Historical Perspectives, Newcastle upon Tyne: Cambridge Scholars Press, pp. 189-218.

Spohrer, Jennifer. 2013): “Threat or Beacon? Recasting International Broadcasting in Europe after World War II.” In: Alexander Badenoch,/Andreas Fickers/Christian Henrich-Franke (eds.) Airy Curtains in the European Ether: Broadcasting and the Cold War, Baden-Baden: Nomos, pp. 29-50.

Vaillant, Derek W (2017): Across the Waves: How the United States and France Shaped the International Age of Radio, Champaign: University of Illinois Press.

Vertovec, Steven (1999): “Conceiving and Researching Transnationalism.” In: Ethnic and Racial Studies 22/2, pp. 447-62.

Welsch, Wolfgang (1997): “Transkulturalität. Zur veränderten Verfassung heutiger Kulturen," In: Irmela Schneider/Christian W. Thomsen (eds.), Hybridkultur. Medien, Netze, Kün-ste, Köln: Wienand, pp. 67-90.

"World Citizenship and Radio" (1926): World Radio July 23, p. 1.

Zöllner, Oliver (2005): Targeting International Audiences: Current and Future Approaches to International Broadcasting Research. Bonn: CIBAR. 



\section{Section 1:}

Asserting IDENTITY: Minorities' Use of Community Radio 



\section{Community Radio and Transnational IDENTITIES}

Caroline Mitchell and Peter M. Lewis

\section{INTRODUCTION}

The area of the Transnational Radio Encounters (TRE) project that was concerned with minorities found its natural focus in community radio, an area in which the co-authors and editors of this section, both specialists in the field, collaborated. Although some minority programming can be found in the schedules of national broadcasters, community radio is the sector where the voices and opinions, for the most part ignored or misrepresented in the mainstream, can be expressed. (Mitchell 2011) Community radio, non-profit in aim, controlled by and representative of a community, can provide the space for the social, cultural and political discourses which are often echoed in, sometime deliberately linked to, places beyond national borders. Among minority ethnic groups - whether historically settled communities, or more recent refugee and migrant communities - radio encounters include connections with a homeland or with a diaspora in Europe and beyond.

Our research had to deal with a large, complex and varied field. A mapping exercise in 2012 by the Community Media Forum for Europe (CMFE) found 2237 community radio stations in Europe. ${ }^{1}$ To explore the kinds of transnational connections likely to be found in a community radio station, we felt that, rather than quantitative surveys, depth research would more effectively provide a picture of experience in the sector. The plan was to focus on one or two case studies in contrasting regions of the UK, using Participatory Action Research (PAR) to explore what TRE's three cross-cutting themes (described below) meant at this level, and thereafter to sample experience in mainland Europe. There, time and resources were not available to go into such depth. Instead conferences, in consultation with the host organizations, were used as a vehicle to reach a wider

1 | http://cmfe.eu/wp-content/uploads/0verview_Communitymedia.pdf 
range of participants. In some cases, 'pre-conferences' overcame the difficulty of bringing activists and volunteer practitioners to academic conferences which usually last longer and cost more than these necessary participants can afford. ${ }^{2}$ During the autumn of 2014, the MEDIANE exchange program ${ }^{3}$ extended the research to Cyprus.

\section{Research Questions}

At conferences and workshops, TRE's cross-cutting themes - Aesthetics and territoriality, Infrastructures and Public Spheres and Archive and Cultural Memory

- were 'translated' to produce the following main research questions:

- What role did mainstream radio play through its representations (or misrepresentations) in bringing your community to the point where you decided to speak for yourselves?

- What do radio programs made by and for different ethnic communities sound like (including use of different languages)?

- In making these programs what do you find helps or hinders your work - at the station level, and beyond

- Does your station/project hold archives that are evidence of the developing relationships between your community and mainstream media or the host community, and between yourselves and counterpart communities in mainland Europe?

We briefly summarize the response at this stage and deal below with some issues in greater depth. The response to the first question, a rejection of mainstream media, was very clear. By contrast, community ownership of a station

2 The following were the occasions for such workshops and presentations: June 2015, Perpignan, Conference Les Frontières de la Radio, organised by GRER (Groupe des Recherches et d'Études sur la Radio) and the University of Perpignan Via Domitia, workshop Connecting minorities across borders: sharing community radio experience; July 2015, Montreal, Crossing Linguistic Borders: A participatory workshop with Third and Native language community radio broadcasters' at 3rd \& Indigenous Language Communities on Air - IAMCR pre-conference in collaboration with the World Association of Community Radio Broadcasters (AMARC); October 2015, Madrid, ECREA Radio Research conference of ECREA with CMFE pre-conference, workshop Crossing boundaries: social, cultural and ethnic minorities in community radio; July 2016, Utrecht, pre-conference Radio, Refugees and Migrants, organised in collaboration with OLON (the Dutch Federation of local radio and television stations) before TRE Final conference.

3 MEDIANE (Media in Europe for Diversity Inclusiveness)'s European Exchanges of Media Practices (EEMPS) program which, under the heading 'Diversity in Community Radio', funded Lewis to exchange visits with Michalis Simonopoulos, Station Manager of MYCY Radio, Nicosia, Cyprus, 7-17 0ctober 2014. 
allows control of what topics are addressed and who can speak, while radio has a special role in reaching listeners in their own language.

In the area of language, the work of Naficy (2001) has been developed by Moylan in her book Broadcasting Diversity (2013) and here, in this volume, where she shows how community radio's informal presentation style, not confined within the routines of mainstream radio, and its close relationship to the community, allows 'ordinary' voices to be heard and conversation to flow.

Infrastructural issues ranging from failures in station management up to the national level - is community radio recognized as a separate sector? Is there sufficient funding? - were reported to us.

Where archives are concerned, digitalization has contributed to new forms of open access, online and collaborative. This has meant that there can be increased access to sonic pasts that can function to enable participation and creative engagement with these pasts through encouragement of active and "public" listening (Lacey 2013). We were able to explore archives and archiving practices of women's, feminist and LGBT radio (Mitchell 2015) and also identify how sound art has been archived and re-circulated through stations such as Resonance FM (London) and through the EU-funded CAPTCHA project. ${ }^{4}$

\section{Methodology}

Community radio, above all else, is participatory: the community owns the station, is represented in its governance and actively involved in the production of programs and the training of volunteers. It therefore seemed appropriate, in researching community radio, to use a participatory method. 'Participatory action research' (PAR) was the approach used in our TRE work.

PAR has its origins in grass roots organizing and empowerment (Freire 1982), has been used in the fields of rural and community development, public health, youth work and education. In the field of community radio, PAR is based on the Ethnographic Action Research method (EAR) which was first developed with funding from the UK Department for International Development (DfID) and UNESCO support in early 2002 to develop an evaluation methodology for a community radio and internet project in Sri Lanka (Slater/Tacchi /Lewis 2002). It combines a holistic approach, looking at the whole social setting of a radio station or project and contextualizing it within the wider economy and government policies, while at the same time, as action research, encouraging

$4 \mid$ The CAPTCHA project worked in partnership with community radio stations and projects in Germany, Ireland, Austria and Hungary. http://livingarchives.eu/ and http://cmds.ceu.edu/sites/cmcs. ceu.hu/files/attachment/article/955/captchafinalreport.pdf 
projects to 'own' the research and its findings and to develop a research culture that allows them to monitor their own practice and develop research tools.

Our research focused on the transnational connections to be found in two contrasting English regions - Bristol in the South West and Tyne and Wear and Teesside in the North East. Both had in common a diversity of population (Bristol's Black, Asian and mixed race communities making up just over $15 \%$ of the population ${ }^{5}$ ) but in very different economic contexts: Bristol weathering the recession with relative success, Tyne and Wear and Teesside suffering from the loss of the traditional industries of mining and ship-building and with one of the highest levels of youth unemployment in the UK. In the two locations after extensive contact and consultation work with local community organizations and networks, 'sharing experience' workshops brought together community radio broadcasters and representatives of minority communities.

We shared our assumption that most transnational encounters take place among minority ethnic groups - whether historically settled communities, or more recent refugee and migrant communities. Encounters might include connections with a homeland outside Europe and/or with diasporic groups in Europe and beyond. By connections, we mean anything from listener groups to arrangements for exchanging or co-producing programming, or exchanges of staff/volunteers. We added that we were also including in our research the use of radio by other minorities such as LGBT communities, stations experimenting with art radio, and women's radio. We went on to 'translate' and list the questions to which we wanted answers. Ideas raised in the workshops resulted in follow-up activities which included interviews among workshop participants led by participants themselves and guided and mentored by us with a small amount of funding to help match other sources. Although it was difficult for these 'community researchers' to find time to follow up their ideas, they appreciated the patient monitoring they received. The plan for the next phase of the research - to act like a dating agency that would connect radios and projects having similar ideas - was a feature that we hoped would result from our interest in mapping. The Radio.Garden, discussed below and in the introduction to this volume, might yet be the platform to facilitate these kinds of connections.

\section{UK EXPERIENCE}

At the Bristol workshop, the 'sharing of experience' was enriched by a presentation from former refugee Dan Cissokho the station manager of Peterborough Community Radio whose later contribution at the Utrecht pre-conference, $R a$ dio, Refugee and Migrants is reported by Judith Purkarthofer in this volume. The

5 | UK, 2011 census: https://www.ons.gov.uk/census/2011census. 
discussions that followed his presentation, that of Katie Moylan (also in this volume), and our own explanations of the research were an illustration of community-based participatory research - testing the relevance of academic work against the insights and experience of people working in the field under study.

In the discussion that followed, one feature of the everyday experience of community radio was made very clear: the lack of time to look beyond the pressure of one's own work, program deadlines, the constant need to raise funding - tasks which account for the fact that the participants were aware of each other's existence and of the work they were doing but had not met before. Nevertheless the 'personal radio journeys' - stories that were told in the workshop became one of the projects taken forward: participants interviewed each other, to tell and record a chain of stories about their transnational radio encounters. These interviews were then broadcast in a series on Bristol's community station, BCFM, introduced by one of the community researchers, Sangita Dewan.

After a second 'sharing experience' workshop in July 2014 at Bede's World, a museum in Jarrow, North East England, discussions included involving community radio in finding ways of recording dialect in the Teesdale community that may be soon lost, and an Iranian group, the Sepanta Cultural Foundation, regenerating an arts program. In subsequent follow-up activities, Hive Radio, a community internet station based in Jarrow took the lead in recording stories of transnational communication, co-operation and cultural differences. The station's logo is 'You tell the story, we broadcast to the world' and one stand out activity - webcasting live from a community festival - involved a 'Transnational Radio table' where people could map, record and listen to transnational experiences of students, refugees and mixed race families. This activity helped form early ideas that contributed to the development of radio.garden, where some of these stories appeared. Another follow-on project was a series of podcasts called "Culture Shock" made with refugees and asylum seekers. ${ }^{6}$

This relatively complex range of research activities: bringing people together for discussions and longer-term broadcast projects, was a key part of Participatory Action Research, working with and through community researchers over a two-year period. Hive Radio was one of the many stations whose subsequent appearance on radio.garden increased its reach and listenership.

In the final months of the TRE project 'Reporting back' workshops in both locations (Bristol in March, South Shields in May 2016) allowed participants to update the researchers on their follow-up activities and the researchers to compare the British experience to what they had heard at overseas events.

6|See https://www.capne.org/hive-radio. 


\section{Overseas Experience}

The Workshop at Perpignan, within a conference devoted to the "Borders of Radio," focused on 'endangered languages.' Producers broadcasting in Basque, Catalan and Occitan played examples of their programming. Most Basque, Catalan and Occitan speakers also speak French. In the other direction, Basque is furthest from French, whereas most French speakers can follow Catalan and Occitan. So the radios are important for cultural identity and as a means to resist what they called the 'normalization' that mainstream media exert on these languages.

Montreal in July 2015 was the location of the annual conference of the International Association of Media and Communication Research ${ }^{7}$ whose call for papers had asked, "How can communication contribute to the empowerment of individuals and groups in their local contexts?" The invitation to our workshop responded: but can people at the margins make their voices heard and contribute to social debate and political change if they use only a minority language? Held as part of AMARC's meeting, 3 rd a Indigenous Language Communities on Air and as a IAMCR pre-conference, its participants included Indigenous language broadcasters (the Wawatay Radio Network) as well as producers of minority ('third') languages in urban radios. A Palestinian Canadian had claimed space to reach communities across the nation with syndicated shows, and organized in 2008 a Radio Marathon linking stations in the USA, Canada, Australia and Britain. A Montreal lawyer with experience in community radio had set up a center to help indigenous people "use community radio as a decolonizing tool." Other participants contributed experience from Australia, Haiti and Taiwan.

In Madrid, we heard from CUAC-FM which broadcasts in Galician, a language forbidden in the Franco era and now the region's common language - but never heard on mainstream Spanish radio. Other contributions were from Austria (the use of minority languages in rural areas), western Hungary where Slovenian, Croatian and German are minority languages, Ireland (Near FM's alternation of English and Portuguese), Poland, Argentina (use of Guaraní in broadcasting with Paraguayan immigrants) and, in development radio in Afghanistan, broadcasts in Pashtun to try to build a bridge across the border with Pakistan.

\section{ARCHIVES}

Archives are important for cultural memory and can be re-broadcast or available online to connect with new listeners. But the informal, often ephemeral, context of programming means that the actual record of a community's broadcasting is often incomplete. As community radio has come of age, some ar-

7| IAMCR (http://iamcr.org/). 
chives of programming and station materials have been established so that documents and programs are stored for the future and the archive becomes both a repository and a maker of cultural memory (Prieto Blanco/Schuppert/ Lange 2015). We found that many individual community broadcasters kept their own, often cherished, archives but within a station they are difficult for a volunteer workforce to maintain and thus re-circulate. Where these archives become more public, for example the Fem FM archive, in whose preservation in digital form Mitchell was involved, (http://archives.bristol.gov.uk/Overview. aspx) or the Radio CORAX's Cultural Broadcasting Archive (https://cba.fro.at/ stations; see also Van Beek in this volume), it is a characteristic of the sector that these archives often aim from the outset to be participatory. For researchers, this is opening up new areas of study and, for a wider range of people and partnerships, new areas of co-production and participatory research.

Community radio producers have become archivists. One example was Amina Marix Evans ${ }^{8}$ who talked about her radio work at the Bede's World workshop and was later interviewed in her archive:

Interviewer: Biography, portraits, is that retrospectives...?

Amina: Yeh, all sorts, Mohammed Ali, Maya Angelou...yes, we've got interviews ... the interview file might be up there if we can find it

Interviewer: Gosh - this is a serious record, this is more than most people would put together. Did you think when you were doing it that you were putting together an archive that is truly one of a kind or was it just a labor of love and something that you did?

Amina: It was something that you did

Interviewer: Were there any chunks that you've not got, any bits that were lost along the way?

Amina: I don't think so. At one point there was something that was lost and then they turned up at someone else's house... (Laughs) Now you've got me wanting to spend the rest of the year in here looking at what we have. There are all these wonderful tapes that haven't been labelled. It's always what you are going to label later, and now it's later and I still haven't...

8 Amina Marix Evans, pioneer free radio producer, Amsterdam and Leiden NL and Tyneside, UK. Amina's program, A Love Supreme, was on a free radio in Amsterdam for decades, a broadcast for justice and truth. Among the subjects she has focused on are treatment of immigrants, the death penalty in the U.S., and the rights of women. She is also a book publisher and founder of The Kittiwake Trust, Borderline Books and the Multilingual Library (www.kittiwaketrust.org.uk).

9 | Interview with Amina Marix Evans by Bridget Hamilton, May 2016. 
Amina's extensive home archiving is relatively common practice but making this archive accessible to a wider public is time consuming. One successful method of airing archives to a wider audience was 'on air ethnography': Slovenian station Radio Študent played archive tapes and discussed them with past and present community broadcasters as part of a regular program. ${ }^{10}$

\section{INFRASTRUCTURE}

In the radio station, ongoing training in broadcasting and digital skills, access to airtime and time and funding to develop transnational relationships are all important components for people to participate in transnational radio. We found that infrastructural arrangements at national, local and micromanagement level influenced the way that communities could operate transnationally. In the UK community radio sector, the policy varies - an example of the way infrastructure affects the local public sphere. In Bristol, a Chinese programmer had to bargain to include 10-15 minutes in Mandarin or Cantonese ("any more would affect the ratings" said the station manager) in her English-language drive time show. Two Polish programmers at the same station experimented with different formats and ended up with one that they thought worked: one hour in English followed directly by an hour in Polish with similar guests and content but not exactly same style. The pair left when the station manager wanted them to translate from Polish to English every few minutes, evidence as they saw it of 'top down' multiculturalist station management policy rather than allowing minorities to define their own self-expression.

At the European level, the need for governments to encourage and support community radio has been noted by the European Parliament and the Council of Europe. ${ }^{11}$ At the national level in the UK, pump-priming funding for the first 15 stations came from a $£ 0.5 \mathrm{~m}$ Community Radio Fund. The fund has not since been increased although there are now over 250 stations in operation, this despite the recommendation of the evaluator of the pilot Access Radio project (Everitt 2003: 139) that some $£ 6 \mathrm{~m}$ would be necessary to support the sector. An example of negative government attitude in Spain was revealed by members of CMFE at the CMFE/ECREA pre-conference in Madrid 2016, quoting a government policy document leaked in El Diario. In the section 'TV and community radio' the underlined sentence translates as "Eliminate this audiovisual cat-

10 | See/hear "30 years rolled by: Archiving physical archives of oldest European non-commercial student radio station Radio Študent Ljubljana" available at https://cba.fro.at/290137.

11 | http://www.europarl.europa.eu/sides/getDoc.do?type=TA\&reference=P6-TA-20080456\&language $=E N \&$ ring $=$ A6-2008-0263.https://search.coe.int $/ \mathrm{cm} / \mathrm{Pages} / \mathrm{result}$ _details . aspx?0bjectID=09000016805d1bd1 
egory" and, circled, "Reject extreme left parties. Justified in view of shortage of frequencies and possibilities [for alternative transmission via] internet and digital media." These two examples relating to underfunding and legislation for community radio's continuation are further evidence of difficulties the community sector has in supporting national and transnational initiatives relating to minority broadcasting.

\section{LANGUAGE}

Community radio certainly crosses national borders in its use of the internet. We found several examples for instance of UK community programs with regular listeners overseas. But to describe the crossings as 'transnational' misses the particular character of encounters in this type of radio which we might rather describe as translingual. In minority ethnic broadcasting, language, the key vehicle of culture, is an important indicator, acting in different contexts as both a barrier and a bridge.

Since the late 1940s, Britain's colonial past has made it a prime destination for successive generations of immigrants whose right to claim citizenship has been of increasing concern to the conservative side of the political spectrum. With the expansion of the European Union, many newcomers are from Eastern Europe, enjoying the right to freedom of movement and employment, while refugees from war, discrimination and poverty in Africa and the Middle East have added to immigration numbers in Britain as in much of Western Europe.

Nowadays, in relatively settled communities, the concern of the older generations is to preserve their native language which is increasingly at risk of being forgotten by the younger generations. Here, radio is often cited as having an important role, especially for those who have never been taught to read and write their mother tongue. However, radio is only one means of cultural reinforcement available to a community which has had time to establish social, religious and educational networks, and in which the use of satellite TV from the homeland is common.

For more recent arrivals, community radio can provide a first haven in which to recover from the shock of entry into the UK. Naficy described the "trauma, rupture, and coercion" which characterizes the experience of exiles and refugees (Naficy 2001:14) and the treatment of refugees and asylum seekers by the British authorities continues to be notoriously harsh. The journeys made by the newcomers are, Naficy comments, "not just physical and territorial but are also deeply psychological and philosophical. Among the most important are journeys of identity, in the course of which old identities are sometimes shed and new ones refashioned." (Naficy 2001:6) 
Focusing on language in this context, the Inter.Media handbook on intercultural media training remarks:

The terms migrant and non-migrant have $[\ldots]$ begun to lose their relevance in terms of language: migrants of the second and third generation frequently do not speak the language of their parents and grandparents as well as the language of the country where they live (Inter.Media 2007:50).

This is the kind of situation revealed in a project, funded in the first HERA wave, Investigating Discourses of Inheritance and Identity in Four Multilingual European Settings (IDII4MES). The UK team explored the cultural and social significance of language and literacy practices of multilingual young people in Birmingham (http://heranet.info/idi4mes/index). As their report succinctly puts it: "migration histories have shaped linguistic heritages and daily linguistic practices." Their young respondents said that moving flexibly between languages when speaking was quite usual: "you automatically, without even thinking, go into Panjabi, then come back into English."

Mitchell found this when she talked to the station manager of CVFM ${ }^{12}$ in Middlesbrough, NE England. His program is bilingual

because my Urdu isn't very good so I tend to do some in Urdu, a bit of Panjabi and about $60 \%$ in English. A lot of people are bilingual. We tend to speak that way. You might use your mother tongue and then flip to English so people talk in a number of different languages -- this is how we normally communicate. You might get a caller whose command of the language isn't as good as his English so the presenter might speak to him in Urdu and he'll give his response in English. I do it quite often myself. There are certain things I can't express in my mother language (Panjabi). The listeners are used to having that approach. ${ }^{13}$

Who can cross the translingual borders? The answer is complex and depends on what is offered by the particular program: is it multilingual - that is combining two languages within one program - or monolingual? It depends also on the generation of the speaker. Younger people, as the Birmingham research shows, can 'flip' with ease between languages - 'translanguaging'. By contrast, Desi Radio, the subject of Nazan Haydari's chapter in this volume has a monolingual policy: the radio, one of the first in the UK to win a community radio license, broadcasts almost entirely in Panjabi.

In Nicosia, the schedule of MYCY radio, operating from the Buffer Zone with a mission to encourage dialogue between the north and south Cyprus, is mainly filled with programs in Greek, Turkish and English, but also includes

12 | www.cvfm.org.uk

13 | Interview by Caroline Mitchell, 2015. 
French, Italian and Spanish and Persian. The producer of the Persian program, pressed on the question of whether he would include Greek or English alongside Persian, said that would lose him listeners. But within his Iranian audience he tried to make Kurdish- and Lori-speakers, as well as speakers of Azeri - his mother tongue - feel included with a few words of introduction in their language to the music that he chose that came from their culture.

The use of different languages within one program has been referred to as 'multilingual' programming, with the term 'polylingual' describing the existence of many programs, each in a different language, in one radio's schedule. The handbook Intercultural Media Training in Europe points out the advantages of multilingual programming: their preparation helps migrants overcome their "linguistic isolation", working with non-migrants can establish "situations based on an equal footing," while, as listeners to such programming,

members of the of the language majority in the broadcasting region are confronted with a situation that usually only migrants experience: finding it difficult or even impossible to understand parts of the program, not being able to join in the discussion, being 'outsiders'. Through the alternation of languages, however, they are repeatedly 'drawn back in'. This makes it easier to accept a foreign language both for non-migrants and for migrants. (Inter. Media 2007:50)

Music plays an important role in this situation. It has the capacity to cross every border while at the same time retaining a special, often nostalgic, appeal to specific groups and individuals. It can be the binding ingredient in multilingual broadcasting.

Hilary Banks has been broadcasting on community radio since 2009. Fi Wi Sintin is a weekly two-hour program, broadcast on Bristol community station $\mathrm{BCFM}^{14}$ and available online. Hilary researches, engineers, produces and presents the show. It is aimed at the African Caribbean community all over the world. In Bristol:

It's an older Caribbean, mainly Jamaican audience. [...].

It's based on triggering memories and culture... and it uses music, stories, proverbs. All the things that are culture we'll use in order to actualize itself. It uses music quite heavily, music of an older generation. I'm literally taking you down memory lane, all pre-1995 - reggae, rock steady, calypso, back to 1900s, 20s, 30s, 40s, 50s. I use stories: in Caribbean culture stories are very potent ways of learning, transmitting messages, moral codes, conduct and so on.

$\mathbf{1 4}$ | http://bcfmradio.com/fiwisintin. 
People are very keen on it ... One of the things that they are so keen on is this music that they haven't heard for a long time... It's doing something for people. It takes them back to - wherever, so that connection, that link is a really important part of the show. It takes me back as well. It connects me with culture and that's powerful and important. It also reconnects with younger audiences (who) listen so it works on that level as well. And that's quite powerful when young people say 'I listened to that ${ }^{\prime \prime 15}$

\section{CONCLUSION}

As for transnational radio encounters in this sector, connections were mainly personal. There were few examples of radio programs circulating transnationally via community radio (a notable exception being Democracy Now ${ }^{16}$ which is taken by many English and Spanish speaking stations worldwide). It was rare to find interaction between radio stations, which costs the time and money long taken for granted by mainstream broadcasting's national and international organizations. Since the recommendation ten years ago in Lewis's report for the Council of Europe that governments should be encouraged to support "program exchange within the European community media sector, and beyond with regions which are the homelands of diasporic communities" and "for exchange of staff and volunteers...between community media projects" (Lewis 2008:32), EU funding has been the occasional support for specific projects. In the 1990 AMARC-Europe was able to draw on this source. More recently, the Community Media Forum for Europe ${ }^{17}$ has been the focus for campaigns to recognize the need to support community media.

For minorities, community radio continues to have a role in providing public space for a social and political voice, and, literally, for voices - and music that are markers of a history and culture, asserting identity in a host-land and connecting with diasporas. Even at a time when social media has become omnipresent, access to the airwaves simply to speak is important in building selfconfidence. Beyond that, learning how to attract and hold listeners with creative audio production is a skill that research has shown to be useful and transferable (see for instance COMAPP: http://comapp-online.de/ and Lewis/Jones 2006). Sharing the experience of struggles to find this space and give effective voice was, we found, a valued part of our research method (PAR) in a sector where initiatives often begin in isolation. For us, too, Participatory Action Research taught us to translate academic perspectives into meaningful dialogue.

15 | Interview with Hilary Banks by Caroline Mitchell, March 2016.

16 | https://www.democracynow.org/about.

17 | http://cmfe.eu/. 
The social and political meaning of identity came sharply into focus in a period when our research was gathering evidence about the rich contribution Moylan's 'accented radio' was making to the mediascape. The role of media in relation to migration is complex. In a paper written in the first year of the project, we quoted Roger Silverstone's observation that

Migration, immigration ... is now a major concern in Europe... what such movements represent are a perceptible if not yet conclusive change in the nature of national cultures and their capacity to sustain traditional boundaries and identities (Silverstone 2007: 83).

Very soon the refugee crisis appeared to give added significance to Silverstone's prophecy, yet within the three years of TRE's duration the issue of immigration, on the ground and in public discourse, has added fuel to xenophobic and racist reactions and the rise of right-wing political parties across Europe whose aim is to restore the concept of national identity. Britain was a prime example: a large part of the motive for Brexit was the result of the exploitation by the right-wing press of fears about 'the other.' The tabloid press generated and encouraged stereotypes and did too little to combat xenophobia and racism. It is in the community radio sector that more recent migrant arrivals are likely to find an important resource that allows a language community to talk to itself and communicate with the host population. The self-organized Refugee Radio Network ${ }^{18}$ is an example of this happening on a networked scale from Germany and there are other good examples of programming and support with refugee communities in different localities. ${ }^{19}$

We leave the last word to one of the community radio broadcasters about the meaning of her program's title:

The title Fi Wi Sintin is patois, meaning 'Our something'. "I use that phrase because I want it to have a cultural message. Those who hear it and understand it straight away will know that it is directed to you. Those who don't, I want it to start a conversation. ${ }^{20}$

18 | https://refugeeradionetwork.wixsite.com/rran/about.

19 |See for instance in UK Spark Sunderland http://www.jaysykesmedia.com/global-sunderland/ and Brighton http://refugeeradio.org.uk/; in Spain Radio Onda Color http://www.ondacolor.org/ and Austria Frei Radio Orange, Vienna: http://094.at/.

20 Interview with Hilary Banks by Caroline Mitchell March 2016. 


\section{References}

Duxbury, Nancy/Garrett-Petts W.F./MacLennan David, eds. (2015): Cultural Mapping as Cultural Inquiry, New York: Routledge.

Everitt, Anthony (2003): New Voices: An Evaluation of 15 Access Radio Projects. London: Radio Authority.

Freire, Paolo (1982): "Creating alternative research methods. Learning to do it by doing it.” In: B. Hall/ A.Gillette/R. Tandon (eds.) Creating Knowledge: A Monopoly, New Delhi: Society for Participatory Research in Asia, pp. 29-37.

Intercultural Media Training in Europe (http://www.commit.at/fileadmin/user_upload/intermedia-handbook-EN-monitor.pdf)

Lacey, Kate (2013): Listening Publics: The Politics and Experience of Listening in the Media Age. Cambridge: Polity.

Lewis, Peter/Jones, Susan (2006): From the Margins to the Cutting Edge: Community Media and Empowerment. Cresskill NJ: Hampton Press.

Lewis, Peter. M. (2008): Promoting Social Cohesion: The Role of Community Media. Report for the Council of Europe's Group of Specialists on Media Diversity. (https://rm.coe.int/CoERMPublicCommonSearchServices/DisplayDCTMConten t?documentId=0900001680483b32)

Mitchell, Caroline (2011): Voicing the Community: Participation and Change in Black and Minority Ethnic Local UK Radio, In: Brunt, R./Cere, R. (eds.) Postcolonial Media Culture in Britain. Basingstoke: Palgrave Macmillan.

Mitchell, Caroline (2015): "Re-Sounding Feminist Radio: A Journey through Women's Community Radio Archives.” In: Feminist Media Histories Journal, 1/4, pp. 126-143. Moylan, Katie (2013): Broadcasting Diversity, Bristol: Intellect

Naficy, Hamid (2001): An Accented Cinema: Exilic and Diasporic Filmmaking, Princeton \& Oxford: Princeton University Press

Prieto Blanco, Patricia/Schuppert, Mirjami/Lange, Jake (2015): The Digital Progression of Community Archives, from Amateur Production to Artistic Practice. A Case Study of Belfast Exposed. Convergence 21/1, pp. 58-77.

Slater, Don/Tacchi, Jo/Lewis, Peter M. (2002): Ethnographic Monitoring and Evaluation of Community Multimedia Centres: A Study of Kothmale Community Radio Internet Project, Sri Lanka, available at http://eprints.qut.edu.au/8701/1/8701.pdf 


\title{
Accented Radio in Miami and New Orleans
}

\author{
Katie Moylan
}

"Accented radio" is an idea I developed drawing from Hamid Naficy's (2001) concept of accented cultural production to explore a specifically transcultural mode of radio production. Through analyses of accented radio production, I argue here that transcultural radio programs can function as an alternative to often reductive top-down radio representations of marginalized and minority communities. My use of this concept builds on Naficy's theory of accented film production as a transcultural mode of production which signifies not only the "accent" of those represented but also the producers' experiences of displacement, movement and settlement which are then embedded in the text produced. An accented mode of production incorporates the sense of duality characteristic of transnational experience, as the migrant or minority subject speaks from a migrant/minority perspective to a migrant/minority community, yet from within the normative communication structures of the host country (Naficy 2001) and/or from within a public sphere characterized by reductive representations of the given community and often by limited spaces for community selfexpression. "Accented radio" provides a critical lens incorporating exploration of elements of production practice (guest and topic choices; information provision; air time for callers in to the show) which reinforce community-building for marginalized and minority communities on air. ${ }^{1}$ Deploying accented radio as an embodiment of transcultural community production enables exploration of what John Hartley (2000) has identified as radio's community-building tendencies, allowing for a combined analysis of aesthetic, political and production components which comprise community forms of programming.

This chapter draws on research carried out in the USA in 2015-16 to examine selected community-focused programming from New Orleans and Miami as examples of accented radio. Accented radio programs are arguably more possible in community radio. Here, the material structures enable those elements of community radio which facilitate greater community representation and

$\mathbf{1} \mid$ See also S. Vertovec, who developed the idea of accented radio separately in an analysis of Berlin's Radio MultiKulti (Vertovec 2008). 
self-representation such as broadcasting live, extended phone-in opportunities and expanded time allocated for discussion and debate of community issues. The project of community radio has historically been conceived of as a grassroots initiative to empower marginalized communities by providing broadcast opportunities for community self-representation (Lewis/Booth 1989; Barnard 2000). I argue that in addition to this crucial capacity for community expression, community radio (ideologically and materially) facilitates communicative avenues for alternative articulations of marginalized and minority experiences which negotiate, counter and challenge normative discursive framings of race which often otherwise dominate mainstream media.

Within the spectrum of broadcast media, community radio has been recognized as 'third sector' media (Lewis 2008) with the recognized capacity to provide alternative fora to those available on public service and commercial radio. In theory and often in practice, community radio thus embodies and promotes a bottom-up, grassroots approach, conceived of as inherently inclusive and allowing for diverse approaches to production practice, in both policy and individual station remits. Broadcasting from within geographically, politically and socially specific contexts, community radio 'covers different approaches, attitudes and precepts that are sometimes defined in terms of modern versus traditional, progressive versus conservative, or even revolutionary versus reactionary' (Barnard 2000: 68). Community radio is additionally typified by a multiplicity of production approaches, which in turn produce greater scope for community expression (Lewis and Booth 1989; Day 2007; Scifo 2008; Gordon et al 2009; Moylan 2013). Accented radio enables grassroots articulations of community issues and expression of community experiences in distinct ways depending on local and regional contextual factors. The format of community radio is consequently structurally well situated to produce such programming, by remit.

Naficy (2001) suggests that 'accented' cultural texts communicate by “expressing, allegorizing, commenting upon, and critiquing the home and host societies and cultures and the deterritorialized conditions of the [producers]." (2001: 4) "Accent" can be initially defined as a heard vocal sounding, communicating regional and social identity but also affiliations: community, educational, faith-based, linguistic (Naficy 2001). While each of us speaks with an accent, value is conferred upon individual accents within a hierarchy in which accents are invested with different degrees of currency, readability and social capital. Given all these factors, "accent is one of the most intimate and powerful markers of group identity and solidarity, as well as of individual difference.” (Naficy 2001: 23) Accent in radio functions simultaneously at an aesthetic level: the heard voice and modes of delivery, and at a social level: accent as articulation of identity but also of situatedness. Accented radio programs additionally and crucially "speak" to and engage with their target communities simply 
through articulating experiences and issues in the accent - and first language of that community. An accented radio program therefore functions at the local level - speaking not only to the community whose members produce it but also to other local (and marginalized) communities - and at the same time articulates a wider, shared and transnational perspective. Yet accented radio retains a specificity through which the material conditions of program production can be heard alongside articulations of individual and community identity. Thus accented radio enables us to listen for identity articulation through uses of voice and delivery within both a localized format and simultaneously within the larger hegemonic paradigm of a normative and co-opted multiculturalism which primarily serves to reinforce established hierarchies.

\section{FIRST LANGUAGE COMMUNITY PROGRAMS IN New OrLeans}

Established as a city in 1718, New Orleans has been incorporated in its current municipal form longer than almost any other North American city. Possessing a unique claim to a distinct cultural richness and identity, it is regularly described (by locals and outsiders alike) as the northernmost Caribbean city, imbued with characteristics of a Caribbean identity in its diversity and emphasis on musical cultures, local festivals and vivid cuisine. Yet in other ways it is quintessentially American; the established infrastructural problems negotiated by New Orleans are characteristic of those faced by other struggling US cities: declining and insufficient schools, inadequate health care, neglected municipal spaces, unreliable public transport. These fundamental municipal problems have only become more pronounced following the devastation of Hurricane Katrina in 2005 .

Community station WRBH's "first language" programming (Langer 2005; Moylan 2013) for Haitian, Spanish and Vietnamese communities reflects the city's linguistic and cultural diversity. WRBH FM was established with a remit to provide an on-air reading service for blind listeners; the station's call sign references the full name of "Reading Radio for the Blind and Print Handicapped." The station began broadcasting 24 hours a day in 1982 and, as of 2016 , WRBH has been the only radio station in the US providing a 24 -hour reading service on the FM frequency. In 2015 the station had four fulltime staff and broadcast from studios in a spacious house on Magazine Street in leafy uptown New Orleans. Station listenership in New Orleans extends well beyond the blind com-

2 Station Manager Natalia Gonzalez recognises that the word 'handicapped' in the station name is today considered offensive; as it is referenced by the call sign letter $\mathrm{H}$ it remains difficult to change this. (From interview with Gonzalez, 13 May 2015.) 
munity; while station resources do not stretch to research into listener numbers, recurring anecdotal evidence from conversations I had while in the city revealed that the daily morning reading aloud of the Times-Picayune newspaper on WRBH was a favorite feature for local professionals, who listened in their cars en route to work. Alongside the provision of its primary service of "reading radio" for blind listeners, WRBH also provides schedule space for linguistic community representation. The weekly schedule includes Haitian, Spanish and Vietnamese programs, all in the first languages of their target communities. La Voix d'Haiti and The Vietnamese Show began broadcasting on WRBH as responses to crises: amongst the Vietnamese community following Hurricane Katrina in 2005 and after the 2010 earthquake in Haiti. At time of writing, The Vietnamese Show on WRBH is the only radio show serving this established and sizeable community in New Orleans. The show has been produced and presented since 2008 by John-Hoa Nguyen, who works by day as an estate agent, and is broadcast between 7 and 8pm on Sundays. Nguyen acknowledges that he is well known in the Vietnamese community and that this is a source of community trust which helps him in presenting and producing the program:

I am lucky enough to be out there in the community quite often. I would say on the West Bank, $75 \%$ of the Vietnamese know me. And throughout the New Orleans metropolitan area I would say $50 \%$ or $60 \%$ of them know me. Every time there is a major function in the community they will ask me to get involved, because my voice is easy to be recognised.

I work with them as a link, because I can link them to different locations, to different people, and we can get together. (Interview with Nguyen, 20 May 2015)

Broadcast on Sundays between 5 and 6pm, La Voix d'Haiti usually incorporates a half hour of talk and discussion in French Creole, followed by a half hour of Haitian music. Producer and presenter Joseph H. Louis Jeune, known and broadcasting as Hector, describes the show's remit:

The purpose of me coming here is to engage the community, to tell them what's going on, to inform the community [...] What is important to me is to see whether I can have my community engaged. (Interview with Jeune, 13 May 2015)

Jeune stresses the importance of the Haitian show being broadcast in the 'first language' of the target audience, and describes how this informs how the community is situated in the city:

In my mind I'm talking to the whole community [...] I have in mind everybody when I'm talking [...] I see Haitian first. Unconsciously the show to me is just Haitian, before New Orleanian. (Ibid.) 
'First language' programming is immediately more accessible to ethnic and cultural communities in which the 'first language' of a majority of members is not English but that of their home or sending country. Hearing their first language spoken on air can confer a sense of belonging in community members in advance of the content of the program that follows. Nguyen too insists on the importance of broadcasting in his community's first language, saying that for the first generation of migrants from Vietnam,

their first language is still Vietnamese. But for most of the second generation who were born in the US, their primary language is English [...] My show is in Vietnamese because most of my listeners are of the first or one and a half generation [...] Maybe now and then we have speakers in English but then we translate simultaneously. (Interview with Nguyen, 20 May 2015)

Both Nguyen and Jeune acknowledge and appreciate the institutional support provided by WRBH for their programs.

The institutional and material support provided by WRBH crucially facilitates the ongoing production of all three 'first language' shows. Alongside their accessibility in relation to first language content and coverage of community issues is the more abstract but nonetheless crucial function of community building in a wider sense. Nguyen discusses the importance of The Vietnamese Show in reinforcing a shared sense of community for New Orleans Vietnamese community members:

The only thing that the Vietnamese have, that other people do not have, or at least we have it stronger, is we have a sense of belonging. See, once you have a sense of belonging, you belong to something, then that is part of you. So the Vietnamese, even though New Orleans is not their primary home of their choice, because their main home was in Vietnam but they were forced to exile, so they made New Orleans their permanent home. And they feel that New Orleans is their home so they have a stronger sense of belonging...

for us to be a community every one of us has to have that sense of belonging. And we have to instill that sense of belonging into people. Otherwise a community is nowhere to be found. (Interview with Nguyen, 20 May 2015)

This encapsulates the ways in which the Vietnamese community consider New Orleans home even as they recognize how this layers on top of their migration experiences (for the first generation) and their held sense of Vietnam as the 'original' home country. This complex identity position and sensibility is articulated and reinforced through The Vietnamese Show and La Voix d'Haiti, in broadcasted content, news and information about community events in the city. 


\section{Bridging layers of Haitian communities In Miami}

Miami's established and emergent diversity incorporates substantial Cuban and Haitian communities alongside smaller Caribbean and South American migrant groups and transient snowbirds. The city's cultural, experiential and linguistic diversity is expressed in myriad ways in a range of community-focused programs broadcast (mainly) on different AM radio stations in Miami. Spanish-language commercial stations WRHC AM and WAQI AM (broadcasting as Radio Mambí) serve Miami's Spanish-speaking Cuban and South American communities, while the Colombian community is primarily served by WSUA AM. In North Miami Beach, WSRF AM, the "first Haitian station in the Nation," broadcasts programs for and by Miami's sizeable Haitian community in a mixture of English and Creole-language programming. In some contrast, Miami's public radio station, the NPR-affiliate WLRN FM, broadcasts a mixture of local and national NPR programs entirely in English, with one exception. Radyo Lekol is an educational news program directed at the Haitian community, and was Miami's first radio program to be broadcast entirely in Haitian Creole. The show goes out on WLRN Monday through Friday at 9.05pm for 25 minutes. Within Radyo Lekol's educational format, Friday's show is hosted by Jan Mapou, who also runs a folklore museum in Little Haiti. The Friday show foregrounds "Haitian culture, traditions, music, folklores and the Creole language," as described on the show's webpage. ${ }^{3}$ Those producers and presenters I interviewed from both WSRF and WLRN's Radyo Lekol agreed that radio was the best medium to reaching members of the Haitian community, particularly newer migrants from Haiti.

Radyo Lekol was developed with an educational remit in response to the needs of Miami's Haitian community and is produced and presented entirely by members of that community. Program producer Carline Faustin describes the context informing the show's inception, and the decision to broadcast in Haitian Creole:

Not too many Haitian people actually are literate. [...] Especially the influx of the boat people, what they called them at the time, were people who were working on the farm, people who were just looking for a better life. The people who were already abroad or people who came from well-off families, they were taught in French. So therefore (reole was a speaking language, not so much a written language. (Interview with Carline Faustin, 8 April 2016)

Faustin's work in Haitian Affairs for the Miami area included developing educational material for newly arrived Haitian families and necessarily involved outreach in the dissemination of information to the community. This work

3 | From http://wlrn.org/programs/radyo-lekol, accessed 10 February 2017. 
led to her recognition that a radio show would be a good format for this, as she explains:

We felt like: wouldn't it be better to continue providing that service in Creole, to the Haitian community, so that [...] you're preparing them, you're informing them what is going on. And that is the purpose of Radyo Lekol. Radyo Lekol keeps the parent informed of what's going on in the community, and what's going on in the school system, what's coming, how the school is doing, how the children are doing, and everything else. (ibid.)

The program's name comes from its educational remit, and reflects the show's foregrounding of Creole as the program language: "It's not the same as French at all, because French is "école". But in Creole it's different. Sounds the same, but different." (Interview with Faustin) Radyo Lekol is produced and presented by a team of four people: Faustin, Simone Degraff, Cherol Marcelin and Jan Mapou. Situating the show's use of language consciously and reflexively is important to the producers, as Marcelin, who works as a linguist, explains:

I realize that the culture is very important, for the Haitian community, for any community, any diaspora, and although we have a cultural show [as part of Radyo Lekol] every Friday, I know that language is the forefront of the cultural list. So my show is focused on the language, and the people need to be reminded all the time of things they used to know in Haiti, and how it is important to know your language.

We came to this country with some kind of frustration about the use of the language, if you speak Creole in Haiti - that's how it used to be - you are not taken very seriously if you don't speak French or English. And they came into this country with this frustration, and this bad image of the language, so I realized that I make a choice, so I talk about the language and how it works...

When you are passionate about it, you can transmit that passion to others, and you can recognize that the language is a very important part of the culture, I've been doing that. But my main job is to give information! (Interview with Cherol Marcelin, 8 April 2016)

On WSRF's daily morning program The Morning Drive, banter, commentary and interviews are broadcast in a vibrant combination of Haitian Creole and English; or as one guest contributor called it, 'Cringlish'. This easy flow between English and Creole words and expressions is inherent to the show and practiced by hosts and guests alike and enables the show to speak from and to the experiences of the first and second generation Haitian-Americans who form the show's regular listenership. However, the show's insistence on using and combining both languages has been controversial to some members of the Haitian community. Rhonel Cinous, Fabiola Charles and Rebecca Laratte have been collectively producing and presenting on program The Morning Drive for over two years, although they each began work on the show at different times. 
In our group interview in spring 2016, the three young Haitian-American program hosts explained that this movement between English and Creole is quite deliberate, enabling them to speak to older and younger generations of the Miami Haitian community all at the same time through a mode of expression everyone can understand and relate to. Rhonel Cinous explains how the movement between Creole and English is inherent to the program's flow.

We know how to speak English, we grew up in the system, we learned Creole from our parents, we learned French, but our experience, and to be accurate, is the flow of it. That's how we speak daily.

And to give that reality, and of course our listeners are very diverse, so it does help, and our genuine experience is speaking like that (Interview with Rhonel Cinous, The Morning Drive, 19 April 2016)

This 'flow' is a quality which the medium of radio particularly lends itself to, of course; however the aesthetics of such a flow, in addition to appealing to listeners, also serves to situate the specific identity positions of the show's producerpresenters - and the show's project. Fabiola Charles describes the show's aim to consistently bridge the generations in the larger Haitian community:

Growing up, you can only hear older people on the radio. And you can never hear [...] the younger generation is never given a voice, to actually say anything.

For us, I feel like, the younger generation needs a voice in the community, and we need to be talking about something that's relevant to them. Because my dad listens to old news, what's going on in Haiti, but the new generation are not really interested in that, they can get that on social media. But they need something that's relevant, about what's going on in the community... that's what they want. So that's why we have this show, to build a bridge between the older generation and the new generation. (Interview with Fabiola Charles, The Morning Drive, 19 April 2016)

Critiques of the show's combination of Creole and English have primarily come from the older generations of their Haitian community listenership, who feel it is inconsistent and have approaches all three producers/presenters with their concerns. Yet all three feel the fluidity of flow between the two languages actually facilitates language learning, and in ways specific to each listener group within the larger Miami Haitian-American community, as Fabiola explains: "With your parents you speak Creole. With your friends you speak English. And then sometimes you need a balance. Like sometimes you take the English word, you put it into Creole, and it comes so naturally now." (Interview with Charles) Cinous agrees, saying, 
Creole was more of a third language for me. Because I grew up in the States, we had to learn English first, it was my first language with siblings, At home you speak as much Creole as you can, but then when you're in school or you're with friends, you're telling a story and when you're playing the part of your mother or father the Creole comes out. (Interview with Cinous)

He elaborates on this, saying all three producer/presenters learn from their listeners too:

\begin{abstract}
Instead of just using a phrase or two [in Creole], sometimes the word itself will change... At first I think it was on purpose, but now it's a bit subconscious. Sometimes we don't realize. The fact that they [our listeners] can learn from us, and the back and forth makes it so much easier for them, not only to tune in, but also to learn.

The cool thing about being interactive with our listeners is that they'll call in and define a word, and I'll be like, I've heard this phrase my whole life... so believe it or not we're teaching Creole at the same time. They're teaching us too. (Interview with Cinous)
\end{abstract}

In The Morning Drive, voice, accent and language have particular complex functions, creating and sustaining connections between community identity (also characterized here by the duality produced through migration and movement) and community histories and articulating this web of experiences through a richly combined flow of Creole segueing into English and back again into Creole, oat times within a single sentence. In a radio text, voice narrates and narrativizes, providing both structure and topic, and establishes a point of view and of identification for the listener. In talk radio, given sufficient time on air, voice can be deployed in process by a given speaker in the form of an individual narrative (Couldry 2010) which serves as a situated "account, implicitly or explicitly, of the world within which they act” in Nick Couldry's formulation. (Couldry 2010: 7) Couldry argues for the importance for everyone to have access to means to enable them to give such an "account of oneself" as a way of articulating individual identity.

Building on my use and explanation of the concept of accented radio at the start of this chapter, I suggest the above programs function as examples accented radio, facilitating articulations of specific cultural, ethnic and linguistic subjectivities simultaneously shaped by the communication structures of the hosting locality. (Moylan 2013) In the current context of what Barnor Hesse identifies as a post-racial horizon, characterized by a "socially recurrent blindness to racism," (2011: 155) marginalized and minority communities of brown and black people remain under-represented or depicted via harmful representative forms. Community radio facilitates self-expression of marginalized and minority communities in accented modes of articulation particular to the given community, broadcasting on radio shows produced by and for communities to speak from and to their particular experiences. 


\section{REFERENCES}

Barnard, Stephen (2000): Studying Radio, New York: Hodder Arnold.

Couldry, Nick (2010): Why Voice Matters: Culture and Politics after Neoliberalism, London: Sage.

Gordon, Janey (ed.) (2009): Notions of Community: A Collection of Community Media Debates and Dilemmas, Oxford: Peter Lang.

Hartley, John (2000): “Radiocracy: Sound and Citizenship”, In: International Journal of Cultural Studies, 3/2, pp. 153-159.

Hendy, David (2000): Radio in the Global Age, Cambridge: Polity Press.

Hesse, Barnor (2011) "Self-Fulfilling Prophecy: The Postracial Horizon." In: The South Atlantic Quarterly, Winter 2011, pp.155-178.

Langer, John (2005): "Multicultural Radio in the Global Era: The Canadian Broadcaster Perspective.” In: Australasian Canadian Studies, 23/2, pp. 113-140

Lewis, Peter M. (2008) Promoting Social Cohesion: The Role of Community Media, Strasbourg: Council of Europe.

Lewis, Peter/Booth, Jerry (1989): The Invisible Medium: Public, Commercial and Community Radio, London: Macmillan.

Moylan, Katie (2013): Broadcasting Diversity: Migrant Representation in Irish Radio, Bristol: Intellect.

Naficy, Hamid (2001): An Accented Cinema: Exilic and Diasporic Filmmaking, Princeton and Oxford: Princeton University Press.

Scifo, Salvatore (2008): “Editorial” In: Westminster Papers in Communication and Culture, 5/1, pp. 1-4.

Vertovec, S. (2008): “An Accented Radio: Fostering Cosmopolitanism Through Media in Berlin.” In: Rovisco, Magdalena/Nowicka, Maria. (eds.) Cosmopolitanism in Practice, London: Routledge, pp. 184-204. 


\section{Radio, Refugees and Migrants WORKSHOP}

TRE Conference, Utrecht, 2016

What role can radio play in greeting refugees and migrants and helping them make connections with homeland and host country? TRE's two researchers concerned with Minorities convened a workshop to share experience in this area. Chaired by Dr. Caroline Mitchell, panelists Dan Cissokho, station manager of Peterborough Community Radio, UK, and Larry Macauley, Founder and Editor in chief of the internet Refugee Radio Network, based in Hamburg, spoke about their work. Anne Ostendorp, of community TV station $\mathrm{N}_{1}$ in Nijmegen showed extracts from a programme produced with Ahmad Naffak, a Syrian journalist and refugee. Judith Purkarthofer, President of Community Media Forum for Europe, commented from a European-wide perspective.

\section{LINKS:}

Community Media Forum Europe:

http://www.cmfe.eu

Nijmegen Nı Televisie:

http://www.n1.nl/

Refugee Radio Network:

http://www.refugeeradionetwork.net/ 



\title{
You Can't Tell My Story For Me!
}

\author{
Community Media as a Means of Expression in Multilingual Local and \\ Globalized Contexts
}

Judith Purkarthofer

\begin{abstract}
So I came here [to the UK] as a refugee, I had no experience in radio before. I didn't know what's behind the desk, I was just hearing it like everyone else. So that mystery behind, I've discovered it and I went to master it now. I can say that. [...] I acquired lots of skills, and now things are changing in my country of origin, I was able to go back there and a group of young people decided to set up a Community Radio station and now I'm supporting them in building their capacity, training them in radio production and helping them to set up their local Community Radio station.
\end{abstract}

This was Dan Cissoko, station manager of Peterborough Community Radio, describing his experience in the UK and back in Senegal in his presentation to the Pre-conference: Radio, Refugees and Migrants Workshop. His is a telling story about Community Media as a means of expression in multilingual, local and global contexts. Along with three other practitioners, he contributed to an afternoon of shared stories and in-depth discussions. As a sociolinguist and Community Media activist, currently in the role of president of the Community Media Forum Europe (CMFE), I was honored to be part of this panel as a discussant. Community Media (CM) are interested in involving citizens as producers and viewers or listeners of media production and aim to (self-) educate people about media content and in media literacy, policy and practice. By connecting individuals and groups across gender, age, cultures and languages, CM become a meeting ground where citizens engage in broader media landscapes and contribute to a more colorful and pluralistic media ecology. The CMFE is a European umbrella organization, with currently about 100 members in 23 European countries; it sees its goal as lobbying at a European level and facilitating exchange between researchers and practitioners in areas of policy, research and practice. As a result of a number of grassroots initiatives, the importance and potential societal gain of CM has also reached national and European legislators: the role of CM was recognized by a European Parliament 
resolution of 25 September 2008 and by the Council of Europe in its Declaration of the Committee of Ministers on the role of Community Media in promoting social cohesion and intercultural dialogue (2009). Both bodies stress the social value of $\mathrm{CM}$ as a source of local content, cultural and linguistic diversity, media pluralism, inclusion and intercultural dialogue, and recommend that member states give legal recognition, access to spectrum (analogue and digital) and funding to the sector. In this way, CM, as the so-called 'third media sector,' has a clearly distinct identity alongside the public service sector and private commercial media.

Community Media stand for a large number of media initiatives, ranging from radio and TV stations to internet-based projects. According to the most commonly shared definitions of CM, they fulfill certain requirements (Lewis 2008; see also Kupfer 2010: 189): they are independent of governments, commercial or religious institutions or political parties; they are non-profit-oriented and are driven by voluntary participation of members of societies and communities (while they do at times employ some paid staff). The ownership is shared and the production and broadcasting processes are meant to be inclusive and enhance exchange in and across languages, cultures and interests. Among the growing body of literature that has emerged in the last decades, the notion that CM are a "means of expression of the community, rather than for the community" is one of the core values (Berrigan 1979; cf. Gordon 2012). 'Community' can be understood with different foci and Browne (2012: 155) stresses three possible constructions, each present in different contexts: "Community as participants, community as audience, and staff and volunteers as community." Depending on the local context, the history of stations and the goals of each initiative, producers will focus on their own expression, the expected interests of local (or linguistic and cultural) communities or else on the societal goals they deem important.

The means of expression that Berrigan (1979) mentioned are still highly relevant for media producers today - and this contribution will focus on multilingual, local and global means of expression with the help of the four presenters in the Radio, Refugees and Migrants Workshop. Being able to speak (or, better, to express oneself) is a fundamental experience that is said to contribute to humanness. Thus, we are already approaching the question of who is speaking, a question that is always linked to what are we speaking about. Fairclough (2015: 3) reminds us that speaking (and writing, for that matter) carries power, but that we should look at the "power behind discourse rather than just the power in discourse." I want to focus on the way Community Media creates spaces for individuals to develop a powerful voice, to broadcast contents worth hearing, but by the same means contribute to $\mathrm{CM}$ as powerful actors in society, enabling discussions and the questioning of hegemonic discourses. It is, as we see in 
Cissokho's introductory vignette, a place for personal encounters and meeting with society.

Finding one's voice is an important motivation for many to interact with the media (Purkarthofer/ Pfisterer/Busch 2010). For those who feel less represented by mainstream media, because of gender, age, cultural or linguistic background or language practices and competencies, this is often perceived as struggle (Peissl et.al. 2010). CM usually are the first place where participation and speaking publicly become possible: especially for minorities, people without a clear affiliation (as it might be the case for children of refugees or migrants) or all those wishing to speak about topics that are not generally considered radio-worthy. Through claiming one's voice, it is not only possible to tell one's own story, at the same time it contributes to the presence of different voices and speakers in the media. Listeners and viewers will feel less isolated when they are presented with shared histories or interests. Media producers who speak about their experiences and about their ideas of society can also engage in myth-busting, a term used by Dan Cissokho to describe speaking up against ignorance and stereotypes. Larry Macaulay, founder and editor in chief of Refugee Radio Network in Germany, added to the point in his insistence that in order for the public to understand and learn, "in the beginning, we had to talk a lot." The traditional, yet also myth-driven image of radio as a musiccentered pastime, consisting of background noise and offering little content, is thus contradicted by the urge to speak and the message to be heard.

Radio is in this sense a deeply personal medium - close to the self and often with the voice as the most immediate (and intimate) form of expression. On the other hand, all media are about the connection to the reader, listener or viewer and Community Media are no exception. CM are a means to reach people, to make one's voice heard by other people. Being able to speak within the frame of a radio station, or being able to produce for a local TV station, as in Anne Ostendorp and Ahmad Naffak's collaboration in Nijmegen gives legitimacy and sets an example of ways for newcomers to engage socially. Ostendorp and Naffak present encounters from everyday life, offering a sympathetic view of Dutch lifestyle and the potential misunderstandings experienced by newcomers to Dutch society, thus opening a space for exchange and encounter.

Another important aspect mentioned by several of the panelists is the knowledge about institutions and possible pathways through society - as well as the need to contact relevant associations and organizations of civil society. Being a legitimate member of a society is a recognition no human being can accomplish for him/herself: we need connections and relationships to help each other grow. Community Media do offer recognition to those who engage and they are able to take on new roles or find their former (professional) roles in a new environment. 
Participants and producers can find and build new ground when they develop their media personality, they can be(come) citizen journalists, entertainers, educators and more, and they can do so without having had formal training. A lot of learning happens on the job, motivated by personal interests and encounters. But CM also provide a place where education and training as journalists are recognized, where qualifications can be used to produce independent news, to acquire local knowledge and combine it with prior training. Developing and reactivating one's professional or artistic identity is a key moment when in doubt about one's role in society. Larry Macaulay describes his work, which consists of various media productions across Germany and Europe, spreading across radio and TV broadcasts as well as other formats. Being visible in the German media scene has also gained the Refugee Radio Network team recognition and airtime on international panels, among them Al Jazeera and UNESCO events. But Macauley's work is also influenced by how people read him and his role. An example is his encounter with a US NGO who contacted them some time ago:

We've participated with Al Jazeera, Unesco, Radio Lora and so on... then corporations in Austria, Paris, Calais, Italy and then they [the US NGO] came all the way from Washington What do you want? They said they've been following our trend for a while and they would like to cooperate with us. $0 \mathrm{k}$, which area of cooperation? Well, they lacked ideas, they were like: We will train you. And I said: Does it look like we need training?

In this example, we see how locally relevant initiatives like Community Media stations are informed and influenced by global movements (as in the case of the refugee movement) but we also see the deeply embedded international relations linked to the networks of each participant. Individuals - and those engaged in media production tend to be especially well connected (see Purkarthofer/Pfisterer/Busch 2010) - carry their stories with them to different spaces of engagement.CM stations also develop their networks over time, not least through EU-funded projects. These moments of exchange, of sharing of knowledge, strategies and instruments add to the perception of coherent media landscapes and the effects of CM that go far beyond the sum of all the parts. Apart from physical exchange and the sharing of media productions, CM relate of course also to social media and many CM projects make use of more than one form of distribution. Radio stations use analogue broadcasting but are just as effectively announce their broadcasts via social networks or get in contact with their listeners on a local and international level through internet fora or telephone calls. As we learned from the participants of this panel, all of them used different means to broadcast, announce and interact - each following the possibilities and preferences of their communities. 
Uniting speakers from different countries of origin (Austria, Nigeria, Senegal, Syria, The Netherlands and the UK) and different countries of residence and work (Germany, Norway, the Netherlands and the UK), the Radio, Refugees and Migrants Workshop was undoubtedly a moment of exchange, not just between the panelists but with practitioners and researchers in the audience as well. The two main topics that will be remembered, along with colorful stories and quotes, are the freedom of personal expression and the social recognition and cohesion that forms around those media encounters. Speakers are personally engaged, as they are able to speak their mind and to bring their own view of the world to the fore, especially when taking into account the complexities of the producers' multilingual life-worlds. But, and these two motivations, the need for personal expression and social recognition, reinforce each other: speakers are also deeply dependent on being recognized as members of (one) society. Speaking can turn from a highly pleasurable experience, if it is shared among many, to a frightening space of loneliness, when it is perceived as being in a void without reaction. The role of CMFE, as a lobbying and umbrella organization, is in my view to carry these experiences and issues on, to make them heard at the policy and political level where media content unfortunately rarely arrives.

European lobbying efforts, drawing on generalized evidence about impact and social gain often find it hard to transmit the immediate experience, so highly relevant for CM. Meetings like this workshop are thus much needed as they can be more outspoken and transmit first-hand experience: for example, when the participants agreed with Larry Macaulay that they "are the only ones with a foreign face. And people who would not meet normally, through the radio they get together." By getting together, we can find and invent means of expression as we see fit. We need people to speak for themselves in the media and we need all of us to listen, because, as Dan Cissokho said: "You can't tell my story for me."

\section{REFERENCES}

Berrigan, Frances J. (1979): Community Communications. The Role of Community Media in Development, Paris: UNESCO.

Browne, Donald R. (2012): "What is 'Community' in Community Radio? A Consideration of the Meaning, Nature and Importance of A Concept.” In: Janey Gordon (ed.), Community Radio in the Twenty-First Century, Frankfurt/Main: Peter Lang, pp. 153-173. 
Council of Europe Committee of Ministers (2009): Declaration of the Committee of Ministers on the role of community media in promoting social cohesion and intercultural dialogue. (Adopted by the Committee of Ministers on 11 February 2009 at the 1048th meeting of the Ministers' Deputies). https://search.coe.int/ $\mathrm{cm} /$ Pages/result_details.aspx?ObjectID $=09000016805$ dibd1

European Parliament (2008): European Parliament resolution of 25 September 2008 on Community Media in Europe (2008/2011(INI): http://www.europarl.europa. eu/oeil/popups/ficheprocedure.do?lang=en\&reference=2008/2011(INI)), http:// www.europarl.europa.eu/sides/getDoc.do?type=TA\&reference=P6-TA-2008$0456 \&$ language $=$ EN\&ring $=\mathrm{A} 6-2008-0263$

Fairclough, Norman (2015): Language and Power. 3rd edition, London: Routledge.

Gordon, Janey (ed.) (2012): Community Radio in the Twenty-First Century, Frankfurt/Main: Peter Lang.

Kupfer, Thomas (2010): “CMFE - Community Media Forum Europe.” In: Telematics and Informatics 27, pp. 187-192.

Lewis, Peter (2008): Promoting social cohesion: the role of community media, Media and Information Society Division. Directorate General of Human Rights and Legal Affairs. Council of Europe. http://www.media.ba/mcsonline/files/shared/ H-Inf_2008_013_en.pdf

Peissl, Helmut, et. al. (2010): Mehrsprachig und Lokal - Nichtkommerzieller Rundfunk und Public Value in Österreich, Vienna: RTR Schriftenreihe. https://www. rtr.at/de/inf/SchriftenreiheNr42010/26969_Band4-2010.pdf

Purkarthofer, Judith/Pfisterer, Petra/Busch, Brigitta (2010): “Free Radio (Austria)." In: Downing, John (ed.): Handbook of Social Movement Media, Thousand Oaks: Sage, pp. 201-205. 


\section{Desi Radio by and for the Panjabi Community: Citizens' Media, Gender, And Participation}

Nazan Haydari

Desi Radio, the project of the Panjabi Centre located in Southall, West London, was started in 2002 by Ajit Khera and his sister, Amarjit Khera, to promote Panjabi culture, language, and history, and build connection and communication among Panjabi community living in the area. The word, 'Desi', is derived from 'Des' "meaning a specific space, locality or homeland," refers to "Panjab: the Land of the Five Rivers," that sits along the border between India and Pakistan. In the 1947 partition of India, the region was divided between India (East Panjab) and Pakistan (West Panjab). The idea that Muslims should be in Pakistan and that Hindus and Sikhs should concentrate in India compelled many to migrate across the new border creating violence, resentment, hostility, and chaos. Since then Punjabis have been one of the most prominent South Asian groups living outside their cultural homeland, concentrated in the United Kingdom, North America, and the Middle East. Southall is a home to the Panjabi community of West London.

Desi Radio defines its mission as to "provide a service for the Panjabi community and the inclusion of Panjabi speakers particularly those facing disadvantage and exclusion," and challenge "social conventions, community racism and casteism, and social prejudice through live debates, alternative music and the social engagement."1 Building dialogue constitutes the main philosophy of the station by questioning the political divide between East and West Panjab, religious divide of Muslim, Hindu and Sikh, gender inequality, and cast division.

Desi Radio is run by the volunteers, and Panjabi women of the community constitute the majority. This paper chapter is based on ten days of participant observation during a visit to Desi Radio and participation in the cultural activities of the Panjabi Centre in 2012; interviews with volunteering women

$\mathbf{1}$ | http://www.desiradio.org.uk/ 
producers of radio, and the founders of the station. ${ }^{2}$ By applying the citizens' media framework by Clemencia Rodriguez (2011), I address the question of how Panjabi women of Southall negotiate their gender, and Panjabi identities in interplay with their participation in radio production and community building.

The citizens' media approach presents a framework for the analysis of community media activities that encompass the lived experiences of the members. Rather than the final media product, this framework focuses on the media production process to see how participation transforms participating individuals and their communities. Rodriguez (2001) draws the concept of citizens' media from Mouffe's (1992) understandings of democracy and citizenship by daily political action and engagement. The notion perceives citizens as individuals in permanent interaction with their contexts, gaining and generating power from social relations. Media are not to communicate, express, or inform, but instead to perform local identities, values, ways of life, cultural practices, and forms of interaction. Through media citizens can learn to manipulate their own languages, codes, signs, and symbols, restructure their identities and connect to local cultures. Citizens' media allow people to not just talk about peace, but actually experience social interactions where non-violence is normalized in multiple ways, creating "the performance of peace building" (Rodriguez 2011: 255). Within this framework Desi Radio facilitates collective communication processes where women can build new relationships to reconstruct their gender and Panjabi identities beyond the divisions of cast, gender, politics, and religion. Music and language play a significant role in redefining and performing Panjabi identity.

Ethnographic research and its signature method of participant observation particularly make a fundamental contribution to how we understand radio as embodied in everyday life, and forms a significant tool to discuss the particulars of citizens' media (see Bessire \& Fisher 2012). Ethnography opens a space for analysing the complexities between production, participation and performances of identities, and contextualizing radio as a medium that is culturally and historically inflected. Participant observation is particularly significant for transnational radio research to identify commonalities and intersectionalities in the experiences of communities and media across borders. As a woman of Turkey, the time I spent at Desi Radio, and continuing relationship I built

2 $\mid$ I am deeply thankful to my Desi Radio friends, Amarjit Khera, Ajit Khera, Anita Matharoo, Amar, Chhinder Dhiman, Paramjit Thind; Rani Surinder Sall for wholeheartedly welcoming me at Desi Radio, and sharing their stories. My relationship with Desi Radio continues since my initial visit in 2012. I visited Desi several times after, and invited Amarjit Khera and Taranjit Chana within the frame of the Erasmus exchange program to spend a week in Istanbul to share their experiences with my students and colleagues in 2014. I also read aloud an earlier draft of this paper in the presence of Amarjit, Anita, Paramjit, and several other volunteers for their feedback and approval during my visit to Desi Radio in July 2017. 
with my Desi friends provided a cross-cultural understanding of how radio can function in a different media ecology and historical setting.

In the theorization of citizens' media framework, Davis argues that overemphasis on the production process might lead to overlooking the "mediating role of trainers, social movement activists, and others who might be influencing both the production of material and the way the material might be used later on". (2015: 230). The roles of Amarjit Khera and Ajit Khera, as founders and facilitators, are crucial in understanding the philosophy, organization, and structure of Desi Radio. With different strategies they both ensure continuation of the founding principles of the station. While Amarjit continuously discusses the philosophy of the station, history of Panjab, and significance of language during daily conversations, Ajit provides guidance about programming strategies and issues to be discussed in the radio. As a Panjabi who grew up and studied in the UK, Ajit Khera talked about how the idea of Desi Radio developed through his life experiences and was an extension of his dynamic political struggle:

I was very much outside of Panjabi culture. In 1984 as I was watching television with my children I saw a news: political conflict in Panjab. That to me was watershed. I do not know what happened to me. My connection with the Panjab, my roots and past was all in my subconscious, and all I needed was a spark! After that I got involved in the movements, and suddenly was in touch with the communities. During the struggles, I came to realize that Hindu, Muslim and Sikhs were all saying the same things. After ten years I walked out of the movement, and spent following ten years reading about political struggles, history, community, and postcolonial literature. If identities are constructed, why not reconstruct them. We started thinking about how to engage people to transcend the religions. First we thought about magazine but then we realized scripts are different and people have oral tradition. Somebody suggested the brilliant idea of radio. By then we approached Amarjit. She had worked in Southall, and knew all about Southall. She has done projects, training, and was very good with people. ${ }^{3}$

Building communication and relationship in the community is an important aspect of Desi Radio, and the role of Amarjit Khera in this is crucial. Feminist scholarship defines interpersonal communication as an essential dimension of generating politics. Scarpora conceptualizes interpersonal interactions as the "practice of relations" which "operates by valorizing the relationships we already have or by activating new ones". This practice, she argues, frees women "from the paradigm of equality and the politics of rights because it attempts to go beyond them." (2004:204) Depending on the people involved the practice of relationships takes different forms and entails rethinking and questioning

3 | Ajit Khera in discussion with the author, January 2012. 
of knowledge through the change and consciousness the interaction brings. Located in the midst of the Panjabi neighbourhood in Southall, the physical location of the Centre, where Desi Radio is also located, facilitates community involvement by creating the feeling that casual visits at any time are welcome. Anybody who walked in was greeted with a warm welcome and made comfortable. Amarjit mediated the relationships among women, community and media. She has a deep understanding of gender inequality and women's realities, and advocates women's participation. Her warm and open communication style and judgement-free attitude made radio a space of comfort for women of the community.

Panjabi Centre and Desi Radio regularly organized workshops (e.g. radio production, and digital literacy) along with cultural activities, events, and festivals to create the spaces of interaction, practice and learning about histories and rituals. During my visit I participated in the Lohri Festival that was exclusively for women and children. Amarjit explained how important it was for women to have a space of their own where they could dance, perform, and act freely to connect with their inner self and body, and with each other. She defined dancing as a means of releasing emotions, and the festivals like Lohri as limited spaces women could freely move their bodies; the presence of men would prevent such free expression. ${ }^{4}$ When several men insisted on entering the festival, the celebration itself became a means of collective struggle for women to claim their space and presence. Men were prevented from entering by the organizers, and a few stopped by with their complaints at the Centre the following day. Amarjit stood up for the decision and tirelessly explained why celebration was only for women and children.

Desi fulfilled a variety of emotional and practical roles for women volunteers, and functioned as a means of therapy, dealing with loneliness, or easing a new phase such as retirement, divorce, or children leaving home. Building relationships and friendships were very important aspect of this process. Radio specifically provided good environment for older women who felt quite isolated. ${ }^{5}$ Anita, who was among the first volunteers of the radio, reflected on her experience:

I was very ill and depressed. My friend literally pushed me here. After the training I did not go to the station a while. At the time my son and daughter were still doing their shows. Amarjit and friends kept calling me and sending messages with my children: 'tell your mother to come.' Then Amarjit phoned and told me "just come and meet everybody and then you can go. I came and continued afterwards. I realized how important it is for women to come here.

4 Amarjit Khera in discussion with the author, January 2012.

5 | Andy Wass in discussion with the author, January 2012. Andy worked as administrative manager to find funding to create training opportunities. He received funds for Pearls and Go Desi projects. 
If I see anybody I encourage them to come and tell their own story. The ladies need to be pushed. When you find a part you can work along, it is just somebody need to ring you. If you have good friends you can get on with your lives a lot easier. I think this radio is wonderful. ${ }^{6}$

Similarly Rani talked about how radio brought a change for her:

I finished working and did not know how to pass time at home. Children got married and left me. I knew that place and listened to the radio, but for some reason did not feel comfortable walking in for a long time. One day I decided to walk in. Amarjit is always very supportive and very positive, it does not matter whether she knows you or not. She asked me to come more often. I said I do not have a good voice, and I am not talkative, I cannot go to radio. I will just come here and make a cup of tea for you. I just want company. She said 'everybody starts like that but then they start presenting.' I have never thought I would do so one day, but now I am presenting a music program. ${ }^{7}$

Desi Radio consisted of music, poetry, news, and discussion programs presented by the volunteers, and call-ins facilitated community participation. Continuous support and training created the feelings of comfort and confidence to ensure the participation of women in producing and presenting the programs. The aural nature of radio technology and lack of visibility intrinsically nurtured the sense of comfort. Potential volunteers first participated in several weeks of training program, and spent time in the station before they started presenting. Pearls that was funded by London Development Agency and Go Desi that was supported by $\mathbf{V}$, the national agency that supports young volunteers in the UK, were among two main training sessions of Desi Radio. For over three years, Pearls training in radio skills for women was given by Women's Radio Group $(\mathrm{WRG})^{8}$, while Go Desi was a training program for young people 16 and 26 years old. Regularly organized trainings were also "a means of getting to know each other and be familiar with the community as there were people from all communities, not only from Panjabi community". "The training sessions took place in English and besides Panjabi women the participants consisted of the members of Somali, West Indian, and Afro Caribbean communities. ${ }^{10}$

6 | Anita Matharoo in discussion with the author, January 2012.

7 | Rani Surinder Sall in in discussion with the author, January 2012.

8 | Women's Radio Group (WRG), previously named Women's Airwaves (WAW), was first established as Women's Radio Workshop in 1979 as a response to under-representation of women on air. WRG's activities included training women for mainstream and community radio stations. (see Mitchell 2000: 95)

9 | Rani Surinder Sall in discussion with the author, January 2012.

10 Andy Wass in discussion with the author, January 2012 
Music was the main tool for the station to construct Panjabi identities beyond religious differences, and divides: "People are always conscious of their identities as Muslim, Sikhs, Hindu or Christian. Music is one way of promoting Panjabi identity that transcends such religious division." ${ }^{11}$ The station mobilized the community to bring their own music and recordings of Panjabi music, digitized them and compiled a large collection of Panjabi music with various categories of Shabad (spiritual), Quami Geets, ${ }^{12}$ Sufi (e.g. Nusrat Ali Khan, Pathena Khan), Christian Songs, Mata Dian (old traditional songs), Anmol Geets (old melodies from 1940 s and 5os), Melody (soft), Bhangra (dance). ${ }^{13}$ When Pakistani Muslim music was played the first time the station was calledin with negative reactions and complaints. But the community slowly started seeing the similarities in music and liked it. Volunteers had their initial experience of presenting a music program by selecting songs from the list: as Anita pointed out "for one month all needed to say was the name of the song, we did not get any phone calls. This gave us a lot of practice. The first year we only do music program. It is a way of getting used to the idea, getting used to the desk."14 All volunteers I talked to emphasized how much they learned through music, and how listening and doing music programs were significant ways of learning about the culture and history. ${ }^{15}$

Language is an important aspect of Panjabi identity. Desi Radio is solely in Panjabi with few English-speaking guests. Spending time at the Centre and doing radio programs made participants more conscious of their Panjabi identity, language and culture. Anita, who has been presenting discussion, poetry, and news programs for several years, commented, "I write poems. Since I started radio I became to realize my Panjabiness and started writing more in Panjabi. Here we have to speak in Panjabi that kind of made me realize. What is there and in me came out. There is so much I did not know before. Being here makes you think!"16 The account of a long-time presenter like Anita illustrates how the radio production process facilitated a relationship between her identity as a program presenter, as a member of Panjabi community, and as a woman.

Poetry is very common for the community. Women cannot really say much so poetry allow them say their words. In story you have to explain everything whereas in poetry you can say so much in short. I encourage people to come and read their own poems. What I write and the content of my poems has changed too. My identity as Panjabi, my language and roots I came

11 Ajit Khera in discussion with the author, January 2012.

12 |'Geets' meaning songs in Panjabi.

13 Amar in discussion with the author, January 2012.

14 | Anita Matharoo in discussion with the author, January 2012.

15 | Chhinder Dhiman and Paramjit Thind in discussion with the author, January 2012.

16 Anita Matharoo in discussion with the author, January 2012. 
from are integrated into my poetry. I have written on being woman, missing my mother, betrayal (that is such a big theme in this community), and separation from your love, from your roots, and your motherland. In my news program, I re-write the news and pick what is relevant to our community and people, include some news from East and West Panjab, and from here, England. In my discussion programs, I try to create awareness on social issues such as honor killing, violence, black magic, children, cleaning and parking on the roads. As I do the program I introduce the issue at the beginning and then ask people to talk about their opinions. Sometimes in women's gathering, an issue comes up and I do a program on that. Now that I am doing the show my mind is always there. Now I can voice my opinion. I can raise my voice and literally shout. It does make a lot of difference. Above all you become more confident within yourself. Women should be confident; they have been suppressed for too long. ${ }^{17}$

Desi Radio creates a collective communication process for the Panjabi community of Southall by providing a space for women to build new relationships, gain new skills and perspectives about their own capabilities, feel empowered, and become more conscious of their gender and Panjabi identities. Speaking Panjabi, and listening and doing music programs make Desi volunteers more conscious of their Panjabi identities and history. Music and language also play an important role to claim and promote a Panjabi identity beyond the divisions of cast, gender, politics, and religion. The physical location of the radio in the midst of Southall, continuous training activities, and the process of radio production also facilitate connection and communication among all communities of Southall. Amarjit and Ajit acknowledge the significance of the UK broadcasting policies of community radio stations for giving voice to diverse communities. With technological developments, Desi started reaching out to the Panjabis beyond the borders of the UK. This is particularly important for wider dissemination of the issues and concerns to promote dialogue and bridge the divides within the communities. For example, while the population of Muslim Panjabis in Southall area is relatively low, online programming gives the opportunity to reach larger Muslim communities. Desi Radio aims to reach larger groups of listeners to promote Panjabi culture and language within and beyond the borders of the UK, but also prefers to remain local and act local to better serve to the communities of Southall. ${ }^{18}$

17 Anita Matharoo in discussion with the author, January 2012.

18 Ajit Khera in discussion with the author, January 2012. 


\section{REFERENCES}

Bessire, Lucas, and Daniel Fisher (2012): Radio Fields: Anthropology and Wireless Sound in the 21st Century. New York: New York University Press.

Davis, Stuart (2015): “Citizens' Media in the Favelas: Finding a Place for CommunityBased Digital Media Production in Social Change Processes.” In: Communication Theory 25, pp. 230-243.

Mitchell, Caroline (ed.) (2000): Women and Radio: Airing Differences. London: Routledge. Mouffe, Chantal (1992): Dimension of Radical Democracy: Pluralism, Citizenship, Community, London: Verso.

Rodriguez, Clemencia (2001): Fissures in the Mediascapes: An International Study of Citizens' Media, Cresskill N.J.: Hampton Press.

Rodriguez, Clemencia (2011): Citizens' Media against Armed Conflict, Minneapolis: University of Minnesota Press.

Scarpora, Susanna (2004): "Feminist Intellectuals as Public Figures in Contemporary Italy.” In: Australian Feminist Studies 19/44, pp. 201-212. 


\title{
Gaywaves: Transcending Boundaries
}

\author{
The Rise and Demise of Britain's First Gay Radio Program
}

Paul Wilson and Matthew Linfoot

\section{INTRODUCTION}

At the beginning of 1982, an array of conflicting forces was working to shape the landscape of Europe's metropolitan radio services, and to alternatively control, commodify or liberate its gay communities. ${ }^{1}$ This paper examines the drivers, which inspired Gaywaves, a nascent weekly gay community radio program broadcasting to an inner London audience on pirate station Our Radio from May 1982 until March 1983.

Though its primary aim was to inform and connect the disparate and sometimes isolated constituents of London's gay communities, it also sought to connect with gay and lesbian movements further afield - in Europe and America - in an attempt to harness collective strength and solidarity. Despite the brevity of the Gaywaves experiment, it was nonetheless a significant attempt to foreground gay lives and experiences on radio, and to use the airwaves to make meaningful connections with communities inside and outside their broadcast range.

\section{COMmUNITY Radio In LONDON}

In London, in the preceding decades, community groups such as the Local Radio Workshop and Com-Com (Community Communications Group) had cam-

$\mathbf{1} \mid$ A note on terminology used here. Although LGBTQ is the modern acronym concerning this field of study, in the period of research under consideration, in the early 1980s, the politics of sexuality followed a binary distinction based largely on definitions grounded in the terms gay and lesbian. There were very few references to the concerns of bisexual, trans, transgender and transsexual identities, and the term queer was problematic due to historic associations linked to homophobia. This paper therefore adopts the terms most commonly in use at that time - gay and lesbian - as its key descriptors. 
paigned against a local radio duopoly controlled by BBC Radio London and two commercially-run services regulated by the Independent Broadcasting Authority (IBA): Capital Radio and LBC. Arguing for equality of access for marginalized voices, and dedicated community-based programming for minorities, they had succeeded in stimulating debate and raising awareness but failed to change the status quo. (Gray and Lewis 1992: 162)

In 1980, several Com-Com members therefore broke away to form London Open Radio (LOR), a group lobbying for 'open access' radio in London - a service open to the contributions of anyone within its listening community, particularly minority groups meeting its social and humanitarian ideals. The inspiration for the initiative came from overseas. Jim Beatson, a leading member of the group, had been involved with a similar campaign in Australia and hoped to replicate its success in London. As Richard Barbrook, another of Our Radio's founders, recalled: “LOR... took the Australian experience and tried to map it onto Britain. But you have to push much harder to change things in Britain." (Hind and Mosco 1985: 46) The group eventually became disillusioned, so when an Australian woman came forward with a donation of $£_{2}, 000$ they opted for a more practical solution. With support from Radio Active, a Tottenham-based pirate station with anarchist leanings, they bought a pair of transmitters and in February 1982 began broadcasting one night per week as Our Radio, with a small roster of programs aimed at diverse interest groups and minority communities. (Hebditch 2015: 124)

\section{Gay Representation on Radio}

It is important to recognize the specific context that characterized notions of disenfranchisement by the media, as experienced by gay communities in the late 1970s. Stereotyped 'gay' TV and radio comedy and drama characters had created a highly distorted public image of gay and lesbian people and their lifestyles. In current affairs programs, representation was generally more sympathetic, if sporadic. However, Nye, Godwin and Hollows, citing lesbian visibility in the 1980 s, argue that the spontaneity of radio phone-ins often resulted in fairer access for the audience and more balanced coverage. (1994: 152)

Meanwhile, genuine gay and lesbian involvement in the production of quality speech output on the UK airwaves continued to be blocked by regulated, mainstream radio, until the 1990 s. Community activist Philip Cox highlighted the inadequacy of the current situation on radio, arguing "Capital (Radio) is aiming at the middle class housewife...they've done fuck-all for gay people." (Cox 1982: C586/330) At a Com-Com meeting with the broadcasting authorities he asked why they never provided anything for the gay audience and was told they weren't interested in "ghetto broadcasting." Speaking to the weekly 
free gay newspaper Capital Gay, Cox added "the people at the BBC and IBA will never allow gay people, black people or women to produce, edit or have editorial control over their own input and output. Even if the producer is gay... bias will be controlled." (Capital Gay November 5, 1982: 16) A dedicated amateur enthusiast with experience of pirate radio, he therefore jumped at the opportunity to create the UK's first radio program "by and for" gay people, when he was offered a slot on the new 'open access' pirate station Our Radio. (Radio is my Bomb 1987: 3)

Teaming up with likeminded friends, notably Gary James and Neil Hoechst, the group began discussions about the concept and aims of the program before it went on air. In surviving recordings of these meetings Cox recognizes the diversity of the likely audience and expresses his desire to take a varied and inclusive approach - airing news stories which the straight media ignore, yet also freely criticizing the gay press (Gay News and Capital Gay) and exploitations of the commercial gay scene. He noted gay radio's potential to "reach a far wider audience than those going to pubs and clubs" and the "radicalizing effect [on those] listening in their bedrooms, wherever they are." (Cox 1982: C586/330) Their agreed aim was therefore to give a united voice to London's many gay rights organizations and support groups whilst simultaneously creating connections with isolated listeners affiliated to none.

Lesbian news and events were covered in the show, but initial attempts to get lesbian program input were unsuccessful. Cox later acknowledged that gay men were "our self-defined audience." (Gaywaves 1983a) He instead encouraged gay women to contribute to Our Radio's Women on the Waves (which targeted both straight and gay women), or to come forward with a proposal for a dedicated program of their own.

\section{The Gaywaves Agenda}

The program was broadcast on a Wednesday, between 7 and 9pm, usually consisting of a series of pre-recorded items (features, interviews, location recordings), linked together by "Anvil Chime", Cox's nom de radio, made with equipment in his own flat. Some of the content suffered a little from technical amateurism (which Cox was unapologetic about), while other elements, such as the comedic skits and satires, demonstrated higher production values comparable to legitimate, network radio.

A duality of interests and responses - sometimes complementary, sometimes conflicting - was inherent in the way the program was approached, and was to be one of the defining experiences of Gaywaves over the course of its short life. It also created a curious paradox. Gaywaves was an act of transgressive activism, challenging hegemony on two fronts - the duopoly of licensed 
radio that ignored community voices, while promoting gay and lesbian stories in the heteronormative media landscape. Unlike most pirate radio, it spurned the easy option of transmitting pop or hi-NRG dance music into gay homes in favor of something much more ambitious - a form of speech-based public service broadcasting. A damning and demoralizing review of the pilot program by listings magazine City Limits should have given the program makers credit for this. (City Limits: June 18, 1982: 75) Gaywaves negotiated a difficult line between the interests of out and proud club-goers, those of isolated individuals living outside the 'scene', and the many who fell somewhere in between.

It must also be remembered that Our Radio was itself unlicensed, and operating illegally. It was therefore an occupational hazard for equipment to be seized during Home Office raids, which in turn meant programs were periodically off air, and there were constant appeals to raise funds to replace confiscated kit. Furthermore, the Gaywaves producers and presenters were also potentially open to prosecution as accessories, hence their use of pseudonyms.

\section{Gaywaves and the International Frontier}

One aspect of establishing this new frontier of gay broadcasting was to explore the lives of gay men and lesbians in other communities, both at home and abroad. As Pullen argues, there is no diaspora for LGBT communities, no point of origin, unlike focal points experienced by ethnic communities. (Pullen 2012: 76) Gaywaves was not reflecting a vision of a former 'homeland', or the shared cultural roots of its target audience, but rather exploring the common interests of a disseminated community inhabiting new urban heartlands. It also sought to rise above the fray of local inter-community quarrels by fostering links beyond the London metropolis, sharing the experience of international partners and of overseas travelers.

An analysis of the archive of 31 editions of Gaywaves held at the British Library (Philip Cox 'Gaywaves' Collection: C586), reveals various ways the program makers approached this rich seam of transnational content.

For instance, the program initiated an occasional feature, starting on July 28, 1982 (audio tape C586/343), in which visiting guests were invited to share their insights into gay life beyond UK shores. Journalist and campaigner Roger Baker discussed a recent visit to Malta but avoided name-checking gay clubs and services. Distancing himself from the travel 'advice' purveyed by established gay tourist guide Spartacus, which some felt encouraged an exploitative form of sex tourism, Baker urged the Gaywaves audience to empathize with the native Maltese experience. In a subsequent program (audio tape $\mathrm{C}_{35} 6 / 351$ : September 22, 1982) 'Paul' shared his first-hand observations of life as experi- 
enced by gay residents of communist East Berlin and gave measured advice to listeners tempted to travel.

In August (audio tape C586/344), Cox interviewed Carl Hill about “Letter to America," a weekly gay rights feature recorded in London by Hill and producer Neil Stewart, then mailed to the USA for broadcast in the San Francisco Bay area by KPFA, a founding station of the Pacifica Radio Network. This new and rare instance of a transnational community radio partnership arose from a notorious incident in which Hill and journalist Michael Mason, travelling to the USA to cover the 1979 Pride parade, were detained by US immigration simply for being gay. The case shone a torch on the US's shockingly discriminatory immigration policy, but was also instrumental in forging an enduring partnership of mutual support between the US-based Stonewall group and British gay rights groups such as CHE.

These attempts to connect the Gaywaves audience with communities and civil rights groups overseas continued into the autumn, including a three-part interview $\left(\mathrm{C}_{5} 86 / 347,349,350\right)$ with Pierre Gandonnière, a founder member of French pressure group GILH (Groupe d'information et de libération homosexuelle) and presenter of Mauvaises Fréquentations, a weekly gay and lesbian show on Radio Léon, a Lyon-based pirate which had recently been legalised by the Mitterand administration. Gandonnière may also have been Cox's introduction to another of France's newly licensed free radio stations, Fréquence Gaie (FG). This station quickly established a large listener base following its launch in October 1981, but endured months of both internal and external conflict before emerging in 1982 as the world's first 24 -hour gay radio station. Fréquence Gaie came under pressure to share its FM wavelength with other newly licensed stations. Opposition to this may have provided the impetus for the station's decision to appoint an outreach officer, Jean-Luc Romero, to raise its profile and attempt to extend its reach to other European urban gay communities. For instance, the station ran a competition in London's gay press, the winners of which were to be announced at an event at the London Apprentice pub on January 27.

Romero or Yann Helise - one of the station's founders and presenters - discussed with Cox the possibility of establishing a live two-way connection between the two stations for a simulcast from this London Apprentice event. For Gaywaves this was impossible since Our Radio was not equipped with a 'link' transmitter and could neither broadcast directly to air from its 'studio' location, nor relay from a third location.

The two stations may also have had discussions about a much more farreaching transnational undertaking - the Paris station's idea to broadcast on AM directly to four of Europe's biggest urban gay communities - London, Berlin, Amsterdam and Brussels. This could have presented an opportunity for Cox to realize two key ambitions - the legalization of Gaywaves' status by 
switching transmission from the doomed Our Radio to Fréquence Gaie's proposed European AM service, while simultaneously extending its reach to a large and vibrant transnational audience. However, in the edition of January 19 (C586/364) Cox demonstrated for the Gaywaves audience a critical technical difficulty which FG would have to overcome to make this possible - the fact that night time longwave reception in London is extremely poor. The idea was never realized.

In the end, on the $2^{\text {nd }}$ February Cox was able to broadcast a recording of the live Fréquence Gaie relay to Paris from the London Apprentice event and used this to ramp up a campaign to establish a Gaywaves support network. The team hosted an awareness raising event and published a press release setting out their reconfigured aims. Central to this was a plan to strengthen Our Radio's gay offering by establishing a sister program for gay women in order to "ensure that gay programming would be an integral part of any future C.R.A.D.L.E. (Community Radio Licensed Experiment) station." (Gaywaves 1983b)

But these ambitions finally came to an end after a Home Office raid in December which seized their equipment, putting the station off air for several weeks. The program briefly returned to the air in 1983, but when the replacement transmitter was also lost, possibly stolen by a rival pirate station, the Our Radio and Gaywaves projects were permanently abandoned.

\section{CONCLUSION}

Despite the brevity of Gaywaves on the radio, the programs proved to be a remarkable and ground-breaking contribution to evolving notions of gay broadcasting: what it would sound like, who would listen and what meanings could be deduced. Subsequent ideas around developing gay identity have focused on sharing experiences and personal stories. (Plummer 1995: 87) Gaywaves provided a platform for the framing and dissemination of these stories. The surviving programs provide a snapshot of some of the recurring themes of gay metropolitan life in the early 1980 s, such as narratives foregrounding police surveillance and harassment; the struggle to secure a lesbian and gay community space in London; fighting for greater visibility and equality in political, social and cultural environments. In reflecting these concerns, the program also took the bold step to reach further afield, to hear from contributors in other countries and cultures, to compare and share experiences, creating a nascent cross-border network. Crucially, and tragically, this short-lived experiment was just on the verge of providing much needed connections of local, national and transnational gay information and community support at the vital moment when the HIV/AIDS crisis was about to emerge. Had Gaywaves continued, it 
might have made an important contribution to the media management of a global epidemic.

\section{REFERENCES}

Bell, Dave and Binnie, John (2000): The Sexual Citizen: Queer Politics and Beyond, Oxford: Polity Press.

Gauntlett, David (2008): Media, Gender and Identity, London: Routledge.

Gaywaves (1983a): promotional leaflet, ca February 1983: Hall-Carpenter Archive HCA/CHE2/13/32 (LSE Library, London).

Gaywaves (1983b): Press release, 11 March 1983, Hall-Carpenter Archive HCA/ CHE2/13/32 (LSE Library, London).

Gray, Peggy and Lewis, Peter (1992): 'Britain: Community Broadcasting Revisited', in Nicholas Jankowski/Ole Prehn/James Stappers (eds.) The People's Voice: Local Radio and Television in Europe, London: John Libbey, pp. 156-168.

Hebditch, Stephen (2015): London's Pirate Pioneers: The Illegal Broadcasters who Changed British Radio, London: TX Publications, pp. 124-126.

Hind, John and Mosco, Stephen (1985): Rebel Radio: The Full Story of British Pirate Radio, London: Pluto, pp. 44-49.

Howes, Keith (1993): Broadcasting It: An Encyclopaedia of Homosexuality on Film, Radio and TV in the UK 1923-1993, London: Cassell.

Lewis, Peter (2008): "Finding and Funding Voices: The London Experience." In: Information, Society and Justice, Volume 2.1, pp. 5-20.

Local Radio Workshop (1983): Capital: Local Radio and Private Profit, London: Comedia. Local Radio Workshop (c 1982) Local Radio in London, London: London Radio Workshop Ltd. Local Radio Workshop (1983) Nothing Local About It: London's Local Radio, London: Comedia. Nye, Sheridan/Godwin, Nicola/Hollows, Belinda (1994): “Twisting the Dials: Lesbians on British Radio" in Gibbs, Liz (ed) Daring to Dissent: Lesbian Culture From Margin to Mainstream, New York: Cassell pp. 147-167.

Plummer, Ken (1995): Telling Sexual Stories. Power, Change and Social Worlds, London and New York: Routledge.

Pullen, Christopher (2009, 2nd ed 2012): Gay Identity, New Storytelling and the Media, Basinstoke: Palgrave Macmillan.

Radio is my Bomb (1987): Radio is my Bomb: A DIY Manual for Pirates, London: Hooligan Press pp. 3-4.

“The Capital's other radio" (1982): “The Capital's Other Radio: Capital Gay Tunes into Gay Waves," In: Capital Gay, November 5, p.16. 


\section{Audio recordings}

Philip Cox 'Gaywaves' Collection, The British Library (C586, tape numbers as noted). See online catalogue at http://cadensa.bl.uk

\section{Websites}

“Fréquence Gaie: Histoire d'une Radio", accessed October 31, 2017 (http://www. hexagonegay.com/Frequence_Gaie.html)

"Phil Cox - A Tribute", accessed October 31, 2017 (http://www.bangagong.co.uk/bangagong.co.uk/Phil_Cox_-_A_Tribute.html) 
Section 2:

Transnational Communities of Aesthetic Practice 



\section{TRANSNATIONAL ENCOUNTERS AND Peregrinations of the Radio Documentary IMAGINATION}

Virginia Madsen

\section{INTRODUCTION}

Ample evidence attests to the emergence of a 'documentary project' in radio by the 1930s, located in multiple sites of creation, many of which developed concurrently, or in dialogue, with the documentary movement in cinema gathering momentum in these same years. Across diverse sites practitioners built bodies of work, some influencing other authors through their ideas, approach or sensibility towards the subjects they chose to explore and reveal. As in the world of film making, a small number of key individuals - auteurs - and centres of production - workshops, studios - helped shape the wider field and offered a vision, as well as encouraging considerable institutional support. Becoming aware of experiments in documentary in cinema, these new radio 'producers' also developed techniques to explore all kinds of subject matter in an array of new forms. They took their microphones and new recording apparatus 'en plein air', gathering the 'acoustic expression of life' to compose a whole new auditory field for documentary creation. More than the "creative treatment of actuality" (Grierson and Hardy 1946: 11), this also included work close to the radio drama. As with cinema, this expansion of the documentary in radio and sound evolved in relation to other arts and literature, and with the rise of another new field: broadcast journalism and reportage. We can encounter a host of new terms employed in the first decades of radio which refer to this emerging international field for documentary; some of these terms also announced a new art form which drew on radio's own distinctive qualities. Here we encounter the 'sound picture', 'actuality', 'acoustic film', 'radio-film' and 'feature' - with terminology in German and Danish ('Hörfolge', 'Hørebilleder', 'Hörfilme',) mirroring some of these terms; in French the 'suite radiophonique', 'mosaïque', and 'film radiophonique' reveals these influences and echoes other media art forms. 
In this chapter I aim to register transnational interactions of ideas, specific programs, departments and producers between key centres of production and individuals. I will also reflect on the role and impact of public service broadcasting (PSB) to this story, identifying distinct traditions and movements of work which crossed national boundaries. The output associated with BBC 'features' and the departments which encouraged this broad experimental field to develop, eg the BBC Features Department (1945-1965), perhaps had the largest impact as ideas, models and practices spread internationally from the pioneering period (1928-) up until the end of radio's so called 'golden age'. Features, "often treated as a kind of broadcasting laboratory" involving the mixing of "drama and current affairs" (Crisell 2002: 41) expanded and gained prestige at the BBC during World War 2 and in the decade after, particularly as BBC International and 'transcription services' directed their content globally, disseminating programs in multiple languages, or following BBC's substantial post war involvement in establishing new or revitalised public broadcasting services in the Axis countries, especially Germany. There is a direct line of development from BBC 'features' to the Radio-Feature tradition adopted and promoted in Germany from 1947, and this field remains strong today.

The German feature culture supported by ARD stations also contributed to the international expansion and ecology of audio documentary forms from the late 1960 s onwards. Key individuals pursued innovation and created new networks connecting radio producers across regions, languages, systems and nations. This opened opportunities for increased distribution, collaboration and adaptation of documentary-inspired work. The International Features Conference (IFC, launched in Berlin in 1975 through Sender Freies Berlin/ SFB) promoted auteur documentary creation across borders, renewed critical understanding of forms, sophistication of practice and the excitement which comes with a range of projects nourished by new and re-energised production centres. By the mid to late 1970 s a radiophonic new wave akin to that of cinéma verité was underway (Madsen 2013). The legacy of these truly transnational developments continues to inform the 'documentary imagination' in radio and audio. From broadcast to podcast, new forms emerge yet draw on these traditions and roots. As these new 'features' become more audible and visible, audiences - the likes of which we have not experienced since radio's first golden age - encounter this porthole onto reality-fiction energized by an expanding auditory imagination. 


\section{Early Sonic Projections and Research Sites: 'Radio Eye' to 'Hear Picture'}

From Dziga Vertov's early actuality ${ }^{1}$ audio and film experiments in Russia, we might also chart the contours of a new radio documentary imagination as it was being born in the early part of last century. To use Vertov's own term, this might be expressed as the birth and evolution of a revolutionary 'radio eye' which could deliver 'the real' to audiences through startling new montaged compositions of documentary images and sounds: "life taken unawares" (Vertov in Zielinski 1999: 121-122). Recorded sounds of life here would no longer be mere entertaining 'affect' (as with earlier film 'actualities'), but provoke and counter popular performed, scripted films.

A 'radio eye' might also be an apt term to describe the new concepts of 'sound pictures' or 'listening/hear pictures' (translations of the German 'Hörbilder'), which could be communicated from reality via broadcasting, in addition to film. While Vertov's pioneering usage of actuality (eg Man with a Movie Camera) occurred before the technological inventions that would allow the new radio broadcasting to open a porthole onto sounding actuality to capture life "sur le vif" (Lumières in Barnouw 1974: 6), this idea we now call 'documentary' was already being proposed through these exploratory interventions in the avant-garde film and sound work he created. As Nichols reminds those who would turn to John Grierson as the founding father of documentary: "Vertov had been making work that would later be labeled documentary for nearly a decade before Grierson" (Nichols 2001: 604). Denis Kaufman aka Vertov also commenced 'kino-pravda' (cine-truth) first in terms of an investigation of hearing, with attempts to transcribe/montage actuality sounds (Zielinski 1999: 122). Although these student experiments in his 'Laboratory of Hearing' (1916) were premature technologically speaking, their failure the reason he turned to film, by the 1930 s they could be understood to be re-entering the possible through radio broadcasting, new experiments in 'acoustic film', and through his own breakthrough sound film, Enthusiasm: Symphony of the Donbass (1930): the first ever feature film to use extensive audio-actuality (Smirnov 2013). The

1| 'In a radio context, the term 'actuality' can refer to mediated simultaneity - 'liveness'- but also to mass culture, current affairs and fashion, as well as, more vaguely, to abstract ideas of contemporaneity...[or] the phenomena of presence [through sound] which were among radio's main innovations in media-aesthetic and experiential terms." This description relates to the Weimar period "when actuality became a key term" but remains apt beyond this. (Edgar Hanrahan 2009: 16)

2 Vertov's term 'radio eye' referred to the Russian filmmaker's aim to project his new 'reality' cinema and make this a new documentary art form radiating like radio (but in image and sound) to the international community of workers now able to participate and understand their shared role and experience in revolution. 
idea for a documentary 'radio-eye' and 'kino-ear' (Vertov) now radiated outwards in two mediums. ${ }^{3}$

And as radio gathered momentum and audiences around the world between the wars, we witness the impacts of 'writer-directors' entering broadcasting as well as the cinema. They came to radio from a range of fields not unlike their cinema counterparts - writers, actors, recent graduates in the 'beaux arts' or technical sciences, or from 'theatres' where the memory of war could not be expunged from mind or body. As David Hendy argues, a 'sonic consciousness' was part of this culture-in-the-making, especially at the BBC. This was a culture, Hendy observed, that revealed a high sensitivity to the disorder, cacophony and simultaneity that came with modern warfare and rapidly industrializing cities - the city as utopian and dystopian site for the modern imagination in war's aftermath. Hendy suggests this sensitivity also helped form the emotional and ideas climate of the early BBC (Hendy 2014, 2013). Drawing on this approach further, we see the first formulations of a documentary imaginary and 'project' in $\mathrm{BBC}$ radio revealing both the interest in, and the influence of, international avant-gardes and their challenges to perception, order and constructions of the real carried forward in reaction to the old world; but also, and often submerged in the focus on these kinds of formalist or constructivist revolutionary utopias. Within the 'microclimate' for BBC's new producer-researchers, programs might be salve or balm, not so much critique-dialectic (as with Vertov): one solution to modernity's dissolution. Mathew Arnold's 'sweetness and light' mixes here with kaleidophonic modernism, a surprising strand of the early Reithian BBC, particularly in producers' experiments in 'actualities' and documentary. Examples include Sieveking's Kaleidoscope 1 and 2 (2LO September 1928; May 1929), made using 'multi-studio techniques' mixing performances (voices, music and effects) paralleling film montage; and A E Harding and John Watt's 1931 Crisis in Spain, a collage of voiced news from radio and print focused on the Spanish civil war, offering 'impressions' designed to take the listener into the actuality and experiences reported upon. New 'internationalisms' and interdisciplinary utopias and dreams intermix with documentary experiment, formalist art, political idealisms and propaganda of left and right in this period, often to strange 'affect'. Take the production of Job To Be Done (BBC 1939) by Pare Lorentz well known for his radical film documentaries. Originally made

3 | In Enthusiasm: Symphony of the Donbas (1930-31), "[t]he sounds of machines [...] identification signals of radio-stations... noises of electric power stations" are to be received beyond language: "endlessly various" Vertov explained, "we are still not used to distinguishing among them." But "[i]ndustrial laborers read these sounds easily, like meaningful signs." (Vertov in Russian State Museum of Literature and Art, see Mackay 2005). This radio eye then delivers a sound symphony of noises to speak across the language/nation divide to workers who now understand themselves as "a worldwide social-perceptual community... a global majority" [MacKay 2005: 6]). 
by the Columbia Workshop (1938), this kaleidophonic 'radio picture' described by Radio Times as a 'radio sensation' purportedly caused Henry Ford to cancel his advertising with CBS. ${ }^{4}$

In the interwar years, Public Service Broadcasting (PSB), initially a British idea as much as a model, became transnational as it was adopted/adapted in the various 'dominions' of Britain's Empire. These years also spawned terrifying racist and militaristic nationalisms and totalitarianisms leading back to chaos, the annihilation of peoples, landscapes....and the almost total collapse of these modernists' and internationalists' first audio-visionary experiments. At the BBC, experiment and 'research' drawing on documentary forms emerged in the context of this inauguration and propulsion of the new 'service' ideal embodied in the Reithian project, and evolved into something other. This ethos drove the modern institution of communication, enlightenment and entertainment or Reith's triad to inform, educate and entertain, providing a suitable medium for an expanded, less doctrinaire documentary idea to take root and multiply. The impulse of bringing the nation together is one aspect of broadcasters like the BBC; but much historical scholarship ignores or misunderstands other impacts and products of national and transnational modernism at play here.

\section{The Birth of a New 'Feature' Tradition in Radio}

Documentary forms found fertile ground in many places. From the 'radio-eye' and 'kino-ear' bequeathed by Vertov, to similarly experimental creative environments establishing in early Soviet and German radio and film, the project radiated outwards to become entangled in a wider idea of the need for, and value of, 'reality forms'. One of these forms developed by broadcasting organizations and pioneered in film were 'actualities'. These emerged in radio through the innovation of 'outside broadcasting' (OB): firstly, of significant public or sporting events. Adapting and innovating with techniques employed in sports and public events OBs (using live commentaries) a range of related forms appeared in the schedules from the late 1920s: audio 'impressions', 'posters in sound', 'mosaics', 'sound-pictures', 'the panorama'. In the BBC, a small group of producers soon realized the mobile microphone could be a channel connecting listeners to worlds, individuals and communities far beyond their own in distance, but perhaps near in other ways. An auditory 'window' opened, capturing and mixing interior life (the private) with more public rituals of 'the people', or peoples

4 | Bernard Hermann who later worked with Hitchcock, collaborated on effects and music, even as Lorentz created many effects like hammers and other tools conjuring factory assembly lines. This was a rousing panorama and call to overcome unemployment in industrial America and was also broadcast by $C B C$. 
understood by or beyond region/nation. This had not occurred before. Arrived at by these new 'features' producers almost accidentally (Scannell 1981, 1986; Shapley and Hart 1996), but a possibility perhaps uniquely suggested by PSB, BBC Manchester's Olive Shapley, Joan Littlewood, Geoffrey Bridson took their new 'life sensitive' microphones into homes, mines, noisy streets and marketplaces, or lonely rural outposts where life continued as it had done for generations (cf. Madsen 2017). Sound scenes could be relayed, built and 'composed', with voices never heard by the mass audience now resonating in an expanded public sphere (paradoxically also in an intimate and individuated way). One world entered another, interpenetrating through the documentary 'impression'. Life was freed from its entrapment in space and time. While audiences listening transformed into a new mass (of receivers), those channeled through transmission now had the chance to speak beyond the private or the local, and even to meet one another. In 1939 Shapley (1996: 53) took a Craghead woman to a comparable French mining village; the feature she made brought the lives of two towns and women together extending their experience to listeners beyond the national and the local. ${ }^{5}$ BBC 'actualities' had transformed from the earlier live 'sound pictures' ${ }^{\prime 6}$ and 'featured programmes' to become something else, offering a new 'imaginary' where the travelling microphone is conduit and aperture, and "ordinary' worlds [are] made unordinary" (Goldie 1938).

Drawing in new adherents and would-be-artisans of the microphone who were experimenting with studios, sound effects, new ways of writing for the ear as well as presenting live and recorded 'actualities' 'en plein air', we see the forms of this hybrid program field expanding in a range of locations in Britain, Denmark and Germany. With Walter Ruttmann's short 'acoustic film' or 'Hörfilm', Weekend - made in association with the Berliner Funkstunde (trans. Berlin Radio Hour) and the radio pioneer Hans Flesch - the artist moves with his new instrument of revelation, leaving the studio behind to eavesdrop on the life of Berliners on an ordinary weekend. The montage he makes from his recordings onto optical sound film does not so much focus on freeing speech to talk back to a larger public, but rather these acoustic traces are snatched almost clandestinely as fragments of life ready to be molded by the 'artist-joiner' (Ed-

5 | Dutch feminist/historian Lilian van der Goot launched the International Association of Women in Radio and Television (IAWRT) in 1949, inspired by this transnational feature, Miners Wives (1939) (Ruhnbro, 2008).

6 | A Newspaper Office at Night (2L0, Dec 16, 1929) was described as a live 'sound-picture' (Brailsford 1929). 7 | The film overlap is also interesting: a "Feature programme' was first an "unseen but heard moving picture" (BBC 1930: 168-69), or like a 'feature' film or newspaper piece, a 'special' thing. The word then lost it's ' $d$ ' becoming associated with "experimental types of radio programme as a whole." (Felton 1949: 99). 
ward Sackville-West, in Rodger 1982: 85$)^{.}{ }^{8}$ This amounts to a different impulse to the Manchester features' team, an innovation nonetheless (Rogers and Barham 2017: 34-39), aural equivalent of the city symphony film genre Ruttmann was already known for - only this was a film without images, both broadcast by radio (1930) and 'screened' in a cinema. ${ }^{9}$ As with Ruttman's 'acoustic film', or the features field emerging in the BBC or with Hörbild/Hørebilleder and Hörfolge/Hörbericht (also indicating reportage), experimental composition and dramatic techniques lead to innovative new forms of non-fiction. Curiously, after 1945, the descriptors Hörbild/ Hørebilleder will largely fall from favour as German producers adopted the BBC nomenclature, feature. Hörbild/ Hørebilleder had become part of the Nazis' propaganda arsenal, thus in the postwar context these could be understood as tainted forms (Madsen 2010). In hindsight, and with the knowledge of what kind of new space, prestige and freedoms the feature could now offer, this adoption of a somewhat imprecise English term by the Germans doesn't seem odd. This label has always suggested a space for possibilities rather than rules or formulas; it should be regarded as a kind of laboratory or crucible for the emergence of new forms of radio - certainly beyond documentary.

The spread of the feature and the BBC model was arguably first enabled through the BBC's decision in 1932 to inaugurate an international 'Empire Service': programs would be disseminated through the development of a transcription shortwave service. This offered a huge number of recorded features, talks and dramas to a range of other broadcasters in multiple languages, all available on gramophone discs. ${ }^{10}$ The director of BBC Transcriptions in 1948 noted: "by the end of 1947, some 50,000 transcriptions of complete programmes will have been distributed during the year. Many of these have been milestones in British Radio" (Gale 1948: 65).

Far from being isolated from one another then, organisations like the BBC provided opportunities for exchange and collaboration between nations starting from the foundational years. To aid the war effort in the early 1940s, Australian, Canadian, South African and New Zealand producers worked for the BBC, some as war reporters or producers, and this mix of internationals, including some

$\mathbf{8} \mid$ "The word artist means 'joiner' and the artist in radio composition is one who joins things together - words, music, all manner of sounds." (Sackville-West in Rodger).

9 | Ruttmann's sound-on-film radio drama was presented at the $19302^{\text {nd }}$ International Congress of Independent Film, Brussels demonstrating "that while film was penetrating radio culture, radio was penetrating film culture" (Ryan 2013: 261).

10 | In 1942, the Overseas division of the BBC absorbed the Empire Transcription Scheme (for the 'D0minions and (olonies'). By 1945 "recordings were made in 20 different languages and distributed in 45 countries representing 87 territories where they were broadcast from more than 500 radio stations in localities as far apart as China and South America" (BBC 1992: 15). Features ensued in many languages. 
exiled from occupied countries, influenced new approaches to documentaries and reportage which the BBC encouraged. The Australian star war commentator Chester Wilmot was seconded to the BBC after brilliant reportage for the ABC live from the scene of battle (Middle East) (Crook 1998; Inglis 1983; BBC 1948). D.G Bridson recounts how in 1943, the BBC sent him to work in Canada and the USA for a year. There he met "the only American radio man who knew what actuality broadcasting implied - a folk song collector Alan Lomax" (Bridson 1969: 478). The two collaborated on Trans-Atlantic Call, a two-way exchange program Bridson started for BBC and CBS in London, ultimately running for 3 years. Michele Hilmes also detailed the links and collaborative transnational projects developed between the BBC and American networks like CBS, some of these from the late 1930s, and others throughout the Second World War: "as much vehicles for national prestige and propaganda as for cultural exchange” (Hilmes 2012: 147). Hilmes discovers two-way transnational impacts: BBC initial influence on the formation of the Columbia Workshop, to BBC importing ideas from this workshop later in its history, as we have seen with BBC adaptions of dramatized documentary work by Americans, eg Pare Lorentz's Ecce Homo/ Job to Be Done (Hilmes 2012: 125-126; BBC 1939). Norman Corwin participated in these exchanges in the war years; and his work, while widely heard via the BBC, ${ }^{11}$ was also adapted for other audiences, eg Australian. Lomax made more than thirty radio and TV programs for the BBC during the 1950s, and "subsequently revealed that working for the Third Programme was his primary source of income while a song hunter in Europe" (Gregory 2002: 137).

\section{Transnational Influence of the BBC Model, Post WAR 'Feature' aND DOCUMENTARY}

The combination of artistic and compositional 'research' of the pan-European avant-gardes ${ }^{12}$ and John Reith's 'mission statement' for public service broadcasting - to inform, educate and entertain - suited the documentary idea, favouring a variety of 'realist forms' and documentary-informed developments in British radio. As a result, a Talks department and a Features or Drama and Features department were essential components of the BBC for many decades, with similarly named departments in other PSBs (Denmark, West Germany, Australia, Canada, South Africa...) These kinds of places and the program

11 An American in England 1942 series, scores by Benjamin Britten; An American in Russia, 1943.

12 Examples from Manchester and London $B B C$ features producers also reveal the influence of documentary film makers Ruttmann and Cavalcanti and Russian constructivists (see Fisher 2002): experiments or essays exploring a 'symphonic' or musicalized montage style can be heard in Bridson's 'Steel: An Industrial Symphony' (BBC 1936) or 'Coronation Scot' (BBC 1938). 
genres born within them were adopted most importantly in the aftermath of war and given new direction and life in these radically changed contexts.

The German ARD system in part was developed from the 'German Service' established by the BBC in 1938. NWDR in Hamburg developed under British (BBC) control in the immediate post war period and its Director Hugh Carleton Greene (later to become Director General of the BBC) encouraged the making of features and talks as part of re-education for Germany (Nerth 1966; Auer-Krafka 1980; Wagner 1997). Radio feature-makers had also already greatly lifted the prestige of the BBC in wartime including on the high profile innovative War Report (Madsen 2017). Millions in occupied Europe and beyond heard the BBC's 'overseas services'. Transnational efforts in features and documentaries fed back into national contexts. Future radio documentary visionaries influenced by BBC features included German writer Ernst Schnabel and Peter Leonhard Braun. Norman Corwin's 'poetic reportage' was a model for Schnabel's features (Auer-Krafka 1980). NWDR would develop radio-features independently from 1948 after the British transferred power back to German control. Here we find a key site for the continued transnational development and renovation of documentary forms in radio to the present.

We also know that from 1946 the state broadcaster of a liberated Denmark (DBC) adopted features in its revised repertoire of programs, these evolving to a high level in the ensuing years, creating a sophisticated documentary - later called 'montage' - tradition in Danish radio. This documentary output became internationally renowned beyond the 1970 s through the work of producers like Niels Peter Juel Larsen but also Stephen Schwartz, an American who migrated to Denmark. These two latter producers were mentored by the Danish 'fathers' of the post war feature - Willy Reunert and Viggo Clausen. Reunert stands out as an internationally under-recognized figure in this transnational mapping of the radio documentary: an Austrian refugee from the war, he proposed high social impact features sensitive to life as it was lived. 'Dangerous radio' was his goal and legacy (see Rogilds 1989; Poulsen 2006 and in this volume). While Danmarks Radio ${ }^{13}$ can trace its documentary traditions back to the late $1920 \mathrm{~s}$ and 30 s with Hørebilleder, developing their own very early mobile recording to capture 'hear pictures' (1934), these traditions were re-established after the occupation under the influence of the BBC features department. ${ }^{14}$ These productive outsider spirits (Reunert, Schwartz), BBC features internationalism, and then cinema, all contribute to this distinctive 'montage' tradition.

13 The Danish Broadcasting Corporation was first the Statsradiofonien, later becoming Danmarks Radio (1959).

14 Laurence Gilliam, Director of BBC Features visited Denmark soon after the war (1946) and the Department was fully established by 1947 on the BBC model (Johanson, 1986: 35). Poulsen also notes $B B C$ features were heard in Denmark during, and immediately after the war (Poulsen 1986). 
The BBC also had a strong role to play in establishing Features Departments elsewhere in the new Commonwealth. Bridson brought with him a model of how a features department in Australia might operate in 1948-49: writers and creative producers should work across boundaries of drama, poetry, journalism and documentary (ABC 1948; Madsen 2017). Sustained interaction between BBC and $\mathrm{CBC}$ Canada in features and drama staff occurred from the war through the 1950 s (eg John Reeves 1956 worked with BBCs Features/ Cleverdon), although $\mathrm{CBC}$ had been very active in documentary making from its earliest programs (Hogarth 2001). The BBC's post war mission embodied in features also influenced other broadcasters formerly of occupied Europe (Whitehead 1989: 10). Neo realist radio documentaries for example evolved to a high level in the post war RAI in Italy influenced by cinema, but also because "English-style journalism [...] presented [...] an essential channel for re-legitimation and recovery of credibility" with the fall of the fascists (Ortoleva 1996: 58 ).

As noted already, an impetus for the continuing development and spread of the feature came most markedly with the BBC's Third Programme (19461970). This was a ‘cultural radio' project (Madsen 2007) which was also adopted in various guises by a range of other PSB and State radio organisations after the war. The idea for 'The Third' had been imagined much earlier than this at the BBC. Robert Reid in a report (1942) imagined a 'programme' which would act as the "prime re-educative agency of the post-war world" - leading to, as Whitehead argued, an "emphasis on culture as a major component of post-war broadcasting” (Whitehead 1989: 10). ${ }^{15}$ This model for a 'cultural program' (Morris 1956; Schickel 1956; Autissier 1997) provided a new kind of space internationally where much more sophisticated and unashamedly intellectual material could be nurtured.

Thanks to the new 'Third', feature makers, notably Bridson, Gilliam, Cleverdon embarked on substantial projects, involving a range of non-BBC collaborators and international commissioning. Bridson's 1960s American documentary series, also available via BBC Transcriptions (British Library sound archive), included The Negro in America and America Since the Bomb. In their entirety, these series represent how using the grand canvas, the audio documentary could become a powerful form for analysis, but also relay vivid experiences of current events and cultural upheaval. These two series are filled with dramatic actuality, the voices of history being made and unmade, and drawn from American sources that Bridson accessed through his networks in American radio built up over decades. In these programs, we sense the same kind of ambition and effort found in cinema's feature-documentaries. Here intellect

15 Whitehead argues that 'The Third' in turn was influenced by the $B B C$ 's transnational Empire Service, especially its Eastern Service where, during the war, intellectual material was encouraged (Whitehead 1989). 
and emotion mix; scenes made with the voices of poets, artists, ordinary people and leaders are relayed through symphonies of civil unrest transporting the listener, it feels, right into the political maelstrom of 1960 s America. Most notably Bridson "jointly edited" this series of epic scale with leading black American writer Langston Hughes (BBC Third Programme Oct, Nov, Dec 1964: 3).

\section{The Documentary's Renaissance Lead From Berlin and the Feature as 'Acoustic Film'}

While the Prix Italia competition, conducted annually since 1948, encouraged distribution of international works and supported authors through significant monetary prizes - and the EBU had been providing funds and resources for documentary features by also assisting in communication between members through other events, master classes and symposia continuing to the present - German producer Peter Leonhard Braun became dissatisfied with the documentaries he was hearing (at the Prix Italia) in the mid 1960s. Few programs were entered into the documentary category: he recalls dull predictable work (Madsen Braun interview). However, BBC drama experiments in stereo actuality recording presented at the Italia Prize inspired this Berliner to explore stereo field recording in documentary, and the team at SFB soon began experimenting with new microphone techniques. By 1973, Braun won his own Prix Italia for a stereophonic epic featuring church bells and carillons recorded across Europe. A year later Braun lead the Features department at SFB.

This "acoustic film" as Braun labelled it without knowing of Ruttmann (Braun to Madsen 2004), was made on location with "5 languages, and 12,000 kilometres travelled” (Braun 1973). Here was impressive sound design with manipulation of 'Original-Ton' or actuality recordings in post-production. Here bells were transformed into more than sounding objects as their voices or 'personas' spoke back to a buried history. In this witness, Braun's sonic consciousness comes to the fore in a performance which paradoxically registered the silencing of the bells of Europe, then their re-entry from the smelters which had turned them to degraded materiel of war. The narration is also of a 'Mutterband' (trans. mothertrack) style, which was an innovation of Braun's - meaning the original narration language can be replaced with multiple other languages for international broadcast. This 'technique' enabled greater possibilities for trans-national adaptations: a tape would arrive for example with the original montage and sounds in place, but no narrator track. The producer simply needed to record a new narration, dub this back in, resulting in a reversioning of 
the program close to the original. ${ }^{16}$ Braun commenced then in SFB following in the footsteps of his own German BBC inflected features tradition to become a visionary of the field, responsible in large part for moving the feature into a 'new wave' 'acoustic film' phase and promoting international expansion. Early in his career, in London, he had met the man we might imagine started it all, Lance Sieveking, but Braun stressed longtime BBC Features Head Laurence Gilliam was really the most important figure: creating a 'culture of the feature' he emulated.

\section{A New Wave For Radio in Multiple Sites}

The ABC in Australia in the 1970s with its cultural second network was also employing new feature makers and documentarians who looked increasingly to the USA, Canada, and to Europe for inspiration. Kaye Mortley returned to the $\mathrm{ABC}$ after a series of European visits with a huge array of international radio features, and new experience as a 'metteur-en-ondes' from Radio France's atelier de création radiophonique (atelier). After his 1971 Churchill Fellowship tour visiting France, Italy, Germany and the UK, Drama and Features Director Richard Connolly returned with a new idea of 'writing on tape' from Italian RAI (cf. Malatini 1981) (Connolly 1972). The atelier influenced Connolly's Departmental ambitions so much at the ABC that he modelled his new 3-hour show, Sunday Night Radio 2 (1972) on Radio France's atelier. Mortley eventually left the $\mathrm{ABC}$ to pursue and develop her own distinctive art of radio 'documentaire' with the atelier of France Culture (Madsen 2005). The work of René Farabet and this atelier offered not only a more poetic, intellectually expansive approach than she found elsewhere, but Mortley, fluent in French, was also championed by atelier founder Alain Trutat (Trutat/Madsen 2003). Farabet's work, along with Mortley's, made for this originally 3-hour space on the airwaves, also provoked new ways of conceiving of a radio program - as a set of poetic and intellectual propositions for the traveler-listener, but also as a sensuous 'vagabondage' (Farabet 1994) where reality and fiction might meet in 'wild sound' essays, like Mortley's On Naxos (atelier 1993) (cf. Mortley 2013). The exterior public world and a more interior private one meet here, renewing the possibilities of the 'film radiophonique' (Farabet 1994). The very notion of documentary opened further than anywhere else conceptually through the atelier, a response to the events of May 68: here film/composition metaphors applied in quite different ways to that of Braun, connecting to cinema-vérité,

16 Anecdotally, adaptation is much less pursued in this way today, although the internet allows for 'Radio Atlas', a site where a live English translation text accompanies an original language audio 'feature' as you listen: http://www.radioatlas.org/. 
situationist- and fluxus-inspired art/writing. This tradition and space inspired beautiful sensuous 'radio-films' or 'documentaire de création' from Sydney to Helsinki to Zagreb. ${ }^{17}$

In places like Montreal at Radio Canada there had been an even earlier new wave (Brault, Perrault) which connects much more to the French film experiments, but strangely this radio-vérité moment predating cinema vérité, has been omitted from Anglophone histories (White 2009). And then other 'experiments' in the USA were part of the birth of NPR, and the rediscovery of 'wild sound' or on-the-street actuality which had experienced a sporadic history in university-educational and some public radio prior to this although the Pacifica Archives reveals a rich tradition influenced by the European feature. CBC Canada also opened spaces like its Sunday Night show, and its Ideas Series. Glenn Gould was invited to compose his contrapuntal documentaries, imagining ideas of 'North' (1967-1977).

This new wave then started around the same time as its film equivalents - free cinema, cinéma verité and Direct Cinema - influencing these too, although this is an extremely repressed strand of the history of documentary. Producers had also here reached a deeper level of practice, research and reflection on their work, a thinking which accompanies, even if accidentally, the revelation associated with listening and recording and 'writing with the microphone' (Farabet 1994; Mortley 2013). While feature programs were regarded as "un genre artistique autonome" long before this new wave (Clausse 1945: 66), here they assumed a new authority, beauty and sophistication. Alain Trutat heralds an international art form closer to that explored by "film documentarists, Ivens, Murnau, Flaherty, Marker, Rouch" (Trutat-Madsen 2003), while his genealogy also takes us to little known visionaries of the 'film radiophonique' of the surrealists (eg Paul Deharme 1930). The question today might be (to conclude): does the podcast universe continue what was started possibly just over 100 years ago with the laboratory of hearing as imagined by Vertov? Or 90 years ago with Deharme or in radio's first real 'lab' at the BBC where an odd group of recruits played with the dials and the sound effects imagining their kaleidophonic modernity which might offer a new audio-visionary art (Madsen 2013; Sieveking 1934) and a form which would influence a much more expansive field to come, across multiple countries and sites? There is undeniably an international field in radio/audio non-fiction forms flourishing, new creativities in the podcast big bang, unprecedented audiences...indeed these were unimaginable ten years ago. But whether the larger 'Kraftfeld' of features or radio films as imagined by Schnabel, Braun, Farabet, Mortley, and many more, is healthy

17 | Swedish Director of Finnish YLE, Barbro Holmberg, modelled her 'atelier' on the French program: to 'study how the radiophonic language can be used to express what is significant in our time' (Holmberg 2004). 
overall, whether diverse forms and experiments are being widely supported by the key public service media who have hosted and nurtured these developments in the past - this is not so easy to assess - or predict. Will it matter or not if these organisations remain committed to, or retreat from, the documentary radio/audio project - a project which for so long has been woven into the fabric of the PSB project itself?

\section{REFERENCES}

ABC (1948): "BBC Writer-Producer Here On Exchange, To Use Australian Subjects.” In: ABC Weekly, January 24, 1948.

Auer-Krafka, Tamara (1980): Die Entwicklungsgeschichte des westdeutschen Rundfunk-Features von den Anfängen bis zur Gegenwart, Wien: Braumüller.

Autissier, Anne-Marie (1997): France Culture: Role et Programmation d'une Radio à Vocation Culturelle, Paris: Université René Descartes-Paris V.

Barnouw, Erik (1974): Documentary: a history of the non-fiction film, New York: Oxford University.

BBC (1930): BBC Year Book, 1930.

BBC (1939): “Job To Be Done.” In: Radio Times, Jan 13, 1939. http://genome.ch.bbc. co.uk/a578044f981a468eaocb8dfd67bo7c4d.

BBC (1992): BBC Transcription: 6o Years of Radio at its Best, London: BBC.

Brailsford, H. N. (1929): “Fleet Street Symphony.” In: Radio Times, December 15, 1929.

Braun, Peter Leonhard (1973): Glocken in Europa/Bells in Europe: A stereophonic documentary, ARD Prix Italia Transcripts, Germany.

Braun, Peter Leonhard/Madsen, Virginia (2004): Interview with Peter Leonhard Braun, Haus des Rundfunks, Berlin: audio recording.

Bridson, D.G. (1969): "Prospero and Ariel: D G Bridson writes about his career in radio.” In: The Listener 81/2089: pp. 477-479.

Clausse, Roger (1945): La Radio, Huitième Art. Bruxelles: Office de publicité.

Connolly, Richard (1972): Churchill Fellowship Report. Sydney.

Crisell, Andrew (2002): An introductory history of British broadcasting. 2nd ed. London; New York: Routledge.

Crook, Tim (1998): International radio journalism, London; New York: Routledge.

Deharme, Paul (1930): Pour un art radiophonique, Paris: le Rouge et le Noir.

Farabet, René (1994): Bref Eloge du Coup de tonnerre et du Bruit d'ailes. References du Huitième art, Arles: Phonurgia Nova.

Felton, Felix, (1949): The radio-play: its technique and possibilities, London: Sylvan Press.

Fisher, Margaret (2002): Ezra Pound's Radio Operas: the B.B.C. experiments, 19311933. Cambridge, Mass.; London: MIT.

Gale, Thomas (1948): “From Santiago To Shanghai.” In: BBC Year Book 64. London: BBC. 
Goldie, Grace Wyndham (1938): The Listener (502), p. 410.

Gregory, E. David (2002): "Alan Lomax, the BBC and the Folk-Song Revival in England, 1950-1958." In: Folk Music Journal 8 (2), pp. 136-169.

Grierson, John/Hardy, Forsyth (1946): Grierson on Documentary. London: Collins.

Hanrahan, Edgar Brian (2009): The Art of Actuality: Radio, Realism and the Hörfilm, 1924-1932. PhD. Columbia University.

Hendy, David (2013): "Representing the fragmented mind: Reinterpreting a classic radio feature as 'sonic psychology'." In: The Radio Journal - International Studies in Broadcast \& Audio Media 11/1, pp. 29-45.

Hendy, David (2014): "The Great War and British Broadcasting: emotional life in the creation of the BBC.” In: New Formations 82/1: 82-99.

Hilmes, Michele (2012): Network Nation: a Transnational History of British and American Broadcasting, London: Routledge.

Hogarth, David (2001): “The Other Documentary Tradition: Early radio documentaries in Canada." In: Historical Journal of Film, Radio and Television 21/2, pp. 123-135.

Holmberg, Barbro/Madsen, Virginia (2004): Interview Recording. Lucerne, Switzerland. Inglis, K. S. (1983): This is the A.B.C.: the Australian Broadcasting Commission, 19321983, Melbourne: Melbourne University Press.

Johansen, Anne Mette (1986): "Danske radiomontager: Forsvarstale for en til tider overhort genre.” In: Specialopgave, Institut for Nordisk Filologi, Kobenhavn.

Kopetzky, Helmut (2004): Response on radio features, Email to Madsen, V. April 25, 2004. Madsen, Virginia (2005): "Radio and the Documentary Imagination: Thirty Years of Experiment, Innovation, and Revelation.” In: The Radio Journal: International Studies in Broadcast and Audio Media 3/3, pp. 189-198.

Madsen, Virginia (2007): "Cultural Radio at the Crossroads: 'When I Hear the Word Culture I Switch on My Radio': Reflections on an Underestimated Form, 'Cultural Radio'." In: Southern Review 39 /3, pp. 16-37.

Madsen, Virginia (2010): “A call to listen: the 'new' documentary in radio - encountering 'wild sound' and the film sonore." In: Historical Journal of Film, Radio and Television $30 / 3$, pp. 391-410.

Madsen, Virginia (2013): “'Your Ears are a Portal to Another World': The New Radio Documentary Imagination and the Digital Domain.” In: Jason Loviglio, Michele Hilmes (eds.), Radio's New Wave: Global Sound in the Digital Era,London, New York: Routledge, pp. 126-144.

Madsen, Virginia (2017): “Innovation, women's work and the documentary impulse: pioneering moments and stalled opportunities in public service broadcasting in Australia and Britain." In: Media International Australia (MIA) 162/1, pp. 19-32.

MacKay, John (2005): "Disorganized noise: Enthusiasm and the Ear of the collective." In: Section 4: No Noise in KinoKultura 7, January 2005 Accessed July 11, 2017. http://www.kinokultura.com/articles/jano5-mackay.html

Malatini, Franco (1981): Cinquant'anni di teatro radiofonico in Italia 1929-1979. Turin: ERI. 
Morris, J. (1956): “The development of the Third programme." In: Cultural Radio Broadcasts: Some Experiences. UNESCO.

Mortley, Kaye (ed.) (2013): La Tentation du son, Arles, France: Phonurgia Nova éditions.

Nerth, Hans (1966): “Das Feature: Gedanken zu einer neuen Kunstform.” In: Die Welt, August 20, 1966.

Nichols, Bill (2001): “Documentary Film and the Modernist Avant-Garde.” In: Critical Inquiry 27/4, pp. 580-610.

Ortoleva, Giuseppe (1996): “From the Past to the Future.” In: Prix Italia (ed.), The quest for radio quality: the documentary, Naples: RAI, pp. 51-60.

Poulsen, Ib (2006): Radiomontagen og dens radiofoniske rødder: Et studie i den danske radiomontage med vægt på dens radiofoniske genreforudsætninger. Frederiksberg: Forlaget Samfundslitteratur.

Rodger, Ian (1982): Radio Drama. London: Macmillan.

Rogers, Holly/Barham, Jeremy (2017): The music and sound of experimental film, New York, NY: Oxford University Press.

Rogilds, Anne (1989): “Radiomontagen og Montoren.” Thesis (Honours), Kobenhavns Universitet Teatervidenskab, Kobenhavns Universitet.

Ruhnbro, C. (ed.) (2008): Voices/Pictures, Amsterdam: International Association of Women in Radio and Television.

Ryan, Michael P. (2013): "Fritz Lang's Radio Aesthetic: M. Eine Stadt sucht einen Mörder." German Studies Review 36 /2, pp. 259-279.

Scannell, Paddy (1981): “They Did It First.” In: Classic Features, Radio 3 Richard Keen. London: BBC.

Scannell, Paddy (1986): “'The Stuff of Radio': Developments in Radio Features and Documentaries Before the War.” In: John Corner (ed.), Documentary and the Mass Media, London: Edward Arnold (Publishers) Ltd., pp. 1-26.

Schickel, Joachim M. (1956): “Experiences de radiodiffusion culturelle en allemagne.” In: The Canadian National Commission for UNESCO (ed.), Les Programmes Culturels Radiophoniques: Quelques Experiences, Canada: UNESCO, pp. 25-27.

Shapley, Olive/Hart, Christina (1996): Broadcasting a life: the autobiography of Olive Shapley, London: Scarlet.

Sieveking, Lance (1934): The stuff of radio, London: Cassell and Company Limited.

Smirnov, Andrey (2013): Sound in Z: experiments in sound and electronic music in early 2oth century Russia, London: Koenig.

Trutat, Alain/Madsen, Virginia (2003): Interview with Alain Trutat. Paris. Recording. Wagner, Hans-Ulrich (1997): 'Der gute Wille, etwas Neues zu schaffen': das Hörspielprogramm in Deutschland von 1945 bis 1949. Arbitrium 18(1), pp. 107-108 · January 2000. White, Jerry (2009): The radio eye: cinema in the North Atlantic, 1958-1988, Waterloo, Ont.: Wilfrid Laurier University Press.

Whitehead, Kate (1989): The Third Programme: a literary history, Oxford: Clarendon Press. 
Zielinski, Siegfried (1999): Audiovisions: cinema and television as entr'actes in history, Film culture in transition. Amsterdam: Amsterdam University Press. 



\title{
Production and Use of Packaging Elements IN RADIO
}

\author{
Concepts, Functions and Styles in Transnational Comparison
}

Golo Föllmer

\section{Research Questions and Approach}

Call signs, interval signals, jingles, on-air sound design, packaging and radio imaging are terms for a range of broadcast elements that were developed very early on in the history of radio, and elements of this kind have been in use ever since in literally every radio station on earth, most probably at increasing rates. As this chapter will argue, they are far more than ornaments or promotional interruptions, as occasional statements from radio listeners and even from radio practitioners would suggest. Instead, I argue that they should be understood as a crucial part of radio's content, its formal construction and its general auditory experience.

Since there has been little coherent scientific examination of the topic to date, a transnational approach has been chosen here to try to grasp the nature and scope of the phenomenon at hand. By interviewing 21 expert practitioners from five European countries about required competences for packaging production, terminology and functions of radio packaging, the study aims to draw a general sketch of techniques and purposes of packaging. It also aims to determine to what extent there are cultural, national or language-based specifics governing packaging practices in different countries.

In Part I, the article gives an overview of the history of packaging, its various elements, and its functions, informed by existing literature. ${ }^{1}$ In Part II, the methodological approach and the results of the interview study with expert practitioners are discussed.

$\mathbf{1}$ | Part I draws upon the author's German language article 'Jingle' (forthcoming). 


\section{Part I: A Brief Theory and History of Radio PACKAGING}

\section{Terminology}

The term 'jingle' was originally used to describe advertising clips for any consumer product in which all information, including product name and advertising message, is sung. In today's professional parlance it refers to pre-produced components of on-air promotion, in which station names or claims are mostly sung chorally to instrumental accompaniment (cf. Karmen 1989: 20; Haas/ Frigge/Zimmer 1991: 473; Goldhammer 1995: 215). In contrast to advertising jingles, which radio stations broadcast for a fee as external or product advertising, these are also referred to as promotional jingles. Colloquially 'jingle' stands for all kinds of pre-produced audio clips that somehow serve the selfpromotion of a radio station.

Today, the jingle in the professional sense of the word, i.e. as a sung clip, is only one of many types of pre-produced on-air promotion. The term 'packaging elements' (German: 'Verpackungselemente') is used in Germany for all forms of pre-produced on-air promotion - including those broadcast elements that serve solely to structure the program and have no primarily promotional function (e.g. a 'news separator'). Therefore, packaging elements are discussed in their full variety below. Jingles are considered separately both in their historical origin and as a stylistic phenomenon.

Up to now, packaging elements have hardly been systematically examined in scholarship. In view of their massive use in almost all radio formats, it seems obvious that not only the relatively well-researched areas of editorial content and music influence the listeners' attention, moods and attitudes, but also the arsenal of jingles, show openers, bumpers, donuts etc. (for definitions see below) plays an essential role. Studies of the design, use and $t$ function of packaging elements therefore promise highly relevant findings from the cultural sciences. They can provide information on how the attention, mood and attitude of the listeners are directed in the interaction of all broadcast elements. The influence of different radio formats, historical conditions and cultural contexts can be observed by means of comparative study, as undertaken here. In addition to the expert interviews used here, historical source analyses, participant observation during production processes, product analyses and methods of empirical listening research (cf. Föllmer 2016: 301f.) are also promisingmethods for this purpose. 


\section{History}

The oldest surviving jingle was created in 1926 for the product 'Wheaties'. The 30-second rhymed advertising text in an a capella choir arrangement was broadcast by the radio station WCCO in Minnesota. The success of advertising jingles was followed by promotional jingles, when the rapid spread of the so-called Top 40 format on US radio around 1954 led to ever greater similarity and competition between programs. Self-promotion was seen as an inherent necessity of the Top 40 format because the stations' playlists, and thus sound, of only 40 hits hardly differed. As Wolfgang Hagen emphasizes, it is impossible for anyone to "hear a format radio station as a 'radio wholeness'. So it remains uncertain whether it is 'there' if 'I' do not hear it. [...] So all that remains is to paint it onto a prospectus. This is the reason why explicit radio marketing is indispensable, which in the American radio market therefore developed at once and immediately together with the 'Top 40' concept" (2005: 322; transl. by the author).

The step from the original advertising jingle to the promotional jingle also formally meant a connection with the call sign already in use since the amateur radio era of the 1910 s. The call signal should regularly identify the transmitter so that listeners with detector receivers that did not provide a frequency indication could orient themselves in the frequency spectrum. With the introduction of frequency scales on tube receivers, this function lost importance (cf. Thürmer 1942: 46). In the USA, however, the regulatory authority FCC still prescribes today that the official 'call letters' (four-digit letter sequence) and the broadcasting location be named every hour near the full hour (cf. Reese 2010: 127).

Call signs also merged with so-called interval signals. These had the task of filling setup breaks between individual broadcasts in the exclusively live operation of the first radio decade and served as time windows in which connected stations could be switched on and off. In the beginning, for example, alarm clock ticking was used because it was easy to create. With the introduction of sound reproduction technologies of broadcast quality in the 1930s, music could be used that signaled national or regional culture (cf. Thürmer 1942: 46). Memorability played a major role in this. In addition to the voice that named the station, a single instrument (often piano, bells, glockenspiel) usually intoned a concise and well-known musical motif at a sustained tempo. According to Susan Douglas, "Broadcasters had to figure out how people would remember specific information and particular personalities. In the process radio voices - from comedians and newscasters to DJs - introduced Americans, over the years, to the concept of audio signatures - from 'Holy Mackerel' or 'This... is London' to the howl of a wolfman" (1999: 12).

The introduction of multi-track technology in the 1950 s led to increasingly complex productions. From 1959, the Cart standard, using tape loops and sensors, simplified the use of jingles even more by making the carrier medium 
ready to play again by itself after it had been played. With the help of digital technology, loading and playback of packaging elements is now mostly automated and allows dynamic changes, such as changes of instrumentation, during playback.

In Europe, call signs were still in use until the 1970s. Only with the introduction of competition from private radio providers - peripherally by commercial pirate stations starting in the 1960 s, officially in the Federal Republic of Germany with the introduction of the dual broadcasting system from 1984 - did a conversion from simple call signs to complexly produced and increasingly differentiated packaging elements take place. Stylistic standards of the US radio market played an important role in this process.

\section{Types, Styles and Production}

Stylistically, the classical jingle is characterized by a stretto five- to seven-part vocal movement with opulent orchestral accompaniment (cf. Rudin 2010: 392). Vocal groups such as The Modernaires, The Four Freshmen and Mel Tormé and His Mel-Tones were the musical role models for them (cf. Deutsch 2009: unpag.). The layering of several successive recordings of the same polyphonic vocal movement (the so-called stacking technique) gives the voices a characteristic depth and intensity. The orchestration of the instrumental accompaniment was long oriented towards the big band style of the swing era, indeed long after the style had faded from musical fashion. This peculiarity contributed to the fact that jingles are regarded as an independent, original radio genre. Later on, the instrumental movement developed more strongly than the vocal movement, for example by adapting contemporary influences from bossa nova and rock'n'roll and even complete individual styles such as those of the Beach Boys or the Beatles (see ibid.). The voices were repeatedly made more attractive by various fashionable effects, e.g. the robotic sounding 'Sonovox', gargled passages or the unusually high voice of Gleni Rutherford, who used the so-called whistle register (cf. ibid.).

The principle of syndication is essential for the production processes and economy of the jingle business. This works in such a way that jingle packages are created on behalf of a certain station, but are then sold (at more favorable conditions) to many other stations by only re-recording the station name and, if necessary, the slogan, while retaining the choral and orchestral parts.

Bill Meeks founded PAMS (Production Advertising Merchandising Service) in 1951, the first company specializing exclusively in jingle production, which became a trendsetter and market leader for decades and also had a formative effect in Europe (cf. Rudin 2010, 392). After decades of being dominated by jingles in the classic PAMS style by a handful of companies from Dallas, Texas, the production market has now become internationalized and differentiated. 
The classic jingle with its characteristic sound is still in use today, but it has been complemented by many other forms and styles. A cursory listing of a selection of important types of packaging elements makes it clear how differently they are used. Definitions sometimes differ considerably (see Haas/ Frigge/Zimmer 1991: 444f.; Hall/Hall 1977: 349f.; La Roche/Buchholz 2013: 300f.; Wolff 2009: 281f.), which is why they have been adapted for the following overview: Jingle (sung 'Claim'/station name), Image-ID (spoken 'Claim'/slogan over audio logo), Show-Opener (open programs or parts of the day), Bumper (Intro for a piece or a section), Stinger (Outro for a piece or a section), Drop-In (speech line or sound, usually 'dry', i.e. without music), donut (finished package of 'bumper', music bed with live presenter and 'Stinger'), trailer or promo (announcement of upcoming program elements), sound effect (sound such as a telephone bell), sounder (electronically generated signal sound), transition (musical transition between two hit titles) and music bed (program- or rubricspecific instrumental music, over which live moderation takes place).

\section{Functions}

Radio practitioners attribute very specific functions to packaging elements. These can be discussed well on the basis of various internationally used generic terms.

In Germany, the relevant literature most frequently uses the terms 'packaging elements' (Verpackungselemente) or 'packaging' (Verpackung). These terms are analogous to the concept of 'framing', meaning the use of formalized frameworks in conversations. According to this concept, speakers change the framework of a certain reference genre by referring their rhetoric and way of speaking to generally known everyday or media scenarios (greetings, interviews, etc.) (Tolson 2006: 51). Likewise, packaging elements activate specific contexts by means of ways of speaking, musical and tonal codes. For example, when changing from entertaining to informing program components, expectations are 'switched over' by signals. For news, for example, the typical fanfares and the Morse code beeping are often used.

The similarly common term 'layout' emphasizes the orientation function by means of auditory marking of program elements. The concept of 'sign-posting' can describe the orientation function of packaging elements. "Radio has nothing but different kinds of sounds, some of which it uses to establish the beginnings and ends of programs for us" (Crisell 1994: 6; emphasis in original). According to Andrew Crisell, sign-posting in the time-based medium of radio replaces the table of contents, headlines and rubric labeling, which can be grasped at a glance in spatial media such as the newspaper (see also Shingler/ Wieringa 1998: 136). Using such elements, however, radio acoustically reproduces the orientation aid of the newspaper's graphic design. As an example, Crisell equates a typographic distinction in the newspaper (e.g. bold) with the 
tone of a voice in the radio, and accordingly the graphic marking with colors or lines with the jingles, as well as the photo with the actuality. He concludes: "Hence we can regard the music and jingles [...] as a form of radio typography" (1996: 114). Similarly, Martin Shingler and Cindy Wieringa understand packaging elements as "aural punctuation, like commas, semicolons, colons and full stops" (1998: 64), which emphasize the syntax of the program flow.

The commonly used international term 'imaging' refers to the image-forming function of packaging elements. On the one hand, image building takes place massively via the music selection of a station (cf. Shingler/Wieringa 1998: 63). However, with the concept of 'footing' (cf. Goffman 1981: 126f.), the prosody and tone of the moderators and the entire design of packaging elements can also be described as identifiers of specific codes that are used to construct a media-effective 'persona' of both the moderators and the station as a whole (cf. Tolson 2006: 46). Packaging elements as pre-produced expressions of this image are of great importance, since they can be constructed down to the smallest detail and are more calculable in use than moderators who depend on their form that day. "They are a highly condensed expression of all that a station stands for, capturing in seconds the essence of a station's character, style and output" (Shingler/Wieringa 1998: 63).

\section{Practice}

Packaging is often designed to attract attention through high intensity, density and changes of production elements as well as to signal positive values such as liveliness, topicality and happiness. According to empirical studies by Robert Potter and Jinmyung Choi, radio stations are successful with this among their target groups: "[T]he more complex a message was structurally, the more positive the attitudes, the greater the arousal and self-reported attention resulted, and the greater the memory" (2006: 416).

In addition to this positive emotional connotation of the program, constantly repeating the station name is regarded as particularly important, because the amount of revenue per minute per advertisement is based on the station's reach, i.e. its average number of listeners. Since this is determined in many countries (e.g. in Germany) by telephone surveys that query which stations you have recently heard, remembering the station name plays an important economic role and is to be promoted by frequent repetition in jingles, among other things. An investigation of advertising clips seems to confirm this mechanism. The frequent repetition of identical content promotes both memorization and the positive evaluation of advertising content (cf. Domenichini/Gaßner 2015: 272).

The motivation to provide a station with an 'image' and thus to stage it as an 'identity' with the most coherent, recognizable characteristics possible can be attributed to the fact that many listeners perceive radio as a lifestyle medium, 
whereby they often choose those stations that reflect their own values and style (cf. Norberg 1996: 6). Music has an ambiguity here. On the one hand, it is seen as the most important product feature and central marketing instrument of many broadcasters (cf. Shingler/Wieringa 1998: 63). On the other hand, practitioners assume that music does not develop sufficient binding power and so it must be additionally created by packaging (cf. Norberg 1996: 17).

Microstructurally, today's packaging elements contain an immense number of different production elements that are assembled and mixed in the recording studio, including music (originally produced for the jingle or taken from hits or databases of so-called 'production music'), voice (usually a specially cast 'station voice'), natural sounds and a broad spectrum of electronically generated sounds. An example of the latter typical for radio is the swoosh, a provocative glissando hiss that exists in countless variations and introduces or exits many packaging elements. Due to its atonal character, the swoosh can be played over the end and beginning of any music without harmonic 'friction' and is therefore suitable for connecting two program elements, e.g. in transitions. At the same time, its intensive broadband impulse attracts attention for the often subsequent naming of the station name or claim. Similar descriptions could be created for many other production elements and would be helpful e.g. in comparative investigations of packaging elements.

\section{Part II: Interview Study With Expert Practitioners ON RADIO PACKAGING}

\section{Research Aims and Methodology}

Between January 2014 and September 2015, interviews with 21 packaging experts from five European countries were conducted. The transnational study was done with three goals in mind:

(1) A basic objective was to explore the terminological inventory of radio packaging experts. Literature states a broad and sometimes confusing range of terms, even more so when taking sources from different countries into account. While speaking to experts in pre-study explorative conversations, discussions often faltered due to misunderstandings resulting from terminological incoherence, for instance about the meaning of the terms 'jingle', 'layout' or 'packaging'. Terminological clarification therefore seemed necessary. However, since other aspects were at the core of the study, interviewees were not systematically asked about their terminology. Instead, they were asked to state their use of specific terms as they came up. 
(2) The study's core objective was to evaluate a set of circulating functions or 'aims' of radio packaging. As in the case of terminology, functionality is dealt with rather disjointedly in literature. Sources recurrently refer to two functions, namely (A) 'to establish a station idenitity' and (B) 'to create a broadcast flow' (cf. Haas/Frigge/Zimmer 1991: 449; Goldhammer 1995: 217-218; Rudin 2010: 391; La Roche/Buchholz 2013: 301). However, these two functions are not always phrased this coherently, their importance is rated differently, and occasionally additional functions are also mentioned. Clarifying this issue was the core aim of the study, driven by the assumption that the functionality and thus the importance of radio packaging as such are generally underestimated. Regarded in the larger scope of research on the general aesthetics of radio, a step towards a more profound understanding of radio packaging's functions appeared crucial. In the study, the first question (after the warm-up question about the interviewee's professional background and current position) asked about the interviewee's understanding of radio packaging's functions by asking them to comment and rate the two functions mentioned above. ${ }^{2}$ This aspect was then explored in-depth, first by asking about strategies used by the interviewee at his radio station to realize the desired functions. ${ }^{3}$ Second, the interviewee was asked to listen to examples brought by the researcher as well as examples proposed by the interviewee him-/herself. Listening was followed by discussions about different aspects of each example. ${ }^{4}$

(3) Finally, the study aimed to survey whether and to what extent experts adopt national and transnational standards in radio packaging. Listening experience and previous expert advice had led to the hypothesis on the one hand that packaging producers follow (and help develop) country-specific styles. On the other hand, it was hypothesized that they aim to apply international standards. The study meant to identify examples of both of these strategies by asking the interviewees whether they listen across borders in their professional

2 Question 1a: "Imaging is often assumed to have two functions: Sustain and structure broadcast flow (connect, divide, mark etc.) and establish a station sound / station identity (>lmaging ). How do you judge the importance of these two aspects? Are they equal? Are there other aspects?"

3 Question 1b: "What do you/does your station do to reach these goals? How is production done? What are underlying concepts and production steps? How is packaging used on air?" Question 1c: "Which role in packaging play musical style / instruments? What are sno-go s sounds / top sounds for your station? Which role in packaging style of vocal delivery / the vocal talent? What makes a voice appropriate for the format and target group?"

4 | Question 2: "Please describe the listening example: Which radio format and target group does it belong to? What type of packaging is it? What is its function? Which elements make you think the way you do? Does the example fulfill its function well? In how far is the example similar or different from examples at your station?" 
work, whether they adopt styles from other countries and in how far they have the impression to work along a local or national style. ${ }^{5}$

The study was designed as a transnational and trans-format study. Prior conversations had suggested that terminology and assumptions about functionality both vary between experts from different countries as well as between experts from different radio formats. Thus, a study describing practices observed in only one country or in only one type of radio format, even if correct in itself, might have been of limited value when presented to people from other backgrounds. A comparative, transnational, and trans-format interview study appeared capable of grasping common denominators as well as differences between different local or national conventions as well as between different radio formats. Due to resource restrictions, no attempt was made to reach representative results. As it was the first study undertaken with this focus, it was instead decided to gather an understanding of the variabilty and degree of agreement that can be found in a diverse sphere.

Semi-structured interviews with 21 packaging professionals were conducted in personal meetings of 45 to 120 minutes. Experts in Germany, Italy, Denmark, the UK and Austria were chosen according to their individual expertise. Requests asked for 'the person responsible for packaging' at the station, while it was made clear that this could mean a head of department just as well as an executive producer. Only experts from highly acclaimed radio stations or production companies were considered. The study attempted to involve radio stations of major formats, approximating market shares. ${ }^{6}$ Geographical reachability played a role in the choice of countries. ${ }^{7}$

5 Question 3: "Do international models or radio imaging play a role in your production processes? Do you focus more on local or international models? Are there general, transnational, worldwide rules that apply to certain formats, audiences, listening modes or programme types and to radio in general (as opposed to television, online media etc.)? Are there typical national styles in radio? What makes a radio sound typically French, American or Italian?"

6 Interviewees represented: Adult Contemporary Radio (7), Cultural Channels (4), Contemporary Hit Radio (3), News / Info Channel (2), International Service (1), unspecified / different formats (3).

7 Interviewees were (in chronological order of the interviews): Uwe Wassermann (RBB 88.8, Berlin), Finn Marquardt (freelance producer, Copenhagen), Morten Steingrim \& Philipp Meisner (DR, Copenhagen), Stephan Randecker \& Kiron Patka (SWR 1, Stuttgart), Frank Berge \& Martin Spiller (HR Info, Frankfurt/M), Mario Sacchi (RTL, Mailand), Marco Lolli \& Andrea Borgnino (RAI Due, Rome), Piero Pugliese (RAI Tre, Rome), Matt Fisher (BBC Radio One, London), Ben Motley (BBC World Service, London), Wolfram Kähler (WDR 3, Cologne), Angela Traud (WDR, Cologne), Torsten Remy (WDR 1Live, Cologne), Christian Wilke (Dradio Wissen, Cologne), Rüdiger Landgraf (KroneHit Radio, Vienna), Andreas Wilke (Spreeradio, Berlin), Ulrich Weichler (Audiowerk, Berlin). With the exception of informal, pre-test conversations with Uwe Wassermann, all interviews followed the question scheme of the semi-structured questionnaire described in footnotes above. 
Data analysis of the transcribed interviews was conducted in the software MaxQDA. An initial, theory-driven code set was expanded with new inductively derived codes to an overall of 60 codes. Main code categories were institution type $\&$ personal self-description, functions of packaging, packaging production \& usage process, sound material used in packaging, transnationality and overall principles in packaging \& terminology. Quantitative indicators were used for such purposes as assessing the use of professional terms and self-descriptions. ${ }^{8}$

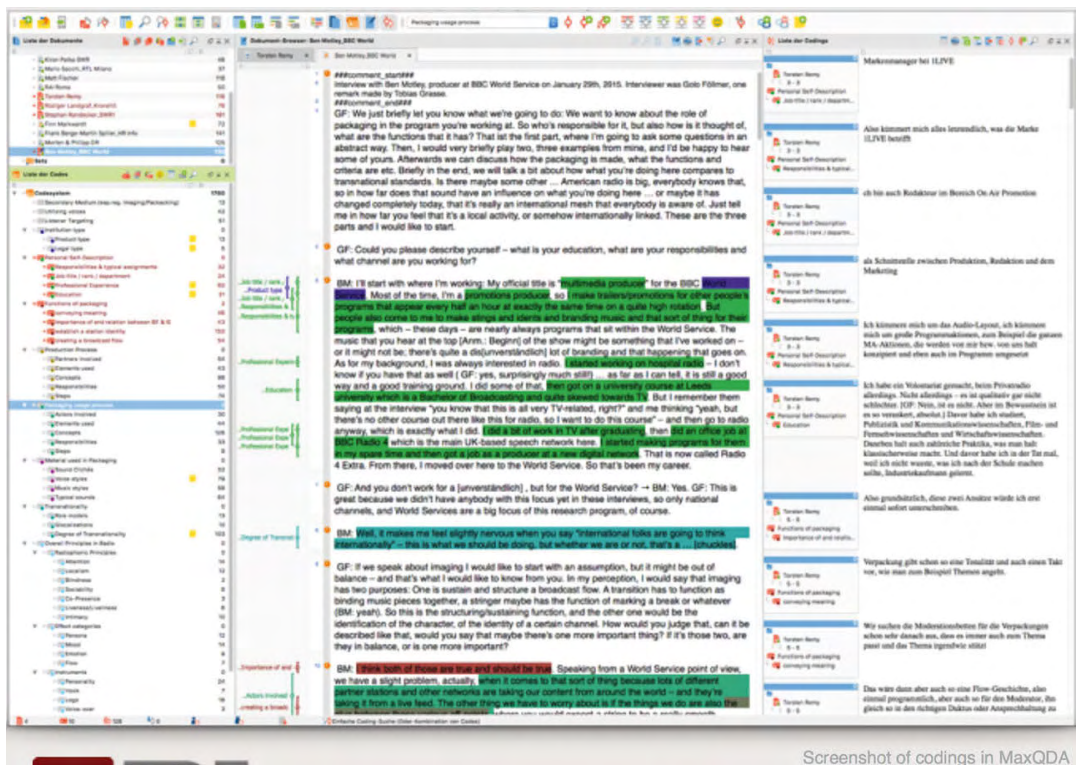

Figure 1: Example of content analysis in the software MaxQDA. On the left, the code set is shown; the center shows a passage from one interview with codings colored according to different codes; on the right, passages from different interviews marked with one specific code are shown.

\section{Results}

A first, unanticipated insight originated from the warm-up question about the interviewee's professional background and current position. Formal professional training as well as job titles proved to vary widely between subjects. Approximately half of the subjects belonged more or less to the management sector and were responsible for station packaging, but did not usually produce it themselves. For some of those, packaging was only one of several respon-

8 Gratitude for this valuable work is owed to Tobias Grasse, who also co-authored the conference presentation of the study's results at the 'Transnational Radio Encounters Conference 2016' in Utrecht. 
sibilities they had, as in the case of program directors, quality or brand managers. Others were responsible for packaging for most or all of their time, as in the case of heads of production or heads of sound design. The other half belonged to executive personnel. Some of them were trained as sound technicians, and producing packaging was one of several recurring tasks they had. Others worked exclusively as producers for on-air design or as editors of on-air promotion.

Subjects consistently stated that required skills were almost never imparted to them, but they had to acquire them autonomously in learning-by-doing processes. This proved valid for typical packaging design skills as well as for an understanding of the individual station sound's nature. As Ben Motley, producer at BBC World Service, puts it:

When it comes to making promotions for [...] the World Service: No-one ever sits you down and says 'this is how we do things.' It's just something that you pick up by listening, like a process of osmosis really. (Interview with Ben Motley, 29.1.2015, London)

Objective (1) of this study, a basic exploration of the terminological inventory of radio packaging experts, brought a set of most commonly used terms to light. In total, the terms 'sound design', 'on-air design' and 'layout' were used most consensually as generic terms for the trade. 'Imaging' was used by British experts only, although recently the term has become more widespread. ${ }^{9}$ The initial research term 'packaging' proved to be used almost exclusively in Germany ('Verpackung'), while the historic 'jingle' was used by two thirds of the subjects, but only rarely as generic term (see the discussion of the term's different uses above). For the purpose of consistency, this article will stick to its initial term 'packaging'.

From the experts' description of their work, the most frequently mentioned types of pre-produced packaging elements were identified to be 'Station IDs' or 'Idents'; 'Showopeners'; 'Promos' or 'Teasers'; 'Bumpers'; 'Stingers'; 'Transitions' or 'Sweepers'; 'Drop-Ins' and 'Music Beds'. In some cases, the replacement of old / outdated terms by current ones could be identified (i.e. the former 'Trailer' is now commonly called 'Teaser').

In addition, a number of important production elements have been identified that are used as raw material or building blocks to produce packaging elements. Those include 'Swooshes' or 'Wooshes', 'Station Voices', 'Hooks', 'Artist Endorsements', 'Logos' and 'Claims'. Some elements, like for instance 'Music Beds', are used as production elements as well as packaging elements.

9 | Two international conferences were held under the title 'Imaging Days' in the Netherlands in 2014 and 2015. 
The study's core objective (2), evaluating the functions of radio packaging, resulted in an extension of the initial two-function model. Experts confirmed the importance of the two functions proposed to them, but differentiated the picture. Function (A), 'establishing a distinct station identity', was confirmed as an important and permanent task as such. However, for function (B), 'creating a broadcast flow', answers suggested broadening the concept to 'structuring content' in the sense of offering orientation, calling for attention, creating consistency (in the sense of the initial 'broadcast flow') and regulating overall energy and pace of a program.

Depending on their station's format, answers varied. Matt Fisher from then CHR station BBC Radio One insisted to focus on music: "So what we want to do is maintain the music flow...” (Interview, 28.1.2015, London). Wolfram Kähler from the cultural channel WDR3 focused on the structuring function: "... in order to separate and announce, really send a signal: 'Attention! Something ends or starts here."' (Interview, 31.3.2015, Cologne) Rüdiger Landgraf from the AC station KroneHit Radio valued this function generally less important in his station: "In format radio the ID function is more important than ... structuring shows..." (Interview, 5.5.2015, Vienna).

Most importantly, a third function of packaging emerged in the discussions. Several experts emphasized packaging's additional task of 'conveying meaning'. In their view, this includes momentary regulation of energy, pace or 'punch' of the program. Tosten Remy from the CHR station WDR ILive explains: "Packaging sets [...] tonality and [...] pulse, how you approach topics for instance." (Interview, 1.4.2015, Cologne) As Remy's statement indicates, it also includes laying appropriate moods or 'tonalities' for specific topics, for featured personalities or shaping the attitude towards a topic or personality. Packaging thus also serves as non-verbal announcement, conveying certain meaning to an upcoming subject or classifying it in a specific sense. Figure 2 shows an extended model of packaging functions.

Question (3), whether and to what extent experts adopt national and transnational standards in radio packaging, showed very clear results. Experts confirmed that listening across borders, visits to foreign radio markets and contact to packaging producers working internationally is a standard in radio packaging. Several subjects emphasized their deliberate orientation towards foreign stations when searching for new ideas in their packaging work. However, they also emphasized that transnational inspiration always has to be format specific. Torsten Remy from the CHR station WDR ILive for instance pointed to BBC Radio One as their major role model: "Of course we have a look. And to be honest: BBC One is THE reference.” (Interview, 1.4.2015, Cologne) In fact, several interviewees judged the radio format to be a stronger influence on their work than cultural specifics. 


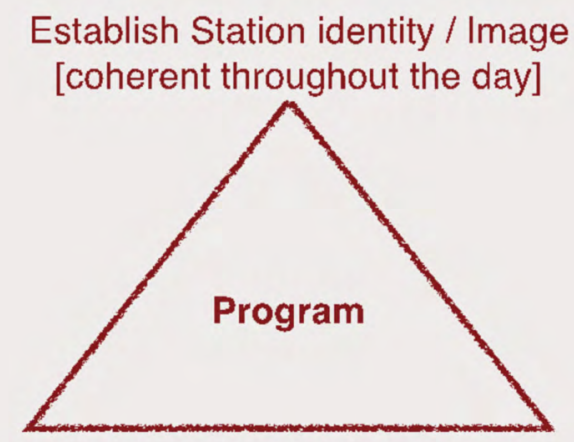

\section{Structure content}

» orientation in program, time of day etc.

» call for attention

Convey meaning

" topics

"broadcast flow

" moods / tonality / pulse

" attitudes / identity markers

» regulate energy/pace

" affiliation to social groups

Figure 2: Extended model of packaging functions.

I think it's more of a format thing than a country thing. In Europe, I don't see huge differences. (Interview with Torsten Remy, 1.5.2015, Cologne)

If you go to an Italian commercial station you will find this sound [...] very similar to every top 40 station in the world. (Interview with Andrea Borgnino, 29.10.2014, Rome)

Formats are stronger than cultural constitution. (Interview with Rüdiger Landgraf, 5.5.2015, Vienna)

However, experts confirmed the existence of certain national and regional differences. They observed single characteristics like the trend in Danish packaging not to sing any jingles. They also reported that North Americans like brass orchestras, Austrians love melodic jingles and Latin Americans use a lot of reverb on voices in packaging.

Furthermore, overall impressions of national production styles were stated, like the image of a 'big American sound' which appears very loud and punchy, of German packaging being not as 'overproduced' as American radio and that Germans prefer a more natural sound design.

\section{Conclusion}

In summary, the clear results suggest that the methods were chosen appropriately. Some terminological confusion could be clarified by correlating terms found in literature with the individual terminologies of the experts. 
Most importantly, three core functions were distinguished: (1) the establishment of a coherent station image through musical, tonal, vocal and linguistic means; (2) the structuring of the program content in order to provide orientation in the hourly rhythm and in the daily and weekly program on the one hand; to highlight the transitions between individual program elements in a syntactic structure on the other hand; sections are thereby clearly separated from one another e.g.; (3) the transmission of information in order to arouse curiosity about program content, address special listener groups and establish topic-specific expectations and moods.

Furthermore, the weight of transnational influences was put into perspective: On the one hand, experts made clear that today's radio formats are stronger than cultural constitutions. On the other hand, rather specific national or language-based styles like i.e. a 'big American sound' vs. a 'more natural German' packaging style were identified.

Finally, a vast amount of profound arguments added up to a strong claim: that today packaging - if well crafted and fine-tuned to the needs of individual programs - is much more than self-promotion: it is a fundamental component of potentially every radio program, because it helps listeners identify a program, find orientation in the program structure, and adjust to changes in program content.

\section{REFERENCES}

Crisell, Andrew (1994): Understanding Radio. New York: Routledge.

Deutsch, Ken R. (2009): The Jingle Book, self-published.

Domenichini, Bernard/Gaßner, Hans-Peter (2015): "Spots zum Hinhören - Eine forschungsbasierte Anleitung zur Gestaltung erfolgreicher Radiowerbung”. In: Media Perspektiven 6, 269-275.

Douglas, Susan J. (1999): Listening In: Radio and the American Imagination. New York: Times Books.

Föllmer, Golo (2016): "From stationality to radio aesthetics: Investigations on radiophonic sounds”. In: Jens Gerrit Papendorf/Holger Schulze (eds.): Sound as Popular Culture: A Research Companion. Cambridge, MA, 301-312.

Föllmer, Golo (forthcoming): “Jingle” In: Daniel Morat, Hansjakob Ziemer (eds.), Handbuch Sound. Geschichte, Begriffe, Ansätze, Metzler: Stuttgart.

Goffman, Erving (1981): Forms of Talk. Philadelphia, PA.

Goldhammer, Klaus (1995): Formatradio in Deutschland. Konzepte, Techniken und Hintergründe der Programmgestaltung von Hörfunkstationen. Berlin.

Haas, Michael/Frigge, Uwe/Zimmer, Gert (1991): Radio-Management. Ein Handbuch für Radio-Journalisten. München: Ölschläger. 
Hagen, Wolfgang (2005): Das Radio. Zur Geschichte und Theorie des Hörfunks. Deutschland/USA. München: Fink.

Hall, Claude/Hall, Barbara (1977): This Business of Radio Programming. New York: Billboard Books.

Karmen, Steve (1989): Through the Jingle Jungle: The Art and Business of Making Music for Commercials. New York.

La Roche, Walter von/Buchholz, Axel (eds.) $\left({ }^{10} 2013\right)$ : Radio-Journalismus. Ein Handbuch für Ausbildung und Praxis im Hörfunk. Wiesbaden.

Norberg, Eric G. (1996): Radio Programming: Tactics and Strategy. Boston, MA: Focal Press.

Potter, Robert/Choi, Jinmyung (2006): “The effects of auditory structural complexity on attitudes, attention, arousal, and memory”. In: Media Psychology 8, 395-419.

Reese, David E. (2010): “Call Letters”. In: Christopher H. Sterling (ed.): The Concise Encyclopedia of American Radio. New York: Francis \& Taylor, 127-129.

Rudin, Richard (2010): “Jingles”. In: Christopher H. Sterling (ed.): The Concise Encyclopedia of American Radio. New York, 391-393.

Shingler, Martin/Wieringa, Cindy (1998): On Air: Methods and Meanings of Radio. London: Arnold.

Thürmer, Ferdinand (1942): "Blick in die Rundfunk-Welt”. In: Welt-Rundfunk 1, 46f. Tolson, Andrew (2006): Media Talk: Spoken Discourse on TV and Radio. Edinburgh. Wolff, Daniel (2009): "Produktions- und Verpackungselemente". In: Peter Overbeck (ed.): Radiojournalismus. Konstanz, 281-291. 



\section{Makrolab as an Apparatus for Global Observation}

\section{Heather Contant}

Imagine perceiving every radio signal floating around you. You could tune into news and hit tunes on AM and FM stations as well as transmissions at frequencies beyond the dial, like the unintelligible digital data streams emitted by cellular devices, wifi routers, and other wireless technologies. You could even hear strange bursts from outer space and audible traces of lightning from the ionosphere. This might remind you that radio is a natural phenomenon, a form of electromagnetic energy left over from the beginning of the universe that humans have only relatively recently learned to interact with for telecommunications purposes. Soon, you might begin to wonder about the potential of these omnipresent radio waves. Could they do more than simply transmit information? Could humanity's interactions with them change? Could they change humanity's interactions?

Now consider Makrolab (Ladomir-Faktura: Third Surface): a mobile art installation that travelled the world from 1997 to 2007 giving individuals, like yourself, the opportunity to experience the planet's vast oceans of radio waves. This ambitious endeavor featured specialized equipment to receive signals at frequencies throughout the radio band of the electromagnetic spectrum from sources like shortwave stations, mobile phones, navigation systems, television broadcasts, and communications satellites. During intensive residencies, Makrolab participants worked on scientific and artistic research projects that creatively engaged with Earth's invisible wireless backbone, its “information networks that provide the operating systems of the planet" (Eshun 2003: 14).

The following discusses one artistic research project from Makrolab's 1997 debut, an experimental composition for German airwaves entitled Signal Territory I, which was later released on CD in 2002. This sonic artwork inspired audiences to imagine new possibilities for global telecommunication by aesthetically repurposing transnational radio signals intercepted by Makrolab. This particular example demonstrates how the artistic and scientific research that took place aboard Makrolab helped answer the question: What can the public gain from creative engagements with transnational radio? 


\section{A Platform or Global Radio Engagement}

In its ten years of operation Makrolab hosted over a hundred artists, scientists, and media tacticians to conduct research on "invisible power structures which at this very moment shape the state of the world" (Peljhan 1997). In particular, its crews studied three global systems: telecommunications, weather and climate, and migrations. This massive undertaking began in 1994 when Slovenian radio enthusiast and theatrical director Marko Peljhan travelled to the Croatian island of Krk during the Yugoslav Wars. Here, he noticed a juxtaposition between the region's silent war-torn landscape and its cacophonous electromagnetic sphere being used to facilitate nearby military operations. This experience inspired him and "a team of young Slovenian hackers, bedroom engineers and radio hams" (Haskel 1997: 60) called the Projekt ATOL Institute to develop Makrolab as a mobile and environmentally sustainable research and life-support station for the seemingly inevitable post-apocalyptic world. Their first diagram for the project - essentially a conceptual artwork - incorporated wind and solar power, heating and lighting units, audio and video manipulation, media transmission, and radio reception. These technological components all rested upon a foundation of theoretical writings by Peljhan, Projekt ATOL, and others like Russian Futurist Velimir Khlebnikov. In 1921 Khlebnikov envisioned "The Radio of the Future," where telecommunications provided "the central tree of our consciousness" connecting all humanity (1990: 155). Today, Khlebnikov's words read like a prophecy of 21st century networked culture, where individuals link to knowledge and one another via worldwide webs of data.

Peljhan's and Projekt ATOL's conceptual plans began to materialize in 1997 when Makrolab debuted as a massive heptagonal prism on Germany's desolate Lutterberg Hill for the documenta X arts festival. Solar panels, antennae, and satellite dishes protruded from this mobile and environmentally sustainable vessel for living and working, which could "support 3 people for up to 40 days" (Haskel 1997: 60). Peljhan described how this autonomous structure promoted a methodology of "insulation/isolation" because it insulated small crews in isolated locations to "produce more evolutionary codes in social relations" by encouraging collaboration among those in residence (1997). These small crews of so-called Makronauts remained wirelessly tethered to the outside world via radio equipment that received frequencies "from only 100 kilohertz to twelve or even thirteen gigahertz" (Marko Peljhan's Invisible Territory 2007). This gave crews access to local and transnational signals from things like satellite telephones, air traffic navigation systems, and the Mir spacecraft orbiting above (Lovink 1997). The angular construction of the Makrolab structure even mirrored these objects of study, looking like a "meteorological research center, or even more, like a stranded space station" (Holmes 2007) amid Lutterberg Hill's 
open wilderness. Instead of looking down on Earth from above though, this futuristic apparatus gazed upwards to observe the constellations of wireless devices hoisted to the heavens for telecommunications.

Over the next decade, updated versions of this iconic structure insulated and isolated crews around the world as Makrolab migrated to Rottnest Island, Australia (2000); Blair Atholl, Scotland (2002); and Isola di Campalto, Italy (2003-2004). Plans to end this journey with a permanent installation in Antarctica underwent revision after trips to the Northern and Southern circumpolar regions (2006-2007) revealed multiple challenges. In a sense, Makrolab continued to live on though, through the Arctic Perspective Initiative (API), a transnational working group founded by Peljhan and former Makronaut Matthew Biederman in 2009. This non-governmental organization applied lessons from Makrolab to promote "sustainable empowerment of the local citizens of the North via new communications, sensing, aggregation, transmission, and information sharing" technologies (Arns et al. 2010: 11).

\section{Interventions AND Possibilities of WIRELESS TERRITORIES}

During Makrolabss debut on Lutterberg Hill in the summer of 1997, crews amassed an archive of wireless transnational interceptions by tuning into frequencies throughout the radio band of the electromagnetic spectrum and recording what they encountered. A group of participants working under the moniker Signal Territory used this material to create an experimental composition called Signal Territory I for German public broadcasting. They developed this hourlong sonic collage by sampling, processing, and remixing Makrolabs archive of interceptions at the Hessischer Rundfunk's Hörspiel Studios in Frankfurt for a series featuring documenta X artists. Projekt ATOL's record label, rx:tx, re-issued Signal Territory I as a CD in 2002. The CD's final track included raw samples and some of the interceptions heard throughout the composition under a General Public License, which encouraged practitioners to continue engaging with transnational radio by repurposing intercepted material in future work as well. Signal Territory's artistic reconfiguration and public redistribution of Makrolab interceptions politically and poetically intervened upon global systems of wireless telecommunications by giving the public a chance to perceive and evaluate its interactions with radio - transnational and otherwise.

Signal Territory's creative redistribution of Makrolab's interceptions politically intervened upon wireless global systems by demonstrating how audiences could appreciate and interact with seemingly forbidden networks of transnational radio communication. The composition began with a voice reading sections of Khlebnikov's “The Radio of the Future" in German before introducing 
listeners to frequencies throughout the radio spectrum. Audiences heard transmissions from rarely encountered sources like the satellite telephone network INMARSAT, which provided worldwide coverage to militaries, media outlets, corporations, non-governmental organizations, and other political entities. In 1997 portions of the INMARSAT network made long-distance telephone conversations possible in remote locations by transmitting voices up to a satellite and back down to Earth using analog radio technology. According to media artist Brian Springer, this meant that Makrolab's inaugural crew could simply tune into frequencies around 1.5 Gigahertz to hear and more importantly understand INMARSAT calls taking place "across five countries or more" without the aid of software to decipher digitally encoded audio (Lovink 1997). This was a moment of transition in the history of telecommunications though, as analog platforms were being "supplanted by the growing spread of digitized data" (Birringer 2000: 154), making this technique of interception more difficult by transforming intelligible voices into unrecognizable streams of digital prattle. When Signal Territory redistributed Makrolab's interceptions as sonic artwork, they encouraged listeners to appreciate analog radio's characteristic sounds before they became an aural relic of the past. Their composition also introduced audiences to the transnational radio activity occurring on seemingly inaccessible networks like INMARSAT, which gave the public a chance to consider the implications of such global systems of wireless telecommunication as they entered the new millennium.

The simple act of publicly rebroadcasting Makrolab's interceptions even flipped narratives of security, surveillance, and control implied by such hightech global wireless communication networks. A clip included as bonus material on the Signal Territory I CD demonstrates that users of this service clearly expected privacy:

Omar: Mark this line is not secure [...] Do you think I should stay on the line? Or if you're discussing something -

Mark: That's a really good question 0 mar. Probably, we ought not to continue this conversation since you're on landline [...] Is there a possibility of you getting to a satellite? (Signal Territory 2002)

As Inke Arns explained, Makrolab's eavesdropping on supposedly secure wireless lines helped audiences "develop their own understanding of surveillance and control methods" by demonstrating that global telecommunications technologies were not only reserved for major political entities (Arns 2004: 67). Makrolab's successful intervention into these communication channels illustrated that anyone with the right receiver could interact with networks like INMARSAT. It also made the case that the public should have the right to interact with such systems because they rely upon radio waves - a common global re- 
source - to function. By remixing and publicly redistributing the interceptions from Lutterberg Hill in an artistic context, Signal Territory I presented these messages from Makrolab to a wider audience in a manner that inspired further reflection on radio's public potential.

This composition also poetically intervened upon global systems of wireless telecommunication by re-presenting them as transnational constellations of material elements prone to public intervention and reconfiguration any time. As Douglas Kahn explained, "the global breadth of any single transmission" results from wireless technology's dependence upon complex amalgamations of human, technological, infrastructural, and environmental interactions to facilitate communication on a planetary scale (2013: 19). You hear the side effects of these frequently precarious technological arrangements whenever electronic stutters, hisses, or dropped calls interrupt your wireless experience. We generally perceive such interferences as malfunction and aim to eradicate them by repairing the individual components within large-scale wireless constellations, including things like poorly tuned resistors, corroded circuits, misaligned satellite dishes, unfavorable atmospheric conditions, and even user error.

However, Signal Territory took a different approach. Instead of trying to fix the so-called disturbances collected by Makrolab, Signal Territory incorporated these noises into their composition. Their inclusion of generally unwelcome sonic intruders became a constant reminder of the entanglement of radio waves with material objects and circumstances throughout Signal Territory I. It revealed both the delicacy and relative openness of the global constellations created by individual material components - a constellation which Makrolab became a part of during its installation on Lutterberg Hill. Giving audiences a chance to appreciate the materiality of global wireless configurations in the present helped the public envision new constellations of wireless technology for the future by illustrating just how easily their material elements could be reconfigured. When, for example, Signal Territory heard a Makrolab interception capturing the final words of a dropped INMARSAT call, they sonically enhanced the disconnected voice in the Hörspiel studio at Hessischer Rundfunk to transform the lines of the following soliloquy:

I'm losing you Jane, so I think we must be, um, going - I'm losing the satellite link, so, um, [...] I don't know if you can hear me anymore, but, um, I'll see you when you get back from holiday and sort things out then, and, um, all the best, enjoy. Cheers then, um, bye! (Signal Territory 2002)

Anyone who has ever experienced a wireless configuration gone out-of-whack can recognize these words, which seemed almost poetic after Signal Territory's in-studio processing added reverb and delay to make them sound especially distant and isolated. The voice's juxtaposition against an insistent hiss of radio 
static invited listeners to attend to the chaotic energy of these electromagnetic waves in a deeper, more contemplative manner. As poet Sean Street explained, when we hear a voice that calls "out to a universe that doesn't answer," we listen carefully for a response in the silence that follows (2016). He compared this experience to a composition called "Sound Fishes" by Pauline Oliveros, which instructs participants to listen "for what has not yet sounded - like a fisherman waiting for a nibble or a bite" (2005: 50). Signal Territory borrowed this expectant trope when it layered the disconnected INMARSAT caller's soliloquy over an unresponsive bed of radio static. Their artistic gesture seemed to summon participation in Makrolab's exploration of Earth's invisible telecommunications systems by inviting the public to carefully attend to a sea of radio energy in order to catch a glimpse of the possibilities flittering just below the surface of its electromagnetic waves.

Signal Territory I provided listeners with an opportunity to observe and reflect upon the political and aesthetic possibilities of transnational radio through a sonic composition that remixed, processed, and redistributed interceptions from Makrolab's installation on Lutterberg Hill in 1997. The composition's broadcast and subsequent release as a CD allowed the public to experience portions of the radio band of the electromagnetic spectrum that they rarely encountered and illustrated what audiences could learn from creative engagements with transnational radio like those that took place aboard Makrolab. This particular project revealed how artistic intervention into global systems of wireless telecommunication can inspire audiences to better understand and imagine new possibilities for public interaction with Earth's radio waves across the planet.

\section{REFERENCES}

Arns, Inke (2004): "Faktura and Interface: Hlebnikov, Tesla and the Heavenly Data Traffic in Marko Peljhan's makrolab (1997-2007).” In: Katja Kwastek (ed.), Ohne Schnur: Art and Wireless Communication, Berlin: Revolver, pp. 62-79.

Arns, Inke/Biederman, Matthew/Peljhan, Marko (2010): “Arctic Perspective Initiative.” In: Müller, Andreas (ed.), Arctic Perspective Cahier No. 1: Architecture, Ostfildern: Hatje Cantz, pp. 10-13.

Birringer, Johannes (2000), Performance on the Edge, London and New Brunswick: The Athlone.

Eshun, Kodwo (2003): “Makrolab's Twin Imperatives and Their Children Too.” In: Makrolab: Arts Catalyst, pp. 6-14.

Haskel, Lisa (1997): "Pretty Good Pirates.” In: Mute 1/9, pp. 60-61.

Holmes, Brian, "Coded Utopia: Makrolab or the art of transition." March 27, 2007 (https://brianholmes.wordpress.com/2007/03/27/coded-utopia/). 
Kahn, Douglas (2013): Earth Sound Earth Signal: Energies and Earth Magnitudes in the Arts, Berkeley, Los Angeles and London: University of California.

Khlebnikov, Velimir (1990): “The Radio of the Future.” In: Charlotte Douglas (ed.), Paul Schmidt (trans.), The King of Time: Selected Writings of the Russian Futurian, Cambridge, MA: Harvard University, pp. 155-159.

Lovink, Geert (1997): "Communications Equipment check with Marko Peljhan and Brian Springer.” July 20, 1997 (https://nettime.org/Lists-Archives/nettime1-9707/msgooo9o.html).

Marko Peljhan's Invisible Territory. Directed by Zemira Alajbegovic. Ljubljana: Radiotelevizija Slovenija, 2007. Retrieved from "Peljhan Territories", January 2007, (http://www.ladomir.net/Marko-Peljhan-s-Invisible-Territory-2007).

Oliveros, Pauline (2005): Deep Listening: A Composer's Sound Practice, Bloomington: iUniverse.

Peljhan, Marko (1997): “Insulation/Isolation Proceedings.” Retrieved from "Makrolab”, August 31, 1997 (http://makrolab.ljudmila.org/peljhanı.html).

Signal Territory, Signal Territory I. CD. Ljubljana: rx:tx, 2002. (https://rxtx.bandcamp.com/album/signal-territory-i)

Street, Sean (2016): "Listening for an echo: The sound poetics of identity." Presentation at Transnational Radio Encounters Conference, Utrecht, The Netherlands, July 5. 



\title{
Transcultural Audio Storytelling: When German, Australian and African VOICEs Meet
}

\author{
Siobhán McHugh
}

Within the genre of crafted audio storytelling, the transnational nature of podcasting delivers huge potential to cross-fertilise culturally different traditions, as producers around the world can listen to, emulate and extend a newly accessible trove of audio aesthetics and content. An imminently productive transcultural liaison was that between the US-based Spanish-language NPR podcast Radio Ambulante and Gimlet Media's hipster internet-themed podcast Reply All (2015), which refashioned a Radio Ambulante story by Daniel Alarcón (2015) about an ordinary Guatemalan woman whose social media post unexpectedly unleashed huge anti-corruption protests. The Radio Ambulante episode, "\#RenunciaYa", was reversioned as "Quit Already", to suit US host P.J. Vogt's scripted "spontaneous" narration and allow him to re-interview the key subject, Lucia Mendizábal, instigator of the campaign. A comparison of both treatments is outside the scope of this article, but merits scholarly interest.

This article will examine in a similar example of transnational liaison what cultural accommodations were made to enable a complex crafted audio documentary created in a German feature making tradition to be adapted to an Australian storytelling style for an English-speaking audience. It will do so by drawing on interviews with the two Australian producers, Sharon Davis and Russell Stapleton, and on comments by Jens Jarisch, author of the original German feature. It will interpolate analysis from two critics, English audio feature producer Alan Hall and Australian scholar Virginia Madsen, who demonstrate a nuanced understanding of the "invisible achievements" (Aroney 2005: 397) of the crafted audio feature and an appreciation of the highly choreographed placement of sound in an excellent radio documentary - an artifact described as "the built form par excellence of radio journalism" (Hendy 2009: 221). The analysis by Hall and Madsen is informed by a framework for criticism and deconstruction of the crafted audio feature form that has been established by the journal RadioDoc Review (2014). This journal, of which the author is 
Founding Editor, was created to fill a gap in scholarship and critical discourse about highly produced audio features, a field that has rapidly expanded since the advent of podcasting (McHugh 2014). RadioDoc Review's analysis matrix identifies key characteristics of optimal audio storytelling. These address storytelling strength, dramaturgical coherence, originality and innovation; journalistic craft and sonic artistry; emotiveness, empathy and audience engagement; depth of research, ethics and complexity of character portrayal.

\section{KINDER VON SOdOM UND GOMORRHA /CHILDREN OF SODOM AND GOMORRAH: A CASE STUdY IN transnational Radio Feature Production}

Kinder von Sodom und Gomorrha (KSG) was first produced in German by German radio producer or features author, Jens Jarisch, and broadcast in 2009 at a duration of $53^{\prime} 25$ on European radio stations RBB, SWR, NDR, WDR and NRK. Jarisch, who was born in 1969, grew up in Berlin, Tehran and Lima, so he came to radio with inherent crosscultural sensibilities. He was an accomplished producer before producing KSG, having won two Prix Europas. Billed as Kinder von Sodom und Gomorrha: Warum afrikanische Jugendliche nach Europa flüchten (Children of Sodom and Gomorrah: why young Africans flee to Europe), the feature won the prestigious Prix Italia in 2010. The core story examines the dumping of toxic e-waste in Africa by western countries and the effects this has on children who scavenge the waste scrap heaps. This investigation is overlaid with the yearning of the poor young Africans Jarisch met, to escape to Europe and its imagined comfort. In 2011, the feature was reversioned in English by an acclaimed ABC Radio National duo: producer Sharon Davis, one of Australia's most awarded feature producers, and Russell Stapleton, an eminent sound engineer who has won Prix Italias for drama. This English-language version, Children of Sodom and Gomorrah (CSG), won the Director's Choice Award at the Third Coast International Audio Festival, 2011.

When Sharon Davis heard Jarisch's original feature, she was struck by its power and contacted Jarisch to see if he would be amenable to the idea of an English version. The complex architecture Hall (2014: 2) describes (“...beautiful sound recordings, even of the most barbarous scenes, an elegant choreography in the compilation of actuality and a narrative architecture that carries the listener through nearly an hour of complex, layered radio in one cinematographic sweep") was pulled apart and reworked from the original recordings made by Jarisch. "He was able to give us the full layout of the original mix on Pro Tools with all the individual tracks delineated (narrator, reporter, interviews, sound, music) as well as copies of the complete original recordings," explains Davis. 
This meant that sound engineer Russell Stapleton and I were able to unpick the mix itself and find additional sound, or original English recordings (because many of the interviews were in English) as well as additional sound, to reconstruct the program in English, and lay in an English narration. It was a time-consuming but worthwhile process. (Davis 2017)

In KSG, the African voices are heard briefly in English before being overlaid with translation by a male German narrator. Just losing that layer of intervention greatly increased the feature's raw power. Other changes were easily accommodated, such as having Jarisch re-record his German narration in English as "The Reporter." Translation brought its own disturbance. "The rhythm and pacing changed a great deal," recalls Davis. "We had to find much more sound to work with under the narration, because the English translation was longer then the German original. We were helped by access to Jens' original recordings and the genius of Russell Stapleton." Stapleton describes it as "an elaborate process of unstitching and re-embroidering. Peeling back the actuality often revealed bits of gold I was able to work in around the script so they'd bounce off each other...I remember it as being very detailed but very rewarding" (Stapleton 2017). For example, in mining the original recordings, Davis and Stapleton found and included a child using the phrase "bad man", not heard in KSG. Interviews with customs officials who spoke in English in KSG were counterpointed with an 'echo' technique of repeating key words of jargon in German; Davis decided the device could still work as an Englishupon-English tier.

Madsen finds echoes of Dante and Milton in the way Jarisch, objectified as The Reporter in the feature, can be seen in the role of a pilgrim or traveler as he traverses shantytowns and villages, bringing the listener on a voyage of interpretation and discovery. She locates Jarisch's production techniques from the Kafkaesque echoing of bureaucratic language to the use of second and third person voice by the cool studio narrator, as being part of a "long and exploratory radio feature tradition, which has nurtured a highly sophisticated auteur culture and practice" in Germany (Madsen 2014: 7). It initially borrowed from styles established by the BBC in the 1930s, before reinventing itself in successive waves after World War Two, particularly in centers such as Berlin and Hamburg.

The historical associations between British and German feature making notwithstanding, contemporary feature producers in Europe and the UK take quite distinct approaches. Practitioners such as Hall speak of a "documentary feature", a poetic, sound-rich work occupying a territory that lies somewhere "between the concert hall and the cinema" (Hall 2010: 101). Respected UK scholar and producer Seán Street suggests that the "documentary feature" is distinguished by the personal mediation by the producer of content, a quality that in one sense links back to the authored European feature: 
A documentary CAN be a feature, when it documents the maker's journey as they [sic] seek a way through their subject, asking questions of themselves as much as their chosen story, often through evocation rather than exposition. (Street 2014: 2)

In the European tradition, a formal narrator is often heard, such as in KSG. Hall admits to feeling discomfort with Jarisch's complex deployment of narrator devices, which he attributes to his own cultural conditioning.

For a British audience, the terms of the contract between documentary producer/reporter and listener are built on expectations rooted in long-established journalistic conventions [...] This documentary, even in its Australian re-versioning, retains the technique of much German feature making in detaching the narrative voice from the author (the reporter or producer) [...] it is Jarisch's experiences that we're invited to share but not his voice that carries the burden of presentation; it is his words we hear but they are delivered, in the German manner, by an anonymous narrator. Jarisch is nevertheless the author. (Hall 2014: 3)

In reversioning KSG, Davis sought to honour the spirit of Jarisch's creative approach. But as an Australian, mixing a version for an English-speaking audience, she was particularly conscious of hitting the right tone for the central narrator role. "We did not want a cold, disconnected voice, which is a feature of some European productions.” (Davis 2017) In Jarisch's original feature, Davis saw the narrator role as

[...] a very 'literary' device, cinematic even [...] It provides a distance and is very clearly an outsider's perspective on the story itself. This is not a story being told by the young African characters in it-it is clearly a story told by a western voice, bringing with it a western cultural perspective that may not be shared by these young African men and women. Yet it is also a voice of warmth and empathy. So one of the key questions for us as producers of the translation was to find a voice that reflects both distance and warmth. (Davis 2017)

Davis eventually settled on the Australian actress Rebecca Massey and coached her until she felt she had achieved that dual effect. But to Hall's English ears, "the uneasy dance of intimacy and distance" (Hall 2014: 4) in the production was still disturbing.

We hear authentic, 'hot', present tense conversations, scenes and events. These are filtered through the usual processes of deliberation - selection, editing, compilation - before being framed for broadcast by a cooler, emotionally detached narrator. The language that the narrator uses is a combination of description, poetic reflection and an emotional engagement with the stories it's sharing. The shifting blend of second and third person narration - speaking on behalf of and then directly to the authentic voices we hear - and further sophisticated production devices (the echo voice, dynamic recording perspectives and jump 
cuts) are intended to enhance the telling of the tale, pulling us into its world. But they just as readily have the effect of distracting us from it, pushing us away. (Hall 2014: 4)

After the initial contact, Jarisch, perhaps wisely, had little to do with the Australian team, but told Davis he was "very happy" with the result. Indeed he told the author of this article that he prefers it to his original (Jarisch 2014).

While Hall hails the feature in both its iterations as a magnificent achievement, he admits to one qualm. “There's something I can't quite shake off. It's brilliant and horrific. The effect is unsettling to the point that I'm not sure that I understand the information it's trying to convey or that I trust my feelings about it." Hall (2014: 3 ) is referring to a woman's piercing scream at the very start of the program. "The effect was - and still is - to put this listener on edge, on guard; it signals foreboding of worse to come." (ibid) Hall's concern is that this scream has been lifted from a 'barbarous' later scene, when Jarisch records the bludgeoning to death of a boy who has been accused of stealing. So what's wrong with that, one might ask? Hall explains:

As a feature maker myself I feel not just a concern to gauge the potential impact on listeners of specific pieces of actuality recording, or potent juxtapositions of material, but an obligation to be able to justify the intention behind their effect. In relation to Jens Jarisch's documentary, I have felt caught between an awed admiration for the courage with which material has been gathered and then composed virtuosically into a narrative and, on the other hand, a suspicion of that same virtuosity, the storyteller's seductive use of the tools of fiction to represent true stories. (Hall 2014: 3)

Suspense is a key tool for any storyteller. But Hall believes that in uncoupling the scream from its context of the attack on the boy, Jarisch is manipulating the listener. Instead of the horror we would feel had he kept it "in situ", we instead lean in, almost titillated, wondering what the scream presages. Davis acknowledges that "as an investigative journalist, there were moments in the feature that I questioned". But she felt it was important to suborn her own authorial voice to that of Jarisch, and "maintain the integrity" of the original feature.

To have changed the beginning, or some of the other 'scenes', or to have combined the narrator and the reporter's voices, would have moved the program away from his intention, and it would have become something other than the program we were re-versioning in English. (Davis 2017)

Even so, warns Hall, with Jarisch's feature, we cannot guarantee that the new, transnational audience will 'get' that original intention.

It can't be assumed that the contract with the listener will be universally signed up to - that conventions, whether predictably fulfilled or meaningfully confounded, will be understood, that the grammar of the piece will necessarily be shared by all. (Hall 2014: 4) 
Hall's feature-maker associate at London-based company, Falling Tree Productions, Eleanor McDowall, has pioneered an elegant way to subtitle audio works online, observable at her Radio Atlas (2017) site. She observes: "every act of translation is obviously a transformation - it's a tool that changes the character of the original documentary into something else" (ibid). In the case of Kinder von Sodom und Gomorrha and Children of Sodom and Gomorrah, while the listener will always bring a subjective understanding to the piece which is coloured by their own auditory cultural baggage, the character and caliber of these two audio features align remarkably well across wide transnational spaces.

\section{References}

Alarcón, Daniel (2015): “\#Renuncia Ya." Radio Ambulante. Audio podcast by NPR, September 29, 2015 (http://radioambulante.org/audio/renunciaya).

Aroney, Eurydice (2005): "Radio Documentaries and Features: Invisible Achievements." In: Radio in the World: Papers from the 2005 Melbourne Radio Conference, Melbourne: RMIT, pp. 397-405.

Davis, Sharon (2017): Personal communication with the author, January 18, 2017.

Hall, Alan (2014): "Children of Sodom and Gomorrah: Review 1." RadioDoc Review, 1/1, doi:10.14453/rdr.vii1.9 (http://ro.uow.edu.au/rdr/vol1/iss1/10/)

Hall, Alan (2010): “Cigarettes and Dance Steps.” In: John Biewen/Alexa Dilworth (eds.), Reality Radio: Telling True Stories in Sound, Chapel Hill: University of North Carolina, pp. 126-137.

Hendy, David (2009): “'Reality Radio': the Documentary.” In: Andrew Crisell (ed.), Radio:

Critical Concepts in Media and Cultural Studies, London: Routledge, pp. 220-238.

Jarisch, Jens (2014): Personal communication with the author, May 12, 2014, Leipzig, Germany. Madsen, Virginia (2014): "Children of Sodom and Gomorrah: a Critical Reflection."

In: RadioDoc Review, 1/1, March 5, 2018 (http://ro.uow.edu.au/rdr/vol1/iss1/11)

McHugh, Siobhan (2014): "RadioDoc Review: Developing Critical Theory of the Radio

Documentary and Feature Form.” In: Australian Journalism Review, 36/2, pp. 23-35.

Radio Atlas (2017), March 5, 2018 (http://www.radioatlas.org).

Stapleton, Russell (2017): Personal communication with the author, January 11, 2017.

Street, Seán (2014): “Poetry, Texas: Review 1.” In: RadioDoc Review, 1/1, March 5, 2018 (http://ro.uow.edu.au/rdr/voli/iss1/4).

Vogt, P.J. (2015): “Quit Already.” In: Reply All, 47, December 3, 2015. Audio podcast by Gimlet Media, March 5, 2018 (https://gimletmedia.com/episode/47-quit-already). 
Section 3:

Staging Encounters: Translating

Places and IDentities 



\section{A Transnational Approach to Radio Amateurism in the 1910s}

Maria Rikitianskaia

\section{INTRODUCTION}

Since radio waves easily transcend national spaces, a transnational approach can enrich the history of radio broadcasting and wireless telegraphy with its focus on a constant exchange of knowledge, techniques, and news over national borders (Badenoch/Fickers 2010). Following previous research on transnational histories of broadcasting from 1925 (Lommers 2012; Fickers/Lommers 2010), this chapter suggests a social perspective on specific users of wireless technology in the 1910s: radio amateurs. The national literature on radio amateurs is frequently limited to national heroes who developed an idea of national radio broadcasting that "evokes notions of national unity" and serves as "an ideal symbol of national togetherness." (Hilmes/Loviglio 2002: xi-xii) In contrast, a transnational approach helps to identify actors who exchanged information about recent inventions, achievements, and policy decisions on wireless communication across national boundaries. This chapter takes such an approach to reflect on the role of radio amateurs who reshaped, played with, appropriated, and familiarized themselves with wireless technology in the 1910s, paving the way for public and commercial national radio broadcasting. ${ }^{1}$

The historiography of radio amateurs usually begins with the 1920 s in the national institutional framework, when the first national societies were formed (see for example Brochand 1994; Hilmes 1997; Lovell 2015). However, in the 1910 sadio amateurs were already prominent actors who engaged in dialogue about the technology. They were technical enthusiasts who introduced radio technology to the public. As such, they should be considered co-producers of

$\mathbf{1}$ | This paper is a part of the project "Inventing European Wireless. A cultural history of wireless from point-to-point telegraph to one-to-many broadcasting, 1903-1927", supported by Swiss National Science Foundation. 
new technologies from the perspective of the social construction of technology (Pinch/Bijker 1984; MacKenzie/Wajcman 1999; Oudshoorn/Pinch 2005; Oldenziel/de la Bruhèze/de Wit 2005). From this point of view, Kristen Haring (2007) and Susan Douglas (1989) have already rediscovered the essential role of early amateurs in helping to shape the development of the radio. However, both emphasized national cases, specifically the US. As this paper will show, exploring the first radio amateurs from a transnational perspective also means redefining the very concept of a 'radio amateur' in terms of social interaction with media technology.

In contrast to national histories, the main hypothesis of this research is that radio hobbyists formed a community from at least the 1910 s onward, and played an important role in spreading radio technology across national borders. Radio amateurs kept up with the most recent news in the field, invented new machines, and demonstrated the use of the wireless to their local communities, such as schoolteachers and priests. They were involved in reception and dissemination of information about the evolution of technology through the letters to technical journals and international organizations, correspondence with each other, publication of books and articles. They followed the political developments on wireless as well, including national and international legislation, and passed them on to the public on national, or even local, levels. Moreover, they posed questions back to political institutions about the obstacles to the use of the technology, providing valuable feedback to the decision-makers. Therefore, in filling the gap in the scholarship on wireless communication in the 1910s, this research hypothesizes the important role of radio amateurs in shaping the medium by questioning and redefining the notion of a 'radio amateur' itself.

\section{Re-defining Radio Amateurism}

In national histories, the notion of a radio amateur usually implies two main features. On the one side, it is opposed to a radio professional - an expert who earns money for their radio activity, usually educated in some form of national professional school. However, in the formative stage of wireless communication and radio broadcasting, specific professional education did not yet exist, and therefore the border between professionals and amateurs was not clearly defined. Apart from a few British operators who received training in telegraphy school, almost all radio operators had begun their career as amateurs (Bartlett 2007).

On the other hand, a radio amateur considered within a national framework is frequently defined by an affiliation to a national association of radio amateurs. This institutional perspective suggests the 1920 s as the start of radio history because that is when various unions, journals, and societies were estab- 
lished. However, there is an extensive range of sources that proves that radio amateurism existed before the establishment of national radio amateur associations. Many individuals operated in different European countries to push the development of the technology forward. The widely-known fact that many European governments prohibited all wireless experiments during the First World War to clear the airwaves and avoid unwanted interception shows that individual stations existed before the war. This policy met with stiff resistance among many individuals who continued to operate illegally (cf. "Wireless in the Courts" 1915). Moreover, the First World War became one of the first wars with extensive use of wireless communication, and some of these amateurs were employed in military forces as technical experts.

In light of these limitations, this chapter reconsiders radio amateurism through the informal nature of this activity by using a combination of different theoretical concepts. First is the idea of a participatory culture (Toffler 1980; Jenkins 1992; 2006). Although the concept has been usually applied to the Internet projects like Wikipedia, YouTube, and Facebook, historians of technology have reminded us that participatory culture is not uniquely characteristic of our time. In fact, early radio amateurs were known for their active experiments with radio, adopting it to public needs and re-inventing its use, which is a part of how participatory culture is defined. They not only influenced understanding of radio, but also made it a completely new everyday life practice, which contributed greatly to the turn from telegraphy to broadcasting (Streeter 1996), or in other words, provoked a "double birth" of radio technology (Balbi/ Natale 2015).

Second, a radio amateur could be considered as a person who experiences pleasure in using the technology and feels enjoyment in relation to the object. The concept of enjoyment has become recently gained appreciation in the history of technology (Bown 2015; Schuster 2016). In Enjoying Machines, Brown and Juhlin argue that the enjoyment is the driving force of using and developing technology, from gramophones to computer games (Brown/Juhlin 2015). Indeed, radio amateurs, as it is evident from their name, experience a keen interest in, and a strong feeling of affection toward, wireless technologies. Their usage of technology is inspired not only by great achievements of communication but the playfulness of technology (Kirpal 2003).

Finally, analyzing technical hobbies, Kristen Haring argues that "radio hobbyists formed their own 'technical culture,' a culture built around and establishing an ideology about technology." (Haring 2007: XV) This technical culture provided the community of radio amateurs a technological identity as a special, socio-technological group. The radio amateurs' community has specific practices, ethical codes and rules, such as social feeling, brotherly spirit, tolerance, politeness, and comprehension (Schiavone 2014: 93), which is usu- 
ally obtained through common practices, exchange of knowledge, and similarities in the patterns of using of technology.

Therefore, this paper aims to understand radio amateurs, not by focusing on national and institutional relations, but instead following three main concepts, participatory culture, enjoyment of technology, and a technical culture, to grasp the informal nature of radio amateurs from a transnational perspective.

\section{Methodology \& Sources}

One of the difficulties of transnational research is finding an appropriate method to collect the sources that would allow one to trace transnational flows without focusing on national differences, even though preserving historical sources is mainly a national prerogative. This research is based on an analysis of a combination of different sources on international and national levels. The main focus is on those issues that were negotiated by international organizations and appeared in various national landscapes.

First, the archive of the International Telecommunication Union (ITU) based in Geneva helped to build a better understanding of an international arena of political regulations. At this stage research also faced the difficulty that another valuable international archive on radio, the archive of the International Broadcasting Union (IBU), held at the European Broadcasting Union (EBU) in Geneva, is not currently accessible to researchers and the public. However, the documents found in the ITU archives compensated for this lack, since these two international organizations corresponded and shared valuable protocols. Second, the main European archive on radio amateurs in Vienna, the Dokumentationsarchiv Funk, provided documents on radio amateurs, such as technical journals, and also written evidence of amateur radio operation: socalled QSL-cards, used to acknowledge reception of radio signals. Third, the analysis included some national sources, such as political discussions, radio amateurs' magazines, and other documents that reflected on radio hobbyists, and the development of radio technology and use. Finally, sources on the history of non-media-related technologies, such as meteorology and geography, shed more light on the professional activity of some radio hobbyists and their entanglements in radio development.

The problem in finding radio hobbyists in these sources is that they were rarely called that because radio amateurs' clubs did not yet exist. One approach is to trace the biographies of those individuals who made significant achievements in national radio broadcasting in the 1920s, to see whether they began their career as radio hobbyists, as is was frequently done in national histories of radio. However, a transnational approach means looking not just at national heroes. To identify the most active and loyal private correspondents and sub- 
scribers, the ITU correspondence register was closely analyzed. Then, the biographies of these most active individuals were closely analyzed using the three concepts outlined above: participatory culture, enjoyment of technology, and technical culture, to distinguish passionate amateurs from those experts who represented a particular company or worked as professional telegraph operators. Finally, sources from national archives and other international organizations provided more details on the accomplishments of the particular personalities.

\section{Case studies: Albin Belar, luis Cirera de Terré, and Jean Abelé}

Approaching the concept of early radio amateurism from three theoretical angles, we found and traced biographies of those individuals who: 1) actively participated in discussion about radio communication through correspondence, subscription to journals, and publications; 2) expressed their individual involvement and passion towards the technology, instead of a professional interest, such as that of a a Marconi Company operator; 3 ) shared specific technical knowledge and culture. Several cases of radio amateurs were discovered during the archival research, and three are discussed in detail in this paper: Albin Belar from Ljubljana, then in the Austro-Hungarian Empire; Luis Cirera de Terré from Barcelona, Spain; and Jean Abelé from Antoing, Belgium. They passionately experimented with radio technology for several decades, from the years of the technogy's initial evolution to the epoch of the established radio industry.

At first sight, the main accomplishments of all three persons lay in other fields, but a deeper analysis show a significant contribution to radio history. Albin Belar was an outstanding specialist in seismology: he was founder of the first modern seismological station in Europe, which remained in operation up until 1919 , and was frequently invited to seismological congresses and to the openings of new modern seismological stations in the Austro-Hungarian Empire (Lee et al. 2003: 1432). Luis Cirera de Terré was a second-generation medical doctor with a particular focus on electrotherapy, which he claimed was indispensable to every medical professional (Enrich 1993: 65; Browne 1933). Jean Abelé is known for his major accomplishments in philosophy and religion: as a Jesuit, he edited and published several philosophical manuscripts that raised questions about the construction of the universe (Platzgummer 2001; Abelé/Malvaux 1954).

Surprisingly, all these vastly different personalities, representing seismology, medicine, and philosophy respectively, shared a passion for radio. The records of their experiments were found in different telecommunication archives, and they also shared their expertise and experience with the ITU. Wireless accompanied their personal growth, although it was usually obscured in the background of other activities. Albin Belar recognized the great potential of 
radio technologies for seismology, which he explained in numerous articles on the use of meteorological reports and time signals in seismology. Luis Cirera de Terré was experimenting with radio waves in medicine, and became one of the first radio pioneers in Spain, operating from Barcelona already in 1904 . Jean Abelé applied his knowledge of the radio during his mobilization in the First World War in the radiogoniometric service, which measured the direction from which radio waves came. After the war, he established a laboratory where he worked on inventing and patenting several radio devices.

In different ways, each was involved in transnational communication about radio technology. In 1913, all of them were receiving the ITU Journal, and exchanged correspondence with the ITU. Luis Cirera de Terré appears only a few times in the ITU records (ITU Archives 1913a, №69; 1913C, №322), Jean Abelé wrote to the ITU when he was in Antoing as a student (ITU Archives 1912, №352, 353), and Albin Belar was a regular subscriber and correspondent (e.g. ITU Archives 1911a, №14; 1911b, №409; 1911c, №135, 137, 143; 1912a, №95, 100, 272; 1913a, №12-13; 1913b, №87, 97, 114, 692; 1913c, №84). None of them limited their inventions to the local level but were involved in different ways with different levels of participation into the transnational network that received the information about political decisions, statistics and news about new inventions.

Participating in dialogue about the latest inventions in radio, they experimented with the technology and shared knowledge with colleagues in their own field of professional expertise. In so doing, they mediated the knowledge about radio technology to different social and professional groups on the national and local level. Albin Belar widely used radio technology to obtain information required for calibrating seismographs and taught other seismologists this technique in his public speeches and publications at the international congresses. Luis Cirera de Terré explored the use of radiology on a human body and shared the latest information in this field in his publications. Even for Jean Abelé, the interest in radio technology was constantly present in his works on physics and philosophy. (Platzgummer 2001) Thanks to their work, more and more people familiarized themselves with radio technology.

Moreover, these amateurs re-invented and re-appropriated radio technology by making several important inventions in the radio field. Albin Belar is known, together with Baron Codelli, for inventing a wireless receiver for accurate time signals applied in seismological research (1910), and as well as for launching the first radio programs in the Slovene language. Dr. Luis Cirera de Terré is known as the first radio pioneer in Barcelona for managing to send a signal to Valencia with crystal receiver in 1913 , and in 1929, he served as the President of the first Congress of Ham Radio in Spain. Working in his modest laboratory, Jean Abelé patented several inventions, such as a device for receiving and amplifying high-frequency electric oscillations (1924) and a receiver for radio-telegraphy and radio-telephony (1926). 
Overall, it is clear that these radio hobbyists were involved in the discussion about radio technology, followed recent news by subscription to the international journals, exchanged knowledge with other hobbyists through publications and correspondence, and mediated their knowledge to the community and general public by applying the technology in their everyday lives before the First World War. In so doing, they re-invented and re-appropriated the technology, facilitated the acquaintance with the technology by inventing new devices and uses of the technology, and consequently reshaped the whole notion of technology.

\section{CONCLUSION}

This paper has demonstrated how a transnational approach to radio history helps to identify the radio hobbyists that started exploiting radio technology widely before the First World War and shared knowledge about their radio experiments and achievements with a wider audience. The analyses of a corpus of international and national archival documents allowed us to identify new actors, who operated transnationally and experimented with radio.

The case studies show that European radio amateurism began not in the 1920 s with the establishment of national institutions and societies, but was preceded by a longer and more nuanced history. These three names - Albin Belar, Luis Cirera de Terré and Jean Abelé - are relatively new to radio history. However, they reshaped the cultural understanding of radio technology and suggested new uses of radio. The influence of these radio hobbyists had previously been captured only fragmentarily in the other fields, but here it fruitfully extends the national frameworks of radio history. This research enriches national histories of radio not only by bringing new actors into view, but also the unforeseen uses of radio technologies in seismology, medicine, and even philosophy. A transnational approach helped to show that achievements and experiments of radio amateurs in the 1910 s went beyond any national history of radio broadcasting.

The evidence that amateurs existed before the foundation of national institutions in the 1920s, and long before the First World War, significantly enriches our understanding of radio history. It shows that the significant rise of radio broadcasting in the 1920 s was not a revolutionary consequence of the First World War, but should be considered as a logical evolution of a medium. Hobbyists pushed development of the radio technology forward, appropriated it, and invented new uses, followed the international political developments, and passed these on to their professional or local communities already in the 1910 s. By inventing new applications of radio signals to their various fields, amateurs introduced the radio into everyday life and made ordinary people see it as a reliable and even indispensable medium. 


\section{REFERENCES}

Abelé, Jean/Malvaux, Pierre (1954): Vitesse et univers relativiste, Paris: Société d'édition d'enseignement supérieur.

Badenoch, Alexander/Fickers, Andreas (2010): Materializing Europe: Transnational Infrastructures and the project of Europe, Basingstoke and New York: Palgrave Macmillan.

Balbi, Gabriele/Natale, Simone (2015): “The Double Birth of Wireless: Italian Radio Amateurs and the Interpretive Flexibility of New Media." In: Journal of Radio and Audio Media 22/1, pp. 26-41.

Bartlett, Richard A. (2007): The World of Ham Radio, 1901-1950: A Social History, Jefferson, London: McFarland.

Bown, Alfie (2015): Enjoying It: Candy Crush and Capitalism, Alresford: John Hunt Publishing.

Brochand, Christian (1994): Histoire générale de la radio et de la télévision en France, Paris: La Documentation française.

Brown, Barry/Juhlin, Oskar (2015): Enjoying Machines, Cambridge (MA), London: The MIT Press.

Browne, A. R/ Cirera Terré, Luis (1933): La electroterapia elemental y práctica indispensable al médico, Barcelona: Manuel Marín.

Douglas, Susan J. (1989): Inventing American Broadcasting, 1899-1922, Baltimore: The Johns Hopkins University Press.

Enrich, Juan Juliá (1993): Radio. Historia y técnica, Barcelona: Marcombo Boixareu Editores. Fickers, Andreas/Lommers, Suzanne (2010): "Eventing Europe: Broadcasting and the Mediated Performances of Europe.” In: Alexander Badenoch/Andreas Fickers (eds.), Materializing Europe: transnational infrastructures and the project of Europe, Basingstoke and New York: Palgrave Macmillan.

Haring, Kristen (2007): Ham Radio's Technical Culture, Cambridge MA, London: The MIT Press.s

Hilmes, Michele (1997): Radio voices: American Broadcasting, 1922-1952, Minneapolis and London: University of Minnesota Press.

Hilmes, Michele/Loviglio, Jason (2002): Radio Reader: Essays in the Cultural History of Radio, New York and London: Routledge.

ITU Archives. Registres de correspondance: radiotélégraphie:

(1911a). Dossier 21 "Réclamations d'expéditions".

(1911b). Dossier 19 "Nomenclature. Vente".

(1911c). Dossier 21 "Liste des indicatifs d'appel".

(1912). Dossier 19 "Nomenclature. Vente”.

(1913a). Dossier 8 "Divers. Demandes de renseignements".

(1913b). Dossier 19 "Nomenclature. Vente".

(1913C). Dossier 21 "Liste des indicatifs d'appel". 
Jenkins, Henry (1992): Textual Poachers: Television Fans and Participatory, New York and London: Routledge.

Jenkins, Henry (2006): Fans, Bloggers, and Gamers: Exploring Participatory Culture, New York, London: NYU Press.

Kirpal, Alfred (2003): "Ernst oder Spiel? Basteln, Konstruieren und Erfinden in der Radioentwicklung.” In: Stefan Poser/Karin Zachmann (eds.), Homo faber ludens. Geschichten zu Wechselbeziehungen von Technik und Spiel, Frankfurt am Main: Peter Lang, pp. 227-254.

Lee, William Hung Kan et al. (eds.) (2003): International Handbook of Earthquake and Engineering Seismology. Part B, London, San Diego, Burlington: Academic Press. Lommers, Suzanne (2012): Europe - on Air: Interwar Projects for Radio Broadcasting, Amsterdam: Amsterdam University Press.

Lovell, Stephen (2015): Russia in the Microphone Age. A History of Soviet Radio, 19191970, Oxford: Oxford University Press.

MacKenzie, Donald A./Wajcman, Judy. (1999): The social shaping of technology, Buckingham: Open University Press.

Oldenziel, Ruth/de la Bruhèze, Adri Albert/de Wit, Onno (2005): "Europe's mediation junction: technology and consumer society in the 2 oth century." In: History and Technology 21/1, pp. 107-139.

Oudshoorn, Nelly/Pinch, Trevor (2005): How users matter: the co-construction of users and technology, Cambridge, MA: MIT Press.

Pinch, Trevor J/Bijker, Wiebe E (1984): “The Social Construction of Facts and Artefacts: Or How the Sociology of Science and the Sociology of Technology Might Benefit Each Other." In: Social Studies of Science 14/3, pp. 399-441.

Platzgummer, H. (2001): Abelé, Jean. In: O’Neill, Charles E./Domínguez, Joaquín María (eds.): Diccionario histórico de la Compañía de Jesús: biográfico-temático, Rome, Madris: Institutum Historicum, p. 4110.

Schiavone, Francesco (2014): Communities of Practice and Vintage Innovation: a strategic reaction to technological change, Heidelberg, New York, Dordrecht and London: Springer Science \& Business Media.

Schuster, Aaron (2016): The trouble with pleasure: Deleuze and psychoanalysis, Cambridge, MA, London: MIT Press.

Streeter, Thomas (1996): Selling the Air: A Critique of the Policy of Commercial Broadcasting in the United States, Chicago and London: University of Chicago Press.

Toffler, Alvin (1980): The third wave, London: Collins.

"Wireless in the Courts" (1915): In: The Wireless World, November, Vol. 3, p. 523. 



\title{
Radiophonic Cities
}

\section{The City Portrait in Transnational Radio Collaborations}

\author{
Jacob Kreutzfeldt
}

The evening of December 7, 1930 saw the broadcast of one of the most ambitions productions for Danish Radio to date when Danish Statsradiofonien aired "Vore Dages København i Radiofoniske Billeder" or in English: "Contemporary Copenhagen in Radiophonic Images." The broadcast was remarkable in several ways. First, it was Danish Radio's first adoption of sound film: that is, sound without images recorded on film and edited for a sound montage in radio. Second, it was the first ambitious portrait of Copenhagen, attempting over the course of 4 hours to relate to the listeners the life and sounds of the Danish capital. And third, Danish Radio had hired the modernist and highly experimental writer Emil Bønnelycke to make the sound film. (Kreutzfeldt 2018)

An excerpt from the program sheet from Danish Radio (DR) gives an impression of the broadcast:

Striking of the hour and carillon from the city hall tower at 6 in the morning.

The factory whistle squeaks - workers turn up at "Burgmeister \& Wain" [shipyard] at Oven-

gaden Neden Vandet.

In the machine halls Overgaden and Sydhavnen.

Sailing trip to Refshaleøen. Riveters, cranes and machines in action." (DR 1930, author's translation)

The montage portrayed contemporary Copenhagen by including not only traditional attractions like the fish market, the flower market, churches, and museums, but also sounds from modern Copenhagen like machinery at the B\&W shipyards, the industrial harbor, the train station, and the modern concert studio. Clearly the route was not following a tourist's tour through the city, but rather one of changing glimpses of life in the city displaying its noisy, as well as more folkloristic, aspects. The structure was one of temporal condensation from early morning carillons and factory bells to afternoon dance and evening entertainment in Tivoli, and the perspective was elevated and de-personified. 
The broadcast was not meant for Danish listeners alone. Rather, as the head of Danish radio Emil Holm relates in an article in Arbejder-Radio, it was aired for Danish listeners first and then later included in collaborations with other national broadcasters:

The intention is that we will continue this work, and in January next year, when we embark on mutual exchanges with larger foreign cities, through which listeners in the different countries will get a radiophonic view into the lives and physiognomy of the cities in question, we will include at least parts of the sound film in these exchanges. (Holm in Anonymous 1930a: 707)

As Holm foresaw, parts of the sound film were included in "Norden paa besøg i København" ("The Northern Countries visiting Copenhagen"), broadcast 9, January 1931, 8-12PM. This program was simultaneously transmitted on all stations in Finland, Sweden, and Norway and involved producers from all the involved countries who were in Copenhagen during the broadcast. Holm clearly makes an effort to present the Copenhagen portrait to Danish listeners as a modern and daring move by Danish radio. In fact, both the use of sound film and the practice of exchanging city portraits was not new. Sweden, Norway and Germany had by that time already completed a round of exchanges of radiophonic city portraits, and by the summer of 1930, the German filmmaker Walter Ruttmann had presented his sound film montage "Weekend" on Berlin radio as well as in a cinema. The city portrait was a highly prestigious genre in early radio, one that called for full production engagement, and one well fit for radiophonic exchanges and collaborations.

This case study explores the idea of the radiophonic city portrait in transnational radio. As illustrated in Holm's statement, the city portrait is imbedded in discourses about national exchange and propaganda, and also activates a vocabulary for the radiophonic experience as not only visiting, but seeing through foreign cities: "looking into the lives and physiognomy of cities." (ibid.) This study investigates the practices of such transnational exchanges from a Danish and Nordic perspective and interrogates how these relate to the complex identity politics of places and nations in modern Europe. 


\section{National Communities and Transnational IMAGINATIONS}

Benedict Anderson in Imagined Communities describes how the industrial spread of print in renaissance Europe created the conditions for nationalism to arise. In Anderson's analysis it was the convergence of capitalism, print technology and what he calls the "fatality of linguistic diversity", that made new national communities imaginable. (Anderson 2006[1983]: 56) Printed books and later on newspapers in national languages made it possible to imagine sovereign and limited political communities - most of which were defined by the spread of a unique and increasingly standardized language.

Anderson sees the decline of hand-written Latin and the rise of national language print books as mass commodities as the major defining factor for the rise of nationalism, and later in the establishment of nation states. He does not give a clear analysis of radio, probably because of a major shift in the historical conditions from the spread of the printing press to the spread of radio. In considering the appearance of national radio in the 1920 s and 30 s we are no longer dealing with an imagined community, but with an institutionally and ideologically given and materialized community. While the printing press in Anderson's theory created the conditions for people to imagine a nation, state radio took as its task to educate and entertain an already existing national public. In the light of this it might be surprising to find that the early commercial imaginary of radio was actually dominated by a fascination with the transnational - much more than with the national. Producers of radio receivers seemed more interested in selling an ideas and images of the world, than the nation and the national language (see Figure 1).

Such imaginaries could indicate that while the state sold national community and culture to the listeners, radio producers simultaneously sold the ability to travel the world by the means of radio receivers. Radio was thus connected both to the national and the transnational, and to a certain extent torn between those two power structures: on the one hand producing and circulating national culture, and at the same time allowing listeners to imagine journeys to the outside. The central question is how these transnational imaginaries were inhabited and explored - not only by market forces and intellectuals like Rudolf Arnheim (1971[1936]), but by radio producers. 


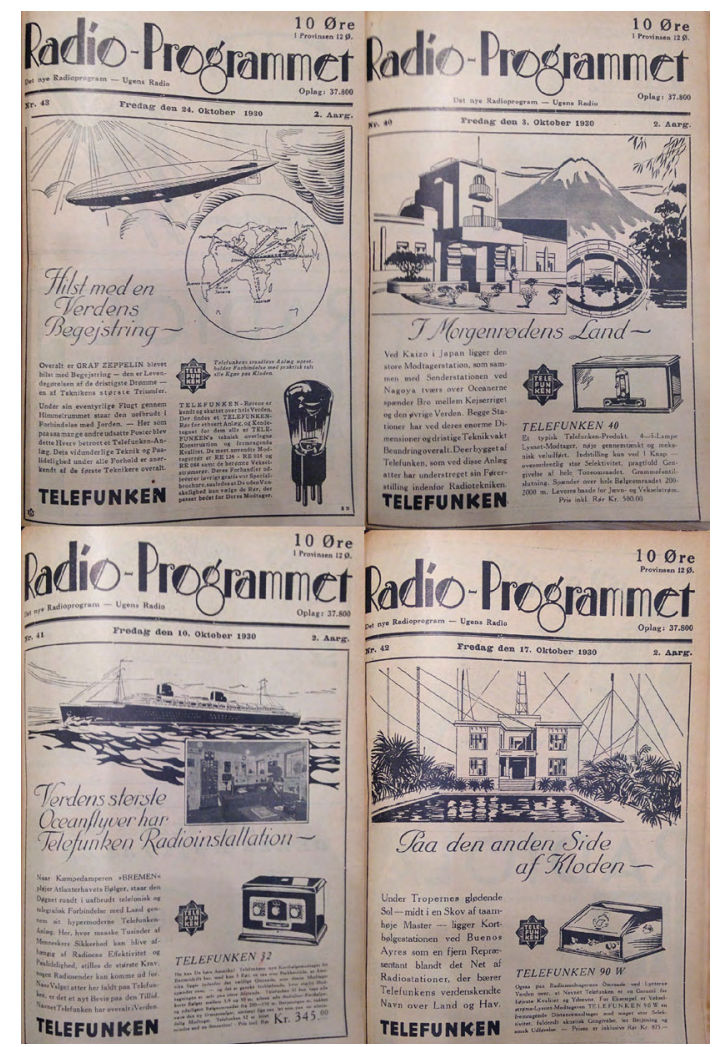

Figure 1: Telefunken adverts from the Danish Listener Magazine RadioProgrammet, September-December 1930.

More recently, Arjun Appadurai's Modernity at Large (2010 [1996]) and the sociology of globalization, argue that we are now dealing with destabilized national identities assembling from various global flows, imagined worlds, and aspirations. Along with ideas such as Manuel Castells's (2010 [1996]) dialectic of space of flows and space of places, Appadurai's theory of global -scapes allow us to conceptualize global dynamics where money, people, images and imaginaries circulate more or less independently of nations and give rise to hybrid identity forms. Appadurai engages head-on with Benedict Anderson's account when he writes about the five types of -scapes in his theory, the ethno-, media-, techno-, finance-, and ideoscapes: "These landscapes thus are the building blocks of what (extending Benedict Anderson) I would like to call imagined worlds, that is the multiple worlds that are constituted by the historically situated imaginations of persons and groups spread around the globe [...]. An important fact of the world we live in today is that many persons on the globe live in such imag- 
ined worlds (and not just in imagined communities) and thus are able to contest and sometimes even subvert the imagined worlds of the official mind and of the entrepreneurial mentality that surrounds them." (Appadurai 2010[1996]: 33, emphasis in original)

Appadurai's imagined worlds transcend the nation and allow counter-official worlds and aspirations to emerge. It is no surprise that global entertainment products play an important role in constructing such imagined worlds according to Appadurai, writing in the 1990s: particularly Hollywood movies, which circulate internationally in cinemas and as video tapes, music and celebrity culture etc.. Like Anderson, Appadurai does not pay much attention to radio. He focuses entirely on electronic media - possibly in extension of Anderson's focus on print media - yet he leaves out radio. Radio seems to occupy an uncertain (if not unimportant) position between national communities and global imaginaries, and the city portrait can be understood as a prime vehicle of such ambivalence.

\section{Case Material}

This study looks into two historical cases of large-scale transnational projects involving city portraits: collaborations between Nordic state broadcasters in the early 1930 s and the Metropolis-series initiated by Studio Akustische Kunst in the 1980 s and 1990 s.

Researching Danish program sheets, sound archive and listener magazines one finds a dense traffic of city portrait exchanges in the early 1930s, but one that seemed to lose its attraction already in 1932 (see Table 1).

\begin{tabular}{|l|}
\hline Nordic Exchanges in the Early 1930s \\
\hline A Round Trip in Oslo and Surroundings (March 16, 1930: No, Swe, N-De) \\
\hline An Evening in Hamburg. Strolling with the Microphone (April 1, 1930: \\
No, Swe, N-De) \\
\hline Visiting Stockholm (April 8, 1930: No, Swe, N-De) \\
\hline The Northern countries visiting Copenhagen (January 9, 1931: Dk, No, \\
Swe, Fi) \\
\hline Helsingfors Broadcasting (February 22, 1931: Dk, No, Swe, Fi) \\
\hline
\end{tabular}


Nordic Exchanges in the Early 1930 s

Transmission from Hamburg via "Norddeutscher Rundfunk AG ” (May 6, 1931: N-De, Dk)

North Germany visiting Copenhagen (September 8, 1931: N-SDe, Dk)

European City Portraits: Stockholm (January 31, 1932: Dk, No, Swe, Fi)

European City Portraits: Oslo (May 22, 1932: Dk, No, Swe, Fi)

Table 1: Overview of large-scale city portraits found in a study of Danish listener magazines. Author's translations of titles from Danish program sheets.

The material is structured in three different rounds of exchanges, first between Norway, Sweden and the North German NORAG, then a new round between Denmark, Sweden, Norway and Finland, and - running in parallel - collaboration between Denmark and NORAG. Of these, only audio material from the "North-Germany visiting Copenhagen portrait" has been preserved in the archive, but all are relatively well described and discussed in listener magazines.

The series of Metropolis city portraits was initiated by Klaus Schöning and produced for Studio Akustische Kunst at the WDR Cologne. It comprises of around 25 unique productions each portraying one city: "Metropolis Paris," "Metropolis Copenhagen," "Metropolis Calcutta." The earliest piece seems to have been Clarence Barlow's portrait of Calcutta from 1980, and while - like in the case of the 1930 s works - there is no clear overview of the material, the years between 1984 and 1996 seem to have been particularly productive. For an exhibition in Copenhagen in 1996, a series of highlights - including an early inspiration by R. Murray Schafer and The World Soundscape Project - were presented (see Table 2). This material exists, excerpts are published in CDs, and other parts can be found in different broadcasters' archives.

\begin{tabular}{|l|}
\hline $\begin{array}{l}\text { Metropolis: City Soundscapes } \\
\text { Copenhagen } 1996\end{array}$ \\
\hline Metropolis Atlanta (Sorrel Hays, 1990) \\
\hline Metropolis Benares (Peter Pannke, 1988) \\
\hline Metropolis Buenos Aeres (Francisco Kröpfl, 1989) \\
\hline Metropolis Calcutta (Clarence Barlow, 1980) \\
\hline
\end{tabular}




\section{Metropolis: City Soundscapes \\ Copenhagen 1996}

Metropolis Cologne - Kyoto (Bill Fontana, 1993)

Metropolis Cologne - San Francisco (Bill Fontana, 1987)

Metropolis Copenhagen (Stephen Schwartz, 1996)

Metropolis London (Karl Sczuka, 1987)

Metropolis New York (Richard Kostelanetz, 1984)

Metropolis Paris (Pierre Henry, 1984)

Metropolis Rome (Alvin Curran, 1987)

Metropolis Sydney (Vincent Plush, 1988)

Metropolis Tokyo (Emmanuelle Loubet, 1990)

The Vancouver Soundscape (R. Murray Schafer, 1973)

Metropolis Venice (Marielouise Franke, 1987)

Metropolis Vienna (Gerhard Rühm, 1992)

Table 2: Overview of the productions presented at the ACOUSTICA INTERNATIONAL. METROPOLIS, City Soundscape exhibition, Copenhagen 1996 (Schöning 1996a).

\section{Functions of City Portraits in Transnational Radio}

Given the historic and geographic differences between the early Nordic exchanges and later Acoustica International projects, it remains to explore why and how the city portrait functions as a genre in transnational radio. The city portrait may be understood to provide a vocabulary for exploring relationships between the national and the transnational, and in the following the cases will be studied further in terms general features concerning territory, technology and aesthetics.

\section{Territory}

Bønnelyche's project may, as the head of Danish Radio Emil Holm stated above, allow us to look into foreign cities, but it will also, he continues, "serve as propaganda for Copenhagen and for Denmark under hitherto unknown forms." (Holm in Anonymous 1930a: 707) Both cases in their serial logic connect places as belonging to the same category while also highlighting each as something unique. They activate a touristic gaze at the foreign city while also building a shared space that connects cities and broadcasters. Schöning describe this function as an acoustic bridge in his curatorial text for the 1996 exhibition in 
Copenhagen: "Sounds of the earth's metropolises salute the Danish capital, this year's European Cultural Capital. They form acoustic bridges between cities of Europe and other continents." (Schöning 1996: 2)

Clearly the city portraits form bridges building on and extending existing geopolitical alliances. In the cases of the 1930 s collaborations, it is the Nordic region that is being explored and inhabited: first in alliance between Norway, Sweden and Northern Germany, and later without Germany but in unison between Norway, Sweden, Denmark and Finland. This delineates the Nordic cultural sphere and tests ideas of "Nordic brotherhood."

Unlike the early collaborations between national broadcasters, the Metropolis series connect global metropolises that are not easily described by an existing geopolitical entity. Instead, the series seems to reach out beyond a European sphere to build a global community. In the context of the European Cultural Capital, the global outreach of the Metropolis exhibition in Copenhagen in 1996 clearly has political implications. Also, the Metropolis series was a significant element in Schöning's endeavours to establish an international sound art community. Schöning had organized three events titled "Acustica International" before the exhibition in Copenhagen: first in Cologne in 1985, then in New York and Montreal in 1990 and in Cologne in 1994 (Schöning 1996b: no pagination). Clearly, as illustrated by the name "Acoustica International," the Metropolis compositions did perform the work of articulating an international community of sound and radio artists, building an international art form from the vocabularies of urban life.

\section{Technology}

While, as we have seen, both projects build territories by means of calling locations, we can also say that they explicitly use technology to connect locations. This function of course lies firmly in the nature of all broadcasting, but what is prominent in both projects is the way that this function of technology is made explicit.

The early 1930s was a time of rapid expansion of cables for quality sound transfer between broadcasters. While earlier co-transmissions had been made in the form of wireless relays, where signals from foreign transmitters had been wirelessly received and then re-transmitted, the new cables allowed high quality transmission from foreign broadcasters. (Lommers 2012) The DanishNorth German collaboration broadcast May 6 and September 8, 1931 were organized as a consequence of the establishment of a North Sea cable for radio transmission, which was discussed during the broadcast (DR 1931: 10.22-10.34). Similarly, but in a more experimental fashion, the two compositions by Bill Fontana in the Metropolis series were the results of temporary satellite connec- 
tions, so-called 'sound bridges', between Cologne and San Francisco in 1987 and Cologne and Kyoto in 1993.

While connections and bridges are explicitly present on a macro level of both projects, putting cities, nations and broadcasters in connection with each other, the practice of connecting places also figures prominently on the micro level of the productions themselves. A daring feature of the German visit in Copenhagen broadcast September 8, 1931 is the re-transmission via short wave from a steamboat in Copenhagen Harbor, something that is articulated as an experiment in itself (DR 1931:10.20-16.30). In Bønnelyche's piece from December 7, 1930, partly rebroadcast in January 9, 1931 city portrait, the use of sound film allow recordings form different places in Copenhagen to be played directly after each other - a montage technique to be explored much more in the later Metropolis pieces. The character of experiment was so prominent that one listener and writer at Radio-Programmet found "sound images" from different places "lively" and "clearly noticed the difference between the machines presented", but lacked some action and concluded that the broadcast was: "As an experiment, amusing. As an institution, barely recommendable." (Anonymous 1930b: 4, authors translation)

\section{Aesthetics}

The productions can be heard as explorations of sonic displacement. From Bønnelyche's early and rough Copenhagen montage in 1930 to Pierre Henry's complex "Paris" composition in 1984 runs a paradoxical concern with site specificity in sound and radio: what does it mean to be listening to sounds from a city - even if it is your own city - in a sound production? How can that be illustrative, satisfactory and even aesthetically appealing?

The above-mentioned comment from Radio-Programmet clearly illustrates that expectations were not always in line with the results. The editorial voice called Radax in Radiolytteren was somewhat similarly disappointed with the broadcast from Finland February 22 1931: "We expect that the foreign city will reveal itself for us [...] We want to hear its noises! Every city has its characteristic noise and tone, if they can be captured! We await carillons, the cries of street vendors, the sensational cries of the newspaper man, the fire engine setting out, the guard parading [...] but how would it be possible to capture all this in a live recording?" (Radiax 1931: 7, author's translation). The answer to the rhetorical question, of course, is that it is not possible at all for a live recording to achieve the desired plurality of sounds, and that experiments with sound film and later sound storage media like discs and tapes would provide new means to pursue this dream of a localized sonic essence. Yet the slight uncertainty in the quote, "if they can be captured" (ibid.), point to the ambivalence of the whole project of finding a sonic essence of a city. 
Pierre Henry, who - with a background from French radio's Club d'Essai and musique concrète - was commissioned to do one of the first metropolis productions: "Metropolis Paris" from 1984 also used the more general title "La Ville Die Stadt", and structured the later CD publication in tracks with generic titles like "stairs" "traffic," and "metro." (Henry 1994) Paris may be heard in the composition, but the overall impression is an abstract and compositional approach to the exercise of portraying a city, and from time to time it seems we are listening to a city rather than to the city of Paris.

Whether the approach is compositional or more realistic and prosaic, a central tension in the material is that of working with displaced sound: sounds presented in an explicitly different context than where they come from. Displacement of sound is a feature in all sound reproduction, of course, but the sonic city portrait as a genre makes this displacement explicit. It would seem that in allowing everyday sounds from designated locations to be heard, the genre also allows aesthetic reflections on this displacement: that the sounds are simultaneously 'here' and somewhere else; that the sounds refer to something known yet slightly foreign; that they allow us to sense, yet not fully grasp, an environment, to decode, yet not fully recognize, the place. In doing so, the city portraits may feed the global imaginary that Appadurai describes.

\section{CONCLUSION}

This case study has provided insights into the role of city portraits in transnational radio. Based on two cases: collaborations and co-transmissions between Nordic broadcasters in the early 1930s and the Metropolis series produced for Studio Akustische Kunst at WDR in the 1980s and 1990s the study has investigated the function of the city portrait in transnational radio. Looking in particular at how these two projects address territory, how they use and articulate technology, and their aesthetic form and judgement, the study has articulated some of the ambivalent affordances that allow the genre to work in the intersections between materialized communities and global imaginaries. These broadcasts confirm existing territories, while also negotiating new alliances; they make the foreign present while clearly stating the distance, and they excel in the aesthetics of displacement that allow us to listen into and dream about a radically-connected global world, while placing the listener safe at home. 


\section{REFERENCES}

Anderson, Benedict (2006 [1983]): Imagined Communities, London \& New York: Verso. Anonymous (1930a): “Hverdagens København I radiofoniske Billeder,” In: ArbejderRadio December 7, pp. 706-707.

Anonymous (1930b): "Hvad Ugen bragte," In: Radio-Programmet December 12, p 4. Appadurai, Ajun (2010 [1996]): Modernity at Large, Minneapolis \& London: University of Minnesota Press.

Arnheim, Rudolf (1971 [1936]): Radio, New York: Arno \& The New York Times.

Castells, Manuel (2010 [1996]): The Rise of the Network Society, Malden \& Oxford: Blackwell.

DR (1930): Program Sheet December 7. (http://www.larm.fm/Asset/eo568181-bddd94ce-22fb-a33698faa25b)

DR (1931): Kopenhagen - ein Städtebild. Nordtyskland på Besøg i København. Broad cast September 88 p.m.-12 p.m. (http://www.larm.fm/Asset/32e7cb6d-o4644e7e-974a-61c3c2c62501/edac766f-ab6c-4355-965e-9221b457a42d).

Henry, Pierre (1994 ): La Ville Die Stadt Metropolis Paris, Mainz: Wergo.

Kreutzfeldt, Jacob (2018): “State-Controlled Avant-Garde? - Emil Bønnelycke's Radio” phonic City Portrait of Copenhagen” in Tania Ørum/Per Stounbjerg/Benedikt Hjartarson/Andrea Killnitz (eds.), A Cultural History of the Avant-Garde in the Nordic Countries 1925-1950, Amsterdam: Brill/Rodopi (forthcoming).

Lommers, Suzanne (2012): Europe - On Air. Interwar Projects for Radio Broadcasting, Amsterdam: Amsterdam University Press.

Radiax (1931): “Finland Gennem Æteren. Nogle Betragtninger I Anledning af Helsing” fors-Transmissionen," In: Radiolytteren March 1, p. 7.

Schöning, Klaus (1996a): Acoustica International Metropolis City Soundscapes, Catalogue text received by the author from Markus Heuger May 32016.

Schöning, Klaus: (1996b): Acoustica International. Lydrejse. 100 værker fra Studio Akustische Kunst WDR Köln (1969-1996), Roskilde: Museet for Samtidskunst. 



\title{
European Music?
}

\section{The International Broadcasting Union's 1930s Concert Series}

\section{Concerts Européens}

\author{
Morten Michelsen
}

\begin{abstract}
Unfortunately, in many cases, the details of these concerts, and above all their dates, were communicated to the office too late, and thus also to the members, to allow them to set up the relay. This is particularly regrettable, as it is a "European Concert" that has a special mission to perform: rapprochement of the peoples, to which the members of the Union are under a moral obligation to participate. ${ }^{1}$ (IBU 1932:1)
\end{abstract}

These words from the International Broadcasting Union's (IBU) British general secretary, A.R. Burrows, point to one of the many major - and banal practical problems in international cooperation concerning radio relays. Also, they spell out clearly a main objective of such cooperation: the coming together of the peoples of the world. The words concern a series of concerts, Concerts Européens, broadcast 1931-39. Each concert was produced by a national broadcasting organization and relayed to interested IBU members. ${ }^{2}$ The technological logistics of the relays were extremely complex, and the concerts became major tests of practical European cooperation. They also contributed to a sonic mapping of Europe by giving specific places within Europe a sound and/or a music. To many organizers, these concerts were among the most prestigious

1 Malheureusement, dans bien des cas les détails de ces concerts et surtout leurs dates ont été communiquées trop tardivement à l'Office et de ce fait aux membres, pour leur permettre d'en effectuer le relais. Ceci est particulièrement regrettable lorsqu'il s'agit des "concerts européens" qui ont une mission spéciale à remplir: celle du rapprochement de peuples, et auxquels les membres de l'Union ont contracté l'obligation morale de participer.

2 | Concerts Européens was one concert series among many. An earlier IBU series, Nuits Nationales broadcasts 1926-31, was based on the same idea, while all kinds of bi- and multilateral cooperations took place all the time during the interbellum years. In the report referred to Burrows mentions that in the previous eight months 195 international concerts were made available to the members. See also Fickers/Lommers (2010: 309-24) and Lommers (2012: 242-43). 
events of their radio activities. In addition, having a national radio station was important to the many new countries in Europe following World War I. Radio broadcasting granted them an equal voice in the ether next to the older nations and allowed them to partake in the emerging democracy of the airwaves.

In the following I will ask how music fitted within a dialectical or paradoxical strategy of nation- and continent-building by discussing one aspect of that strategy, namely: how did interbellum radio organizations and leaders use music in the concert series Concerts Européens. What music did the orchestras play, how did the broadcasting houses contextualize it, and how did they communicate nationality and/or transnationality in music and in concert programming? In her book on transnational radio, Michele Hilmes addresses this paradox in detail and describes it succinctly:

[... the inherent transnationalism of broadcasting's cultural economy [is] constituted both by the demands of the nation and the equally compelling impulse to go beyond, to provide a conduit to speak to other nations and let other influences stream into the national space. These two capacities operate in considerable tension. Transnational elements in broadcasting's cultural project were (and are) resisted and denied as often as they are acknowledged and encouraged. (Hilmes 2012: 2, italics in the original)

\section{THEORETICAL BACKGROUND}

I will begin from the assumption made by Arjun Appadurai about contemporary cultural economy that its complex and messy flows cannot any longer be understood according to simple bipolar models like center/periphery or consumers/producers. (1990: 296) Appadurai points to a difference between then (less complex) and now (more complex) which makes perfect sense from the perspective of now. But when trying to understand historical circumstances, there is considerable reason to assume that the time in question appeared just as complex to its contemporaries as our times do to us, which is why I will apply Appadurai's assumption to a much earlier phenomenon: European radio between World War I and II. His statement may help explain the elements of the complex paradox of nationalism and transnationalism in music broadcasting.

It is hard to decide whether or not music has national marks. Questions of context and reception are more important than nationally defined styles or composers' and performers' national backgrounds. (O'Flynn 2007) In general, there was an abundance of radio-related discourses linking music and nationality or music and universality. Such contextualizations often marked music as either national or transnational, and if you look at national programming in general, there is no doubt that most broadcasting organizations applied both 
discourses. At a daily level, programs that celebrated each nation's great musi$\mathrm{cal}$ and literary sons (hardly ever daughters) and the playing of the national anthem at the end of each day were two obvious practices supporting the national perspective. The Radio Times, for example, lists BBC series Six concerts of British Music broadcast between 1 and 12 January, 1934, and the 17-part Pilgrim's Way: A Tale of Everyman's Journey through Life, and of his Many Moods. An Anthology of Poetry and Music, broadcast throughout 1934 and 1935, mixing British music and poetry. On the other hand, the frequent music relays from other countries supported the transnational perspective. In between was a large grey area where questions of national belonging could be answered differently according to circumstance.

At a transnational level, the emerging radio structures supported by the IBU did not adhere to the center/periphery principle practiced in the nation states, but to a network principle. The IBU saw its main obligation as coordinating the construction of a European radio infrastructure. (Fickers/Lommers 2010: 314) Contrary to nation-building, this 'continent-building' was new and followed the ideals of the then new League of Nations. It was based on technological coordination and distribution (e.g. relay frequencies) and the ideology of peaceful, modern man. (Lommers 2012: 84-85) In order to discuss these questions in detail I will briefly explore two types of materials casting light on the series: the IBU's intentions as understood from IBU archive materials and the actual concert programs themselves.

\section{IBU INTENTIONS}

Suzanne Lommers's book about the IBU (2012) is based on extensive archive study, particularly IBU documents held in the written archives of its successor organization, the European Broadcasting Union (EBU). It includes a full chapter on the IBU concert activities and to some extent it demonstrates IBU's reasons for setting up the series. Sadly, the EBU archive was closed to researchers not long after her book appeared, so for this research we have had to make do with Lommers's fine work, with some archival documents collected by Alec Badenoch on research visits 2006-2010, and with traces of the concerts in national programming schedules and radio magazines. ${ }^{3}$

3 I would like to thank Alec Badenoch for sharing the documents he collected. The magazines consulted in this connection with this research are the Austrian Radio Wien (1924-38), the Danish Radiolytteren (1925-54), the British Radio Times (1923-), and The Listener (1929-91). Danish and British programming schedules from before World War II may be found at www.larm.fm and genome.ch.bbc. co.uk. 
These sources show two important aspects of the IBU's intentions with regard to the concerts. First, in a 1932 letter from the general secretary to the members, he mentions that the IBU developed a program politics "with the aim of spreading the notion of radio's usefulness and making the public understand that there exist certain manifestations of art that can unite all European listeners." (quoted in Lommers 2012: 244) The (art) music in question should legitimate the still questionable medium of radio and at the same time point to a nonspecific European unity. Second, when it came to the actual music broadcasts, the IBU tried to set high standards. Rather than establishing artistic quality as the primary concern, they related the notion of high quality to concerns like sound quality, number of participants, a sense of liveness (and thus a sense of community), and the uniqueness of the concerts. And further, rather than placing the European art music canon at the very center of its activities, the IBU, according to Lommers, favored "light but artistic music" rather than full symphonic works. This music somehow still fitted the ideals of art music for the first years of the European Concerts. Later on IBU opened up for: "all genres [...] as long as they were of the highest quality and performed by artists of the highest standing." (quoted in Lommers 2012: 270) IBU's move away from high art ideals focusing on works of art towards a focus on quality of performance during the 1930 s was a rhetorical gesture which did not resonate in the actual programs because hardly any broadcasting corporations adhered to the IBU intentions in terms of the breadth of genres. Also, the IBU asked its members to refrain from vocal music because the lyrics would not be understandable to listeners in other countries. This request was ignored by most countries.

\section{Concert Repertoires}

I have identified 50 concerts in the Concerts Européens series from the sources mentioned in footnote four. The 50 concert programs found were broadcast from 22 different European cities - and one from Cairo, which, while it is not within most definitions of Europe, is within the European broadcasting area. ${ }^{4}$ To analyze how the concerts fell within national and transnational paradigms of music, we can look specifically at three key realms where elements of the music can be flagged nationally, transnationally or both: people, instrumentation and genre.

4 | A complete list of works and performers for all 50 concerts and statistics can be found at www. ramund.ikk.ku.dk. 
A breakdown of the concerts according to these elements reveals:

Composers and music performers:

- All music in all concerts was composed by composers related to the country broadcasting

- All music was performed by soloists and ensembles from the hosting country ${ }^{5}$

Instrumentation:

- Use of more or less full orchestra (1 exception)

- Inclusion of vocal music (soloists and/or choir) (41 concerts)

Genres:

a) Folk music

- Basic arrangements performed by art musicians (rather than music composed on the basis of folk materials) (5.5 concerts)

- Folk musicians/ensembles (1.5 concerts. Irish musicians play at two different concerts and two 'gypsy' orchestras play at a third (Hungarian) concert)

b) Light music (2.5 concerts)

- Excerpts from popular stage works (Austria, UK)

c) Art music (40.5 concerts, nearly half of which included contemporary works, falling into three categories)

- Historical art music (to stress what "we" have accomplished), for example Hector Berlioz (1803-69), Franz Liszt (1811-86), W.A. Mozart (1756-91), Franz Berwald (1796-1868), J.S. Bach (1685-1750), Palestrina (1525-94)

- Contemporary (to stress what "we" are accomplishing), for example Bohuslav Martinů (1890-1959), Carl Nielsen (1865-1931), Frederick Delius (1862-1934), Karol Szymanowski (1882-1937)

- National (to stress musical representations of local/national nature or "the people" using elaborate orchestral and/or vocal arrangements of folk music or national hymns) for example Hamilton Harty (1879-1941): Movement from the Irish Symphony, Vincent D'Indy (1851-1931): Symphony on a French Mountain Air, Sabin Dragoï (1894-1968): Rustic Divertissement, Youssef Greiss (1899-1961): Movement from the Egyptian Symphony, The Desert. Finale

Operating with genre labels in the taxonomic manner chosen here in particular has its obvious pitfalls, but in the short form of this article, it may help to shed light on the main tendencies in the overall corpus. Some of the concerts clearly

5 | There is one exception: The concert broadcast from the free city of Danzig 16 January, 1939, had British pianist Ella Martins as soloist. The city was under Nazi rule at that time. 
fall into two distinct parts belonging in different genres, and I have chosen to categorize such concerts in two categories, each with 0.5 points. Thus, the total amount of concerts is still 50 . The general categories of folk, light, or contemporary include quite a lot of music, but there are nevertheless a number of categories not represented in the concerts. What is missing is dance music, especially of the modern, US-influenced variety, but also to a great extent old dance music (the Strauss family etc.). Apparently, such music was not considered appropriate for presenting a country's image, even though old and modern dance music was the bread and butter of all European radio stations. The one exception was Austria, which devoted an evening to the operetta composer Franz Léhar (18701948), evoking the iconic Viennese dance culture. Instead, sometimes an educational, sometimes an elitist stance seems to lie behind the programming policy. And this seems to contradict the IBU policies as outlined above.

The bulk of the repertoire was composed during the 75 years prior to the 1930 s. Most of it was in a romantic or late romantic style, but relatively modern music was presented as well. Relatively modern, because radicals like Schönberg or the expressionist Bartók could not be heard (though some of his late romantic work was). It is also noticeable that older styles like classicism, baroque, and renaissance were also not well represented, and European art music's strong center/periphery structure with the Vienna classicists at its epicenter is not present in the programming. Many countries' wish to present their own construction of a national musical heritage saw to that. The Herderian notion of folk music's double role in constituting the national and the universal is important here. In this line of thought folk music and folk songs as the voice of the people could represent both all of human culture and specific cultures. (Bohlman 2011[2004]: 28-29) This became manifest in the broadcasts of folk ensemble performances, in simple arrangements, and in folk-based, elaborate compositions, often called national romanticism.

\section{Conclusions}

Concerts Européens became a framework for many slightly different cultures, but still based on what radio officials regarded as "universal" principles of music: that is, the historical importance of roots or folk music and the qualities of the European art music tradition based on notation, tonality, instrumentation, and aesthetic function. This left out modern dance music, jazz, and many European folk music traditions not filtered through the art music tradition. Contrary to the IBU's instructions, vocal music with lyrics seems to have been important in order to convey ideas of the musicalized nation: perhaps the sound of language and its semantics were deemed important. Most concerts (80-90 $\%)$ must be considered highbrow (also contrary to the IBU instructions). Even 
though the IBU's wish to standardize the broadcasts did not succeed, the diverse programming practices demonstrate an ideal associated with the League of Nations: that of a democracy of the air where each voice or country had their say within a set framework.

In the relays, nationality and nation were explicit while transnationalism was implicit. Transnationalism was a consequence of the complete series of concerts (the joining together of different voices), and transnationalism was inherent in the ideology of radio itself, in the transnational organizations facilitating the concerts, and musically, in the standards of quality which the IBU tried to impose. Radio came to present 'the other' as belonging within the nation state. 'The other' could take different forms: it could be local, peripheral provinces within the nation states and it could be very different cultures beyond the nation's borders. In this way, certain genres of music and of radio helped build the imagined community of the nation and, at the same time, to view this community as part of something even larger - a continent - audible as 'European' music. The permeability of the nation as an imagined community is intriguing, especially when it is articulated through music's ability to embrace difference and sameness in the same gesture without any problems. It crosses borders while demonstrating them musically.

So to return briefly to the quote by Michele Hilmes: the considerable tension that she has detected in the relations between the US and the UK might, in this instance, be less tense because the music in its historicity articulated so precisely the dialectic between the national and the international. The articulation of this dialectic was not new to the tradition of art music, but it was one of art music's - and in other contexts popular music's - most important contributions to the then new medium of radio.

\section{REFERENCES}

Appadurai, Arjun (1990): "Disjuncture and Difference in the Global Cultural Economy.” In: Theory, Culture \& Society 7/2-3, pp. 295-310.

Bohlman, Philip V. (2011[2004]): Music, Nationalism, and the Making of the New Europe. New York and London: Routledge.

Fickers Andreas/ Lommers, Suzanne (2010): "Eventing Europe: Broadcasting and the Mediated Performances of Europe." In: Alexander Badenoch/Andreas Fickers (eds.): Materializing Europe: Transnational Infrastructures and the Project of Europe, Basingstoke: Palgrave McMillan, pp. 225-251.

Hilmes, Michele (2012): Network Nations: A Transnational History of British and American Broadcasting, New York and London: Routledge. 
IBU (1932): "Commision de Relais: Développement des relais internationaux depuis octobre 1931.” Série No. 3167, 20 mai 1932. IBU Box 85, Relais, File Concerts Européens et Internationaux, (EBU written archives, Geneva).

Lommers, Suzanne (2012): Europe-On Air. Interwar Projects for Radio Broadcasting. Amsterdam: Amsterdam University Press.

O’Flynn, John (2007): "National Identity and Music in Transition: Issues of Authenticity in a Global Setting.” In: Ian Biddle/Vanessa Knights (eds.): Music, Nationalism, and the Politics of Location: Between the global and the Local, Abingdon, Oxon: Ashgate. 


\section{From Enzensberger to Clausen: An Auditive TRANSFORMATION}

Ib Poulsen

The radio feature is one of the most prominent genres in the historization of radio. Based on an extensive study of Danish radio montage and its roots, this contribution considers the montage genre in Danish radio and - in particular the transnational influence that helped shape it. Danish radio feature producer Viggo Clausen's adaptations of Hans Magnus Enzensberger's radio essays to Danish radio features will be discussed as an example of transnational inspiration and creative re-production.

In 1964, Hans Magnus Enzensberger published a book entitled Politik und Verbrechen, i.e. Politics and Crime (Enzensberger 1964). The book consisted of a number of essays, originally broadcast as radio features on Hessischer Rundfunk in Frankfurt am Main a couple of years earlier. Thematically and historically, the book comprised a rather varied bunch of flowers. From Russia on the edge of revolution in the second half of the 1800 s to Italy in the 1950 s, and from the execution of a deserter to the murder of a young girl and to the steep fall of dictators. Among them, there was also a story about the gangster era in Chicago in the 1920 s.

Each of Enzensberger's essays had a clear didactic purpose. The story should not only be told and understood as such, it should also be related in what respect this story was a symptom of something more general. As a listener, you were told a story, but you were also instructed as to how it should be understood.

Viggo Clausen read Enzensberger's book in 1965, and he also heard the original German radio features. He became fascinated by the stories and decided to produce a Danish version. Thus over the next fifteen years, twelve essays were transformed into radio montages. One of the first was Viggo Clausen's version of Chicago Ballad, broadcast on Denmark's Radio (Danish Broadcasting Corporation) on August 21st, 1965.

However, let us start with a few minutes from the original German version of this gangster story. Below an English translation: 


\section{Enzensberger: Chicago Ballad, Start}

The cello case snaps open; on the burgundy velvet lining rests a pristine machine gun. The bodies are discovered at dawn: The milkman on his rounds finds them next to the fire hydrants, the elevator boy in the hotel lobby, the warehouse keeper between the oil cans in the warehouse. The leading hosiery shop in the area has put a sign in the window reading: Bullet holes in clothing repaired here - guaranteed invisible mending at very reasonable prices. (Enzensberger 1966: 76)

Apart from a somewhat lucid beginning, Enzensberger's version is most of all reminiscent of an academic dissertation. After this beginning, the thesis is formulated: The gangster is one of the 2oth century's myths, and mob boss Al Capone is a key figure in this myth - not as a historical person but as a mythical person. After that, the background is briefly outlined, followed by a review of the development of the gangster system. First John Colossimo with his business methods rooted in the 19th century, then the industrial Torrio who systematized both production and distribution, and then Al Capone who created a modern group and a monopoly. Within a decade, the development of the capitalistic system is illustrated: From a one-man business over an industrially organized business to the monopoly. Al Capone is portrayed as a modern businessman on the one hand, but also as a mobster for whom business is not based on legal rights, but on mutual loyalty. The conclusion is that it was possible to create such a business model because society was ready for such regression - as later in Italy with fascism and in Germany with Nazism.

Different voices read Enzensberger's text, however, apparently only for variation. In any case, with the exception of the reading of Al Capone's quotes, it is not possible to identify a specific voice connected to a specific role. Thus, it seems that the use of different voices has no communicative purpose beyond variety. Music, primarily ragtime, is also one of the means of expression, often used in the transition from one chapter to the next. Finally, the positioning of the listener is one that you are being informed and to some extent even lectured, especially in the end where the analysis is carried out and the conclusion is drawn.

The Danish version is different, and particularly the auditive expression has changed.

\section{Chicago Ballad, Danish Version, Start}

(Chopin's Funeral March, ambient sound recording with horse hoofs on pavement (six seconds), speaker's announcement of the program with the ambient sound in the background, 
after the announcement the ambient sound is back full strength for approximately ten seconds and subsequently softer as background throughout the entire fictitious commentary).

Reporter: Today (p)1 on November 14, 1924 (p) Dion 0'Banion is carried to his grave (P)2 with mounted police leading the way, the two kilometer long funeral procession makes its way through the streets of Chicago (P) Dion 0'Banion (p) florist (p) shot down in his shop diagonally across from the Holy Name Cathedral ( $p$ ) where he sang in the choir as a boy ( $p$ ) and has since attended mass so often.

Commentator: Dion 0'Banion (p) mob funeral large-scale supplier (p) of flowers (p) and wreaths ( $p$ ) and right (p) now his own last and biggest customer.

Reporter: Four days ago he was in the back room of his shop ( $\mathrm{p}$ ) arranging chrysanthemums $(P)$ when a blue limousine pulled up by the door $(P)$ there were four men in the limo $(P)$ one remained behind the wheel $(p)$ the other three got out and went into the store $(p) 0^{\prime} B a n i o n$ came out to meet them, hand extended.

Commentator: So reckless! (P) Why didn't Dion 0'Banion greet his customers in the usual way (p) standing ( $p$ ) legs astride (p) right hand firmly resting on his hip (p) left hand in his pocket (p) automatic pistols ready in the tailor-made suit? (p) He must have known his killers very well (p) have felt entirely safe.

Reporter: Now Dion 0'Banion rests in a 10.000 dollar coffin (p) specially in from Philadelphia on a chartered train ( $p$ ) the coffin is made of bronze ( $p$ ) two layers of bronze (p) and silver plated ( $p$ ) 0 'Banion rests on a bed of satin ( $p$ ) a lace pillow under his left hand.

Commentator: Police attribute 25 murders to Dion $0^{\prime}$ Banion ( $p$ ) but he has not yet been brought to trial for a single one ( $p$ ) of his 32 years of life ( $p$ ) only one has been spent in prison $(p)$ and that was in his youth $(p)$ the amateur years $(P)$ with the prohibition came his era of greatness $(P)$ all of northern Chicago became his territory $(p)$ and not only the speakeasies but also all of the gambling joints had to pay him protection money (0.00-2.56).

This account has two levels. There is the reportage of the funeral and of events leading up to it, and there is background information and speculation as to why things turned out as they did. Each level has its own voice, and the difference between the two voices is rhetorically underlined. The reporter's sentences are short and descriptive, in contrast with the commentator's greater variation. And then there is the irony - on the one hand it is a radio report of a funeral worthy of a king, on the other it is emphasized that we are at the burial of a florist who has murdered several people.

With an opening like this, several narrative advantages have been achieved. It provides a frame in which you can present a milieu, social norms and persons, and at the same time you can include the whole gangster myth, that

$\mathbf{1} \mid$ (p): Pause less than a second

2 | (P): Pause more than a second 
comprises the connection between business, organizations, territory and corruption woven into society in general. In addition this framing reflects the immense wealth and influence of the very few, rough and cold-blooded gangsters, who also have a specific code of conduct in a conflicting atmosphere with brutal shootings and good manners. In words and sounds it is not the gangster period as a historical phenomenon, but the media designed version of it. In that respect, the opening is not only the beginning of the story, but a prelude that gives you an impression of the whole feature and an anticipation of the end.

The German and the Danish versions follow two different rhetorical strategies. In contrast to the German version, the Danish version is constructed more like a drama or a fiction piece. E.g. music plays a more prominent role in the Danish version compared with the German one. More pieces of music are used, and in several cases a theme is shortly introduced, and later a more extended part is heard. The first time this happens is in connection with Jim Colossimo's death. He was a man of the old school, and he preferred to put his money in diamonds:

\section{Chicago Ballad, Danish Version:}

Commentator: Money should not be put in diamonds ( $p$ ) it needs to be put to work ( $p$ ) making new money (P) Colossimo did not see the huge opportunities the prohibition offered for a decisive and financially powerful leading personality type $(P)$ (slightly less distinct and with a slightly deeper voice) that is why he died (p) on May 11, 1920 (p) a bullet through his head ("Nearer My God to Thee", organ interlude, 7 seconds.) No, we will not be joining the procession in the first of the big mob funerals $(P)$ they are passing by down there $(p)$ the judges and the brothel owners ( $p$ ) the Senators and the bootleggers, the highly esteemed Member of Congress and the notorious gunman ( $p$ ) they will be meeting often ( $p$ ) in cemeteries over the next half-score years ( $p$ ) perhaps unaware (p) that they are accompanying an era to the grave? (P) while the little shovelfuls of dirt fall on the coffin and the Apollo Quartet sings "Nearer My God to Thee" (the Mills Brothers quartet lends its voices) preparations have already been made for the assumption of power by men with the weapons of the new era ( $p$ ) bookkeeping machines and machine guns

(The Apollo Quartet sings: "Still all my songs shall be// nearer my God to thee// nearer my God to thee// nearer my God to thee", concluded by the organ interlude). (17.00-19.32).

First you hear the brief organ interlude with the main theme of the well-known funeral hymn. Later the title of the song is mentioned, and then you hear a longer sequence - a well-known and often used narrative trick, called set-up/pay-off. 


\section{Chicago Ballad, German and Danish Version:}

The cello case snaps open; on the burgundy velvet lining rests a pristine machine gun. The bodies are discovered at dawn: The milkman on his rounds finds them next to the fire hydrants, the elevator boy in the hotel lobby, the warehouse keeper between the oil cans in the warehouse. (Enzensberger 1966: 76)

The cello case snaps open, and on the burgundy velvet lining is a brand new machine gun. The bodies are discovered in the early hours of the morning. The milkman on his morning rounds stumbles over one by a fire hydrant; the night clerk can't open the door because there is a dead man behind it; the warehouse keeper moves a couple of oil barrels in the warehouse, and there are the bodies. (Clausen 1965: 5)

The story is the same, but the Danish version is more lucid. You can image more clearly what happens. One example is the body at the hotel. It is not merely found, but it prevents the night clerk from opening the door. And the milkman does not simply find the bodies, he stumbles over one of them. Secondly, information is divided into more full sentences, as seen for example when comparing the last sentence in the German version to the last two sentences in the Danish version. Thirdly, the Danish version is more precise and adequate idiomatically. The word morgendæmring in Danish ('dawn' in English) has a poetic and solemn touch compared with the more precisely reporting expression de tidlige morgentimer (in the early hours of the morning), and in this specific context of simply reporting an event the latter is more adequate to the genre than the former. Similarly, a machine gun can be 'pristine', but 'brand new' is better, the product taken into consideration.

Generally speaking, the Danish version is more lucid, as mentioned, but also comprises a clearer psychological profile characterizing the different characters involved. They simply present themselves more distinctly psychologically. This is achieved in two ways: More quotes from each person and consistent use of a specific voice for each person - i.e. a consistent role-specific and more expressive/outgoing use of voices. As mentioned, this is not the case in the German version, except for the quotes of Al Capone.

Finally, a few brief remarks on the critical-analytical reflections that are so dominant in the German version. This same dominance is not found in the Danish version. However, in relation to Viggo Clausen's features from the 1950s, the critical dimension is stronger in Chicago Ballad. Not as contemporary social critique, but as a critique of history writing and its immanent ideological assumptions. As such, both Enzensberger's feature and Clausen's version represent a preliminary version of the ideology critique, which became popular among social scientists in the 1970s. 
168 Ib Poulsen

\section{REFERENCES}

Enzensberger, Hans-Magnus (1964): Politik und Verbrechen, Frankfurt am Main: Suhrkamp.

Poulsen, Ib (2006): Radiomontagen og dens rødder, Part 5 “Den Clausen'ske feature”, Copenhagen, pp. 437-523. 
Section 4:

Doing Transnational Radio Research

AND the Digital Archive 



\section{Transnational Radio Research and the Digital Archive: Promises and Pitfalls}

Sonja de Leeuw

The beginning of the present century among many things marked the European Commission's recognition of the critical role of digitization in stimulating access to European cultural content. (cf European Commission 2001) Consequently the Commission launched several initiatives to help create the necessary conditions for a so-called European continuum of digital heritage. ${ }^{1}$ Expectations ran high in terms of access across borders, transnational cultural cooperation and raising awareness of the diversity and richness of European culture. (cf European Commission 2004) Over the years that followed, several European programs provided the financial and cultural frameworks needed to meet these expectations. These programs, to mention just MEDIAPlus, eContentPlus and the ICT Policy Support Program, set prerequisites for transnational collaboration between European nations so as to support common data models and services to which national initiatives could conform. They resulted in digital heritage platforms such as the European Film Gateway, Europeana Sounds, TEL (The European Library) and EUscreen.

The notion of the transnational indeed appears often in the reports and speeches delivered by the European Commission. It reflects a true belief in the role of cultural (digital) content in shaping a common Europe. According to Information Society and Media Commissioner at the time, Viviane Reding, "Information technologies can enable you to tap into Europe's collective memory with a click of your mouse." (European Commission 2006) Later on, the European Commission's communication on the progress of digitization, accessibility and digital preservation of cultural heritage in Europe changed the metaphor of "collective memory with a click of your mouse" into "Europe's cultural heritage at the click of a mouse." (European Commission 2008) This is not to say that the notion of memory has become less important; on the contrary. The wording rather emphasizes how much digitization and preservation

$\mathbf{1} \mid$ According to the proceedings of the conference Strategies for a European Area of Digital Cultural Resources: towards a continuum of digital heritage, held September 15-16, 2004, The Hague. 
of Europe's cultural heritage precede the construction of a collective European memory.

As Europe's cultural heritage is stored in archives, the European Commission's efforts in the last decade focused increasingly on establishing a European digital library, combining multicultural and multilingual environments with technological advances. Europeana, the access portal to Europe's cultural heritage, is the most prominent result of these efforts. It was launched in 2008 and has since then developed into a professional network and multi-sided access platform for use and re-use of digital heritage content from across Europe. Europe's present policy reflects a belief in Europeana's potential to strengthen its cultural and digital innovation value for the European community at large through user oriented projects and technological advancement. (Council of the European Union 2016) In this chapter, I will discuss some of the promises and pitfalls faced when doing transnational media research with digital archives. The main focus will be on the implications of the transition of the archive from a storage place of objects and documents to an interface generating digital data.

\section{Access to Radio Archives}

Where is radio in this context? When initiating research from a transnational perspective, Europeana Sounds may well be the first place to look. This project selected and aggregated radio programs from a number of European stakeholders ranging from national libraries such as the Statsbiblioteket Denmark and the British Library in the UK to archives (Netherlands Institute of Sound and Vision) and public bodies, such as Rundfunk Berlin-Brandenburg. The Europeana Sounds collection is publicly accessible through the Europeana website and enables cross collection linking as a result of the technical infrastructure and enriched descriptions of the material, developed within the project. The project's foremost objective is to unlock sound collections from across Europe for a broad audience. As the very title of the project suggests, it mainly is about sound, and not radio per se as a communication medium, which includes production and distribution practices, aesthetics and listener engagement strategies. The radio programs collection on Europeana Sounds is limited indeed.

Why is access to radio archives and radio programs mostly limited and fractured? Constraints follow mainly from national policies in the first place, yet many nations seem to have them in common; as a consequence, there's even less in the way of transnational access. The core issues here are copyright, metadata descriptions and technology. No matter the different legislation rules that nations follow, and the different stages of digitization they are in, there are common issues indeed. Being mostly public bodies, funded with public money, the question becomes pressing how stakeholders are able to address 
their public mission to reach out to the public and to transfer knowledge about their holdings, whilst copyright legislation limits access to in-house consultation only. Therefore, stakeholders often struggle with the balance between preservation and dissemination, with a focus on preservation rather than on usability. ${ }^{2}$ As Knapskog (2010: 23) argues, this is very much an area of policy in the making indeed on issues of access (to whom), commercialization (in relation to public service ideals), and the public interest (how best to be served?). As a consequence, we need to be aware how much the availability of digital sources may act as the shaper of the research design, whilst the availability in turn is the result of pre-selection by archivists (Corner 2003: 277).

In this context it is important to acknowledge the need for close cooperation between archives, libraries, broadcasters and researchers for several reasons. Researchers can help prioritize digitization and online access and even help to describe the content of specific programs, especially with radio, where lots of information is simply unknown. Moreover, digitization allows for a deeper engagement by users with the digitized content and thus for increasing usability. In order to support stronger engagement with digital heritage, contextualization is key (De Leeuw 2012: 7; Snickars 2012: 36); here researchers come in again providing signifying practices around digitized content. Finally, such collaboration is essential to carry out transnational research. Digital access across borders would facilitate such transitional research, and at the same time serve the policy of the European commission to open up European cultural heritage for all European citizens. Ironically, European money seems to be needed to construct such transnational radio research networks and projects (such as with the TRE project) and support standardization and harmonization of existing data models and technical services into interoperability. In the meantime, a probably more realistic option would be for stakeholders to confine to the Europeana data model that would allow for a much easier exchange of content. As national rights legislation remains restrictive, this would call for a harmonized intellectual property rights (IPR) model, under the current EU copyright framework for instance, which was already described in great detail in the 2001 Infosoc Directive on Copyright in the Information Society. ${ }^{3}$ The EU intends to use this existing framework to grant access for educational, scientific and research purposes on a large scale; it is possible, yet according to the current legal framework, not mandatory. Another approach would be to strive for a "digital

2 Constraints have been discussed in a panel National archives' transnational archive agendas, C0penhagen May 28, 2015. Panellists were Bas Agterberg (Netherlands Institute of Sound and Vision), Carl Davies (BBC), Jeroen Depraetere (EBU), Ditte Laursen (State Media Archive Denmark), and Paul Wilson (British Library).

3 |See http://ec.europa.eu/internal_market/copyright/copyright-infso/index_en.htm (accessed January 11, 2017). 
commons" on the Internet, a non-commercial virtual arena for information, education, and entertainment (the commonly agreed on core tasks of public service), which was followed in the BBC's Creative Archive Project (Knapskog 2010: 24).

\section{The Archive in Transition}

So far we have discussed the European policy context of digital curation as well as the core constraints of accessing digital heritage collections, while pointing to the notion of the digital library as a key place for content storage. The digital library basically is a digital archive, consisting of digital artefacts that in one or another way represent the (construction of the) past. From a theoretical point of view digital heritage mediates between past and present, between history and memory in the making, as Nanna Bonde-Thylstrup will further elaborate in her contribution in this volume. It has the potential to bridge existing academic history, constructed with the help of traditional sources, with popular memory, based upon stories about the past that are available in the public domain, as communication studies scholar Craig Robertson suggests (2011: 5). Digital libraries thus combine history and memory and in doing so they create a culture of memorizing that supports the continuous production of memory. ${ }^{4}$ However, we need to acknowledge that digital heritage is not the equivalent of memory. The act of memorizing takes place whenever heritage is being transformed "into the cultural intermediary of memory" as Zinaida Manzuch, a library and communication studies scholar (2009: 6) puts it. In other words, it needs to be made meaningful to its users to become a part of memory.

Digitization per se seems to have further supported the production of memory, making more room for the so-called "archival turn" (Robertson 2011: 1). With the archival turn, the archive entered a stage of transition from storage to curation, emphasizing the role of the archivist in the formation of the archive. This shift has implications for the research practice, the production of knowledge and on how to account of the historical sources as records that contain data. This holds even more for the digital archive. In the words of museum researchers Fiona Cameron and Sarah Kenderdine, the digital archive involves "taking up the challenge to address the shifting paradigms of knowledge and power." (2007:3) The archive in transition then refers to the dynamic character of digital heritage as it is being continuously redefined in relation to its archivists and users, who both share acts of agency.

4 | Hoskins in his keynote address, 'Media, memory and the connective turn', EUscreen International conference, Rome, October 7, 2010. (cf. Hoskins 2004) 
Let's take a closer look at the role and function of the archivist. Archivists make decisions every day as to what to keep and catalogue, and what not, how to order and classify. No matter how much budget limits, staff resources and storage space influence these decisions, they are not just technical, rather political as sociologist Richard Harvey Brown and information specialist Beth DavisBrown describe (1998:18). Their argument centers on the role of the archive in preserving a shared past, "the received truths of tradition", that build national memory and identity (Brown/Davis-Brown 1998: 19). Professor of Archive Science Eric Ketelaar (2001: 131) convincingly argues how the meaning of archives could only be understood by deconstructing their "tacit narratives." The situatedness of archival work within historical and cultural contexts not only assigns the archivist agency, also it points to informed processes of preserving and archiving. That is why Ketelaar (2001: 133) coined the term "archivalization", meaning "the conscious or unconscious choice [...] to consider something worth archiving." Archivalization thus precedes archiving; the procedures involved in archiving impact on the hidden narratives that the records contain. Accordingly archiving is not just preservation; rather it is an act of cultural and historical knowledge construction. The tacit narratives are therefore informed by the power of those in charge and constitute the archivalization and formation of the archive (examples are discussed in this volume by Carolyn Birdsall in discussing the history of radio archives and Alexander Badenoch when he addresses the preservation of a transnational radio archive).

Building on Derrida, Verne Harris (2007) discusses the archive and archiving not only as culturally and historically bound, but also as fundamentally political; the result of power relations. As the chief archivist at the Nelson Mandela Foundation he discovered not all voices are being archived. In this context the issue of community archives as addressed by archivist Terry Cook (2011) is relevant. He advocates the role of community archives that initiate the inclusion of unheard community voices and hidden community records in the broader (digital) archive (2011: 183). This way, these community records become part of the archive at large and eventually of historical investigation and popular memory (cf. Bastian /Alexander 2009; Joost van Beek's contribution in this section zooms in on one such initiative).

When doing national or transnational research with digital radio archives, it becomes imperative to be able to deconstruct the discursiveness of records and archives. This would call for transparency at many levels, something that is hard to find in existing archival and curatorial practices. What stands out from this discussion though is the apparent need for contextual information, so as to be able to value the historical source in the social-cultural context of its time. This too remains a dynamic practice for researchers, as valuing depends on the historical issues at stake and the lens through which these are addressed. Programs at the time of production do not think of themselves as historical 
valuable and some media production even is pre-historic as with radio in the 1920 s and television in the 1950 s when recording technologies did not yet exist. (Scannell 2011: 44)

\section{Contexualization}

Ketelaar's conceptualization of the archive as a site that contains multiple meanings waiting to be (de)constructed, by definition involves contextualization of the archive and the archival record alike. To some extent, context comes with the record, mainly in the form of metadata, thesaurus terms and tags, all added by the archivist. Yet for researchers answers to the who, what, where, when, and why of source criticism remain a preliminary condition for contextualization and historical interpretation of the records (Fickers 2012: 25).

Contextualization in the digital age allows for shared agency among archivists, researchers and general users, acknowledging the dynamic nature of digital archives that is self-evident and speaks to a continuous revisiting of archival data. (cf. Noordegraaf 2011) Computer scientist Isto Huvila (2008: 34) refers in this context to the participatory archive involving the notion of decentralized curation, radical user orientation and a both broader and deeper contextualization of records and the entire archival process. Still, this is not common practice; instead, curatorial authority remains assigned to archivists and in some instances to researchers alike, for example in collaborative work on virtual exhibitions and portals. Examples are the virtual exhibitions on the EUscreen portal, or Europeana Remix World War One. ${ }^{5}$

The mutual relationship between curatorial and humanities research work is the focus of the work of archive scholar Arjun Sabharwal, more specifically of his analysis of curatorial and research practices: "Without a robust and trustworthy repository, there is no reliable scholarship in the digital humanities, and without a well-supported digital humanities community, there is little context for digital curation." (2015: 25) Again, metadata (data about data) are key here and usually archives conform to the generally accepted Dublin Core metadata schema and/or the Linked Open Data model of Europeana. Such common metadata schemas and models are a necessary condition for digital humanities researchers to search across different digital collections and find relations between collections or records, not known as such before. Europeana Sounds again is an example where this works. Consequently, it allows us to pose new research questions and explore new historical pathways whilst using digital

5 | For Euscreen VE's, cf. http://oldportal.euscreen.eu/exhibitions.html. Voor Europeana Remix cf. http://remix.europeana.eu. 
technologies and methods. These will be briefly discussed as Digital Humanities below.

Media scholar Wolfgang Ernst (2004: 46) goes so far as to claim that without context the archive is just a storage space and has no memory at all, as each narrative (we could read this in the sense of context or added information, SdL) comes from outside, as we also discussed with the help of Ketelaar above. For Ketelaar (2001), there are hidden stories in the archive and in deconstructing these stories, the role of the archivist as an agent of knowledge production is crucial. Ernst is less focused on curatorial practices than on the spatial and temporal relations of the archive in transition. He believes archival objects (he refers to the objects per se, without metadata, thesaurus terms and tags) do no tell stories: "only secondary narratives give meaningful coherence to its discontinuous elements" (2004: 48). The archive is a space or place, dealing with storage. Memory only comes into being by adding context and in dealing with digital collections this would involve computerized data mapping and data processing so as to create interoperability between collections. Hence data become temporally rather than spatially locatable and are subjected to pattern recognition algorithms. (Ernst 2004: 51-52) There is a challenge here ahead of us to deconstruct these algorithms, but practically this will turn out to be a mission impossible for humanities researchers and curators alike, as we will further discuss by the end of this chapter.

Digital contextualization already faces immense challenges according to media scholar Pelle Snickars (2012: 36 ). He points to the proper question of how to deal with the wealth of available digital data, as these could no longer be analyzed and searched in traditional ways. Snickars anticipates a more dynamic understanding of digitized heritage, taking advantage of the opportunities of analyzing data with digital media (2012: 39). This takes us to the discipline, if that is what it is, of Digital Humanities.

\section{Doing Digital Humanities}

Historian Joshua Sternfeld (2011: 64) compares various search systems using formal lists (for guided searches), tag clouds (indicating the frequency of cited terms), and user tags in order to demonstrate how search interfaces assist in the con-textualization of retrieved information. The importance of the role of information architecture in archival public services, outreach, and digital curation is widely acknowledged (Sabharwal 2015: 93). After all, the technology of the interface allows for a diverse, though limited, number of navigation paths, finding hypertextual relationships and therefore ways of producing knowledge. In order to search across collections, and even more so across collections transnationally, meaningful links need to be created. Elsewhere, I have suggested 
the notion of connectivity as a way of looking at the interface as an intersection of digital nodes in the archive that appear once we start searching (De Leeuw: 2011). Within the Digital Humanities, these nodes themselves are the primary objects of reconstruction and interpretation. "Here it is no longer a question of reactivating objects, but of relations." (Ernst 2013: 83)

Digital Humanities indeed is about researching these relations, about building and analyzing tools and platforms for humanities research, about curating online collections and mining large cultural datasets. It involves both qualitative and quantitative methods and cuts across a diversity of disciplines. In presenting research results, it is also about digital storytelling and visualizations (Burdick et al. 2012: 123). An example is Radio Garden, the online exhibition that allows users to explore an interactive globe filled with radio's past and present (http://radio.garden). Another one is a Virtual Exhibition on the history of Radio Luxembourg/RTL. ${ }^{6}$

Digital Humanities is thus concerned with the intersection of computing and the discipline of the humanities and preferably is self-reflexive. As Bakhshi et al. emphasize, humanities researchers have to offer a "fundamental understanding of how technologies transform and re-order knowledge by exploring how information is collected, stored and retrieved." (Bakhshi et al. 2009: 6) How would this work when doing transnational radio research with digital archival material? Elsewhere we argued for media archaeology as an approach to think about digital historical media research. (Van Gorp/De Leeuw/Van Wees/ Huurnink 2015)

Media archaeology by definition is self-reflexive; a method of intellectual inquiry that stresses non-human agency, that is to say it focuses on the deep material structure of media technology. (Parikka 2012: 12) Media scholars Erkki Huhtamo and Jussi Parikka (2011) have put media archaeology firmly on the research agenda, leading the way of historiography in the digital age. They claim that media archaeology is not only a historiography of technologies from past to present, rather it comprises an inquiry into the discursive and the material manifestations of culture. The archive is a key site where media archaeology takes place as nowadays it is also a key site of digital software culture and, as a result, media archaeology relates to Digital Humanities. (Parikka 2012: 15) Wolfgang Ernst (2011: 239) explicitly understands media-archaeology as an alternative method to media historical narratives and stresses that media themselves "become active 'archaeologists' of knowledge." Or, to put it differently, digital software produces cultural articulations.

Following Huhtamo and Parikka (2011), radio research with digital archives would involve an investigation of the material structures of technologies used to produce digital historical radio data as well as an investigation into the cura-

6 | The VE is developed by the University of Luxembourg: http://h-europe.uni.lu/?page_id=4767 
torial practices of the radio archive. As we argued above, this is to be considered another type of contextual information, necessary to value the provenance of research data at the main levels of their production. Ernst (2011: 249) already points to the competence in informatics researchers would need in the digital age to reach the sub-semantic strata of media culture as well as the non-cultural dimensions of the technological regime making cultural analysis calculable. This is but one of the big challenges we now face.

\section{The Transnational and the Digital: Challenges}

I started by referring to the EU policies on digital heritage, acknowledging the importance of access to Europe's cultural heritage at large. Creating access is vital so as to acknowledge that remembering as a continuous process takes place in a dynamic interaction between present and past, allowing for a diversity of memory narratives. Creating access across borders is a preliminary condition for searching and researching the commonalities and differences among European radio and to understand how we remember radio and why we remember it the way we do. Apart from access, we also need much more contextualisation, which by definition involves collaborative work between archivists and researchers. Conditions for collaborative projects need to be created from both ends. Once working together in such projects, participatory indexing (tagging) by researchers would additionally enrich existing metadata and thus allow for further research. On top of that, I advocate the approach of media archaeology outlined above to investigate the provenance of the digital data in the first place, yet definitively also of the technology used to generate these digital data. This speaks to collaborative work between archivists, media researchers and computer scientists. Only then we will be able to offer new perspectives of the study of radio transnationally.

\section{REFERENCES}

Bakhshi Hasan/Schneider, Philippe/ Walker, Christopher (2009): "Arts and Humanities Research in the Innovation System: The UK Example," Journal of Cultural Science, 2/1, pp. 1-23: http://www.cultural-science.org/journal/index.php/culturalscience/article/view/27/54.

Bastian, Jeannette A./Alexander, Ben (eds.) (2009): Community Archives: The Shaping of Memory. London: Facet.

Brown, Richard Harvey/Davis-Brown, Beth (1998): “The making of memory: the politics of archives, libraries and museums in the construction of national consciousness," In: History of the Human Sciences, 11:4, pp. 17-32. 
Burdick, Anne/ Drucker, Johanna/Lunenfeld, Peter/ Presner, Todd/ Schnapp, Jeffrey (2012): Digital_Humanities. Cambridge (MA): The MIT Press.

Cameron, Fiona/Kenderdine, Sarah (2007), “Introduction.” In: Fiona Cameron/Sarah Kenderdine (eds), Theorizing Digital Cultural Heritage. A Critical Discourse. Cambridge (MA): The MIT Press, pp. 1-15.

Cook, Terry (2011): “We Are What We Keep; We Keep What We Are': Archival Appraisal Past, Present and Future." In: Journal of the Society of Archivists, 32/2, pp. 173-189.

Corner, John (2003): "Finding data, reading patterns, telling stories: issues in the historiography of television.” In: Media, Culture \& Society, 25, pp. 273-280.

Council of the European Union (2016): Council conclusions on the role of Europeana for the digital access, visibility and use of European cultural heritage, adopted by the Council at its 3471st meeting held on May 30-31, 2016.

De Leeuw, Sonja (2012): "European Television History Online: History and Challenges." In: VIEW. Journal of European Television History and Culture 1/1, pp. 3-11.

Ernst, Wolfgang (2004): "The Archive as Metaphor. From Archival Space to Archival Time." In: Open, 7, pp. 46-53.

Ernst, Wolfgang (2011): "Media Archaeography: Method and Machine versus History and Narrative of Media.” In: Erkki Huhtamo and Jussi Parikka (eds) (2011): Media Archaeology: Approaches, Applications, and Implications, Berkeley-Los AngelesLondon: University of California Press, pp. 239-255.

Ernst, Wolfgang (2013): Digital Memory and the Archive. Electronic Mediations, vol. 39. Minneapolis: University of Minnesota Press.

European Commission (2001): Lund Action Plan (http://www.cordis.lu/ist/digicult/ lund-principles.htm).

European Commission (2004): Making Citizenship Work: Fostering European Culture and Diversity through Programs for Youth, Culture, Audiovisual and Civic Participation, (https://eur-lex.europa.eu/legal-content/EN/TXT/?uri=celex:52004DCo154)

European Commission (2006): European Commission steps up efforts to put Europe's memory on the web via a European Digital Library (http://europa.eu/rapid/pressReleasesAction.do? reference $=\mathrm{IP} / 06 / 253)$

European Commission (2008): Europe's cultural heritage at the click of a mouse: progress on the digitisation and online accessibility of cultural material and digital preservation across the EU, (http://ec.europa.eu/information_society/activities/digital_ libraries/doc/communications/progr ess/communication_en.pdf).

Fickers, Andreas (2012): "Towards a new digital historicism? Doing history in the age of abundance,” In: VIEW. Journal of European Television History and Culture 1:1, pp. 19-26.

Harris, Verne (2007): Archives and Justice. A South African Perspective. Chicago: Society of American Archivists.

Hoskins, Andrew (2004): “Television and the collapse of memory.” In: Time Society, 13, pp. 109-127. 
Huhtamo, Erkki /Parikka, Jussi (eds) (2011): Media Archaeology: Approaches, Applications, and Implications, Berkeley-Los Angeles-London: University of California Press.

Huvila, Isto (2008): "Participatory Archive: Towards Decentralized Curation, Radical User Orientation and Broader Contextualization of Records Management.” In: Archival Science 8/1, pp. 15-36.

Ketelaar, Eric (2001): “Tacit Narratives: The Meaning of Archives.” In: Archival Science $1 / 2$, pp. 131-141.

Knapskog, Karl (2010): “Archives in Public Service.” In: Critical Studies in Television, 5/2, pp. 20-33.

Manzuch, Zinaida (2009): Proceedings: Cultural Heritage on line. Empowering users: an active role for user communities, Fondazione Rinascimento Digitale, (https://www.researchgate.net/profile/Zinaida_Manuch/publication/268056977_ Digitisation_and_communication_of_memory_from_theory_to_practice/ links/547eoog8ocf241bf4b5b9eo1.pdf).

Noordegraaf, Julia (2011): "Who knows television? Online access and the gatekeepers of knowledge.” In: Critical Studies in Television 5/2 , pp. 1-19.

Parikka, Jussi (2012): What is Media Archaeology? Cambridge: Polity.

Robertson, Craig (2011): "Introduction: Thinking about Archives, Writing about History.” In: Craig Robertson (ed.), Media History and the Archive, London: Routledge, pp. 1-7.

Sabharwal, Arjun (2015): Digital Curation in the Digital Humanities. Preserving and Promoting Archival and Special Collections. Oxford: Elsevier Science \& Technology-Chandos Publishing.

Scannell, Paddy (2011): “Television and History: Questioning the Archive.” In: Craig Robertson (ed.), Media History and the Archive, London: Routledge, pp. 40-54.

Snickars, Pelle (2012): "If Content is King, Context Is Its Crown." In: VIEW. Journal of European Television History and Culture 1/1, pp. 34-39.

Sternfeld, Joshua (2011): "Archival Theory and Digital Historiography: Selection, Search, and Metadata as Archival Processes for Assessing Historical Contextualization." In: The American Archivist: Fall/Winter, 74/2, pp. 544-575.

Van Gorp, Jasmijn/de Leeuw, Sonja/Van Wees, Justin/Huurnink, Bouke (2015): “Digital media archaeology: uncovering the digital tool AVResearcherXL.” In: VIEW. Journal of European Television History and Culture 4/7, pp. 38-53.

Williams, Andy (2016): Hyperlocal News in the UK: Its Current State and Future Prospects (http://impress.press/news/hyperlocal-news-in-the-uk.html). 



\title{
Cultural Memory in the Digital Age
}

\author{
Nanna Bonde Thylstrup
}

Radio archives are central sites of cultural memory. They contain records that can be consulted to understand our past and project our future. Today, most of these institutions are in the process of digitization or seeking to digitize their collections, often responding to political and popular calls of bringing analogue cultural memory artefacts online. This chapter seeks to examine the politics of this process, asking: how can we conceptualize sound and radio archives as sites of cultural memory? What politics does digitizing it produce? And what are the implications of it for radio research?

\section{From national to Transnational Cultural Memory}

Cultural memories are, by definition, mediated memories (Ong 2013[1982]; Assman 2008; Erll 2008); they need vehicles of memory to transport them across space and time beyond the finite human bearer of memory, such as books, buildings, radio programmes, the body, visual art works, natural objects, museum institutions, media institutions, natural landscapes, and so on. Via these vehicles, cultural memories allow individuals and groups to orient themselves in time and space by constructing and connecting to their past. Until recently, cultural memory vehicles were primarily confined to movement within the nation-state paradigm. (see for example Nora 1996) ${ }^{1}$ The main reasons for this confinement were two-fold: firstly, the cultural technologies mediating cultural memory often had limited geographical reach; secondly, the

1 Importantly, there was always an asymmetry between the nation-state and cultural memory, however. This is for instance outlined in Jay Winter's Remembering War in which he notes: "Collective remembrance - or, if you will, collective memory - is rarely what the state tells us to remember. There are always too many people who construct their own narratives which are either at a tangent to those constructed by politicians or their agents, or which are totally inconsistent with what the state wants us to believe happened in the past." (Winter 2006, 277) 
political-legal frameworks regulating these technologies were rooted in the nation-state apparatus.

Digitization processes and the connectivity of digital technologies are reshaping the nation-state paradigm of cultural memory, bringing it from a national to a transnational framework that allows both global circulation of cultural memories as well as research on the dynamics of this circulation. As Aleida Assman notes, this new transnational cultural memory paradigm is not only dependent on new technological structures, however; the work of new transnational actors and institutional networks also need to be taken into account (Assman, 2014). The transnational cultural memory paradigm thus raises not only technological questions about how to develop new forms of cultural memory circulations; it also raises political questions about why and for whom.

If one wishes to examine the implications of the transnational memory paradigm for radio research, one is required to work from an analytical framework that includes both technological infrastructures (memory artefacts included) and the actors that construct and perform these infrastructures. Such an endeavour carries a promising potential not only for memory studies, but also for inquiries into the relationship between cultural memories and their technological infrastructures. This contribution will outline central issues to consider in this respect, focusing on the infrastructural transformations of cultural memory brought on by digitization, and the political contexts in which these transnational memories are being formed.

\section{The Implications of Digitization for SONIC CULTURAL MEMORY INFRASTRUCTURES}

The dynamic infrastructures of radio archives present a special case study of transnational cultural memory. Radio archives are archives in motion (Røssaak et al 2010) that collect not only static objects such as static texts and images, but also dynamic streams of information. The dynamic nature of radio archives presents specific infrastructural archival conditions that have significant implications for its migration into the digital sphere as well as the legal-political questions this migration raises.

The infrastructural cultural memory work of radio archives operates in two modalities of content and infrastructure. Listening to an old recording brings back memories much like Proust's famous madeleine cookie: the diction of the presenter, the hit-list music, the covering of a major political event can all transport one from the present to the past in a split-second. Indeed, archival artefacts are logistical entities that operate not only across space, but also across time, bringing historic moments into the present as well as the listener into the past. Old radio recordings are not only vehicles for cultural memory through 
the content they transmit, however, but also through the audible dimension of its infrastructural construction: the distinct noise of the rotating cylinders, the muffled sounds of long-wave, the bodily noises of speakers (e.g. coughing, huffing, laughing).

Until recently, these two levels of memory were inherently entwined by an indexical tie between the infrastructure of cultural memory (e.g. lacquer, magnetic tape and vinyl) and its content. Today, however, digitization processes convert these media archaeological artefacts into digital streams of malleable ones and zeros. This conversion has significant implications for how we might understand sound archives as sites of cultural memory. While digitization may appear to merely transpose audio recordings from one medium to the other, it in fact forcefully restructures its entire being. Indeed, as Wolfgang Ernst notes, the conversion of analogue to digital media archives represents not just another mode of cultural memory, but rather a dramatic infrastructural transformation of its essence (Ernst 2014). The following sections will examine this infrastructural transformation focusing on three central points: storage capabilities, spatio-temporal regimes and connective affordances.

\section{StORAGE}

Storage space is a basic condition for cultural memory, whether it is the storage space of a scroll that holds a bureaucratic record, a building that shelters a vast archival collection, a vinyl record whose groove holds a recording, a polaroid strip that offers a tune or a hard-disk that saves a life's worth of work and play. Within these storage spaces, time becomes space, exempting memory objects from the flow of time to keep them in a dormant state. Yet digitization has radically altered this dormant premise, partly because it radically transforms its storage capacity and partly because it transforms the storage space from static to dynamic mode of existence.

A brief glance at the accelerating evolution of the storage capacity of external memory and some arbitrary numbers of the relation between digitized and non-digital memory indicates how conditions for memory storage have changed: the quantity of data that humankind has stored to an external memory medium so far (i.e. not just created but saved to some medium that still makes it accessible, including material such as clay tablets) is today estimated in two-digit zettabytes. Yet, less than $1 \%$ of this information is in non-digital form. While these numbers are arbitrary, and outdated almost as soon as they 
are put on paper, they signal a fundamental shift in the storage paradigm of cultural memory from a regime of scarcity to a regime of ubiquity (Hayles 2005). ${ }^{2}$

Cultural memory brings together memory and storage, the machinic and the biological, into a constantly evolving cultural archive (Chun: $133 \mathrm{ff}$ ). As Wolfgang Ernst emphasizes, all these storage spaces, as vehicles of cultural memory, differ from human memory; where the human brain re-members through complex biological and intellectual processes of association, the technologies of cultural memory sites rather re-call data through mathematical and alphabetical principles (Ernst 2010). The differences between storage occur not along a man-machine axis, however, but also along a material axis of medium specificity: if old phonographic cylinders could store around 2-4 minutes' worth of audio recording, the $45 \mathrm{rpm}$ record up to six minutes per side, the audio cassette up to 60 minutes per side and reel-to-reel up to 48 hours. The development of various uncompressed and compressed digital audio file formats and inexpensive mass storage have revolutionized audio storage, allowing days', even months', years' and decades' worth of audible cultural memories to be stored on servers, ready to be activated at the user's behest.

Digitization thus radically alters the storage sites of cultural memory, in both temporal and material terms. While phonographic cylinders and vinyl records house dynamic cultural memories that require motion to be activated, they are themselves relatively stable modes of inscription: apart from the entropy that befalls any earthly material, they remain in a stable material state. The digital, as Wendy Chun notes in her astute analyses of the storage capabilities of digital archives, is different: "If our machines' memories are more permanent, if they enable a permanence that we seem to lack, it is because they are constantly refreshed - rewritten - so that their ephemerality endures, so that they may 'store' the programs that seem to drive them" (Chun 2011: 170). Digitization thus changes the nature of sound storage from a relatively stable mode of preservation to highly dynamic processes of constant regeneration. Cultural memories are no longer preserved in static terms, but rather depend on constant infrastructural migration. Hence, electronic memories represent a paradox: they become more permanent the more they are constantly refreshed, so that only "their ephemerality endures." (ibid.)

The dynamic quality of digital storage also has implications for how we think about storage. As an EU bureaucrat working with audiovisual archives once confided in me: "digitizing films is not a way of preserving films... you need to ensure to keep software, ensure migration, that you keep the media. So when you go into digitization you enter an active process that never ends." This active process helps to preserve cultural memories in an enduring ephemeral

$2 \mid$ As Viktor Mayer-Schönberger notes this reversal has implications not only for the circulation of cultural memory, but also for its legal and ethical frameworks (Mayer-Schönberger 2005). 
state, yet the active processes of digital remediation and regeneration often also introduces a constant process of memory loss: the loss of metadata, context, materiality. The dynamic nature of digitization thus produces not only new modes of cultural memory; it also produces new modes of cultural forgetting.

\section{Spatio-temporal Regimes}

As the above section shows, digital forms of storage change the archival function from one that arrests time to one that requires constant motion. This infrastructural transformation also has significant impact on the spatio-temporal regimes of sound archives.

Cultural memory archives that operate on the level of listening are temporal technologies belonging to a specific time and place. Thus, while some archives such as libraries and natural history museums span millennia, some even millions of years, the temporal regime of sound and radio archives by comparison has a much shorter lineage, reaching back only a few centuries (see Carolyn Birdsall's chapter in this volume). Yet, despite its limited temporal scope, the temporal experience of sound archives is arguably much more transgressive than that of the written letter because of its ability to perform the sounds of men and women in a-historically present ways. Thus, as Ernst notes, rather than relying on textual witnessing, people with sound recordings actually "can listen to the voice of the dead." (Ernst 2015: 103) The effect, Ernst argues, is a "technologically induced trauma" rooted in a conflict between the intellectual experience of listening to history and a phenomenological experience of listening to someone who is with one here. This shock, Ernst notes, "has not been epistemologically digested yet." (ibid.)

The resonance of the past isn't only a site of trauma, however. It is also a point of more productive connection. Foregrounding the corporal dimension of sound and the ways in which it brings human bodies together across time and space, Brandon LaBelle suggests that everyday "acoustic territories" are "full of dynamic resonance" that create "connective moments" (LaBelle 2010: xxiv). ${ }^{4}$ Apart from their macro-temporal scale, sound archives are, as Wolfgang Ernst reminds us, also premised on the microtemporalities of their capture, production and storage sites. Magnetic tape recordings of sound thus contain temporal

3 Indeed, as Peter Krapp notes, radio was regarded, in its infancy, as a possible means to contact the dearly departed (Krapp 2004, p. 78)

4 | In this sense digitized sonic archives not only provide new vehicles of cultural memory but also bring about new opportunities to research the audibility of history (Walraven 2013). Important new questions emerging with these new opportunities revolve around how to transform sonic artifacts from cultural memory objects to historiographical sources (Smith 2001; Bijsterveld 2008). 
layers within their very materiality: they rely on a chemical process of developing; a time consuming processes of editing and limited modes of manipulation. Transferred to the digital environment, however, these temporal layers are radically reconfigured and laid bare to time manipulation in new ways; digital regimes thus offer new modes of stretching, delaying, replaying and sharing time. Digitization often also lifts cultural memory collections from a regime of preservation to a "regime of anticipation" (Mackenzie 2013) in which our cultural memories and the way we access no longer concerns our relation to our pats, but also attains a future dimension in the form of probabilistic outcomes: 'If you like this, you might also like...'

If sonic archives are temporal technologies on both macro- and microscales, they are also territorial and spatial technologies. They thus manifest the territorial dimensions of, for instance, the ethereal imaginary of radio waves, linking it to its technical and legal infrastructures. As Brandon LaBelle points out, radio was always veiled in "a set of aerial fantasies whereby transmission features as means for emanation and transformation" but these fantasies also always came "hand in hand with the radio tower" as a marker of an infrastructural networks (Labelle 2010: 207). Radio transmission was thus always equally about "imaginary emanations" and "national infrastructures of communication networking" (ibid.). Sonic archives often exacerbate the national infrastructural component, circumscribing the ethereal radio waves in an archival collection circumscribed by a nation-state paradigm that both gave rise to the archives and govern their content. Thus, for instance, the sonic collections in the Danish state library reflect the cultural and regulatory trajectory of its territory, mostly containing records spoken in Danish, about Danish affairs, displaying Danish music tastes and operating according to Danish regulatory frameworks and taxonomies (see Badenoch's chapter in this volume on the fate of international broadcasting archives).

Digitization rehearses the dual order of ethereal fantasy and territorial reality. Most striking is the ability of digital sound environment to provide immediate and direct access to, and interaction with, the digitized sounds across time as well as disciplinary and geographic borders. As Wolfgang Ernst notes, "being always-on is an affordance of electronic media. (Ernst 2014, 17). As opposed to magnetic tape recordings held in an analogue storage facility, which requires the potential listener to travel to it and perhaps also to facilitate the correct apparatus to play it, digital sound files can be retrieved instantly via a number of points and routes. This is, for instance, visible in the digital cultural memory platform Europeana, which allows the listener to enter into its audio collections 
through a wide variety of entry points, from sound and genre-based categories to mapping tools ${ }^{5}$ such as time mapper. ${ }^{6}$

Yet, while these new digital collections appear to release the latent ethereal nature of radio from the temporal and spatial constraints of the analogue archive, digitized collections are in fact constrained by new spatio-temporal regimes of bandwidth and copyright frameworks. In the case of Europeana, these constraints appear in the form of a lack of radio recordings. As Sonia Leeuw notes in this volume, access to radio programs is rather limited, primarily due to national policies on copyright and privacy. Thus, while digitization often gives rise to new forms of "aerial fantasies" that might provide transnational access, these fantasies are again reined in by territorial realities, this time in as a lack of transnational copyright regimes but also new technological challenges.

Hence, while digitization offers the possibilities of circulating cultural memory objects outside the production environment, the territory that gave rise to them and the temporal frame of most broadcasting institutions' regular websites, as well as new ways of modulating and manipulating sound files, digitization has not done away with temporal and spatial regimes. Rather, digitization poses new challenges to audio-visual memory institutions, raising questions about who has the right to access and circulate digitized material, in what forms, and whose voices are allowed to take part in narrating cultural memories of the past and present.

\section{Connective Conditions}

If aerial fantasies are hampered by spatial and temporal conditions, access nevertheless remains a central mantra in cultural memory circles concerned with digitization, reverberating under slogans such as "sharing is caring" and "freedom of access." (Sanderhoff et al 2014) As an EU bureaucrat shared with me in 2010, "digitization is giving us is the possibility of providing access in a way that we have never imagined before. So that is the point of digitization, of providing access." What access opens up is not only the possibility of processes of inscription and reading, but also of connecting. The technical development of the digital has thus offered new ways of connecting objects and users.

The connective paradigm has led some memory researchers such as Andrew Hoskins to suggest that we should understand memory in the framework of the connective turn. What this means is emphasizing the fluidization of digital content and acknowledging its malleability and flexibility. Within this paradigm, memory institutions are no longer prescribed only through clusters

$\mathbf{5}$ | http://www.europeanasounds.eu/sounds.

6 | http://timemapper.okfnlabs.org/anon/yumuul-travelling-through-times-with-sounds. 
of static institutions and organizations. Rather, they connect with objects, individuals, institutions and corporations to form new distributed digital domains of sociality. This is visible in Europeana, in which projects such as Europeana Sounds have emerged as an assemblatic EC-funded project that connects and aggregates 24 partners from 12 countries to not only enrich the platform with sound and sound-related material, but also increasingly to include social and cultural participation from users in its curatorial practices. Europeana Sounds' turn from 'mere' connectivity to sociality is part of a larger digital tendency where online services have shifted from offering channels for networked communication to becoming interactive, two-way vehicles for engineered networked sociality. (Dijck 2013)

As the previous section pointed out, connective memory upends the traditional temporal and spatial metaphors of memory. It thus not only provides new memory infrastructures but also prompts a rethinking of concepts that were previously a stable in cultural memory research vocabularies. In cultural memory theory, for instance, the spaces of cultural memories are often described as relatively stable sites such as a concert hall, a museum space, a park or even one's living room in front of the radio or television. It is often clear who the sender, or at least, the benefactor, is: a state, a figure of authority, a charismatic voice. Often, the receiver's part is often a receiving audience, first taking in and digesting the memories and only later performing remembrance again. And the governance framework of cultural memories would often be delineated clearly as public and private domains.

The deconstruction of the walls and voices of traditional cultural memory institutions produce new forms of governance and authority. Thus public institutions that once served as the primary stage for cultural memory are now increasingly embedded in private and privatized networks through public-private initiatives and digital communication channels such as social media (Huang 2015; Thylstrup in press). These infrastructural transformations also impact the ontological status of cultural memory institutions. Thus, digitization repositions what were once conceived of as central memory institutions to merely representing another node in increasingly complex memory ecosystems. As Marianne Ping Huang notes, this shift from closed - and often publically funded - circuits to networked commercial channels is among other things illustrated by a new cultural memory discourse in which the concept of "resource" branches out into new "communities of practice," just as it is made evident by the new emphases on "new markets", "new stakeholders" or "new partners" for emerging "value chains" within in business plans for digital cultural heritage organizations. The infrastructural modulations of cultural memory also have significant impact on the delineations of cultural memory: if collective memories on the one hand were formerly internalized as personal recollections, private memories are today also increasingly externalized in cultural 
memory sites for all to trace, share, and mine. The digital archiving of cultural materials thus acts as a vehicle for memory but also brings these memories into the public sphere by the social activity of its users.

\section{The Politics of Cultural Memory in the Digital Age}

As the sections above show, digitization gives rise to new questions for transnational cultural memory research. Digitization alters the storage space of cultural memory institutions and their relations to active processes of remembering; it transforms their territorial and spatio-temporal regimes; and it produces new cultural paradigms of connectivity. These transformative processes raise a final question: what kind of memory politics do these transformations produce?

The infrastructural changes of cultural memory brought on by digitization, and the transnational implications it presents cultural memory with, do not happen magically by themselves in a political vacuum. Rather, digitization and its connective teleology, have been - and continue to be - undergirded by national and transnational policy frameworks that support digital transformation of access to digital-based resources, materials and knowledge production. This support is visible for instance in the discursive shift from history to memory in cultural memory institutions, and in the developments in transnational policy regimes such as copyright.

Memory has become a key concept in institutional initiatives for digitization (Stainforth 2016). While the discursive shift from history to memory has a distinct historical backdrop in the analogue world ${ }^{7}$, it is, as Stainforth notes,

$7 \mid$ As Jay Winter notes, the memory discourse that dominate cultural heritage institution today had its own political motivation, spurred on by a series of 20th century events and movements, of which one of the most important ones was the idea of the 'duty to remember' after the Holocaust. Emerging in the 20th century as a historical category in its own right, consolidating in the academic discourse in the 1970s, and the institutional discourse in the 1990s the 20th century thus saw an increased interest in the subjective aspects of history, that is, in collective and cultural memory. This shift in perspective from the objective tradition of historical positivism to the subjective perspective of cultural memory also implied a general semantic shift in the professional and political discourse on repositories of public knowledge such as libraries, archives, museums and galleries; they were now no longer addressed as historical institutions, but rather framed as 'memory institutions'. The semantic shift from history to memory not only gave rise to a new discourse, but also implied a methodological shift in curatorial practices; if historical institutions were seen as objectively mediating historical facts, cultural memory institutions were rather framed as active co-constructers of cultural memory. The implications of these theoretical and practice-based changes also implied new institutional questions. Informed by the topical common denominator in scholarship concerned with memory, namely the ways in which people construct a sense of the past (Confino 1997), institutional questions no longer 
also symptomatic of a political framework that wishes to foreground the connective power of digital media and promote transnational cultural integration, in particular in Europe. As Sonia de Leeuw notes in this volume, Europe has thus long sought to create financial and cultural frameworks to undergird and advance transnational collaboration in Europe by developing common data models and services that national initiatives could speak into.

Transnational memory projects such as Europeana not only link platforms in technical terms, however; they are also programmed with a specific objective. The new cultural memory environments draw on the ideological and technological foundation of new media in which creation and exchange of user generated content, for instance through participatory indexing as mentioned by de Leeuw, is key. In many ways they thus act as continuations of existing memory politics with its inclusive and dynamic scope. They thus often build on already existing institutional ideals drawing on cultural memory theory that position people as individuals that increasingly seek to properly understand their own existence in the grand scheme of historical events by means of sharpening their own remembered experience and the testimonies of others against available state-sanctioned versions - official documents, exhibits, text books etc. It also continues the agenda and methodological approach of cultural memory theories that recognize - formally at least - that the primary institutional objective is no longer to construct authoritative canons and official narratives, but rather to discover and construct different cultural indexes in the archives such as gender, race, class and sexuality among others. The digital continuation of the institutional turn to cultural memory is reflected, among other things, in the way digital platforms of cultural memory increasingly include personal accounts, 'small histories' and other ego documents to reflect and refine the complexities of grand historical narratives. ${ }^{8}$ Such weaving of 'my story' and 'everyone's story' into a coherent whole, as well as an exact marking of time, has long been a core aspect of radio (Scannell 1996), and radio archives in the digital ago potentially offer vast resources for including such material. The BBC's recent online publication of the back catalogue of the program Desert Island Discs, where famous people tell their life stories using a series of their

revolved primarily around 'what happened?' but rather 'what do we remember?' and focus changed accordingly from notions of objective truth, source criticism and sobriety to the use of things and the emotions attached to the use history.

8 See for instance the online exhibition project Europeana 1914-1918 which aggregated content from national collections and combined the material with European roadshows where memory professionals collected citizens' manuscripts and memorabilia from the war to be digitized. In addition to the roadshow, the exhibition project also featured an online collections form, where personal stories and images could be uploaded. 
favorite records is a case in point. ${ }^{9}$ Long a go-to resource for BBC producers as a source of instant soundbytes of celebrities, it is now open for inclusion and interpretation in any number of digital stories. Yet the connective potentials of the digital domains allow transnational sociality to become an even more pronounced factor of cultural memory institutions accelerating a merging of the creation of cultural artifacts, their production and distribution, their curation, preservation and consumption across borders. Arguably these convergences have given rise to new forms of transnational audio cultures, new ways of engaging with those cultures and new modes of more inclusive and more transnational memory cultures.

The connective turn has also prompted criticism about the politics of digital cultural memory, however. Bernard Stiegler, for instance, examines new memory technologies as "technologies of power," focusing on the loss of control we face when submitting our memories to the control of digital platforms (Stiegler 2006). With the exteriorization of memory, argues Stiegler, comes a loss of sovereign memory and of knowledge, which is experienced in our daily lives in the feeling of powerlessness, if not of impotence, when it comes to acting without these devices. Paradoxically, he notes, this impotence arrives at the exact moment when the extraordinary mnesic power of digital networks make us all the more sensible to the immensity of human memory, which seems to have become infinitely reactivatable and accessible. Other prominent criticisms focus on the ways in which participatory cultures increasingly resembles new forms of digital labor (Terranova 2006), while yet others examine the ways in which mass digitization, rather than doing away with territorial politics, instead gives rise to new forms territorial memory politics. (Thylstrup, in press)

The most important political issue of digital radio archives from a transnational perspective remains, however, the politics of copyright regimes. The latent transnational dimension of cultural memories still in many instances confronts the new bordering mechanisms of immaterial rights, copyrights, and standards for digitized resources that uphold institutional gatekeeping of access, use and re-use of archival material. The most remarkable thing about this political problematic is that it shifts the questions of borders from a public question about state policies to a privatized terrain involving industry stakeholders and memory professionals. Understanding the implications of this shift from public policy to private governance for transnational memory research remains a main task for anyone interested in conducting research into the politics of sonic cultural memories.

9 | http://www.bbc.co.uk/programmes/articles/5qhJd1byxhTBYbSCFmw580y/desert-island-discs-podcasts. 


\section{REFERENCES}

Assmann, Aleida (2014): “Transnational Memories” European Review, 22/4, pp. 546-556.

Assman, Jan (2008): "Communicative and Cultural Memory." In: Astrid Erll et al. (eds.) Cultural Memory Studies: An International and Interdisciplinary Handbook, Berlin and New York: Walter de Gruyter, pp. 109-118.

Cock, Buning/Bruin, M, R W./Belder, Lucky (2015): Cultivate!: Cultural Heritage Institutions, Copyright \& Cultural Diversity in the European Union \& Indonesia, Amsterdam: DeLex,

Bijsterveld, Karin (2008): Mechanical Sound: Technology, Culture, and Public Problems of Noise in the Twentieth Century, Cambridge, Mass: MIT.

Chun, Wendy (2011): Programmed Visions Software and Memory, Cambridge, MA: MIT Press.

Confino, Alon (1997): "Collective memory and cultural history: problems of method," American Historical Review December, pp. 1386-1403.

Dijck, José Van. (2013): The Culture of Connectivity: A Critical History of Social Media, New York: Oxford University Press.

Erll, Astri (2008): "Literature, Film, and the Mediality of Cultural Memory". In: Astrid Erll et al. (eds.) Cultural Memory Studies: An International and Interdisciplinary Handbook, Berlin and New York: Walter de Gruyter, pp. 389-39o.

Ernst, Wolfgang, (2010): “Cultural Archive versus Technomathematical Storage,” In: Eivind Rossaakm (ed.) The Archive in Motion, Oslo: Novus Press, pp. 53-73.

Ernst, Wolfgang (2014): Temporalizing the Present and Archiving Presence: The Impact of Time-critical Media Technologies. Textual material, related to lecture at Concordia University, Montreal (Canada), Department of Communication Studies, 2014. https://www.musikundmedien.hu-berlin.de/de/medienwissenschaft/ medientheorien/ernst-in-english/pdf/micro-temporealities-montreal.pdf

Ernst, Wolfgang, (2015): “History or Resonance? Techno-Sonic Tempor(e)alities," Journal of Visual Culture. 14/1, pp. 99-110.

Hayles, N. Katherine (2005): My Mother Was a Computer: Digital Subjects and Literary Texts, Chicago: University of Chicago Press.

Huang, Marianne Ping (2016): “Archival Biases and Cross-Sharing," Nordisk Tidsskrift for Informationsvidenskab og Kulturformidling 5/1, pp. 53-62.

Krapp, Peter (2004): Déjà vu: Aberrations of Cultural Memory, Minneapolis, MN: University of Minnesota Press.

LaBelle, Brandon (2010): Acoustic Territories: Sound Culture and Everyday Life, New York: Continuum.

Mayer-Schönberger, Viktor (2009): Delete: The Virtue of Forgetting in the Digital Age, Princeton: Princeton University Press.

Nora, Pierre (1996): Realms of Memory: Rethinking the French Past, edited by Lawrence D. Kritzman. New York: Columbia University Press 
Ong, Walter J. (2013[1982]). Orality and Literacy: The Technologizing of the Word, New York: Routledge.

Røssaak, Eivind (2010): The Archive in Motion New Conceptions of the Archive in Contemporary Thought and New Media Practices, Oslo: Novus Press.

Sanderhoff, Merete/Edson, Michael Peter (eds.) (2014): Sharing is Caring: Openness and Sharing in the Cultural Heritage Sector. Copenhagen: Statens Museum for Kunst.

Scannell, P. (1996): Radio, Television and Modern Life, Oxford: Blackwell.

Smith, Mark Michael. (2001): Listening to Nineteenth-century America. Chapel Hill: Univ. of North Carolina Press.

Stainforth, Elizabeth (2016): "From Museum to Memory Institution: The Politics of European Culture Online," Museum and Society 14/2, pp. 323-337.

Stiegler, Bernard (2006): "Anamnesis and Hypomnesis: The Memories of Desire," In: Louis Armand/Arthur Bradley (eds.), Technicity, Prague: Litteraria Pragensia, pp. 15-41.

Terranova, Tiziana (2006): “Of Sense and Sensibility: Immateriality Labour in Open System,” In: Joasia Krysa (ed.) Curating Immateriality: The Work of the Curator in the Age of Network Systems, pp. 27-37.

Thylstrup, Nanna, (in press): The Politics of Mass Digitization, Cambridge, Mass: MIT Press.

Walraven, Maarten (2013): "History and its Acoustic Context: Silence, Resonance, Echo and Where to find Them in the Archive.” Journal of Sonic Studies, 4/1 http://journal.sonicstudies.org/volo4/nro1/ao7

Winter, J. M. (2006): Remembering War: The Great War between memory and history in the twentieth century, New Haven: Yale University Press. 



\section{Worlding the Archive: Radio Collections, Heritage Frameworks, and Selection Principles}

Carolyn Birdsall

In this case study, I develop critical perspectives on institutional radio collections, in the form of sound recordings or other print-based materials. While the institutional practice of recording, editing and archiving radio sounds prevalent in European broadcasting from around 1930 onwards - largely took place within a framework of national significance, these collections were also governed by aspirations to capture and order the sounds of the world. The present article attends to this 'worldly' (if not universalist) scope - and the 'worldmaking' qualities of archival practice (Ong 2011; Cook 2013) - for radio collections that often had a dual focus on long-term historic preservation as well as the needs of program production.

The main case study examined here will be the BBC, in Great Britain, whose documentation and information activities - in the form of libraries and archives - swelled from their modest beginnings to large and elaborate operations during World War II (1939-1945) and afterwards. While a range of departments were responsible for the recording, editing and archiving of radio sound, sound archiving at the BBC is usually credited to a number of pioneers. Most prominent among these are the early members of the Recorded Programmes department, such as Lynton Fletcher, Timothy Eckersley, and Marie Slocombe (Rooks 2012). While Slocombe is popularly known as the 'founder' of the BBC sound archive, having initiated the Permanent Library or 'historic archive' from 1937 to the early 1970s, this essay draws on recent archival research that highlights both Slocombe's influential role in compiling, classifying and curating recorded sound as well as issues of gendered agency evidenced in the limitations and frustrations experienced by Slocombe and many of the female library and archival staff (Birdsall 2017).

The transnational perspective on archival collections and practices will be articulated through three sections, which will emphasize the global and imperial background to (sound) recording technologies and archival praxis, and how 
the collections reflect multiple and changing concepts of 'heritage', with particular attention to the dominant narrative of global and historical significance linked to the recording and preservation of radio sound linked to World War II (1939-1945). The conclusion will synthesize the findings of this case study and critically reflect on the need for further transnational research about radio sound archiving that goes beyond the limitations of the single case study presented here, one whose Eurocentric orientation risks reinforcing the centrality of the imperial metropole, if not other East-West and North-South divisions (Stoler and Cooper 1997; Shohat and Stam 2014; Scales 2013). I will therefore point to the significance of investigating other models, sites and historical periods for radio archival praxis, particularly those that might provide alternatives or challenges to the "audio nationalism" (Western 2015) and "technological imperialism" (Taylor 2002; Yang 2010) in evidence in the case study introduced here.

\section{Global AND Imperial Dimensions to SOUND ReCording AND ARCHIVING}

Radio, from its inception, often relied on recorded music drawn from the transnational circuits of the gramophone music industry (Gronow/Saunio 1998; Denning 2015); the gramophone as a cultural form and consumer good, as scholars like Lisa Gitelman (2003, 2004) and Jonathan Sterne (2003) have highlighted, was bound up with racialized and gendered imaginaries. As part of a broader sound media landscape - including telegraphy, telephony, phonography, and sound cinema - radio was largely conceived as a 'live' transmission medium from the 1920 s onwards. While its ephemeral qualities certainly contributed to the desire to archive radio, the introduction of recording and archiving techniques also met with resistance in Germany, Great Britain and the US, with fears of a loss of radio's purchase on liveness, or due to market conditions of syndication networks and copyright restrictions (Russo 2004). Nonetheless, the establishment of disc and tape-based archiving was subject to systems of ordering, for which broadcast staff increasingly developed elaborate workflows and systems, such as index cards and catalogue editions. Radio libraries and archives, similar to the phonogram archives found around 1900, had multiple dimensions to their holdings. Within Slocombe's "Permanent Library" at the BBC, for instance, there were a number of historical wax cylinders, along with selected off-air recordings of programs considered to be of historical importance; representative examples included recorded speeches by former UK Prime Minister William Gladstone or then-Prime Minister Winston Churchill. In addition to program pre-recording and off-air recordings, the early catalogues of European broadcasters such as the BBC or the national broadcaster 
in Berlin (Reichs-Rundfunkgesellschaft) indicate a range of recorded sound holdings from famous international figures and musical performances to station interval signals (local and international) and test broadcasts. In particular, the sound effects libraries of local and national broadcasters also appear in archive catalogues; while diverse in scope, these collections, their description and use in program production reflect attempts to amass 'typical' sound of other places and cultures, some of which were derived from ethnographic sound collections (Birdsall forthcoming). Sound recordings of radio content, finally, also circulated within affiliate systems, such as in North America's commercial networks, but also between international markets, such as the BBC "Transcription Disks", which were in competition with the pre-recorded programs offered by companies such as the World Broadcasting Library or Frederick W. Ziv Company (Kompare 2006: 25-26, 33-34; Potter 2012: 102-10).

\section{Heritage Discourses and the Sound Archive}

In 2015, the British Library Sound Archive launched a campaign to appeal to the wider public about the financial aid needed to address urgent preservation agendas with their recorded sound and their increasingly obsolescent carriers. On the campaign website, "Save our Sounds: Saving the Nation's Sound Heritage," the canonical example provided is that of Winston Churchill "rallying the nation just before the Battle of Britain" during World War II (British Library 2015). Despite the diverse and transnational composition of the British Library Sound Archive, built on the earlier British Institute for Recorded Sound (founded in 1955), this campaign appealed to the public on the basis of 'our' national sound heritage (Müske 2011). A critical response to this would be to ask "whose heritage?" (Hall 1999), and to consider how such recordings have become valued and canonized in public discourse and popular memory (Birdsall 2016).

The case of sound recording and archiving at the BBC is a useful case for considering heritage dynamics in the constitution of recorded sound collections, and the increasingly transnational dimensions to - and perceived value of - content recorded in the context of World War II. If we examine the BBC Recorded Sound catalogues from the mid-1930s, we can find numerous priorities at play in the creation and collection of recordings considered nationally, culturally or politically important, as well as illustrative examples of the radio medium itself.

Firstly, the mid-1930s BBC recorded sound catalogue included historic recordings of past events, such as Armistice Day, New Year's Eve celebrations, or famous figures, such as the suffragette Emmeline Pankhurst. Secondly, there were recordings of European monarchs and international political leaders, such as Woodrow Wilson, Franklin Roosevelt, Benito Mussolini, former German 
chancellor Paul von Hindenburg, Adolf Hitler and Joseph Goebbels. The third category was reportage of recent topical events, as for instance related to 'Abyssinia Crisis' of 1935, unemployment, the dissolution of the British parliament, and elections. Fourthly, there were recording that appeared to be representative examples of contemporary radio, such as the weather forecast, a news bulletin, a quiz show, an "unrehearsed debate", station intervals, test records and program trailers, sound effects and important figures from the BBC, such as directorgeneral John Reith or newsreader John Snagge.

Significantly, however, there are other items that attest to an international orientation with samples of Czech radio, reportage from Nazi Germany, the well-known US radio newsreel “The March of Time” (1931-1945), and Lynton Fletcher's own “Looking Backwards” compilation program, which was a monthly news review for the BBC Empire Service. This is suggestive of an early effort, on the part of Fletcher, not only to maintain collections of important voices or materials for program re-use, but also seeking to preserve representative examples of radio-specific materials in a British and international context.

With the later establishment of the Permanent Library under Marie Slocombe, the curation of historically-significant recordings became more formalized. Nonetheless, Fletcher and Slocombe's efforts to frame and promote their collections in terms of national and cultural significance was also, in part, in response to the internal challenges posed from the late 1930 s into the war, to the remit of the Recorded Programmes department. The department was criticized by BBC Engineering as usurping the role of their own Technical Recording units, and by program producers, who either wanted to have their own program-specific sound libraries, or complained about slow disc processing (BBC WAC 1943). One of the critiques articulated by engineer Martin Pulling was that in the US context, CBS and NBC did not maintain extensive recorded programs and archival services, but rather left such tasks to national libraries such as the Library of Congress. While the internal reviews allowed the Recorded Programmes Department to remain intact, these criticisms lead to Fletcher being forced to step down as director (BBC WAC 1943).

\section{Selection Principles and the Archive as 'MEMORY ACTOR'}

Prior to his dismissal, Fletcher and his colleagues participated in a number of programs and promotional activities to inform the public about the importance of sound recording and archiving for program production during war, as well as preserving the memory of the war for the future.

In Museum of Sound (1943), interviews are conducted with the heads of the BBC Recorded Programmes Department (Lynton Fletcher) and Engineering 
Department (Martin Pulling), who are described as responsible for the recording and technical operations of the BBC. The film begins with the narrator reading the text "Old Sounds are Kept Safe and Sound in the Recorded Programmes department." During an interview with Fletcher, he notes that the Recorded Programmes department has to respond to all requests that come in, often needing to edit and rearrange material, due to the different needs of programming for home listeners as opposed to overseas services. He describes the Permanent Library as striving to preserve recordings for future re-use, as emblematic of "some of those things that characterize our life and times." Fletcher then concedes that the recordings themselves are produced by the BBC Recording Service. Martin Pulling, superintendent engineer of the Recording Service, describes the four methods of recording in regular use: magnetized steel tape, large disc recording, recording on film and lacquer-coated metal discs. They play several sequences of Winston Churchill, an Edison recording of William Gladstone, as well as a sequence about the voices of present-day leaders like Stalin and Roosevelt, as being useful for future generations.

In this same period, a recording of a four-part series, titled "You Have Been Listening to a Recording" was broadcast on Saturday afternoons in March-April 1942. During this 'guided tour' of the items in the Permanent Library, Fletcher subsequently notes the benefit of their collection for interested people and 'serious' historical scholars in future, who he imagines as being given access to "scenes and events from the present" and the voices of "men who shaped our world." He qualifies these statements by noting that ordinary people's voices are also represented, and then introduces Slocombe, who mainly plays clips with recordings of male voices, a number of which are military personnel providing testimony to their experiences of World War II. Marie Slocombe served to reinforce her gatekeeping role in determining which voices, musics and sounds were worthy of recording and archiving (Birdsall 2017). In the post-war era, Slocombe continued to be interested in regional accents, dialects and musical forms, due to her involvement in the BBC Folk Music and Dialect Recording Scheme (as well as the International Folk Music Council), but she also acted here as a 'gatekeeper' in determining which field recordings would be acceptable enough to fit the criteria of 'broadcast quality' (Western 2015).

Beyond such promotional vehicles, internal correspondence has shown the extent to which the BBC's recording services expanded in the context of around-the-clock wartime programming, with employees also assisting wartime language services, which - during the course of the war - included 36 different languages. While supported by disc recording and pre-recording services, most of these language services do not seem to have been selected for the Recorded Programmes library, and have only - in some cases - been incorporated into European exile government collections, such as the Dutch holdings 
now preserved by the Netherlands Institute for Sound and Image (Beeld en Geluid n.d.).

The BBC's collaboration with American radio, and the Armed Forces Radio Service (AFRS), during the Allied Force invasion of Europe from 1943 onwards, produced recordings - often made on new portable disc recorders - that were copied and added to the Recorded Programmes collections (Bishop 1945). In the wake of the war, a number of noticeable developments contributed to the preservation and canonization of wartime broadcast recordings. Firstly, the large numbers of discs in wartime radio had expanded the scope of the Permanent Library, which by late 1948 included the Transcription Service Library, and had 12,500 discs (BBC WAC 1948). The idea that war-related recordings should be held by the BBC is also supported by an attempt, in 1949, to arrange for 7500 disc recordings of the Allied military tribunals in Nuremberg (between 1945$46)$ to be held at the BBC's Maida Vale archive facilities. Allied Forces, while occupying Germany, had also seized matrices of National Socialist radio recordings; the dubs, known as the "RRG recordings" were also brought to the $\mathrm{BBC}$ in London after the war, and are today held by the British Library Sound Archive (Birdsall 2016). Previously, National Socialist officials had seized radio collections and other sound recordings during the occupation of Western and Eastern Europe; towards the end of World War II, some historic radio collections were brought to Prague, Graz and Wrocław for safekeeping, with some of these materials later rediscovered in the Czech Republic and Russia during the 1990s (Birdsall 2016).

The war had heightened the sense of radio recordings as culturally valuable, with some of these damaged and destroyed, while others were confiscated as war trophies during and after the war. In terms of canonization, the previous has shown how BBC staff like Fletcher and Slocombe were keen to demonstrate the re-use of recordings of voices by famous leaders like Winston Churchill, while transcription programs were re-used, intermittently, in the US from the 1930s, and played an important role in fueling "the nostalgia for (and marketing of) 'old time radio' (aka 'OTR') in the 1960s” (Kompare 2006: 34). Indeed, an important development in the post-war era was the release of records with compilations of significant recordings, some of which were intended for school pedagogy. One such example is Historic Voices and Music from World War II (1966) in the US, or the highly-successful box set Nederland 1940-1945 (1965), which was compiled by the Dutch sound archivist Rolf Schuursma. Another important theme in the early post-war period was a growing awareness that the diverse recording methods used during the war were at risk of deterioration. At the BBC, towards the end of the war recommendations for long-term cooled storage of lacquer disks, matrices, pressings, films and magnetic tape were received from the film and music sector, in this case by representatives from EMI, the British Homophone Co, and the National Film Library (later 
British Film Institute). This example is suggestive of how certain 'best practices' for archival preservation were already circulating between film, music and radio institutions, which later became more formalized in the context of international organizations like the International Association of Music Libraries (IAML), and later the International Association of Sound Archives (IASA) which grew out of it in 1969 .

From the perspective of the present, it is crucial to critically consider the importance of archivist selection practices, and keep in mind the multiple forms of historical exclusion inherent to broadcasting's institutional practices (Stoever 2016). Writing about the US context, Susan Douglas (1995: 5) has noted that "[w]hile radio brought America together as a nation in the 1930 s and 1940s, it also highlighted the country's ethnic, racial, geographic, and gendered divisions." From the outset of broadcasting, therefore, there was a highly selective understanding of who was included in radio's imagined audiences and national public sphere. These conditions had repercussions for broadcast content, who produced it, and how it sounded, and also, subsequently, which programs were pre-recorded or recorded off-air for historic preservation. While there were a variety of exclusions and blindspots, in the context of World War II, one of the major criticisms of the British media - and the BBC in particular - concerns the limited reporting on the persecution of Jews in Europe prior to 1945 (Seaton 1988).

\section{CONCLUSION}

This chapter has examined sound recording and archiving practice at the BBC as a case for considering the possibilities of transnational perspectives on the early history of radio sound archives. The first section sketched the pre-existing developments of global markets for recorded music, sound reproduction technologies and technical expertise, and noted the rise of sound archives as an example of the "heritage of empire" (Swenson 2013) in the context of European imperial centers, often within science institutions that collected the voices and music of 'other' cultures. The second section then attended to the content of radio collections, taking up the pervasive national discourse in past and present imaginations of national broadcasters like the BBC, while also highlighting the heterogeneity of recordings - and the transnational relations and exchange influencing the content and orientation of the archive. This section emphasized how the lead up to and aftermath of World War II not only expanded the scope of sound recording and archiving activities. The following and final section further outlined the prioritization of these wartime recordings in archival selection and canonized through re-use in programs and LP compilations; this resulted in marked absences and the reproduction of blindspots endemic to both program schedules and in archival selections. 
While I have highlighted the national and transnational dimensions to the first decades of sound recording and archiving at the BBC, I would like to emphasize the necessity for further transnational research about radio sound archiving beyond this single case study with a largely a Eurocentric orientation. Firstly, this case study has emphasized a national broadcaster (with international services) that is consistent with the public service tradition of broadcasting; the archival practices studied here could thus result in further comparison with not only other public and state broadcasting contexts, but also commercial and 'mixed' models.

Secondly, in terms of other sites, it would be productive to focus further attention on regional comparison, with attention to broadcast practices that were established in the wake of decolonization and anti-colonial struggle, as well as other types of radio, such as free radio, underground and communist radio, student radio or internet radio. For these considerations it is instructive to build on the critique of the archive by gender, sexuality and queer studies, and acknowledge the importance of community radio interventions and archive/documentation initiatives, particularly from the 1960 s onwards (Mitchell 2016). Another important context for the re-use and consumption of radio archival materials is their use as audiovisual aids in education; this is not only significant for the reproduction of certain historical canons (such as the World War II materials discussed here), but represents the present-day potential for encouraging an 'archival consciousness' in pedagogy and research (Birdsall 2015; Ehrick 2017).

Examining other sites and types of radio also require researchers to take a critical view on the "fetishized investment" in sound recordings for historical radio research (Dolan 2003: 67). This tendency can overlook the role of the myriad of 'paperwork' involved in broadcasting, with written archives - such as the BBC Written Archives Centre in Caversham - as crucial to researching the histories of recording and archiving. This chapter has highlighted how such 'soundwork' was as much about sound technical work as paper-based procedures (such as indexing, cross-indexing, and cataloguing).

Finally, the periodization of the present chapter, largely focused on the period around 1930-1945, concerns sound recording and archival practices at the $\mathrm{BBC}$ were reliant on analogue based storage media, such as phonographic discs, steel tape and film. This acts as a prompt for further research developing transnational perspectives on later developments in radio archival practices, in particular for the introduction of other technical formats such as magnetic tape and, later, digital recording and preservation strategies. Recent scholarship, for instance, has also emphasized the importance of studying amateur, fan and other "rogue" archival practices (Brandellero et. al. 2013; de Kosnik 2016), which is a necessary perspective in radio scholarship on recording practices and archives, in order to do more justice to audience listening, consumption and recording practices, particularly in transnational frameworks, such as 
across the Cold War's 'Iron Curtain' (Badenoch/Fickers/Henrich-Franke 2013; Bohlman 2017). In this vein - considering transnational radio consumption and memory processes - Jaimie Baron (2013) has argued that the digital circulation of archival materials calls for new perspectives beyond official institutions, such as the BBC or British Library Sound Archive, and attending more to how these materials produce experiences for its present-day audiences.

The present chapter has emphasized the institutional origins of radio sound recording and archiving as an under-researched and a rich site of enquiry. The task of investigating the transnational dimensions to radio history - and recording and archiving in particular - also contributes to the larger project to consider "entangled" media histories, which, as Michele Hilmes (2017:142) has pointed out, encourage researchers to "consider the many ways that the development of media and its crucial (but too often neglected) role in shaping world history has reached across national borders, encouraged exchange and cross-influence, spread across media platforms, and flourished outside the traditional frameworks within which they have been primarily understood." As such, this chapter's effort in 'worlding the archive' is a first experiment in enquiring into the formation of radio archival institutions from such perspectives of transnational collaboration, exchange, and circulation, with particular attention to the formative role of World War II as a site of 'world history' and heritage-making.

\section{REFERENCES}

Badenoch, Alexander/Andreas Fickers/Henrich-Franke, Christian, eds. (2013): Airy Curtains in the European Ether: Broadcasting and the Cold War. Baden-Baden: Nomos.

Baron, Jaimie (2013): The Archive Effect: Found Footage and the Audiovisual Experience of History. London and New York: Routledge.

BBC WAC (1936): Written memo, 12 February 1936, In R45/83/1 Recorded Programmes General Memos, 1935-1936.

BBC WAC (1942): Recording Service Enquiry: Report and Evidence 1942. In: R13.340 Departmental - Recorded Programmes Department.

BBC WAC (1948): Draft memo, 31 December 1948. R13/104 - Departmental, Entertainment Division, Recorded Programmes Policy: Permanent Library and Processing Unit, 1946-1950.

Beeld en Geluid (n.d.): Radio Oranje 1940-1945. http://in.beeldengeluid.nl/kanaal/ 3124-radio-oranje-1940-1945.

Birdsall, Carolyn (2015): “Can We Invent a Field called Radio Preservation Studies?” In: FLOW: Online Journal of Media and TV Studies 21, www.flowtv.org/2015/05/ can-we-invent-a-field-called-radio-preservation-studies/. 
Birdsall, Carolyn (2016): "Sound and Media Studies: Archiving and the Construction of Sonic Heritage.” In: Holger Schulze/Jens Gerrit Papenburg (eds.). Sound as Popular Culture: A Research Companion. Cambridge, MA: MIT Press, pp. 133-148.

Birdsall, Carolyn (2017): "Divisions of Labour: Radio Archiving as Gendered Work in Wartime Britain and Germany.” In: Special Issue on Gender and Archiving: Past, Present and Future. Jaarboek voor Vrouwengeschiedenis 37, pp. 107-133.

Birdsall, Carolyn (forthcoming): "Radio Documents: Broadcasting, Sound Archiving, and the Rise of Radio Studies in Interwar Germany." In: Special Issue: Listening to the Archive: Histories of Sound Data in the Humanities and Sciences. Technology and Culture.

Bishop, Harold (1945): "Landmarks of Wartime Broadcasting in the Engineering Division.” In: BBC Year Book 1945. Norwich/London: Jarrold \& Sons, pp. 38-40.

Bohlman, Andrea (2017). "Making Tapes in Poland: The Compact Cassette at Home." In: Twentieth-Century Music 14/1, pp. 119-134.

Brandellero, Amanda, et. al, eds. (2013): Special issue: Popular Music as Cultural Heritage. International Journal of Heritage Studies 20/3.

British Library, The (2015): Save Our Sounds, campaign website. http://support. bl.uk/Page/Save-our-sounds.

Cook, Terry (2013): “Evidence, Memory, Identity, and Community: Four Shifting Archival Paradigms.” In: Archival science, 13/2-3, pp. 95-120

Denning, Michael (2015): Noise uprising: The Audiopolitics of a World Musical Revolution. London and New York: Verso.

de Kosnik, Abigail (2016): Rogue Archives: Digital Cultural Memory and Media Fandom. Cambridge, MA: MIT Press.

Dolan, Josephine (2003): "The Voice that Cannot be Heard: Radio/broadcasting and the Archive." In: The Radio Journal, 1 (2003), pp. 63-72.

Ehrick, Christine (2017): “Teaching Radio History to Help Save It?: Listening, Radio Preservation, and the History Classroom.” In: Cinema Journal Teaching Dossier 4/3 [Special Issue on Teaching with Primary Sources: Media Studies and the Archive]. Accessed via: http://www.teachingmedia.org/teaching-radio-history-helpsave-listening-radio-preservation-history-classroom/.

Gitelman, Lisa (2003): "How Users Define New Media: A History of the Amusement Phonograph." In Thorburn, David/Henry Jenkins (eds.), Rethinking Media Change: The Aesthetics of Transition Cambridge: MIT Press, pp. 61-79.

Gitelman, Lisa (2004): Recording Sound, Recording Race, Recording Property. Hearing History: A Reader, pp. 279-294.

Gronow, Pekka/Ilpo Saunio (1998): An International History of the Recording Industry. London and New York: Cassell.

Hall, Stuart (1999): “Whose heritage? Un-settling 'the heritage', re-imagining the post-nation." In: Third Text 13/49, pp. 3-13.

Hilmes, Michele (2017): “Entangled Media Histories: A Response.” In: Media History 23/1, pp. 142-144. 
Kerslake, Evelyn (2007): “'They Have Had to Come Down to the Women for Help!' Numerical Feminization and the Characteristics of Women's Library Employment in England, 1871-1974." In: Library History 23/1, pp. 17-40

Kompare, Derek. Rerun Nation: How Repeats Invented American Television. New York: Routledge, 2004 .

Lastra, James (2000): Sound Technology and the American Cinema: Perception, Representation, Modernity. New York: Columbia University Press.

Leavitt, Donald L. (1971): "Some Tasks for the International Association of Sound Archives.” In: Phonographic Bulletin 1, pp. 3-5.

Mitchell, Caroline (2015): “Re-Sounding Feminist Radio.” In: Feminist Media Histories $1 / 4$, pp. $126-143$.

Müske, Johannes (2011). "Constructing Sonic Heritage: The Accumulation of Knowledge in the Context of Sound Archives." In: Journal of Ethnology and Folkloristics 4/1, pp. 37-47.

Ong, Aihwa (2011): "Introduction: Worlding Cities, or the Art of Being Global." In: Roy, Ananya/Aihwa Ong (eds.), Worlding Cities: Asian Experiments and the Art of Being Global. Oxford: Wiley-Blackwell, pp. 2-26.

Potter, Simon J. (2012): Broadcasting Empire: The BBC and the British World, 19221970. Oxford: Oxford University Press.

Richards, Pamela Spence (1989): "Aslib at War: The Brief but Intrepid Career of a Library Organization as a Hub of Allied Scientific Intelligence, 1942-1945.” In: Journal of Education for Library and Information Science 29/4, pp. 279-296.

Rooks, Simon (2012): "What Happened to the BBC Sound Archive?" In: Journal of the Society of Archivists 31/2, pp. 177-185

Russo, Alexander (2004): "Defensive Transcriptions: Radio Networks, Sound-on-disc Recording, and the Meaning of Live Broadcasting." In: The Velvet Light Trap 54/1, pp. 4-17.

Scales, Rebecca (2013): "Métissage on the Airwaves: Toward a Cultural History of Broadcasting in French Colonial Algeria, 1930-1936.” In: Media History 19/3, pp. 305-321.

Seaton, Jean (1988): “Atrocities: the BBC and the Holocaust.” In: Jean Seaton/Ben Pimlott (eds.). The Media in British Politics. London: Constable, pp. 123-156.

Shepherd, Elizabeth (2016): "Hidden voices in the archives: pioneering women archivists in early 2oth century England.” In: Fiorella Foscarini et. al. (eds.), Engaging with Archives and Records: Histories and Theories. Facet Publishing, London, pp. 83-103.

Shohat, Ella/Robert Stam (2014): Unthinking Eurocentrism: Multiculturalism and the Media. 2nd edition. Oxon and New York: Routledge.

Slocombe (1964): “The BBC Folk Music Collection.” In: The Folklore and Folk Music Archivist 7/1, pp. 3-13.

Stoever, Jennifer (2016): The Sonic Color Line: Race and the Cultural Politics of Listening. New York: New York University Press. 
Stoler, Ann/Frederick Cooper (1997): “Between Metropole and Colony: Rethinking a Research Agenda.” In: Frederick Cooper/ Ann Stoler (eds.), Tensions of Empire: Colonial Cultures in a Bourgeois World. Berkeley, CA: University of California Press, pp. 1-56.

Swenson, Astrid (2013): “The Heritage of Empire." In: Proceedings of the British Academy, 187 , pp. 3-28.

Taylor, T. D. (2002): "Music and the Rise of Radio in 1920s America: Technological Imperialism, Socialization, and the Transformation of Intimacy.” In: Historical Journal of Film, Radio and Television, 22(4), pp. 425-443.

Thompson, Emily (2004): "Wiring the World: Acoustical Engineers and the Empire of Sound in the Motion Picture Industry, 1927-1930." In: Veit Erlmann (ed.), Hearing Cultures: Essays on Sound, Listening and Modernity, Oxford: Berg, pp. 191-209.

Western, Tom (2015): "Securing the Aural Border: Fieldwork and Interference in PostWar BBC Audio Nationalism.” In: Sound Studies 1/1, pp. 77-97

Yang, Daqing (2010): Technology of Empire: Telecommunications and Japanese Expansion in Asia, 1883-1945. Cambridge, MA: Harvard University Press. 


\title{
Radio Diffusion: Re-Collecting International Broadcasting in the Archive of Radio Netherlands WorldWide
}

\author{
Alexander Badenoch
}

In 2012, a vital era in international broadcasting came to an end. Radio Nederland Wereldomroep (also known as Radio Netherlands Worldwide, hereafter $\mathrm{RNW}$ ), an organization that had long been in the forefront of shortwave broadcasting, had its budget slashed, effectively ending most of its operations and services (RNW 2012; Dohmen 2012), leaving only a small organization aimed at countries where press freedom is threatened. Besides closing down most future production, this also meant RNW's operations to maintain and re-use its own past would end. As a statement from the station's direction put it specifically in reference to the archive of the station's website: "Archives cost money. RNW unfortunately can't permit itself to keep its full archive together on its current, lower budget." (Quoted in: Schaap 2015) ${ }^{1}$ This archive of journalism on the website was just one of many archived materials of RNW, both digitized and physical, that would have to find either a new home or oblivion.

Following a period of uncertainty surrounding the fate of many materials, agreements have now been made between the Dutch national audiovisual archive, the Netherlands Institute for Sound and Vison (Nederlands Institut voor Beeld en Geluid, hereafter NISV ${ }^{2}$ ) and the National Archives of the Netherlands (Nationaal Archief, hereafter NA) to preserve the bulk of the sound, photographic and written records. (Lauwers 2017a) The process of transfer, selection, (digital) preservation and cataloging implied in this decision remains to be done as of this writing, but observing the process up to now provides a key glimpse into the ways in which such processes can shape the stories of radio. In particular, the collections' movement from a working broadcasting institution (mostly) into dedicated public, national archives allows us an impor-

1) This and all other quotes from Dutch sources translated by the author.

$\mathbf{2} \mid$ While most acronyms in this chapter are based on their original Dutch title, NISV uses both its English title and acronym in international settings, so I have used that here. 
tant glimpse into a process of archivalization. This term was coined by archival scientist Eric Ketelaar to refer to the "conscious or unconscious choice (determined by social and cultural factors) to consider something worth archiving." (Ketelaar 2001: 133) In the case at hand, archivalization appears in a process of re-contexualization of records that were already preserved once and about which new choices, based in part on new social and cultural factors, are being made (ibid.: 137). Crucially, this notion demands a reflexive view of archival records: archivalization speaks not only about the records selected, but about the nature and values of the archives themselves. With this in mind, there arise as well the more radio-specific questions raised by Shawn VanCour in relation to the US Radio Preservation Task Force: what is the nature of the radio archive in the present age, and what is it good for? (VanCour 2016: 396)

Understanding this particular process of archivalization is doubly vital given the peculiar - and usually peripheral - place international broadcasting generally, and RNW specifically, has tended to occupy within national consciousness and history. As the 'voice of the nation,' either addressing foreign populations or national diasporas - and usually both - the national significance of international broadcasters has been long-established at both national and international level (Codding 1959; Spohrer 2013). Explicitly aimed beyond the boundaries of the nation, however, often in languages unintelligible to much of the 'home' population, their activities do not always fit neatly within the canons of national identity or history. Unlike domestic national broadcasters, whose mission of serving national publics has been somewhat consistent, international broadcasters have had divergent, evolving and overlapping purposes (Browne 1982). These can include serving national diasporas (Robertson 2008), strengthening colonial and post-colonial ties (Potter 2012), psychological warfare and propaganda in times of conflict (Wood 1994: 2-4; Nelson 2003; Briggs 1970), promoting national trade, and supporting global development ${ }^{3}$ All of these have played some role in RNW's development. Making those missions known to domestic audiences has often been a separate operation, very often relying far more on visual media (Komska 2015; Badenoch and Hagedoorn 2018: 12-15), which in the case of the RNW involved maps, newsreels, and the image of its purpose-built airplane-shaped building in Hilversum. In its early years, RNW met with strong skepticism for broadcasting in foreign languages - particularly non-Western ones (Haslach 1983, 89) - only to see these services later become far more the core of RNW's mission (ibid.: 98-99). For that matter, the budget cuts that led to RNW's closing reflect a similar marginal status in public consciousness, and statements from the xenophobic party supporting the governing coalition at the time further highlight enduring suspicions of its

$3 \mid$ n the difficulty in defining international broadcasting, see David Fernandez Quijada in this volume. 
mission. (Dohmen 2012) As Gillespie and Webb show, international broadcasting's obvious international stories of a nation maintaining various forms of contacts beyond its borders are built upon a number of transnational stories, not least of various diasporic actors whose work and hybrid voices make up the program output and their interactions within the broadcasting institution. (Gillespie and Webb 2013)

Heritage collections in the digital age are largely approached in terms of what might be called 're-collection:' that is, how archival material can be linked, networked or aggregated potentially to tell new stories (see Sonja de Leeuw's chapter in this volume). Large aggregator portals such as EUscreen and Europeana have moved from being merely central repositories focused on access to attempting to provide themed portals around specific content, themes or events usually in a transnational perspective, such as Europeana's First World War (https://www.europeana.eu/portal/en/collections/world-war-I), or migration collections https://www.europeana.eu/portal/en/collections/migration. A significant amount of the work of collecting and preserving in the digital era thus involves making digital heritage assets findable and linkable. At the same time, such activities are based around conditions of 'diffusion': distribution of heritage objects across separate institutions and collections the boundaries of which (digital) networking promises fruitfully to obviate or explode - at least in theory. Surveying the US archival landscape, VanCour notes this dynamic at work, stating that

[w] hile working to reaggregate programming materials that networks dispersed throughout space and time, broadcasting archives have remained themselves divided in their locations, constituencies, and institutional mandates. (VanCour 2016: 397)

As I will show in the case of the Netherlands, a smaller country with somewhat more centralized broadcasters and archival institutions than the US, diffusion can nevertheless occur at several levels and at several moments, particularly at the moment when archival material moves from one institution to another. Decisions about preservation and location of archival materials can quickly raise the tension between what the professor of archival studies Charles Jeurgens calls thinking in terms of a collection; that is, what stories the totality can tell, and thinking in terms of the individual 'documents,' which evaluates different types of document separately and tries to place each accordingly. (personal communication, 15 Feb 2018)

This chapter examines these dynamics of diffusion and re-collection as they play out in the archivalization of RNW's materials to show how these give shape to the stories that may be told using them. It takes a roughly ethnographic approach, drawing on internal documentation produced around the process, 
as well as communication with key people involved in the preservation process, and my own experience with some of the archives in question.

Ultimately, it shows how two sets of factors intertwine to give shape to what will be RNW's archival legacy. The first set concerns the practicalities of archiving: the physical nature of the material, available space and facilities for its storage, how it is currently catalogued and how it would need to be converted, adapted or translated. The second set of factors regard the values and priorities driving preservation: what is deemed worthy of preservation, but also where and 'as what' it is preserved. After a brief overview of RNW's history and missions, I will look at the archival landscape, and in particular the collecting remits of the national archives involved to explore their priorities in collection, and how these shape their view of RNW's material. Finally, I examine how RNW materials and archival practices intersect with the archival landscape, and how this shapes the selection, location and interpretation of the material.

\section{The Diffuse Missions of Radio Netherlands}

As an institution, RNW was formally founded 15 April, 1947 during the postwar reconstruction of the Netherlands, but its roots lie in two predecessor broadcasters that strongly shaped both its mission and its international profile. First, the station built on the pioneering shortwave station developed by the Philips corporation in 1927, specifically aimed at the Dutch colonies in the East and West Indies: the Philips Omroep Hollands-Indië (Philips Broadcasting Dutch Indies, PHOHI). During the war, the shortwave broadcaster had been taken over by the Nazi forces along with all other broadcasting. At the same time, the Dutch government in exile in Great Britain soon gained airtime on the BBC with its official voice Radio Oranje, aimed back at the occupied country. (Sinke 2009; Haslach 1983: 48-58) Radio Oranje is the second important predecessor of RNW: many of its members, including its first director, were key players in Radio Herrijzend Nederland (Radio Netherlands Resurrecting) - the broadcaster under Dutch military control in the newly liberated country. Rather than becoming the domestic civilian broadcaster, this organization instead became the international broadcaster RNW. (Haslach 1983: 61ff) RNW was a foundation that was granted exclusive rights to broadcast on shortwave from the Netherlands, and also received much of its budget from the Dutch Ministry of Foreign Affairs.

After Radio Netherlands was re-established, a set of program services was established that reflected much of the former and still ongoing colonial presence of the Netherlands: Dutch, English, Afrikaans, Spanish, Indonesian, and Arabic - Portuguese was later added as well as French, initially for cultural elites in Soviet-bloc Europe, and returning later aimed at Francophone Africa. 
The Dutch-language service was aimed largely at expatriates from the metropole - as well as projecting Dutch presence in the (former) colonies. Indeed, one of the station's very first tasks included entertaining the Dutch colonial troops during the war for Indonesian independence 1945-1949. The aim of the other language services was "to 'project' the Netherlands, and to be the calling card of our nation." (RNW 1960: 22)

Each language service had its own editorial and announcing staff, alongside a general editorial staff. Beyond its direct broadcasts, two other activities were key to the organization. For one, RNW also had a very active transcription service: broadcasts produced to be included in the programming of other stations. These were produced by the same departments that made the regular broadcasts. Particularly in more recent years, programs produced and distributed locally in partnership with RNW also formed a core part of the station's mission. Beyond these efforts, the station, together with the Dutch Ministry of Foreign Affairs, also founded a (still-running) training center for foreign journalists in the 1968 (see https://rntc.com/), which served international development as well as diplomatic goals, creating lasting relationships with the Netherlands. Such an overview barely scratches the surface of RNW's activities over the course of 65 years and more, but gives an indication of the breadth of material that it might have collected.

\section{The Archival Landscape}

For those working to preserve the archive, it seemed clear that RNW's archives were of national significance and as such belonged in a national archive, although it was not immediately clear which material should go to the national audiovisual archive NISV, and which should go to the National Archives. To an extent, this is a question of the classification of RNW as national institution, funded directly by the national authority or as an (international) broadcaster, primarily concerned with media production.

Before the question of locations was posed, however, the more basic question of what items would be preserved at all was the order of the day. To guide the process of preservation, selection and re-location, a so-called 'committee of sages' with expertise from the various archives as well as broadcasting history was assembled to make a selection. (Lauwers 2017a) The focus of the committee's attention was the written - in this case paper - records of the management and of the company archives (the "directiearchief" and the "bedrijfsarchief," respectively). The former includes board meetings, internal directives and external relations of the station with entities such as the Dutch government, as well as other national and external broadcasters (the records' classification of stations from the Netherlands Antilles as 'external' though they were formally 
part of the Kingdom of the Netherlands is interesting in its own right). The company archives consist roughly of all other documents relating to the operations of RNW and includes manuscript material, listener research, correspondence, photos and a number of other items.

In its collection remit, NISV also lays out a basic division of labor. For material 'outside the audiovisual domain' it maintains a partnership with two other major national heritage institutions, the Royal Library (Koninklijke Bibliotheek or KB) and the NA, where the latter is considered "storage place for the archives of (national) authorities." (Lauwers 2013: 11) For its part, NISV's general collection policy defines its remit as "collect[ing] primarily Dutch national audiovisual heritage." This means audiovisual works produced by Dutch people in the Netherlands or abroad, or recorded or made in the Netherlands. (Lauwers 2013: 21) While it states that it aims at "including different cultures, regions, and periods" that capture "the diversity of Dutch society," (ibid.) it does not explicitly state a language policy, which turned out to be a key issue.

The arrival of the RNW collection came during a shift in NISV's collection policy on written archive material. Their 2013 collection policy makes a clear distinction between the 'core collection' of audiovisual material and the 'context collections' of equipment, photographs, scripts, and other written records which "support and deepen our understanding of the content and production of the audiovisual collections." (Lauwers 2013: 59) A recent fusion with the press museum, a re-orientation toward 'media' more generally, and the recent acquisition of a number of written archives, led to new policy that looks at written records as having independent value. The procedure for acquiring company archives of media archives were in many ways adapted directly - and literally - from the policies surrounding RNW. (Lauwers 2017b)

Unlike NISV, paper archives are central to the holdings of the National Archives, and they possess both storage space and expertise in preserving and digitizing such records. Their remit includes "the national government and social organizations and individual persons who are (or were) of national importance." (www.nationaalarchief.nl/over-het-na/ons-verhaal/missie-en-meerjarenvisie). Jeurgens notes that particularly in the digital age, it matters less whether material is placed in different institutions than that there is a single catalogue or inventory that will allow a user to find the documents, and approach them as part of a collection rather than as individual documents. (personal communication 15 February 2018) While it is not explicitly named within the documents surrounding RNW collections, the NA participates in a number of national and international networks that could potentially add meaning to the RNW collections, including the national Netwerk Oorlogsbronnen (War Sources Network, www.oorlogsbronnen.nl) that combines material about the Second World War including much on RNW's precessor Radio Oranje, as well as Gedeeld Cultureel Erfgoed ("Shared Cultural Heritage"), an international 
program devoted to Dutch trade and colonial history, in which RNW material could potentially be of interest (https://www.nationaalarchief.nl/over-het-na/ gedeeld-cultureel-erfgoed).

\section{From Institution to Archive: the Diffusive ENCOUNTER}

When examining the power of archival practice, the underlying narratives of selection are very often considered implicit and unspoken - and indeed tacitness is part of their power. (Ketelaar 2001) In the case of the RNW archive, these were made an explicit part of the process by posing the question of what needs to be reconstructed from the material. Specifically, from the point of view of the NA, this meant in the first order consideration of RNW's ins and outs as an organization - this includes the bulk of the management archive minutes of board meetings, correspondence, and annual reports. (Lauwers 2017a: 3) Based on the recommendation of RNW's archivist, documents relating to the RNTC have also been marked for inclusion. (Lauwers 2017a: 2) Consideration of program materials, particularly logbooks and program listings, were also considered part of this essential, uncontroversial core of the archive. While recommending preservation around specific themes, these have not yet been chosen.

While understanding the institution was posited as a core criterion for deciding on what records to preserve, institutional practices have strong implications for what there is to be preserved in the first place (see Birdsall in this volume) - and for the way that their collections take shape in public archives. Nearly all broadcasting collections are somewhat prone to diffusion due to the nature of broadcasting work. Preservation practices often grow somewhat organically out of a range of practical considerations not directly related to the needs or interests of academic research, but rather to an institution's demands on its own past.

Formal written documents such as board meetings and annual reports, for example, are usually produced and kept within organizations, not least for legal reasons. With regard to radio programming, preservation of written records depends on various institutional cultures which can lead to calamitous - or serendipitous - conditions for historical researchers. A mountain of paper gold for researchers was kept at RNW in the form of logbooks for transmission. From 1947 until into the mid-196os the station kept logs that not only documented the programs in the sequence they were broadcast, but also included complete manuscripts (often with last-minute handwritten edits) for most of the programs and complete listings of records played, as well as usually handwritten notes on the extent to which the broadcast actually went according to plan. 
(Sleutjes 2015a) The detailed nature of the logbooks would allow us to reconstruct programming flow on RNW better than many of the preserved sound records, which are preserved as discreet segments. ${ }^{4}$ Because of their obvious relation to programming, these logbooks also fit well within NISV's existing collection policy, and were among the first items from the RNW collection to be taken on. While most other paper records have remained in storage, the logbooks have been catalogued and available for researchers to consult at NISV since 2015 .

With the logbooks, however, a division of institutional practice has also become a division of archival location. RNW programs were divided according to three different target audiences, defined geographically in terms of the signal's direction and the language of the broadcasts: the Dutch-language service, the International Service (English and Spanish) and the Eastern Service which included broadcasts in Arabic and Indonesian. (Sleutjes 2015b) While the Dutch and International services have come to NISV, the Eastern Service logbooks have found another home in the collection of the Royal Netherlands Institute of Southeast Asian and Caribbean Studies (Koninklijk Instituut voor Taal-, Land-en Volkenkunde, hereafter KITLV) in Leiden, the collections of which have been in the care of the Leiden University library since 2014. The KITLV was founded in 1851 as a research institute dedicated to the linguistic and ethnographic research in the then-Dutch colonies. (see "Our History" n.d.) They have since digitized a selection of the logbooks into pdf documents, one per month of transmission, and placed them online (http://lampje.leidenuniv.nl/KITLV-docs/open/RNW/ rnw.html). Underlying the placement of the "Eastern Service" logbooks at the KITLV was in part the lack of Indonesian or Arabic speakers at NISV. (Sleutjes 2015b) At the same time, however, this separation also makes an interpretation, and even narrative, by moving those programs from 'national heritage' into an institute dedicated to the study of former colonies - a 'them' rather than an 'us.' Services aimed at the other former colonies in the West Indies, however, are included in the material at NISV, rather than the KITLV.

Most of the remaining written archives of the RNW are, as of this writing, in a storage space. While it is impossible to judge precisely what these boxes contain, an inventory of the contents grants a vital overview as to what is there to be selected from and what kinds of stories might be told from the archive. ${ }^{5}$ These include the books of press clippings surrounding various themes, from RNW itself to specific people such as the polyglot presenter of the flagship program Happy Station Edward Startz, and other important personalities. Much of the remaining documentation attests to the role of the international station

4 | See, for example, the Eastern Service for January 1950 (about 77 hours of broadcasting in total), which runs to 1244 pages http://lampje.leidenuniv.nl/KITLV-docs/open/RNW/1950-01.pdf

$\mathbf{5}$ | This section is based upon an Excel sheet inventory the material held in storage. 
not only as a broadcasting organization, but a listening organization, gathering information both from and about listeners, and also other media organizations throughout the world. The station's research department contains various audience measurements over a 20 -year period, and individual departments, in particular Spanish and to a lesser extent Arabic, contain assembled listener correspondence as well. Particularly in many of these relations, RNW's archive can reveal transnational actors and connections. (Hilmes 2017a: 143) The issue of language competence that arose in considering the location of the logbooks will arise once more very clearly in the decision surrounding the various collections of the non-Dutch language desks which make up more or less one third of the material.

In contrast to paper records, preservation of audiovisual contents is largely driven by the considerations of re-use in production. To this end, RNW had a vast digital archive of sound material, searchable and sorted by decade. ${ }^{6}$ Even transfers of digital material are not necessarily straightforward, however: decoding the formatting of the digital archive proved a challenge for NISV. Furthermore, the metadata of a production archive and that of the audiovisual collection at NISV are quite different so that they will need additional enrichment before they can be included in the main catalog. While Dutch-language audiovisual material was brought into the collection without any question, (Lauwers 2017a: 1) as with the logbooks, it is not entirely clear to what extent the foreign language audio material will be selected for keeping as part of the collection, and thus how much of it will be available. In the absence of a clearly-defined policy on language as selection criterion, the selections that do take place will end up as a de facto story of the archive, either rendering a mono- or multilingual version of this chapter of Dutch broadcasting history.

\section{Diffusion Beyond the Collection}

As noted above, in the case of RNW, national archives were considered first and foremost, but the deliberations between NISV and NA did not cover all of the various collected materials from RNW. Some of RNW's collections had already entered into the heavily networked national archive landscape before the cuts took place. Much of the written documentation for Radio Oranje, for example, which had been in the possession of its successor RNW (some of which had initially been in possession of the BBC) was given to the Netherlands Institute for War Documentation (Nederlands Instituut voor Oorlogsdocumentatie, NIOD) in 2009, while its audiovisual collection is at NISV. As such, the movement of

6 | I am grateful to Martien Sleutjes for allowing me to explore this archive before it was transferred. 
RNW's collection will allow the continuities between the organizations to be traced, and the periodization of war and post-war to be explored more closely.

After the 2012 budget cuts, a very different fate befell RNW's music collection of over 20.000 LPs and $50.000 \mathrm{CDs}$, which had been collected and curated separately from the sound and paper archives. About one-third of this collection was 'World Music' acquired by RNW on location in many parts of the world (van Hamersveld 2013), seemingly an extension of the ethnographic concerns of early sound archives to collect the sounds of the world (see Birdsall, this volume). Like the paper archives, these were threatened with destruction if a salvage operation had not been undertaken. The ultimate solution for this material has not been directly a cultural heritage institution but Musidesk, a music lending library in the East of the Netherlands that makes both recordings and sheet music available to a broad public (https://www.musidesk.nl/). While this solution will both preserve the collection and make it accessible, it is not yet clear to what extent this material will be identifiable as originating from RNW and graspable as a collection.

Another moment of diffusion has happened prior, and in parallel, to the formal processes of dealing with RNW's archive. Jonathan Marks, a former director of programs at the station, as well as veteran of both the BBC World Service and freelancer for Radio Austria International, and long-time producer and presenter of RNW's flagship program Media Network, (1981-2000) has worked in parallel to institutional processes to make his personal collection and some of his recollections available online, explicitly for use by scholars and interested amateurs. The program itself documented technical and institutional developments - often in real time - as well as history, across a broad spectrum of the media landscape. It was also pioneering in its use of phone-ins, and was very well-known in the shortwave world (Berg 2010: 243-44). The online Media Network Vintage Vault now has over 485 episodes of the program, including a new 2018 edition, downloadable as podcasts on http://jonathanmarks.libsyn. com/. Each program is given by broadcast date, and accompanied by a short note about the events in it, though without the extensive metadata or categorized metadata that would make it easily linkable in the digital sphere. This collection highlights the increasing amount of valuable historical content that is coming available online in the form of amateur archives, not to mention platforms such as YouTube. (VanCour 2015; Yurtaeva 2016) It is precisely aspects of radio that fall outside of standard national canons of broadcasting, often with transborder reception, which in Europe tend to include 'pirate' and offshore broadcasters, broadcasters such as American Forces Network but also shortwave and DXing communities, that are most often recorded in such informal archives. As both producer of the programs he curates and globally recognized expert on the subject matter they cover (see Berg 2012: 430-32), Marks hardly fits into the category of 'amateur' in terms of his relation to the radio material, 
but rather in his role as archivist and curator. His is a voice that would ideally be brought back into dialogue with formal archives.

\section{CONCLUSION}

Many stories of RNW remain to be told, and thanks to the efforts of the individuals and institutions highlighted here, the sources to support those stories will be preserved and made accessible to scholars and to the broader public within the foreseeable future. Furthermore, as these materials emerge into the digital realm, they have strong potential to be re-collected and interwoven - as radio itself is - into a number of vital stories of transnational heritage: of (post-) colonial migration and diaspora, of the role of a small Western European nation between the Cold War and increasing integration of Europe, of shared experiences and events. At the same time, mapping how traces of international broadcasting find their way within a national archival landscape also holds up a mirror to how archivalization might shape those stories. We have seen here that in many instances a logic of thinking in terms of individual classes of documents rather than a collection as a whole has led to a diffusion of the archive across several institutions. Their re-collection will depend to an increasing extent on their digital tags and metadata, the digital infrastructures in which they move and the finding tools employed to discover them.

In addition, following the paths of RNW's diffusion throws new light on

the question of what constitutes 'the radio archive' in the current era, and in particular what counts as the 'national radio archive'. While VanCour (2016) highlights an ever-widening range of institutions in which diverse radio collections might already be found, this chapter has shown how a single collection might be distributed across a range of institutions, from recognized archival institutions to amateur archives and non-archival organizations. Such diffusion is not only thematically linked to collecting remits, but also highlights the role played by the material to be archived in determining how - and whether - it will become part of a radio archive. While the sound files of programs belong almost without question to the collection, many of the paper records produced by a broadcasting institution would require much deeper scrutiny to be considered worthy of keeping. Indeed the role of paper seems to be moving from one of auxiliary importance to the 'content' of sound files, to one that has importance in its own right (Dolan 2003; Keeler 2011). One of the more intriguing questions regards the various ways in which an international broadcaster listened to, recorded, and understood - and preserved - a view of the world and the radio audience. Beyond that, records such as those of RNTC further open up our view of radio beyond direct production and distribution of programs and 
into a deeper understanding of the transnational production and circulation of radio expertise.

This chapter has above all shown how seemingly 'practical' decisions on archiving can have ideological effects, especially with regard to what constitutes a 'national' radio archive. In a recent lecture, Michele Hilmes has suggested that transnational archives are among those most prone to disappear from history (Hilmes 2017b). The pragmatics of language expertise that separated the Eastern logbooks into a separate institution has both the potential to network and enrich this material around some stories, while at the same time removing them from the 'national' story. To an extent, they even inadvertently mirror the Dutch government's statistical mapping of the population into 'Western' and 'non-Western' foreigners. (cf. Yanow/Haar/Völke 2016) Similar views of a largely monolingual, Western-oriented nation could have similar preservation effects with regard to sound files. Ironically, the preserved and digitized (paper) logbooks might serve as a record of the extent to which those voices have been silenced in the sound archive.

\section{ACKNOWLEDGEMENTS}

Many thanks are due to Martien Sleutjes, Charles Jeurgens, Mieke Lauwers and Bas Agterberg for keeping me abreast of developments with the RNW archive.

\section{REFERENCES}

Badenoch, Alexander, and Berber Hagedoorn (2018): "TV on the Radio/Radio on Television: European Television Heritage as a Source for Understanding Radio History," In: VIEW Journal of European Television History and Culture 7/13, pp. 1-18. https://doi.org/DOI: 10.18146/2213-0969.2018.jethc145.

Berg, Jerome S. (2010): Listening on the Short Waves, 1945 to Today, Jefferson, NC: McFarland.

Berg, Jerome S. (2012): Broadcasting on the Short Waves, 1945 to Today, Jefferson, NC: McFarland.

Briggs, Asa (1970): The War of Words,Oxford: Oxford University Press.

Browne, Donald R. (1982.): International Radio Broadcasting: The Limits of the Limitless Medium, New York: Praeger.

Codding, George Arthur. (1959): Broadcasting Without Barriers, Paris: Unesco.

Dohmen, Joep (2012): “Tot zover de Wereldomroep,” NRC, 21 April 2012. https://www. nrc.nl/nieuws/2012/04/21/tot-zover-de-wereldomroep-1098201-a433765.

Dolan, Josephine (2003): “The Voice That Cannot Be Heard," Radio Journal: International Studies in Broadcast \& Audio Media 1/1, pp. 63-72. 
Gillespie, Marie, and Alban Webb (2013): “Corporate Cosmopolitanism: Diasporas and Diplomacy at the BBC World Service 1932-2012," In: Marie Gillespie/Alban Webb (eds.) Diasporas and Diplomacy: Cultural Contact Zones at the BBC World Service 1932-2012, London: Routledge, pp. 1-20.

Hamersveld, Ineke van. (2013): "Muzikaal Erfgoed Op Straat! Verslag Expertmeeting," Boekman Stichting. 15 April 2013. https://www.boekman.nl/blog/muzikaalerfgoed-op-straat-verslag-expertmeeting.

Haslach, Robert D. (1983): Netherlands World Broacasting, Media, PA: L. Miller.

Hilmes, Michele (2017a): “Entangled Media Histories: A Response,” Media History 23/1, pp. 142-44.

Hilmes, Michele (2017b): "Spies, Commies, and Hairdressers. The Perfidious Entanglements of Media History” Keynote lecture, “Tracing Entanglements in Media History” Lund University May 18

Keeler, Amanda (2011): “'Only the Sound Itself”?: Early Radio, Education, and Archives of 'No-Sound," Sounding Out! (blog), 24 October. https://soundstudiesblog. com/2011/10/24/the-sound-itself-early-radio-education-and-archives-of-no-sound/.

Ketelaar, Eric (2001): “Tacit Narratives: The Meanings of Archives," Archival Science 1/2, pp. 131-41.

Komska, Yuliya (2015): “Sight Radio: Radio Free Europe on Screen, 1951-1965," In: Anna Bischof/Zuzanna Jurgens (eds.) Voices of Freedom - Western Interference? 6o Years of Radio Free Europe in Munich and Prague, Göttingen: Vandenhoeck \& Ruprecht, pp. 55-75.

Lauwers, Mieke (2013) “Collectiebeleid Beeld en Geluid” Policy document, Hilversum: Netherlands Institute for Sound and Vision http://files.beeldengeluid.nl/pdf/Collectiebeleid_BeeldenGeluid.pdf

Lauwers, Mieke (2017a): “Rapportage verloop en uitkomsten Comité des Sages” Internal report, January 2017, Hilversum: Netherlands Institute for Sound and Vision

Lauwers, Mieke (2017b): "Selectiebeleid geschreven archieven Beeld en Geluid. Version 2.0" Internal policy document, October 2017 Hilversum: Netherlands Institute for Sound and Vision

Nelson, Michael (2003): War of the Black Heavens: The Battles of Western Broadcasting in the Cold War, London: Brassey's.

"Our History" (n.d.): KITLV http://www.kitlv.nl/our-history/.

Potter, Simon (2012): Broadcasting Empire: The BBC and the British World, 19221970, Oxford: Oxford University Press.

RNW (1960): Radio Nederland Wereldomroep Jaarverslag 1960, Hilversum: Radio Nederland Wereldomroep

RNW (2012): "Wereldomroep neemt afscheid van de Nederlandse radioluisteraar" Press Release, Radio Nederland Wereldomroep, 25 March 2012 https://web.archive.org/web/20120325204300/http://corporate.rnw.nl/nederlands/persbericht/ wereldomroep-neemt-afscheid-van-de-nederlandse-radioluisteraar 
Robertson, Emma. 2008. “'I Get a Real Kick out of Big Ben' BBC Versions of Britishness on the Empire and General Overseas Service, 1932-1948” Historical Journal of Film, Radio and Television 28/4, pp. 459-73.

Schaap, Wijbrandt (2015): “Archief Wereldomroep volgend slachtoffer van bezuinigingen" https://www.cultureelpersbureau.nl/2015/o1/archief-wereldomroep-volgendslachtoffer-van-bezuinigingen/ 26 January.

Sinke, Onno (2009): Verzet vanuit de verte: de behoedzame koers van Radio Oranje. Augustus.

Sleutjes, Martien (2015a): “Logboeken,"Histomotiv (blog). 24 November. http://www. histomotiv.nl/logboeken/.

Sleutjes, Martien (2015b): 'Logboeken Indonesisch en Arabisch'. Histomotiv (blog). 24 November. http://www.histomotiv.nl/logboeken-indonesisch/.

Spohrer, Jennifer (2013): “Threat or Beacon? Recasting International Broadcasting In Europe After World War II,” In: Alexander Badenoch/Andreas Fickers/Christian Henrich-Franke (eds.) Airy Curtains in the European Ether: Broadcasting and the Cold War. Baden-Baden: Nomos, pp. 29-50.

VanCour, Shawn (2015): “The Informal Economy of the Amateur Archive: Collectors as Cultural Intermediaries,” Flow, May 19. http://www.flowjournal.org/2015/05/ the-informal-economy-of-the-amateur-archive/.

VanCour, Shawn (2016): "Locating the Radio Archive: New Histories, New Challenges," Journal of Radio \& Audio Media 23/2, pp. 395-403.

Wood, James (1994): History of International Broadcasting, London: IET.

Yanow, Dvora/Marleen van der Haar/Karlijn Völke (2016): “Troubled Taxonomies and the Calculating State: Everyday Categorizing and 'Race-Ethnicity' - The Netherlands Case." Journal of Race, Ethnicity and Politics 1/2, pp. 187-226.

Yurtaeva, Yulia (2016): "Private Internetplattformen Als Medienarchive Und Neue Forschungsräume," In: Sascha Trültzsch-Wijnen/Alessandro Barberi/Thomas Ballhausen (eds.), Medienarchive als Gedächtnis- und Erinnerungsorte, Köln: Herbert von Halem, pp. 204-12. 


\title{
Promising Prospects, and the Hurdles Along the Way
}

\author{
Sharing and Archiving Community Media Content Online
}

Joost van Beek

Community media, most pithily defined as broadcasting "for, by and about the community" (UNESCO 2001), produce an extraordinary range of politically, culturally and artistically valuable and topical content. Defined by a mission to serve and represent communities rather than generate profit, independence from commercial and governmental interests, and a participatory, volunteerdriven model (Coyer/van Beek 2010: 136-138), they have in particular demonstrated an "extensive and sustained" engagement with migrant groups through (often minority-language or bilingual) community programming as well as programs with an explicitly intercultural or anti-racist focus. (Titley 2010: 141145) Given its focus on community building and bottom-up production models, this media sector should in theory benefit especially from the increased availability of interactive digital platforms for sharing and archiving content. Since on-air broadcasting is an inherently evanescent medium, digital archives can play a key complementary role in preserving and sharing the stories that are told on community media.

Even if the impact of community media is by intention primarily local, online access to their content can also expand opportunities for (intercultural) dialogue both regionally or nationally and in diaspora communities. In reality, online publishing practices unfortunately remain patchy, as do efforts to operate communal, networked archives. Consequently, programming that could make valuable contributions to broader cultural and socio-political conversations has remained underutilized.

In this chapter, I will draw on the findings of the EU-funded project CAPTCHA - Creative Approaches to Living Cultural Archives (2013-2015, http://livingarchives.eu/), in which we explored community media archiving practices across Europe, and the study conducted during the project (van Beek 2016), in order to identify best practices for preserving and sharing content online and the challenges standing in the way. 


\section{The Promise of Networked Archives}

While community media audiences can develop an especially personal or loyal bond with the station through its opportunities for active participation or its focus on grassroots concerns, their expectations have changed in line with the ever-expanding scope of streaming and on-demand content. As Radio Orange's Jan Hestmann warned, people want to be able to listen to "what they're interested in, [..] wherever and whenever they want." (ibid: 9)

In our study we found that community media often struggle to keep up with this sea change in media use. Many are slow to embrace a transformation of what 'making radio' means - from solely producing on-air broadcasts to publishing media content in a variety of formats and interacting with listeners across different platforms. They are constrained mostly by lacking financial and organizational resources, but a cultural disconnect between the realms of radio and online plays a role as well. Those constraints also affect their capacity to not just maintain in-house archives, but ensure their public or online accessibility. All too often, legacies that represent not only a particular station's history but that of whole communities are, as the Broadcasting Authority of Ireland's Anne O'Brien warned, "at risk of being lost forever." (ibid: 9)

In this light, online initiatives to exchange and archive programming on joint public platforms like the Spanish/Latin-American Red Nosotras en el Mundo (http://www.rednosotrasenelmundo.org/) play an especially valuable role, but they also face oversized challenges. The examples of EPRA (Échanges et Productions Radiophoniques), which once presented 11,000 hours of French community media content; Cross Radio, which involved radio stations from across former Yugoslavia; the program exchange platform of Ireland's Community Radio Forum; and the Belgian community media database RadioSwap illustrate how they are often confronted with fatal hurdles, falling victim to funding short-falls, technical failures, or lacking organizational capacity.

Nevertheless, Austria's Cultural Broadcasting Archive (CBA https://cba.fro. at/) and Germany's Freie-Radios.net, hosting over 80,000 audio files each, have grown well beyond program-sharing tools of the community media federations that support them, into collaborative archives which present a rich documentation of contemporary history. Crucially, they have helped broadcasters publish content online, and highlight or integrate it on their own sites, even when they lack the resources to create their own archiving structures. Most stations only upload a selection of their broadcasts to them, however. Moreover, they seem designed primarily to serve the needs of participating broadcasters, rather than to provide listeners at large with user-friendly interfaces to browse and search the wealth of community media content they offer (van Beek 2016: 88-92). 


\section{REASONS TO EXCEL}

In principle, community media should be particularly motivated to ensure the preservation of their content and excellently positioned to optimize online interaction with it. After all, each of the defining strengths of community media finds its parallel potential online.

Community media spring from the same groundswell of DIY culture, in which people claim "the right to be heard rather than be spoken to," as the "acts of [...] independent, collaborative or participatory media-making" which have flourished especially online (Deuze 2006: 267, 273). Their participatory ethos, which identifies citizen-producers rather than passive consumers, overlaps with that of citizen journalism (Bosch 2013: 29), e.g. at similarly volunteer- and mission-driven hyperlocal news sites. (Williams 2016) Social media can help them fulfill their key mandate "of engaging with audiences in participatory ways, and allowing audience members to determine content through collaborative journalism." (Bosch 2013: 37)

Community media provide "artists and creative entrepreneurs [with] a platform for testing new ideas and [...] content that cannot be conveyed in the mass media" (European Parliament 2007: 9). Austrian Dorf TV, which cofounder Otto Tremetzberger called "a hybrid of TV and Internet," showcases how embracing the online recruitment, development and archiving of "user-generated television" can provide them with a complementary medium. Instead of trying to pull a spatially dispersed community of producers into in-house production structures and set broadcasting times, its portal allows them to store, work and interact on their videos remotely as well.

Community media capture unique content that is "intrinsically interwoven with the lives of local community members" (Raveendran 2016) and gives voice to grassroots communities that are underrepresented in mainstream media and institutions. Theirs are the memories that are most vulnerable to being lost. Archiving this content "will ensure the voice of the 'ordinary' people will be recorded and available for future generations" when "the majority of mainstream archives [...] tend to be the voices of those in power and authority" (Loughran 2015). Otherwise, Jörg Depta of Berlin's Pi-Radio warned, "while the public service broadcasters enjoy the luxury of having their own archive at the German Broadcasting Archive, nothing will be left for historians [...] from the 'free radio stations' and their predecessors, the pirate stations" (van Beek 2016: 9-10).

Community media help "strengthen the identities of specific communities of interest" (European Parliament 2007: 6), presenting locations of cultural encounters as well as platforms for "the participation and emancipation process" of minority groups (Online/More Colour in the Media 2004). Archiving presents a key tool for protecting cultural heritage, and interactively publishing 
content online presents an opportunity to rouse engagement with minority cultures across geographic, community and generational boundaries. Online community broadcaster Radio Kultura, for example, addresses a diasporic Basque audience as well as a bicultural local audience of French and Basque listeners.

Greater use of on-demand and social media, already home to virtual communities that play an especially important role as "spaces for identity, expression and participation" for diasporic populations (Georgiou 2013: 84), could expand the parameters of community media to become "a cosmopolitan space of cultural netizens," geographically fragmented but symbolically connected (Nassanga/Manyozo/Lopes 2013: 259). On the site of one rural Irish community station, a remote listener commented to say: "Can't wait to go back home to Connemara. Listen to you guys every night. Helps me get to sleep. You're keeping me going until I can move back" (van Beek 2016:116).

\section{SOBERING REALITY}

In short, community media should be "well equipped to take on" the challenges of digital platforms: "they are grounded in an experimental ethos" in using technology and "cater for specific [...] interests but also connect communities across boundaries and distances" (Hallett/Hintz 2010: 159). And yet, the publication, distribution and archiving of content online is a scattershot affair, often lacking an overarching digital strategy (Leindecker 2015: 14). Many smaller broadcasters are yet to advance beyond "simulcasting [...] web and FM transmissions" which was already "increasingly common" a decade ago (Lewis 2008: 25). Others only embed some selection of audio content in playlists, blog posts or news items, with at most few and inconsistently applied metadata. Sometimes, more structured archives exist only for specific programs or initiatives; a fragmented practice which is exacerbated by having to rely on short-term, project-specific funding opportunities.

A review of community radio stations in Germany's umbrella association BFR revealed that only one in five offered ways "to access (posts with) past audio content by theme or topic" and "just under one in four allowed listeners to navigate to past audio content by day, week or month" (van Beek 2014). The rates were even lower among Spanish community media. Endeavors to highlight, structure and contextualize archival content in interactive or narrative ways that would ensure its discoverability in the long term (Leindecker 2015: 15) remained a remote prospect.

Online archiving efforts have often depended on the work of lone, passionate individuals, who might be increasingly challenged by ever more complex technologies. Switzerland's Radio LoRa has been uploading its full program since 2002 thanks to the pioneering work of Christoph Lindenmaier, whom 
his colleagues described as "a genius, [who] made everything himself" (van Beek 2016: 53). But its system has remained essentially unchanged since then, meaning you now need auxiliary software to listen to archived broadcasts, since they are still being uploaded as Real Media files.

Our study found relatively few examples of collaborations with comparably grassroots, activist communities of online developers, and hardly any recruitment efforts that targeted potential volunteers with a primary interest in web or tech rather than on-air radio. Spain's CUAC FM, where software engineers volunteered to develop a mobile app and an open-source system to automatically record and archive broadcast content, demonstrates the benefits of doing so.?

The extent to which content is archived in-house varies too. While Slovenia's Radio Študent maintains an internal archive with 40 thousand objects, an interviewee at one radio station confessed that "we have a few cartons of stuff, but that's basically our archive". Current broadcasts now seem to be universally recorded and stored, but if this content is not labelled and organized its accessible preservation is still under threat.

Much historical material may have "scattered" and only survive "in a drawer, in the attic" of former volunteers or listeners (Brunow 2015: 9). On the bright side, the capacity of community media to cultivate active volunteer and sympathizer communities means this is an opportunity as much as it is a danger. At Radio Dreyeckland, former volunteers return to digitize the programs they themselves made. Radio Študent "crowdsourced" the station's historical record in an experiment it dubbed 'on-air ethnography', and even reconstructed its first ever broadcast.

\section{What's Holding Them BaCK?}

Essentially, it remains true that "the sector lacks the skills, resources and notably the regulatory support" to fully utilize the digital media environment (European Parliament 2007: 51). In addition to scarce funding opportunities, the main challenges community media face relate to copyright, volunteers, conflicting objectives, and data capacity and security.

When legal rights issues hinder the web archiving efforts of much larger institutions (Sierman/Teszelszky 2017), it is no surprise that community media wrestle with them. Specifically, copyright regulations that preclude or limit the online publication of musical content played a major role in discouraging most every station to some extent from uploading content - not just music programs, but mixed-content journalistic broadcasts as well. Only concerted, sustained

7 |See https://cuacfm.org/novas/2017/02/nova-version-da-app-android/ and http://radioco.org/ en/about/. 
advocacy can offer long-term relief. When Austrian community radio stations succeeded, after years of negotiations, in concluding a ground-breaking threeyear collective agreement with collecting societies (Neuwirth 2014), CBA contributors uploaded over 500 files in a single day.

Community broadcasters rely on volunteers who are eager to learn and motivated by a sense of idealism. But this also means they can't necessarily be obliged to take on the additional tasks of uploading and categorizing their content, and stations have to rely on persuasion. High turnover and divergent levels of digital literacy of volunteers, many of whom might be from disadvantaged communities, affect the consistency of archiving and the quality of metadata. Centralizing the process is often unfeasible, not least with multilingual programming, so community media must continuously invest in training and guidance.

Contradictory use cases hamper the discoverability of archived content. Community radio websites, focused on helping regular listeners catch up with specific programs, tend to replicate on-air structures: hour-long units, fitted into archives by date and/or program that have frequently mushroomed into complex content trees which mix audio and non-audio content. But a new generation of (mobile) online-only listeners might not recognize program names or care about when something was broadcast. Consistent use of tags to identify subjects and genres as well as design shortcuts to highlight where audio content is available serve to mitigate this dilemma to some extent. But stations increasingly face a choice between maintaining intricate but cumbersome parallel navigation structures, as German community broadcaster Radio Dreyeckland did, and making a strategic decision to focus structures primarily on the online-only visitor, as Belfast's Northern Visions seemed to do when establishing a stand-alone archive site (van Beek 2014: 81-83).

The "digital archive needs active and constant care"; truly safeguarding long-term preservation involves not just multiple backups but regularly checking their integrity and migrating them whenever formats and carriers become obsolete (Pop 2015: 50). This is a daunting prospect for most community broadcasters. Stories about significant amounts of content being lost when servers failed or websites were overhauled or migrated were disturbingly frequent.

Lacking the resources to build online archiving structures, many broadcasters understandably rely on commercial third party services. Without their free accounts on Soundcloud, Mixcloud, iVoox and Vimeo, a vast span of community broadcast content would never find its way online. But delegating the online accessibility of their content makes broadcasters dependent on companies which can change or restrict access, features and pricing at will, or fail altogether and take entire archives down with them, while conceding those companies legal control and financial profit over their content. 
If community broadcasters are to "maintain the relevance" of their media-political principles, they need to carve out autonomous, pluralist spaces in the digital media landscape the same way they did on the radio waves (Leindecker 2015: 13-14). That means doing it the hard way, building and utilizing non-commercial, open-access and open-source tools and infrastructures which they alone control, and can expand and customize at will. Doing so requires reaching out more to open source communities, recruiting primarily IT/web-focused staff or volunteers (as Radio Študent and CUAC FM did), partnering with local tech companies with similar values (as Germany's Radio Wüste Welle did), developing open source software that could also meet the needs of other community broadcasters (as Pi Radio did with metadata management tool "calcms"), and creating avenues for stations to pass on lessons learnt (as the CAPTCHA project aimed to do). Stronger national community media organizations would make the effort considerably more feasible. While networked efforts by German stations to build a "Freie Radio App" appear to have faltered, the CBA remains an excellent example of a joint initiative that, more than just creating a shared archive, provides even modestly sized stations with tools to publish program content on their own sites. In all, a formidable challenge indeed; but community radio was itself born of a struggle that achieved improbable success against daunting odds.

\section{REFERENCES}

Bosch, Tanja (2013): "Social Media and Community Radio Journalism in South Africa.” In: Digital Journalism 2/1, pp. 29-43.

Brunow, Dagmar (2015): “Ten Propositions on the Practice of Archiving Community Radio”. In: Captcha conference reader no.2, pp. 8-11, (https://issuu.com/lealegrand/docs/captchaheft2_web).

Coyer, Kate/van Beek, Joost (2010): "Community Radio in Bosnia and Herzegovina: Opportunities and Challenges.” In: Tarik Jusic (ed.), Communication and Community:

Citizens, Media, and Local Governance in Bosnia and Herzegovina, Sarajevo: Mediacentar Sarajevo and Center for Social Research Analitika, pp. 131-185.

Deuze, Mark (2006): “Ethnic Media, Community Media and Participatory Culture”. In: Journalism 7/3, pp. 262-280.

European Parliament (2007): The State of Community Media in the European Union, study by Kern European Affairs (KEA) for the Committee on Culture and Education.

Georgiou, Myria (2013): “Diaspora in the Digital Era: Minorities and Media Representation”. In: Journal on Ethnopolitics and Minority Issues in Europe 12/4, pp. 80-99.

Hallett, Lawrie/Hintz, Arne (2010): "Digital broadcasting - Challenges and Opportunities for European Community Radio Broadcasters". In: Telematics and Informatics 27, pp. 151-161. 
Leindecker, Ingo (2015): “CBA - die Radiothek der Freien Radios Österreich”. In: Captcha conference reader no. 3, pp. 12-16.

Lewis, Peter Maynard (2008): Promoting Social Cohesion: The Role of Community Media, Report prepared for the Council of Europe's Group of Specialists on Media Diversity.

Loughran, Paul (2015): “A Digital Archive for a Discreet Collection: The NEAR Archiving project in Ireland”. In: Captcha conference reader no.2, pp. 5-7. (https:// issuu.com/lealegrand/docs/captchaheft2_web).

Nassanga, Goretti Linda/Manyozo, Linje/Lopes, Claudia (2013): “ICTs and radio in Africa: How the uptake of ICT has influenced the newsroom culture among community radio journalists." In: Telematics and Informatics 30, pp. 258-266.

Neuwirth, Pamela (2014): "Zeitgeist und Vielfalt in europäischen Online-Archiven”. In: KUPFzeitung 151, pp.18-19.

Online/More Colour in the Media (2004): European manifesto to support and to underline the importance of minority community media (http://web.archive.org/ web/20040202032044/http://www.multicultural.net/manifesto/index.htm).

Pop, Liviu (2015): "Open Source Folklore Archives - Disseminating Small Memory Boxes.” In: Review of the National Center for Digitization 26, pp. 47-52.

Raveendran, Ritu (2016): "Why audio archiving matters" (http://uccommedia.in/ news/audio-archiving-matters/).

Sierman, Barbara/Teszelszky, Kees (2017): "How can we improve our web collection? An evaluation of webarchiving at the KB National Library of the Netherlands (2007-2017)." In: Alexandria: The Journal of National and International Library and Information Issues 27/2, pp. 1-14.

Titley, Gavan (2010): Broadcasting in the new Ireland: Mapping and envisioning cultural diversity, Maynooth: National University of Ireland, Maynooth.

UNESCO (2001), African Charter on Broadcasting (http://archive.niza.nl/docs/ 200207191410309398.pdf).

van Beek, Joost (2014): Community radio broadcasters in Germany and online archiving: Are we there yet? (http://livingarchives.eu/community-radio-broadcasters-germany-online-archiving-yet-2/).

van Beek, Joost (2016): Bold strides or tentative steps? How community broadcasters share and archive content online, Budapest: Central European University. 
Section 5:

Digital Radio Landscapes -

Transnational Challenges, National SOLUTIONS? 



\section{Making DAB Work: New Opportunities for Digital Radio in Europe}

Lawrie Hallett

\section{INTRODUCTION}

Digital Audio Broadcasting (DAB) is now commonplace in a number of European jurisdictions. However, in the greater scheme of things, its success, when compared to early predictions, has been somewhat limited. Technologies it was intended to supplant (most notably analogue FM broadcasting) continue to thrive, whilst alternative platforms, such as the smartphone and connected speakers (e.g. Amazon's Alexa and Google Home) have recently gained rapid mass acceptance. In addition, new programme delivery methods (podcasting, and "listen again" services etc.) within the online environment, have emerged to further diversify the reception options available.

Although such developments are, doubtless, complicating factors, this chapter suggests that it is not these that are primarily responsible for limiting DAB's wider international success to date. Rather, it is argued, the key issue is DAB's historic inability to provide an all-encompassing transmission platform, suitable for use across the entire broadcast radio sector. Bluntly put, DAB has not been seen as a comprehensive replacement technology. Unlike FM broadcasting before it, DAB has yet to prove itself capable of meeting the needs of all types of radio broadcaster, that is to say from the largest public service operators and commercial concerns, right through to the various smaller commercial and not-for-profit community radio service providers.

A key difficulty with the technology has been its historical inability to deliver small-scale broadcast coverage on a cost-effective basis. In addition, such a lack of flexible scalability in terms of coverage has tended to be reinforced by DAB coverage planning approaches and spectrum occupancy plans that have, perhaps understandably, or even conveniently, assumed minimal use of the platform by such smaller operators. 
Beginning with an historical examination of the development of DAB, this chapter both explores such difficulties and focuses on current approaches intended to improve upon the technology's suitability for smaller scale broadcasting operations. In particular, consideration is given to the recent emergence of alternative technological and regulatory approaches that may yet see DAB delivered in ways that both expand and enhance opportunities right across the broadcast radio sector in all its increasing diversity.

Although regulatory frameworks vary from jurisdiction to jurisdiction, an almost universal truth is that demand for broadcast licences outstrips their supply. In many countries, this is particularly acute at the small scale, for community based services and smaller commercial stations. Availability of DAB for such operators is one issue for them, historically, the other has been cost.

In terms of technology, the past decade has seen a confluence of conditions that have made lower-cost approaches to DAB delivery more practical. Open source DAB software emerged to take advantage of the falling cost and rising capabilities of digital hardware. Rather than use expensive bespoke hardware solutions, it is now possible to use generic computer hardware in conjunction with somewhat more specialist (but nevertheless readily available and relatively inexpensive) programmable hardware, in the form of a, so-called, software defined radio (SDR) to generate and transmit DAB signals. Initially, however, such nascent technological advantages had a minimal impact. It took time for the radio industry to realise that they allowed for a use of DAB that had not previously been assumed possible. Only when individual national regulators, such as Ofcom in the United Kingdom, began to allow field trials did the potential material impacts of such new approaches begin to become clearer.

For smaller scale community radio services and commercial radio stations, it is now apparent that the potential of these new approaches to DAB could be profound. Suddenly, cost effective options for digital broadcasting alongside larger stations may be possible. The alternative, that smaller operators could instead be left in a so-called "analogue backwater" on FM or AM (when all major broadcasters may have abandoned such platforms in favour of a digital-only future), now seems, potentially at least, a little less likely. The resultant challenge, for governments and regulators alike, is how to develop legal and regulatory environments that can best facilitate a broader digital uptake.

\section{DAB AS TECHNOLOGY}

Historically, DAB has always been a transnational project. The underlying objectives that drove the development of DAB at the outset were focused on the technical modernisation and improvement of broadcast radio delivery. The European Union-backed research project behind DAB, known as Eureka 147 
(Bower 1998), was formed in order to develop a programme platform technology capable of delivering such changes. The project drew in both broadcasters and technology companies from a variety of European countries and was quickly embraced by others outside the European Union, including, for example, the Canadian Research Council (more of which later).

Specifically, back in the 1980 s, the fundamental issue was capacity; demand for additional radio broadcasting licences could not be met, simply because, using the existing technologies of the day, there was insufficient radio frequency capacity within which to accommodate new services. The goal, therefore, was to develop a broadcasting platform that would deliver greater spectral efficiency and, additionally, improve audio quality and resistance to interference, as well as enhance operational flexibility. Such improvements over traditional analogue broadcasting platforms (AM and FM) would provide for the expansion of the medium, directly benefiting both broadcasters and listeners alike.

\section{The "Hype" of New Technologies}

Since its introduction the view of DAB and the degree to which this technology has delivered against its early objectives have largely followed a recognisable trajectory, what has become known as the "hype cycle" (see, for example, Fenn/ Raskino 2008; Gartner 2017). Originally developed by the business consultancy firm Gartner, the hype cycle hypothesises that any new technology results from a "technological trigger" (in this case the need to improve the carrying capacity of broadcast radio transmission systems). Thereafter, the theory suggests that a new technology will go through distinct phases: a "peak of inflated expectations" and "a trough of disillusionment" before reaching a "slope of enlightenment" and then, hopefully, "a plateau of productivity" (ibid.).

This conceptual cycle can be criticised, not least because of its use of subjective terminology. However, for DAB at least, it does appear possible to map the emergence of the technology to the various phases of the cycle. Indeed, a more detailed breakdown of the hype cycle (Crawford 2013) identifies further traits, such as the role of early adopters, mass media promotion and negative media coverage, each of which can be similarly mapped against the historical development of DAB. It is, therefore, arguable that the underlying proposition of the hype cycle may have some validity (at least in this instance). Thus, it may also be useful in providing some contextual understanding as to how DAB came to be positioned as it is today. Smaller scale broadcasters (both commercial and community based) have historically tended towards a negative view of DAB, both on ground of cost and, more fundamentally, in relation to the standard's seeming inability to deliver more tightly focused geographical coverage. Without access to DAB coverage of relevant scale at manageable cost, smaller opera- 
tors understandably fear the emergence of a potentially dominant broadcasting platform, from which they would effectively be excluded. Their views of DAB's hype cycle and indeed their impact on its development are therefore both relevant and particular.

Having been in existence for some three decades, DAB might by now be expected to be well into its productivity phase; however, in some ways at least, it still appears to be climbing the slope of enlightenment towards this goal. There are various reasons for this lack of clarity, not least the fact that different jurisdictions have tackled the introduction of DAB in different ways and with differing degrees of enthusiasm. Successes in some countries have often been tempered by failures in others.

As DAB technology has gradually matured, both its benefits and its weaknesses have become increasingly apparent. Moreover, analysing the impacts of DAB roll-out quickly suggests that the distribution of its benefits and the impact of its weaknesses has not been spread equally across all sectors of the broadcast radio industry. A brief examination of DAB's origins soon suggests why this might be the case.

\section{The Early History of DAB - Inflated Expectations?}

Back in the late 1980 s when the original Eureka-147 Digital Audio Broadcasting standard was first conceived, the world of radio broadcasting was a very different place (Kozamernik 1995; O’Neill 2009). Key differences were not just technological; they were fundamentally structural, concerning both economics and regulation, reflecting the degree to which the zeitgeist has changed over the intervening years. The number of broadcast radio stations operating was considerably smaller, with commercial radio still expanding in many countries and with community radio services much less pervasive than they are today. Moreover, the economics of the commercial element of the industry in particular tended towards being both more heavily regulated and less conglomerated. Despite subsequent commercial conglomeration, over the intervening years the industry as a whole has become increasingly diverse, particularly where a rapid expansion of smaller scale community radio services has since taken place.

When the European Union agreed to fund the original Eureka-147 research project, such small-scale operations were far from a priority. Proponents of the new digital radio broadcasting standard were composed primarily of larger European public service broadcasting (PSB) organisations, along with research institutions with a particular interest and expertise in digital audio and radio frequency transmissions. Meeting the demands of large-scale radio broadcasters, both public service and commercial, (making room for additional services and improving coverage etc.), was the priority. Thus, the emergent technical 
standard came to reflect this reality and subsequent frequency planning and regulatory approaches in support of the standard did the same.

In order to achieve its objectives, the Eureka 147 project team designed a system that had some characteristics that were very different from those of traditional analogue radio transmissions. The primary difference was the use of a multiplex, combining multiple stations into a single transmitted signal, for separation and selection by the receiver. A larger block of radio frequency spectrum is required for such an approach, however not only does it allow for a greater number of services to be broadcast within a defined amount of radio spectrum (when compared to FM transmissions), but such an approach also provides intrinsically enhanced resistance to interference.

For PSB and larger commercial operators, the advantages of digital radio are generally, and quite obviously, realised by the DAB standard. Fundamentally, the benefits centre around improved spectral efficiency, creating the ability to carry a greater number of services within a given amount of radio frequency spectrum (so, for example, the BBC could add Six Music, Radio 1 Extra and Radio 4 Extra, as well as the Asian Network, plus the BBC World Service to its roster of services broadcast across the United Kingdom). For politicians and regulators, the greater spectral efficiency of DAB, realised in particular for networked services that can re-use the same frequency allocation multiple times (in what is known as a Single Frequency Network [SFN]), was also a material prize.

\section{Relevance to Smaller Radio Stations}

The benefits summarised above are, however, of little relevance to the majority of smaller broadcast radio stations, typically employing a single transmitter for their operations. For such broadcasters, there are two key problems with the use of DAB broadcasting. First, there is the issue of cost. Historically, since DAB has been introduced, capital costs of equipment and, in particular, recurrent operational costs, have been higher for DAB than those required for equivalent coverage using the traditional analogue FM platform. Second, there is the matter of access, in particular defined by spectrum planning approaches, which, historically and for the reasons discussed above, has rarely prioritised, or really even seriously considered, the economic and operational requirements of smaller broadcasters.

Such difficulties aside, DAB still offers one overarching potential benefit when compared to analogue broadcasting: its service-carrying capacity. The limited amount of analogue radio frequency spectrum available for radio broadcasting means such resources have not been able to meet the continuing high levels of demand for additional radio broadcasting licenses. By bringing new frequency allocations into broadcasting use, and by using these efficiently, 
digital broadcasting technologies, such as DAB, offer a way to reduce this longstanding imbalance between supply and demand.

\section{Emergent Shortcomings - Disillusionment?}

In 1997, the Eureka-147 Project Office published an overview of the standard in what has now become a useful historical document, 'Eureka-147 - Digital Audio Broadcasting', which is still available online (Eureka 1997). The opening page of the project office publication states:

Digital Audio Broadcasting, DAB, is the most fundamental advance in radio technology since the introduction of FM stereo radio. It gives listeners interference-free reception of highquality sound, easy-to-use radios, and the potential for wider listening choice through many additional stations and services. (ibid.: 2 )

Referring back to the hype-cycle, clearly, such statements can be thought of as being typical of the initial "expectation" phase, which arguably, in the case of $\mathrm{DAB}$, can broadly be thought of as covering the 1990s. The above statement is representative of much of the writing about DAB at that time, highlighting benefits alone without reference to any of the system's operational limitations, in terms of issues such as scale and cost.

Around this period, proponents of the standard not only promoted the technology's functional capabilities, but they also made various wider ambitious claims about its potential to change the broadcast radio ecology. David Withero, the then president of EuroDAB (the then European DAB Forum), interviewed for the US industry journal, Radio World (RW) optimistically suggested that the technology was "on its way to becoming - if it is not already - a world standard for digital radio" (Clark 1996: 1).

Withero's comment came approximately a year after the start of regular networked DAB broadcasting in Norway (NRK 2017), Sweden (Sveriges Radio 2008) and the United Kingdom (Withero/Lavern 1995) during the Summer and Autumn of 1995. Even then, however, the potential for "disillusionment" was already apparent. The USA was fast back-tracking from its earlier commitment to the standard, instead beginning the development of what would eventually become HD Radio, its current domestic digital radio standard (see, for example, Anderson 2013).

By the first decade of this century, DAB had clearly begun to move through the hype cycle, away from the earliest expectation stage towards the disillusionment stage. Along with increased interest from academics in the development and implementation of DAB (see, for example, Lax 2003), it was Community 
Radio campaigners that were some of the first to really identify the limitations of DAB for smaller-scale broadcasters.

Perhaps the earliest comprehensive analysis of the implications of DAB for such operators came from the Netherlands Community Radio support organisation, OLON. "Eureka! Een Oplossing Voor Digitale Kleinschalige Radio" (Eureka! A Solution For Digital Small-Scale Radio), published in 2002 (OLON 2002), identified various issues around the standard and attempted to suggest possible alternative approaches, both within the DAB standard and through the use of alternative digital systems, such as Digital Radio Mondiale (DRM).

In some respects, the OLON publication was ahead of its time, clearly identifying the issues of cost and access, however, the solutions put forward were of somewhat limited relevance. In essence, not only were technological solutions still some years off, but also the operational impacts of DAB were still to be fully understood. Moreover, the driver of so-called "digital switch-over" (a wholesale move away from analogue broadcasting) was, at that time, not given serious credence.

Public awareness of DAB was increasing throughout the first decade of this century, as was the degree of coverage in the press. Critical reporting tended to focus on issues of the availability and reliability of reception (coverage) as well as the audio quality of DAB transmissions (see, for example, Schofield 2006 and Robjohns 2009). It is perhaps not surprising that DAB coverage was perceived as unreliable during its launch phase, not least because network roll-out cannot be completed overnight, as it takes time for any such network to be fully planned and completed. Towards the end of the first decade of this century, the importance of duplicating DAB coverage in such a way as it was perceived to be at least as good as the FM services it was intended to replace had been recognised by both proponents of the standard and by regulators. In the UK, Ofcom (The Office of Communications) made it perfectly clear that British DAB planning would seek to duplicate existing analogue coverage:

As part of the government's Digital Radio Action Plan, Ofcom is currently leading a process to consider the future spectrum planning requirements of digital radio, to prepare for the digital radio upgrade ... This process will establish and agree the current levels of acceptable coverage of $F M$, which will provide the benchmark for all future planning, and determine the most technically efficient way of matching DAB coverage to FM. (Ofcom 2010: 20)

More recently, the European Broadcasting Union, in bringing together recommendations for the successful delivery of digital radio services, noted that: "At the end of the day digital radio coverage must be the same as analogue radio" (EBU 2014: 7). Emphasising the point, the same document added: "Listeners will not accept losing coverage in comparison with analogue services" (ibid.). 
Issues relating to audio quality can perhaps best be understood in the context of early claims that DAB would provide "near-CD quality" (Spikofski and Klar 2003) audio or even “'CD-quality' audio” (O’Neill et. al. 2010: 87). The early days of DAB were:

[A]ccompanied by a tremendous optimism buoyed by its technical achievements concerning the potential for innovative new dimensions to radio as a medium. A key feature ... was its promise of exceptional audio quality. (ibid.)

While it was, and still remains, that case that a DAB multiplex is theoretically capable of delivering a small number audio services of very high audio quality, in practice, such an approach has not been the norm:

More often than not, however, bit-rates are determined by the minimum necessary for acceptable listening, not the maximum or even the recommended levels for effective audio performance. (ibid.)

By sharing out the finite capacity of a given DAB multiplex between a greater number of services, listeners are provided with more choice, albeit at the price of reduced audio fidelity. O'Neill notes the reality that, "broadcasters (and consumers) have tended to prefer quantity over quality” (ibid.).

\section{Finding Solutions - Towards EnLightenment?}

Grant Goddard brings together the various concerns about the DAB standard in his book DAB Digital Radio Licensed to Fail. (Goddard 2010) By the time this was published, regulators had begun to recognise that at least some of the issues identified as problematic with DAB did warrant further examination. In the context of the hype cycle DAB had begun to climb "the slopes of enlightenment". Now, with the advantage of considerable operational experience over some fifteen or so years, the benefits of the standard had become properly understood. However, so too had the material problems that remained to be addressed if DAB was to succeed as a long-term universal digital replacement for analogue broadcasting.

In the UK, after considerable preparation and liaison with Ofcom, the Department for Culture Media and Sport (DCMS) published the first version of its Digital Radio Action Plan (DCMS 2010). This, along with subsequent more detailed work, such as Ofcom's “DAB Coverage Planning Report To Government" (Ofcom 2012) sought to address coverage (and other) concerns, in order to enhance the uptake of DAB. Since 2010, Ofcom's Communications Market 
Digital Radio Report has tracked the uptake of DAB and other forms of digital radio listening (Ofcom 2016a).

From around the same time, the British regulator has also sought to address some of the shortcomings of DAB technology as these relate to the operations of smaller-scale broadcasters. The previously identified issues of cost and relevant coverage were considered key to the regulator's approach. If capital and operational costs could be substantially reduced and if additional localised frequency resources could be identified, might it then be possible to make DAB a viable option for such stations?

\section{SMALL-SCALE DAB TRIALS}

Ofcom began by examining new technical approaches to the delivery of DAB through the use of open-source DAB technology, selecting Central Brighton as the location for initial tests in 2012 (Ray 2013; Mustapha 2013). Operating under a so-called "Test and Development Licence" these transmissions from a single DAB transmitter were not intended for public reception. Rather, they were designed "to inform policy makers of the practicalities of low cost DAB solutions when used to serve small areas" (Mustapha 2013:1), using software based alternatives to traditional transmission infrastructure.

The equipment and systems used to deliver the Brighton transmissions did not simply emerge fully-formed from the UK regulator's radio engineering team. Rather, Ofcom employed open-source technology which had originally been developed by the Communications Research Centre (CRC), a government funded body in Canada, which released its original DAB transmission software under a General Public Licence (GPL) in 2009 (ibid., 6). Although the original CRC project ended some years ago, its work continues to be built upon by Open Digital Radio (ODR), a Geneva-based not-for-profit association, which also has close links to the European Broadcasting Union (EBU), that regularly runs workshops and conferences to promote and develop DAB in all its forms (Coinchon 2010).

It should also be noted that Ofcom was not originally proactive in relation to the initial Brighton test, rather it merely acquiesced to an internal request from an individual employee. That said, once the initial test proved successful, Ofcom did move quickly to further examine possibilities for smaller-scale DAB transmissions with a series of trial broadcasts, this time intended for public reception. The trials, in ten locations across England and Scotland, were supported by the relevant British Government department (DCMS), and each began during 2015. Initially intended to last for only nine months each, in early 2016 Ofcom extended all of the trials for a further two years, such that each would run through into 2018. More recently, with both the UK Government 
and Ofcom struggling to finalise and introduce a new regulatory framework, these trials have been further extended into the Spring of 2020 .

The wider trials have been able to investigate additional elements of the DAB standard. In particular, they have made use of open source approaches to the creation of SFNs (Ofcom 2016b: 4) and have been proactive in the promotion of a newer version of the DAB standard known as DAB+ (see, for example, Herrmann et. al., 2007; and Sabel, 2013). Indeed, the ten localised trial multiplexes have arguably been instrumental in demonstrating the attractiveness of this new version of DAB (Ofcom 2016b: 15). Using DAB+ allows for an increased number of programme services to be carried by a single multiplex at a given perceived audio quality. By extension this means that the operational costs of running a multiplex can be shared between a greater number of stations, thus further tackling the issues around recurrent operational costs for smaller-scale broadcasters.

\section{Consulting on the Future}

The currently extended trials also have wider objectives than those of their predecessor. Beyond further examining the capabilities of software-based DAB transmissions, they are also intended to evaluate possible regulatory approaches to the operation of such services on a permanent basis in future. Ofcom was also keen to gauge the likely demand for such services and to see how such DAB multiplexes might be structured, managed and operated going forward.

In the trial, various operational structures were permitted. Some multiplex operators established themselves as independent commercial, for-profit, companies, others as separate not-for-profit organisations, whilst others still were established within existing community-based or commercial station operating companies. The specific approach to trialling the technology was based on achieving outcomes of relevance to radio broadcasting within the UK. However, the approach to various underlying regulatory issues certainly has wider international relevance. The fact that similar trials have since been adopted in other jurisdictions demonstrates just how similar the underlying issues can be across national borders.

During the experiment each operator was independent from the others, but the question of ownership in the longer term has, for some at least, become a major concern. In British Community Radio, no two stations can be owned by the same company (or other type of body corporate) (HMSO 2004: 4) and individuals may not hold any such licence (ibid.). The objective of this approach is to preserve local ownership and control of such stations. This is something that has almost entirely disappeared from British commercial radio broadcasting, a result of corporate consolidation through mergers and acquisitions over 
a number of years since ownership rules in that sector began to be gradually relaxed towards the end of the Twentieth Century.

Many in the British Community Radio sector (including its representative body, the Community Media Association) recommend a similar approach to the ownership of the new tier of localised DAB multiplexes. Pointing to the protections offered to Community Radio stations, they argue that the multiplexes themselves should be similarly protected against corporate approaches to avoid the creation of networks potentially devoid of local character (CMA 2014: 2).

Early in 2017 , the UK Government successfully piloted legislation through the British Parliament that set out a broad framework for the future licencing of permanent localised DAB multiplexes (DCMS 2017; House of Lords 2017). Much operational detail is missing from this framework, and, at the time of writing, although a DCMS consultation has been run, its conclusions have yet to be published. Once they are, Ofcom intends to consult, in detail, as to how the legislation should be put into a workable regulatory regime that could both serve the interests of smaller-scale broadcasters and ensure the distinctiveness of a new tier of localised DAB multiplexes.

Concerns around ownership and coverage, not least around ensuring effective equivalence of service availability, are just some of the issues that the forthcoming Ofcom consultation is likely to address. As ever there remains a tension between the interests of the small-scale commercial sector and those of the not-for-profit community sector. However, in this particular instance, the potential benefits to both seem to outweigh long standing ideological rivalries, as both sectors suffer the same lack of digital broadcasting opportunities as each other. Both also share concerns that this situation is becoming an increasing disadvantage when compared to the benefits of digital transmission, which larger PSB and commercial stations have been enjoying for some time.

The trial multiplexes carry a range of commercial, non-commercial and new entrant broadcasters and it would seem likely that this is the model that will form the basis of future permanent operations. However, concerns remain about how carrying capacity on these localised multiplexes will be shared. Might, for example, there be reserved capacity for local community radio services, or, indeed, for local commercial stations that otherwise have no access to digital broadcasting platforms?

\section{CONCLUSIONS}

Over the years, wider technological developments, as well as changes in broadcasting policy and regulatory environments, have not made life easy for the proponents of DAB. The consumption of curated audio content is no longer almost entirely the preserve of radio broadcasting alone. Traditional radio has now 
been joined by various alternative "radio-esque" platforms, including streamed audio and podcasts. It could therefore be argued that such developments negate the need to replace traditional analogue broadcasting platforms with a digital alternative of similar ubiquity. However, when it comes to audiences, the consumption of traditional free-to-air radio continues to dominate in terms of absolute audience numbers and listening hours (Ofcom 2016c: 111).

It is now over thirty years since permanent DAB services were first introduced and it does appear that the technology is gradually moving towards the final stage of the hype cycle, within which a "plateau of productivity" may finally be reached. Linked to the hype cycle, "Amara's Law" states that: "We tend to overestimate the effect of a technology in the short run and underestimate the effect in the long run" (Deighton / Kornfeld 2013). It may not yet be possible to conclude that this law applies to DAB, but the original Eureka 147 technical standard has certainly evolved over the years, not least because of the introduction of the enhanced $\mathrm{DAB}+$ standard, which is now beginning to make its presence felt. Arguably however, it is potential changes to the material implementation of DAB that may have as great, or even greater, potential to enhance the practical beneficial impacts of the standard. If this proves to be the case, then the longer-term impacts of DAB will indeed be greater than might have been expected only a few short years ago.

\section{REFERENCES}

Anderson, John Nathan (2013): Radio's Digital Dilemma: Broadcasting in the Twenty-First Century, New York and London: Routledge.

Bower A.J. (1998): “Digital Radio - The Eureka 147 DAB System.” In: Electronic Engineering Magazine April 1998, pp. 55-56. (http://downloads.bbc.co.uk/rd/ pubs/reports/1998-10.pdf).

Clark, Marguerite (1996): “Eureka 147 Continues to Spread.” In: Radio World Magazine 10th July 1996 , p. 1.

Coinchon (2010): "Open Software Defined Radio" (Technical Presentation). (https://tech.ebu.ch/events/webinar_opensoftware-definedradio).

Community Media Association (2014): “Response to Ofcom's Small-Scale DAB Trial Consultation (October-December 2014)". (https://www.ofcom.org.uk/_data/assets/pdf_file/0024/74382/community_media_association.pdf).

Crawford, Adam J. (2013): "Profiting from the Hype Cycle." (https://www.caseyresearch.com/articles/profiting-hype-cycle)

Deighton, John/ Kornfeld, Leora (2013): “Amazon, Apple, Facebook, and Google.” Harvard Business School Case 513-060, January 2013. (Revised December 2013.) (http://www.hbs.edu/faculty/ Pages/item.aspx?num=43983). 
DCMS (2010): Digital Radio Action Plan (v1.0). London: Department for Culture Media and Sport.

DCMS (2017): Broadcasting (Radio Multiplex Services) Bill - Explanatory Notes. (https://www.publications.parliament.uk/pa/bills/cbill/2016-2017/0028/ en/17028en.pdf).

EBU (2014): “Digital Radio Toolkit. Key Factors In The Deployment Of Digital Radio.” (https://www.ebu.ch/files/live/sites/ebu/files /Publications/EBU-MIS_ Digital-Radio-Toolkit.pdf)

Eureka (1997): “Eureka-147 - Digital Audio Broadcasting.” (http://www.teilar.gr/ dbData/ProfAnn/profann-1a29fba4.pdf).

Fenn, Jackie/Raskino, Mark (2008): Mastering the Hype Cycle: How to Choose the Right Innovation at the Right Time, Boston: Harvard Business Press.

Gartner Consulting (2017): "Research Methodologies - Gartner Hype Cycle." (http://www.gartner.com/technology/research/ methodologies/hype-cycle.jsp)

Goddard, Grant (2010): DAB Digital Radio Licensed to Fail, London: Radio Books.

Herrmann, Frank/ Erismann Larissa Anna/Prosch, Marcus (2007): “The Evolution of DAB.” In: EBU Technical Review, July 2007 (https://tech.ebu.ch/docs/ techreview/trev_311-dab_dmb.pdf).

HMSO (2004): “Community Radio Order, 2004 (No. 1944) (As Amended).” (http:// www.globalmediapolicy.net/sites/default/files/uksi_20041944_en.pdf).

House of Lords (2017): "Broadcasting (Radio Multiplex Services) Bill (o6th February 2017)". Available on-line at: https://www.publications.parliament.uk /pa/ bills/lbill/2016-2017/0099/17099.pdf).

Kozamernik, Franc (1995): "Digital Audio Broadcasting - Radio Now and for the Future.” EBU Technical Review, Autumn 1995, pp. 2-27. (https://tech.ebu.ch/ docs/techreview/trev_265-kozamernik.pdf).

Lax, Stephen (2003): “The Prospects for Digital Radio Policy and Technology for a New Broadcasting System.” In: Information, Communication \& Society, 6/3, pp. 326-349.

Mustapha, Rashid (2013): "Small Scale DAB. The Potential for Lower-Cost Transmitting Stations in Support of DAB Rollout," (Ofcom Research Document). (https://www.ofcom.org.uk/__data/assets/pdf_file/oo24/ 44808/softwaredab-research.pdf).

NRK (2017): "Radioen Det Første Massemedium [Radio - The First Mass Medium]”. (https://www.nrk.no/organisasjon/radioen---det-forste-massemedium$1.6512029)$.

Ofcom (2010): “The Communications Market: Digital Radio Report (Ofcom's First Annual Digital Progress Report).” (https:// www.ofcom.org.uk/__data/assets/ pdf_file/0020/63191/report210710.pdf).

Ofcom (2012): “DAB Coverage Planning: Report To Government.” (https://www. ofcom.org.uk/__data/assets/pdf_file/0020/3719o/dab_statement.pdf). 
Ofcom (2016a): The Communications Market: Digital Radio Report (Ofcom's Seventh Annual Digital Progress Report). ( https:// www.ofcom.org.uk/__data/ assets/pdf_file/o032/94838/The-Communications-Market-Digital-Radio-Report-2016.pdf).

Ofcom (2016b): “Small Scale DAB Trials - Final Report (26th September 2016)". (https://www.ofcom.org.uk/__data/assets/pdf_file/o021/91371/SSDAB-Finalreport-26-Sep.pdf).

Ofcom (2016c): “The Communications Market 2016: Radio \& Audio." (https:// www.ofcom.org.uk/__data/assets/pdf_file/ooo9/21411/uk_radio.pdf).

OLON (2002): Eureka! Een Oplossing Voor Digitale Kleinschalige Radio, Nijmegen: OLON.

O’Neill, Brian (2009): “DAB Eureka-147: A European Vision for Digital Radio.” In: New Media \& Society 11/1-2, pp. 261-278.

O’Neill, Brian (Editor) (2010): Digital Radio in Europe - Technologies, Industries and Cultures, Bristol: Intellect.

Ray, Bill (2013): “Bloke In Shed Starts Own DAB Radio Station - With Ofcom's Blessing.” (https://www.theregister.co.uk/2013/o8/06/open_source_hacks_ dab_to_the_masses/).

Robjohns, Hugh (2009): “Sounding Off: Is DAB A Disaster?” (http://www.soundonsound.com/people/sounding-dab-disaster)

Sabel, Les (2013): "Overview of the DAB+ System." (https:// www.worlddab.org/ public_document/file/442/DAB__Overview_2013.pdf?1394188480).

Schofield, Jack (2006): "DAB Should Be The New Wave, Not Medium Wave." In: The Guardian 26 October 2006 (https://www.theguardian.com/technology/2006/oct/26/comment.comment).

Spikofski, Gerhard/Klar, Siegfried (2003): “DAB and CD Quality - Reality or Illusion?"In: EBU Technical Review, October 2003. (https://tech.ebu.ch/docs/ techreview/trev_296-dab.pdf).

Sveriges Radio (2008): “Om Sveriges Radio [About Swedish Radio]”. (http:// sverigesradio.se/sida/artikel.aspx?programid=3113\&artikel=1971599)..

Withero, David M. L. / Lavern, Philip A. (1995): “Digital Audio Broadcasting - The Future of Radio." Paper presented at the IBC International Broadcasting Convention, 1995 (http://ieeexplore.ieee.org/document/ 475385/). 


\section{Opening up the Debate: Irish Radio, Facebook, and the Creation of Transnational Cultural Public Spheres}

Daithí McMahon

\section{INTRODUCTION}

As the world's mass media become more digitised and globally integrated, radio's spontaneity, flexibility, and adaptability render it uniquely capable of embracing this change. Over the past decade radio has adopted new technologies and taken advantage of the opportunities presented by social media platforms. Professionals in the field have recognised the changes in audience preferences and consumption habits, and have expanded radio's remit into a multimedia product with bespoke entertainment and culturally relevant content to suit their audience.

This case study of the independently owned and operated Irish commercial radio station Radio Kerry will illustrate how a station broadcasting to a rural audience with a unique cultural identity, and a large diaspora, has used its Facebook page as a meeting point and forum for cultural discussion and debate. The case study highlights the importance of radio to an overseas audience as a source of information and a connection to home. The study aims to demonstrate that Radio Kerry has an active audience listening and engaging online from abroad and that the station is keen to maintain connections with this audience. The research methodology for the study involves data drawn from multiple methods including: interviews with Radio Kerry management and production staff $(\mathrm{N}=5)^{1}$; an in-depth interview with an expatriate originally from Kerry but now living in the United States $(\mathrm{N}=1)$; an audience survey of

1 Interviews were conducted with the station's General Manager, the News \& Current Affairs Editor, The Sales \& Marketing Manager, the Terrace Talk Producer and the Terrace Talk Presenter. 
respondents $(\mathrm{N}=54)^{2}$; and textual analysis of the station's Facebook page over a two-week period, from July 1-15, 2016. Using this methodology, the author presents a case study of how Irish radio stations are using Facebook to connect with people locally, nationally, and transnationally.

\section{Importance of Social Media}

The radio audience is much different today than it was a decade ago. What were once loosely connected groups of listeners, are now much tighter networked publics (boyd 2010) actively embracing convergence culture and spreadable media (Jenkins 2006, Jenkins et al. 2013). The emergence and prevalence of social media and the resulting impact on radio production and audience engagement is therefore a growing area of interest to researchers.

With the audience's time and attention increasingly difficult to gain and maintain, this has placed growing pressure on radio stations to compete. Since 2008 , the Irish radio industry has been adopting numerous social network sites (SNSs) and looking at ways in which this once-perceived threat could be turned into an opportunity. To date, it has been Facebook and Twitter which have integrated best with radio programming in Europe (Bonini 2014), although youth stations employ a wider number of social media platforms. Radio Kerry claims to have looked at strategic ways in which staff can use Facebook and Twitter to expand the station's product without taking anything away from the quality and primacy of the on-air output. The proclaimed key for Radio Kerry is engagement with the audience, aiming to offer the listener/online user content that piques their interest and encourages them to consume Radio Kerry's content either on-air or online. This commercial aim of Facebook use by radio stations in Ireland has been driven by the outlets' strategic aims to grow and develop their commercial potential. This strategy has, for instance, been realised by another Irish radio station, Beat 102-103, which has successfully managed to commodify its largely Millennial Facebook audience and offer them to sponsors as part of wider sponsorship and/or advertising packages (McMahon 2016).

One of the important prospects that Facebook offers users is the visual and multimedia elements which remove, to a degree, the medium's longstanding characteristic of 'blindness' (Crisell 1994). Secondly, Facebook also has the advantage of having established networks of connected individuals who can share information around the world quickly and without much cost or effort.

2 The survey was conducted by the author online using Survey Monkey. It was advertised and distributed via Facebook posts on the Radio Kerry Facebook page. There were 14 questions on the themes public spheres and community. Respondents were asked to rate their responses on a five-point scale and provide written elaboration if desired. 
However, Radio Kerry representatives agree that redistributing on-air content via this tool alone is not sufficient to engage and grow a loyal audience. A radio station must understand who its listeners are - their expectations, likes and dislikes, where they spend their time and to what they lend their attention. The latter refers increasingly to SNSs, which, due to connectivity through mobile apps, means users are potentially always reachable. Radio Kerry producers have stressed that they have learned that in order to engage digital audiences, a station needs to use Facebook strategically to hook the audience's interest and maintain their attention. As this case study argues, an effective way to capture and hold the audience is for a station to generate communication from and between users, thus further connecting users with each other, with the station, and with Kerry and its culture.

\section{Radio KerRy and its Audience}

Radio Kerry is a full service commercial radio station broadcasting to a largely rural audience in the south west of Ireland. The station has weekly listenership reach of 83,000 , a figure which represents $70 \%$ of the available listeners aged $15+$. The station also holds a $53 \%$ market share in the county with the rest of listeners tuning in to the regional and national stations (Ipsos/MRBI 2017). The official Radio Kerry Facebook page had just over 74,300 Facebook 'Likes' as of March $1^{\text {st }}, 2018$. According to management, one of the main reasons for Radio Kerry's success as a local radio station is an understanding of the audience which enables the production team to deliver what listeners want. Specifically, this relates to content in the form of local Kerry news, current affairs, sport, entertainment and culture. Such local programming cannot be offered by the national public service stations at the same level of quality and therefore Radio Kerry is able to offer a highly bespoke product to a niche audience. Staff at Radio Kerry believe that Kerry people are very proud of their cultural background and heritage, and producers use this to tailor specific on-air programming and online content to match the audience's tastes. In the words of McLuhan, Radio Kerry beats the tribal drum, and this drum beat resonates with the Kerry tribespeople (McLuhan 1994).

Along with having a strong connection to the land for tourism and agriculture, sport forms a significant part of the cultural heritage and identity of Kerry people. The Kerry men's senior football team are the undisputed champions of Gaelic football in Ireland. As with sport in general, Gaelic football is a highly emotive topic for Kerry people with almost all people taking an interest to some degree. Radio Kerry management and production staff understand and appreciate how much the listeners follow sport as a central aspect of the local culture. Sporting content is therefore extremely popular and the evening sports 
programme, Terrace Talk, and the Weekend Sport show both rival the flagship news and current affairs programme Kerry Today in terms of ratings and audience engagement. The strong listenership figures coupled with consistent audience participation via text, phone and email, as well as the high levels of online engagement through Facebook, are further evidence that the Kerry audience is keen to follow the in-depth discussion, analysis, and debate on all sports.

Ireland as a nation has experienced high levels of emigration for centuries with ebbs and flows dependent on economic conditions both home and abroad. As a rural county inherently lacking a strong economic base, Kerry has been particularly exposed to such changes in employment and opportunity during the recent economic recession (2008-2016). Regardless of where the Irish diaspora go, the people always maintain a strong sense of pride and an affinity to family, friends, and the cultures and traditions that they left behind. In this study, survey respondents identified Facebook as an easy and useful tool to keep in touch with family, friends and associates at home, or indeed in other parts of the world. Furthermore, survey respondents stated that they turn to Radio Kerry and its Facebook page, whether living in Kerry or elsewhere, as a source of information, entertainment, and cultural conversation. One respondent stated their reason for following Radio Kerry on Facebook was, "to know what's going on in Kerry" (respondent \#4). Another respondent wrote about the Radio Kerry Facebook page, "Living abroad, it makes me feel more in touch with the goings-on at home" (respondent \#1). The data suggests that current information and general knowledge are key factors in developing identity and association with place - that the more they know about Kerry, the closer they feel to home and the people.

The interviewee for this study ('CK') identified his reasons for tuning in to Radio Kerry from abroad was to connect with home and maintain his Kerry identity. CK emigrated to the Boston area in the 1950s when employment and opportunity were scarce in Ireland. For CK, living far from home is made easier by having a reliable and consistent source of Kerry-centric information and entertainment available to him. CK believes that if he did not have the information that Radio Kerry offers, Kerry would seem more distant from him. Speaking of Radio Kerry, he stated, “It keeps me up to date all the time, I wouldn't know how to go without [...] it makes me feel a lot closer to home, I know what's going on and I know everything that happens in Kerry is at my fingertips [...] Radio Kerry is on here 24 hours a day". As a result, CK finds "it's like living there actually [...] It makes you feel like you're a part of Kerry". Feeling part of Kerry and its immediate community is important to maintaining his identity and for him, this is achieved by being involved in conversations on Kerry football. CK's testimony highlights trusted and culturally relevant information from 'home' as being central to what the Kerry diaspora yearn for and what Radio Kerry provide through their on-air output and online platforms such as Facebook. 
Users recognise that they are sharing a communal space with others with similar interests and tastes. "Even though it's all online", one respondent said, "I feel part of the global community based around the station and the locality" (respondent \#7). This respondent's sentiments of being part of a community of Kerry people that are dispersed throughout the world but share common connections, are reminiscent of Benedict Anderson's 'imagined communities' (1991). The sense of being in touch with home through the quality of information is where Radio Kerry maintains connections with its transnational audience. Even though the members of the diaspora are not a directly saleable commodity to advertisers, station management and production staff nonetheless consider the overseas audience just as valuable and an important part of the 'family'.

\section{Production Strategies}

The focal point of sport on Radio Kerry is the highly popular, multi-awardwinning sports program, Terrace Talk, hosted by the equally popular Weeshie Fogarty. Fogarty identifies his connection with his audience as the key to his programme's success. He claims to understand the power of sport, most importantly Gaelic football, and the way it draws Kerry people together to share their passion. Consequently, the audience have high expectations from media reporting on the subject. Fogarty regularly receives emails from listeners around the world including North America, the UK, Australia, the Middle East and beyond. By reading these comments and requests out on-air, he strives to make expatriates part of the listening Kerry community. Fogarty describes Terrace Talk as "the listeners' show", and he is careful to treat audience members living in far off lands with just as much, and often more, care and attention as those living locally. Fogarty regularly takes trips abroad to meet with members of the Kerry diaspora and collect their stories, and the resounding sentiment is that Radio Kerry is "their connection to home". According to Fogarty, radio brings Kerry culture into their home, and many of them rely on Terrace Talk to know what is going on at home in sport. On his travels he has found that Gaelic football is a focal point of the expat community that draws people together in their adopted home.

For Fogarty and his programme producer, social media supports on-air broadcasting. It provides wider content which expands upon what is on-air and provides another channel by which Radio Kerry can communicate with its audience. The strongest reaction from Radio Kerry's online audience was to content posted to Facebook that affected the user emotionally. Such Facebook posts garner 'likes', 'comments' and, most importantly, 'shares' with other users in their social network. According to the Terrace Talk team, having emotional impact is effective especially when addressing expatriates as it helps to connect 
the transnational audience with home, and over time this helps maintain an affinity with the radio station.

\section{Cultural Public Sphere}

The Radio Kerry Facebook page has emerged as a portal which acts as a mutual meeting point for Kerry people. This has been verified by analysis of the Facebook page and the comments made by users in which they reveal their current location, often during live Gaelic football matches. Due to the ephemeral nature of social network sites, it is important from a production point of view to be always sharing something new. Therefore, producers need to refresh the content constantly.

One theory which can explain what is occurring on the Radio Kerry Facebook page is McGuigan's cultural public sphere theory (2005). McGuigan introduces the concept of the cultural public sphere, defining it as a place where users interact on emotional issues as opposed to political or economic matters of Habermasian public spheres (Habermas 1989). A key element of the cultural public sphere, which distinguishes it from the Habermasian public sphere, is the presence of 'affective communication' as well as 'cognitive communication'. According to McGuigan, "the cultural public sphere provides vehicles for thought and feeling, for imagination and disputatious argument, which are not necessarily of inherent merit but may be of some consequence" (McGuigan 2005: 435). In this instance, we are considering discussions around sport which in the eyes of some is a trivial matter. However, for those involved the topic is of enormous consequence due to the place sport holds in their lives. When users come to the Radio Kerry Facebook page they engage in debates, discussions and sometimes arguments regarding issues that are of importance to them. Due to the emotional involvement users have with sport, their contributions involve affective communication. It is evident from the comments and discourse on the Radio Kerry Facebook page that users are using both affective and cognitive communication. 


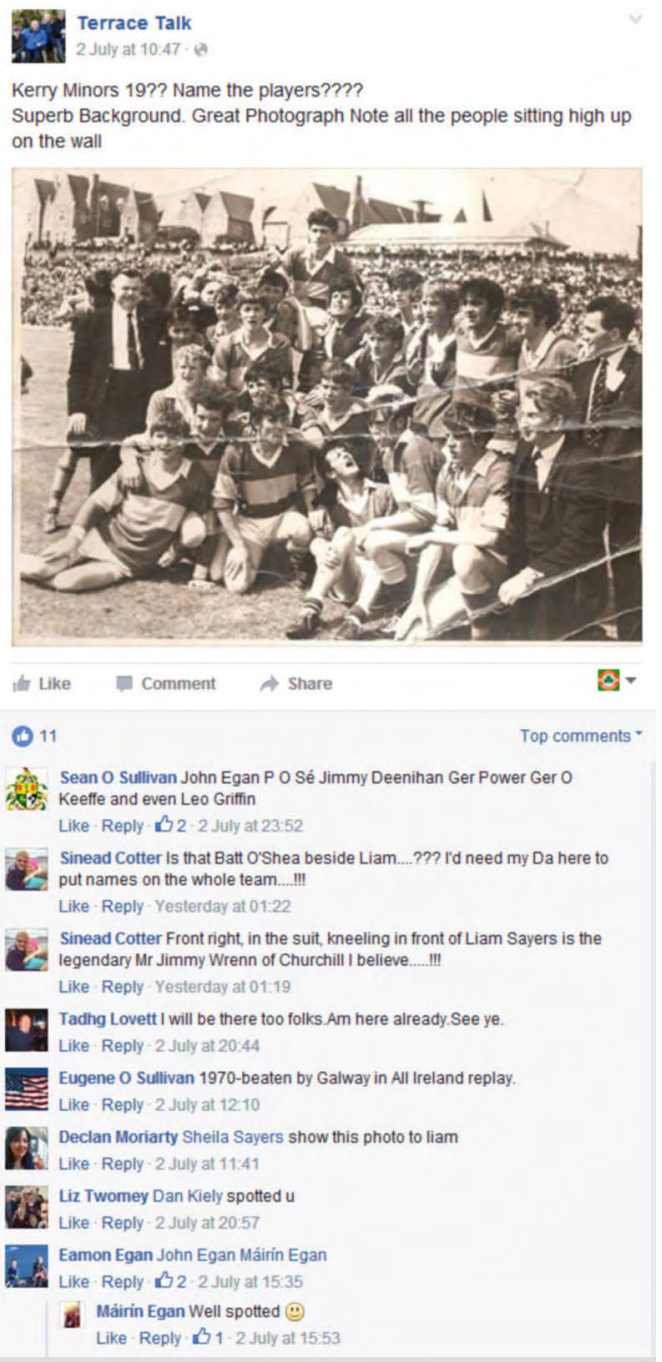

Figure 1: Example of cultural public sphere on Terrace Talk Facebook page.

The above (Fig. 1) is an example of content that engages audience members in cultural discussion and debate which was posted on the Terrace Talk Facebook page and subsequently linked through to the Radio Kerry Facebook page. The programme presenter posted a photograph from his own archives of a Kerry Minor Football team and instigated discussion by asking the audience to try to identify the year, and name as many individuals in the photograph as possible. As the comments section below the post show, a number of people were engaged by the challenge and offered their suggestions. The post was shared, 
by means of 'tagging', with four other individuals who became involved in the discussion. This screen shot was taken the day the post was published on July 2, 2016 with people contributing and interacting through comments or reply until July 12th, meaning the post had a life of ten days. During that period of time there were eighteen comments made, including replies, involving eleven individuals (four of whom were tagged), all contributing to a worthy conversation testing the audience's knowledge of Kerry football. In terms of emoji reactions, a further fifteen people 'liked' the post, one person 'loved' it and one person shared the post on their own timeline meaning a total of 28 individual Facebook users were involved in the discussion. Although the numbers of individuals involved in the discussion is relatively small considering the number of followers of the Radio Kerry Facebook page, it is but one of many examples of the 'micro-cultural public spheres' that are created and engaged with over the course of a year. Such content appeals to the audience's love of football, tests their historical knowledge and generates feelings of nostalgia. Here nostalgia proves to be a powerful emotive tool that engages the audience. It can relate to a yearning for the past or, for those living abroad, can also create a yearning for home. In the above case, it achieves both.

\section{CONCLUSION}

Despite emigrating abroad, the interviewee and a number of survey respondents involved in this research project identified that they maintain contact with their culture and heritage, stay informed of current events, network with friends and relatives, and reaffirm their Irish identity through cultural reinforcements. Facebook is a good example of a platform that helps the Kerry diaspora maintain connections with home, and emotional engagement through nostalgia is a highly effective method of maintaining an audience despite geographical distances. The Radio Kerry Facebook page acts as a site of discussion and debate around topics of interest to the audience. The dynamism, liveness, and spontaneity of radio makes it well-suited to Facebook and other social media, and is one of the main reasons the two platforms, radio and Facebook, run so closely alongside one another. The integration of Facebook into Radio Kerry's production remit has allowed it to further engage audiences beyond audio broadcasting and made the station's product a multimedia experience. For expatriated Kerry men and women Radio Kerry's Facebook page allows them to keep up with current affairs in Kerry while engaging with other members of their cultural community. The Radio Kerry Facebook page has thus become a form of transnational cultural public sphere where carefully curated content is used to attract and engage audiences. 


\section{REFERENCES}

Anderson, B. (1981): Imagined Communities: Reflections on the Origins and Spread of Nationalism, London: Verso.

Bonini, T. (2014): "Networked Self: Identity, Community, and Culture on Social Network Sites.” In: T. Bonini/B. Monclús (eds.), Radio Audiences and Participation in the Age of the Network Society, London: Routledge.

Crisell, A. (1994): Understanding Radio (2 ${ }^{\text {nd }}$ Ed.), London: Routledge.

boyd, d. (2010). "Social Network Sites as Networked Publics: Affordances, Dynamics, and Implications.” In: Z. Papacharissi (ed.), Networked Self: Identity, Community, and Culture on Social Network Sites, Oxon: Routledge.

Habermas, J. (1989): The Structural Transformation of the Public Sphere, Cambridge: Polity Press.

Ipsos/MRBI (2017): Joint National Listenership/Readership Survey, Dublin: Ipsos/MRBI.

Jenkins, H. (2006): Convergence Culture: Where Old and New Media Collide, New York and London: New York University Press.

Jenkins, H./Ford, S./Green, J. (2013): Creating Value and Meaning in a Networked Culture, New York: New York University Press.

McGuigan, J. (2005): “The Cultural Public Sphere.” In: European Journal of Cultural Studies, 8/4, pp. 427-443.

McLuhan, M. (1994): Understanding Media: The Extensions of Man, London: Routledge. McMahon, D. (2016): "With a Little Help From My Friends: The Irish Radio Industry's Strategic Appropriation of Social Network Sites for Commercial Growth.” In: Analyzing the Strategic Role of Social Networking in Firm Growth and Productivity, Hershey PA: IGI Global. 



\section{New Radio and Social Media: Public Service Radio Forms of User Participation AND INCLUSION}

Per Jauert

\section{INTRODUCTION}

One of the most prominent phrases one finds in strategic public service broadcasting (PSB) documents from the late 1990's and early 2000's was that PSB has to be 'present on all platforms.' Visions and initiatives for cross-media and cross-platform engagement were numerous in the early days of the transformation from public service broadcasting to public service media (PSM). (EBU 2002, Nissen 2006) From the perspective of PSB institutions, cross-media engagement opened up for new integrated production procedures, for recycling of program content, and inclusion of external producers, among many other things. From an audience perspective, the broadcasting aspect was supplemented with different types of 'on demand' features, facilitated by streaming and podcasting from the PSM web site.

Another major buzzword in the early days of the PSM roll-out was 'user generated content', which covered a variety of applications including news production, audience/user forums, blogging, and chat rooms etc. - all due to the development of digital media technology. These new interaction affordances are embedded in the traditional European version of PSB obligations: stimulating and facilitating public debate through public participation in, or access to, broadcasting. (McNair and Hibberd 2003) The notion of 'user generated content' carries with it the former key aspect of democratization through media, but it also points to a wider range of user or audience involvement, not only related to traditional political issues, but more dominantly to popular phenomena. Recent developments within this 'democratic turn' in PSM products are especially taking place within social media - in the Scandinavian countries especially through Facebook. In recent years you can observe a doubling of the official PSM websites on the program level with an open access FB profile, and 
for some program genres the Facebook program site seems to have more traffic and user interaction than the 'official' one. (DR 2013-2016)

It can be argued that this transformation of the public service remit, which was to a large extent initiated by the European Broadcasting Union (EBU), represents a contemporary form of transnational radio, not defined by program content or radio programs distributed across national borders, but instead by mutual inspiration and adaptation of program genres, distribution on different platforms - and audience involvement.

The aim and goal of this chapter is to shed light on some of the core elements in the process of transformation from PSB to PSM from two perspectives. First, what consequences did this turn have for radio as 'medium of everyday life' as it often is called in scholarly literature. Second: which PSM strategies have been developed in the Scandinavian countries in order to 'meet the audiences where they are', i.e. on different platforms (social media, program web sites etc.), and include them in the programs. Third: a short presentation of an audience study (2013-2015) of Mads og Monopolet (Mads and the Monopoly), one the most popular radio shows at DR - The Danish Broadcasting Company - for over more than a decade illustrating some of the impacts on radio as a medium, distributed on different technological platforms.

\section{The Use of Radio: Everyday Media Practices}

In scholarly literature, radio is often described as 'the medium of everyday life', based on its dominating functions as background or companion for household routines - you are listening, but not always 'listening in'. Radio is often part of the background, hardly ever becoming the focus of attention, but instead remaining part of the place or the situation. Radio listening in this sense is a secondary activity. (Åberg 1999: 77) But it can also be a very personal, almost intimate medium because of its personal way of addressing the listener (ibid). In his phenomenologically approach to radio and everyday life, Paddy Scannell emphasizes the incorporation of radio in the time schedules of everyday life, and thus considers radio as "a here and now medium", giving programs an aura of "liveness" that is perceived by the listener, even though it may not be a live program (Scannell 2005: 134). Furthermore, Scannell claims that the relationship between the audience and the radio throughout the day and over the week is in fact a real-time experience, particularly when talk is part of the program, and when the host addresses the audience directly. Thus, Scannell calls radio "the universal, communicative medium of everyday life" (1996: 23). The listener-radio relationship is individually anchored, but simultaneously the listener experiences being part of a larger community, imaginarily connected 
to other listeners though the core quality of radio as a broadcast medium: its communicative ethos (Scannell 1996:23).

However, has radio in its digital forms, digital radio and web radio, affected the specific characteristics that Scannell posits: its 'here and now"' presence, its ability to evoke the feeling of being part of the listening community, the 'sociability' of radio broadcasting? Does the presence of radio on different platforms - analogue and digital - mean that this special quality of radio listening is lost when the listeners can download the programs as podcasts: radio on demand, independent of time and place? This core question will examined further in the audience study presented in the final part of this chapter.

In many ways, phenomenologically framed radio research and the theory about the domestication of media are cognates. Domestication theory was originally introduced by British media researchers, first and foremost Roger Silverstone, who over the years was part of several research teams that studied the role of media in everyday life (e.g. Silverstone and Hirsch 1992). The notion of domestication is a metaphor, expressing the 'taming' of wild or the unmanageable (animals or technologies) and incorporation into the household. Inspired by ethnographic methods (participant observation, field studies, interviews) domestication research explores the correlation between media and technology in a context situated in the routines of everyday life, and the embedding of media in social and communicative patterns. Thus, it distances itself from the media text-centered exploration of media content and audience use.

The idea of the passive media consumer is replaced in this research tradition by empirically-based studies of active media and technology users, and their interaction with media in everyday life, not only in the household (the family), but also in the interaction with the outer world. With the expansion of new digital media types, not least the internet, it is increasingly difficult to sustain the previously clearer distinction between work and leisure time, and between the private and public domains. On the one hand, media are physical artefacts, which can be handled in different ways, like the mobile phone serving as a platform for sound, visual and print media. On the other hand, they can be considered as immaterial elements, embedded in different parts of the social exchanges in everyday life, as happens through the so-called social media such as Facebook, Twitter, and Instagram.

\section{Radio on Different Platforms - Institutional Strategies, Audience Reactions and User Patterns}

Since the mid-1990s, the Nordic public service institutions have engaged in developing digital strategies for radio and television broadcasting as a consequence of the intensified competition with the growing national and interna- 
tional commercial broadcasting companies after the break-up of the public monopolies during the 1980 .

\section{The PSB/PSM Challenge}

The public service broadcasters were confronted with two major challenges. Above all, they had to secure a central role in the establishment of a terrestrial digital radio and television transmission system, and furthermore they had to restructure and develop the institutions in order to be able to offer content at 'all relevant platforms.' This meant not only redistributing the radio and television programs they already produced, but also came to mean an expansion of content production. (Søndergaard 2008: 45) The strategy had to secure the historically-based, core mission of PSB: the universality of the services, or, in other words, accessibility for all citizens in the country. But as a consequence of the new technological affordances and the fragmentation of audiences, the new digital distribution platforms were established also to serve small target groups (audience segments) and offer different, individualized services, such as podcasting and streaming. (ibid.)

The transformation process from PSB to PSM has in reality called for a redefinition of the public service remit, most prominently addressed in the 2007 volume of the RIPE book series. (Lowe / Bardoel 2007) One of the key challenges for the PSM institutions - and for the public service research agenda - has been to determine the demarcation lines to the commercial broadcasting sector, after the public service media entered the market plac.e (Nissen 2005; Nissen 2006; Hujanen/Weibull/Harrie 2013; Lund/Lowe 2013) On the basis of the report to the Council of Europe on Public Service Media in the Information Society (Nissen 2006), Karol Jakubowicz took up the task of redefining the public service remit in the PSM era on background of three major challenges:

- In general, the mainstream, market-based media are not meeting individual needs. The public service remit is then to serve the individual citizen, providing content and services to small groups with specific needs.

- The impact of internationalization and globalization processes have called for a defense of national culture as well as cultural diversity as part of the democratic process within the nation state. The public service remit here is to produce and distribute content distinctive from commercial providers and services for large audiences.

- The fragmentation and individualization processes in society call for enhancing social, political and cultural cohesion. It means a wide reach of PSM: the service has to be used regularly. (Jakubowicz 2007:39) 
How do we place Denmark, Norway, and Sweden in relation to these three regulatory-based definitions of the PSB/PSM remit? Sweden is in a special position since the body of laws on radio and television, based on the charter between the people of Sweden and the government on public service radio and television from 1956, simply states in what areas SVT (Swedish Television) and SR (Swedish Radio) is to deliver programming, but not how - i.e. on which distribution platforms (Moe \& Mjøs 2013: 83). The 2013 charter, running until 2019 (in Swedish: "Sändningstillstånd") simply states that SR has to broadcast four nationwide radio channels, one of these divided into regional services, for the whole country. Furthermore, SR has a complementary possibility to distribute digital radio. But other distribution platforms - particularly web radio and Internet services - are not mentioned.

In Denmark, DR's task is defined in the Danish Radio and Television Broadcasting Act. Its $\llbracket 10$ states that “[...] the public service activities in total through television, radio, the Internet or the like must ensure the Danish inhabitants access to a wide range of programs and services within news, enlightenment, education, art and entertainment. The services must strive for quality, versatility, and diversity."

According to Moe's categorization, it seems that the Swedish body of law circumvents the problem of defining the PSB/PSM remit, leaving it to the broadcasters, while the Danish Radio and Television Act as quoted above is closer to the British solution by giving equal ranking to the 'old' broadcast media and the Internet - and whatever may come: "and the like."

In Norway the tasks of the main national radio and television broadcaster NRK are stipulated in The Act of Broadcasting and Audiovisual Subscription Services, and the distribution options are not defined as 'radio', 'television' or 'the Internet', but instead called 'electronic communication networks,' opening up for supplementary distribution and communicative options, in a similar way to the Danish phrase 'broadcast media and the like.'

\section{Digital Radio Strategies - DR, NRK, SR}

The transformation process from PSB to PSM has reinforced the political debate about public service remits, and especially the PSM expansion on the Internet has led to regulatory interventions in many European countries. This has been influenced by supra-national media regulation within the EU, but mainly by commercial competitors, who have argued for the implementation of public value tests of new PSM initiatives, and furthermore for restrictions on the content and character of PSM websites in order to restrain unfair competition.

The overall digital radio strategies in the three Scandinavian countries seems quite homogeneous, taken from the legal provisions and the official policy papers, but under the surface once can detect differences in journalistic 
and editorial guidelines, in areas of special importance, and not least in the way program genres are organized.

In Denmark the overall public service remit is stated in $\int \mathbb{\int} 10$ and 12 in the Danish Radio and Television Broadcasting Act, as well as in DR's annual Public Service Contract with the Danish state on the basis of the present Media Agreement, which normally runs for four years. In the 2013-2014 contract DR activities on the Internet are ranked alongside radio and television: "DR must secure a varied supply of programs and services to the entire population via TV, radio, Internet and other relevant platforms." (DR 2013-2014: 2) This explicit platform neutrality and the term "other relevant platforms" points again to the inspiration from the BBC Charter. In Norway the public service remit rests in the NRK-Plakaten (Norwegian Broadcasting Corporation: Statement of Commitments) which is part of the NRK Regulation, chapter 2. The remit for NRK radio and television is listed in the second paragraph, describing the NRK remit (』13), while NRK Internet activities are described in paragraph 24: "The Corporation should be present, and develop new services, on all important media platforms so as to achieve the broadest possible reach for its overall program services." Obviously, the Internet and "similar" platforms are considered "an extension of broadcasting," as described by Moe (2010: 5).

As stated previously, SR's digital activities are not mentioned in the legal foundations, not even in the recent charter. Nevertheless, sr.se does not differ substantially in its content from nrk.no or dr.dk. On the whole, every radio program has its own site with basic information, download or streaming options of previous programs, and some will have references or links to the program's Facebook, Instagram or other websites.

\section{Social Media: A Disputed Aspect of Digital Strategies}

Since Facebook became a rapidly growing phenomenon in Europe around 2005 , DR, NRK and SR have supplemented their program web sites with Facebook sites and later included references to other social media such as Twitter and Instagram. As Moe points out, the Scandinavian broadcasters' engagement with primarily Facebook was initiated by enthusiastic journalists and producers trying out the new possibilities for engaging with the public, motivated by an ambition to reach new (younger) audiences with Facebook's sharing facility, and to develop new kinds of journalistic practices (Moe 2013: 117), similar to the development of web services in the mid-1990s (Brügger 2012). With the rapid growth of Facebook over the years it soon became more legitimate - at least seen from the broadcaster's perspective - to systematize and increase Facebook engagement. "You have to be present where the users are" was the general statement from the broadcasting institutions. This initial enthusiasm and more or less anarchistic expansion on Facebook was replaced little by little 
by a less ambitious and more organized practice. The regulatory bodies as well as commercial actors in the media landscape questioned the legal basis for a public broadcaster to publish publicly funded media content within the domain of a multinational, commercial company, which cannot be regulated either by the broadcasters or the national media regulators. (Moe 2013: 119) In his 2011 report, DR's internal ombudsman criticized DR's way of using Facebook. Since only half of the population have a Facebook account, and even fewer are active on Twitter and Instagram, then the other half is cut off from taking part in debates as well as from originally produced DR content (DR 2011). In 2013 internal guidelines for the use of social media were included in DR Ethics (DR's etik). Social media are considered as supplementary to DR's own channels, and not a replacement of dr.dk. (DR 2014) "The use of social media must not be similar to advertisements, i.e. through an unnecessary amount of references to Facebook or through praise of specific social media" (DR's Etik 2014: 49). Similar internal guidelines have occurred in Norway (NRK 2010: Sådann lager du en god facebookside for NRK--- retningslinjer og gode råd, Internal guidelines, 30 November, NRK; Oslo - cf. Moe 2013: 119 and 121), and in 2013 SR published Social Media. A Handbook for Journalists in 2013, produced by the Communications Department in SR (SR 2013 and 2017)

This short overview of the digital strategies of the Scandinavian public service radio companies illustrates the efforts made to rephrase the public service remit in light of the digital transformation of radio. The future of radio in a European context seems to be digital, given some specific conditions in each of the countries. (Jauert et al. 2017) This tendency is reflected in the ratings for radio listening in the Scandinavian countries. In Denmark the share of daily listening on digital platforms has increased slowly over the years. From 2012-2016 it has raised from 20 to $37 \%$ of the listening time (DR Medieudviklingen 2017: 16). In Norway listening on DAB radio has increased rapidly recent years. As a result, the Norwegian Parliament decided to shut down the FM band in December 2017 and replace it by DAB+, even though the percentage for a switch over to DAB+ had not reached $50 \%$. (Medietilsynet, Norge - Årsrapport 2017). In contrast to Denmark and Norway, Sweden has decided not to implement DAB or $\mathrm{DAB}+$ after an unsuccessful trial period in the beginning of the century and to rely instead on internet-based services for radio distribution. However, radio on different platforms and an increased use of social media as return channel and interactive options has been a constantly growing tendency for radio use during the last decade. 


\section{Mads og Monopole: Radio Talkshow: On Air, ON DEMAND (PODCAST) - AND ON FACEBOOK}

Through tracking use via PPM (People Portable Meter) or surveys, based on diaries/logs on daily listening, it is possible to conduct quantitative research about radio listening. Understanding user patterns, where the goal is to trace the relations between listening to a specific radio program independent of distribution platform, and the use of additional services (web sites, podcasting etc.) presents methodological challenges, however. To show how we might come to grips with this, the final part of this chapter will describe the research design of a qualitative audience study from 2013-2015, and present some of the main findings.

The program Mads and the Monopoly was launched in September 2003, and has aired since then on every Saturday morning between 9 and 12, except for holiday seasons. DR $\mathrm{P}_{3}$ is a full service channel for the younger audience, 20-39 of age, with music, news, sport and entertainment. The program host through all the years has been Mads Steffensen, a very popular radio and television host on DR. The concept of the program was not changed, but in January 2016 it was moved to $\mathrm{P} 4$, a channel more in line with the audience composition. For many years it has been the most popular radio program in Denmark - peaking in 2017 with a weekly audience of 1.4 million. (Kantar Gallup 2017)

Basically, it is a 'problem page' program, where people can phone or write to the program and present an everyday, personal dilemma. Mads Steffensen will then select the ones to be aired, and then the person will participate directly in the program by phone or by e-mail. For dilemmas presented by e-mail the host will read aloud the mail. For direct participation the host will introduce the caller, and the caller will present the dilemma. Then the dilemma is discussed by a panel, known as 'the monopoly,' which consists of three persons, all celebrities - mainly from media: actors, stand-up comedians, musicians, authors, journalists etc. After the conclusion, the caller, who has to be silent during the discussion, will comment on the advice or solution, as summed up by Mads. The monopoly are recruited by Mads by himself, and out of a group of around 25 monopolists, they are selected in changeable combinations from program to program.

Even though Mads og Monopolet can be characterized as a 'problem page' program, it takes in elements from other genres as well, and as such it can be considered a genre hybrid. Since the problems presented are dilemmas from everyday life, mostly of a character you as a listener can identify with, many of them related to areas of intimacy, such as one dilemma on the Mads and the Monopoly Facebook profile from November 2013: 
I have a boyfriend that I love for sure, but he has been working abroad for a period of three months now, but will be back in two weeks. I have for some time been flirting with a colleague on the job, but now it seems to have developed into something more. A week ago I had sex with him after a dinner in town- and now I am in doubt. Shall I tell my boyfriend about it, or shall I wait and see what happens when my boyfriend is back?

This 'twist of reality' is often observed in the dilemmas, not always about sex, but also related to conflicts in the family, among friends - and some deal with social manners or how to behave. Some of them on the edge of the plausible, and quite a few among our respondents in the audience study point to that. Another core component in the program is talk: arguments, discussions and conversations - in a special, friendly, teasing and joking atmosphere, always kept on the right track by Mads.

The program concept avoids the extreme positions. You will never experience dilemmas dealing with health issues, social or psychological problems, violence in families or similar severe problems. The attitude from the monopolists towards the dilemmas may be cheerful, but never close to satire or mockery. Perhaps the most important element of the program is 'sociability' which is

the most fundamental characteristics of broadcasting's communicative ethos. The relationship between broadcasters and audiences is a purely social one, that lacks any specific content, aim or purpose. This, of course, is not to deny that a very great deal of broadcast output has content, aim and purpose. (Scannell 2006: 23)

This sociability is assisted by the activities on the Facebook site during the program. Listeners will comment on the dilemmas, ask questions to the panel or to Mads, and Mads will upload photos from the studio - sometime small videos, and on the DR program website one can participate in the nomination for the dilemma of the day and win a t-shirt. Approximately an hour after the show the podcast will be available for download at both the Facebook and the DR sites. It is without the music, making the length just one hour.

For the next few days one will still find comments and discussion threads on the Facebook profile, but the traffic declines rather fast, until the middle of the week, when Mads typically will post a follow-up on one or two of the dilemmas from recent shows, often the dilemma presenters themselves reporting on the decisions they have taken on basis of the recommendations from the monopolists. Thursday Mads will give another update about the upcoming show Saturday - and reveal the names of the monopolists. This update will always end with: "This is going to be fabulous!"

The main reason for choosing this program for the audience study is its constant popularity for more than ten years without any changes of the program concept. Furthermore, Mads og Monopolet is a 'segment crusher'. The 
designated listener to $\mathrm{P}_{3}$ is $20-39$ years old, but according to the Kantar Gallup Radio-Meter 2015, most of the audience for this program is $40+$, most of them leaving their preferred DR channel, mainly $\mathrm{P}_{1}$ (talk and culture) or $\mathrm{P}_{4}$ (regional, music, news and entertainment). The majority of the listeners are women: $53 \%$. All in all, we found that the program contains elements connected to some of the core qualities of 'traditional' radio and as such suitable for studying the connection between the program and the additional services offered on the web - dr.dk and Facebook.

\section{Research Design}

The study on Mads og Monopolet was conducted in cooperation between DR Media Research Unit (Peter Niegel) and Aarhus University (Per Jauert and research assistents Janne Nielsen (MA) and Signe Skou (MA)). The research design for our user study had three components: focus groups, followed by individual interviews with the participants, and finally each of the participants allowed us to track and store all traffic on their Facebook profile in a period of two months - one month before and one month after the focus group had taken place. This mapping and archiving was made possible by use of the web analytical tool Digital Footprints (https://digitalfootprints.dk/), which allows one to collect and analyze closed Facebook data with user consent.

The objective of the focus groups was to gather core listeners of Mads og Monopolet to discuss and evaluate the program and its qualities. The participants in the focus groups were recruited from the DR Panel, a collection of 3000 volunteers statistically representative for the Danish population. Since the program is a 'segment crusher' we aimed at gender balance, age spread and also different social backgrounds (education, occupation). All respondents should be active on social media, especially Facebook, and have knowledge of the program related sites. 20 participants were selected in the Copenhagen area, and 20 in Aarhus, where the focus groups were arranged in late spring and in mid-autumn 2013. The final selection of the six participants in each group took place after we had been able to follow the activity on their Facebook profiles during four weeks.

\section{Central Findings and Research Perspectives}

Taken from the focus groups, and confirmed by the individual interviews, it became quite clear that Mads og Monopolet carries traditional core qualities as a radio program, mainly related to its unique atmosphere, created by the conversational style among the people in the studio and the callers. The listeners can identify with many of the dilemmas, not least the most generally applicable, and this creates moments of seriousness. But it is balanced by the more unusu- 
al or odd dilemmas, which have clear and fascinating entertaining qualities, calling for reactions among our respondents like: "I am happy that this shit is not happening to me."

It is also a common view among our respondents that the monopolists are celebrities - it would not be the same, if they were 'ordinary people.' The monopolists with the most significant positions and rhetorical skills are the most popular. Even though our respondents had different rankings, they agreed on these qualities as vital for the program atmosphere. Another highly estimated celebrity quality was "honesty, clear arguments, no spineless positions," but also an ability to listen to arguments, and being able to "open up for personal experiences - to offer something of your personality". Finally, humor was important: "there must be some good jokes, some teasing and striking one liners."

All these qualities - and more - create the unique atmosphere for the core listeners: "No Saturday morning without Mads og Monopolet - it gives the feeling of Saturday morning." You do not have to sit down and listen carefully, you can do some cleaning or similar domestic activities, you can go shopping and listen to the program in your car - or you can bring it with you to the fitness center, listening on your smartphone, $\mathrm{P}_{3} / \mathrm{P}_{4}$ app etc. And if you have missed the outcome of one of the dilemmas, you can download the podcast soon after the live broadcast has ended. Mads og Monopolet carries core elements of 'sociability' through its unique atmosphere, which is not confined to the domestic space, but can be experienced anywhere and anytime, but for more of our respondents the "feeling of live" is important.

The core qualities of the program relate to what we could call 'the Facebook experience.' The blurring borderlines between the public and private have been aggravated since the introduction of social media. Some of the respondents note that the tendency to share everything, also the most intimate or private issues, on social media is reflected in programs like Mads og Monopolet - and in general on television, radio and on the Internet. Speaking of their own attitudes to Facebook use, all respondents stressed the need for privacy. Even though all respondents are core listeners, unfortunately none of them were active, participating users of either the program web site or the Facebook site. They were all using the download facilities, most of them would check the mid-week announcement of the next show, but only very few have 'dropped a comment' on Facebook.

The most striking observation in the focus groups and in the interviews as well was the respondent's fascination and engagement with the program flow during the week. Mads and Monopolet did not end Saturday at noon: its duration was extended through the podcast option and, not least, through the midweek announcement and the Facebook thread during the week. "The kettle is kept on the boil for the whole week", as one of the respondents remarked. 
Similar research in other European countries has pointed to this as a common tendency in radio being part of a cross media interaction, especially to give importance to all listener feedback on radio talk-shows, whichever platform it comes from: e-mail, phone call, SMS, Facebook, Twitter. (Bonini 2014: 83). The personalized and 'storified' content is another common denominator for the successful communication between the program hosts and the listeners (ibid.), similar to what our study of Mads og Monopolet observed. The 'sociability' of radio listening seems to have developed, refined and extended through the multiplatform options for ongoing engagement and inclusion.

\section{REFERENCES}

Åberg, C. (1999): The Sounds of Radio. On Radio as an Auditive Means of Communication, Stockholm University. (Phd. dissertation)

Bekendtgørelse om lov om radio og fjernsynsvirksomhed [The Danish Radio and Television Act]. https://www.retsinformation.dk/Forms/Ro710.aspx?id=161625; In English: Promulgation of the Radio and Television Broadcasting Act. https://english.slks.dk/fileadmin/user_upload/dokumenter/medier/radio_og_tv/Engelsk_ side/Promulgation_of_the_Radio_and_Television_Broadcasting_Act_2010.pdf

Bonini, T. (2014): “Doing Radio in the Age of Facebook”. In: The Radio Journal-International Studies in Broadcast \& Audio Media 12/1-2, pp. 73-87.

Brügger, N. (2012): “The Idea of Public Service in the Early History of DR Online,” In: M. Burns/N. Brügger, Histories of Public Service Broadcasters on the Web, New York: Peter Lang, pp. 91-104.

Digital Footprints, https://digitalfootprints.dk/ DR: Medieudviklingen [The Media Development] 2013-2016.

DR's Public Service kontrakt 2013-2014. [DR's Public Service Contract for 2013-2014] . http://www.kulturstyrelsen.dk/medier/tv/dr/public---service---kontrakt/

DRs Etik (2016): https://www.dr.dk/NR/rdonlyres/D8F466AE-9EFB-4617B8CD-5737425911FD/6139855/DRs_Etik_o6_o1_2016.pdf

EBU (2002): Media with aPurpose. Public Service Broadcasting in the Digital Era. A Report from the EBU Digital Strategy Group, https:/www.ebu.ch/CMSimages/ en/DSG_final_report_E_tcm6-5090.pdf

Hujanen, T./Weibull, L./Harrie, E. (2013): “The Challenge of Public Service Broadcasting in the Nordic Countries”, In: U. Carlsson (ed.), Public Service Media from a Nordic Horizon. Politics, Markets, Programming and Users, Göteborg: Nordicom, pp. 17-50.

Jakubowicz, K. (2007): "Public Service Broadcasting in the 21st Century. What Chance for a New Beginning”. In: G. F. Lowe/ J. Bardoel. (2007), From Public Service Broadcasting to Public Service Media, RIPE @2007. Göteborg: Nordicom, pp. 29-49.

Jauert, P. et al. (2017): "The Future of Radio Revisited: Expert Perspectives and Future Scenarios for Radio Media in 2025." In: Journal of Radio and Audio Media 24/1, pp. 7-27. 
Kantar Gallup Denmark 2017. http://tvm.tns-gallup.dk/tvm/rpm/default.htm

Lowe, G.F/Bardoel. J. (2007): From Public Service Broadcasting to Public Service Media, RIPE @2007. Göteborg: Nordicom.

Lund, A.B./Lowe, G.F. (2013): "Current Challenges to Public Service Broadcasting in the Nordic Countries”. In: U. Carlsson (ed.), Public Service Media from a Nordic Horizon. Politics, Markets, Programming and Users, Göteborg: Nordicom, pp. 51-73.

McNair, B./Hibberd, M. (2003): “Mediated Access. Political Broadcasting, The Internet and Democratic Participation”, In: G.F. Lowe/T. Hujanen, Broadcasting and Convergence: New Articulations of the Public Service Remit, RIPE@2003. Nordicom: Göteborg. [indsæt sidetal]

Mediepolitisk aftale 2012-2014 [Media Policy Agreement 2012-2014]. Available at: https://kum.dk/uploads/tx_templavoila/Endelig\%2omedieaftale\%2oaf\%2o 9\%20oktober\%202012\%20DOK1496920.pdf

Medietilsynet, Norge - Årsrapport 2017 [The Media Authority, Annual Report 2017]. http://www.medietilsynet.no/globalassets/dokumenter/rapporter/medietilsynet-arsrapport-2017.pdf

Moe, H. (2010): “Defining Public Service beyond Broadcasting: The Legitimacy of Different Approaches”. In: International Journal of Cultural Policy, First published on: 04 September 2010 (iFirst) pp. 1-17.

Moe, H. (2013): "Public Service Broadcasting and Social Networking Sites: The Norwegian Broadcasting Corporation on Facebook”. In: Media International Australia 146 (February 2013), pp. 114-122.

Moe, H./Mjøs, O.J. (2013): “The Arm's Length Principle in Nordic Public Broadcasting Regulation”. In: U. Carlsson (ed.), Public Service Media from a Nordic Horizon. Politics, Markets, Programming and User, Göteborg: Nordicom, pp. 75-92.

NRK-Plakaten: https://www.regjeringen.no/globalassets/upload/kkd/nrk-plakatenengelsk.pdf

NRK vedtekt [NRK charter]: https://www.nrk.no/informasjon/nrks-vedtekter1.5392438

Nissen, C. (ed.) (2006): Making a Difference Public Service Broadcasting in the European Media Landscape. John Libbey Publishing: Eastleigh.

Nissen, C. (2005): "Epilogue: The Public Service Nun. A Subjective Tale of Fiction and Facts”. In: G.F. Lowe/P. Jauert, Cultural Dilemmas in Public Service Broadcasting, Göteborg: Nordicom, pp.317-325.

SR Charter: Regeringen, Kulturdepartementet: Tilstånd for Sveriges Radio AB att sända ljudradio. 2014-2019. https://sverigesradio.se/diverse/appdata/isidor/ files/3113/14011.pdf

Scannell, P. (1996): Radio, Television and Modern Life, Oxford: Blackwell.

Scannell, P. (2005): “The Meaning of Broadcasting in the Digital Era”. In: G.F. Lowe, G.F./P. Jauer (eds.), Cultural Dilemmas in Public Service Broadcasting. Gothenburg: Nordicom, pp. 129-142. 
Silverstone, R./Hirsch, E. (1992): Consuming Technologies. Media and Information in Domestic Spaces, London: Routledge.

SR 2013 and 2017. Sociale Medier. En handbook för journalister [Social Media. A Handbook for Journalists]. Available at: https://sverigesradio.se/press/bilder/SocialaMedierhandboken_v2_Sveriges_Radio.pdf

Søndergaard, H. (2008): “DR's digitale strategier”. In: F. Mortensen (ed.), Public servive i netværkssamfundet, Frederiksberg: Samfundslitteratur, pp. 31-66. 


\section{The Role of Boundary ObJects in Collaborative Radio Production}

Bruce Berryman

\section{INTRODUCTION}

Digital network technologies have multiplied opportunities for radio producers to collaborate in new ways across geographic and cultural boundaries; creating the expectation that with the right technology producers can work collaboratively and creatively anywhere, at any time on participatory projects. However, as Henry Jenkins (2006) has argued, media convergence needs to be understood as a cultural process rather than a technological endpoint. While participatory media might be a cornerstone of a participatory culture, technology cannot in itself ensure participation.

This case study posits that collaborative production is the result of a dynamic interplay between both technological and social factors, examining some of the ways boundary negotiating artifacts, or boundary objects, can enable effective collaboration between radio producers in co-located and distributed networked environments.

The study began with a cross-border project bringing together radio students from the UK and Australia to work on a radio documentary. Underlying this project was the belief that technology had sufficiently stabilised to enable established processes from analog radio production to be transposed into a networked environment and that any challenges that might arise would be technical in nature. By project end this assumption had been turned on its head, with the emergence of a number of important non-technical obstacles. Over the next five years, initial project insights were challenged, developed and fine-tuned, using a participative action research approach that enabled action (change and improvement), and research (understanding and knowledge), to be achieved at the same time. Central to the study is an understanding of collaboration in co-located and distributed settings and the development of a set of boundary objects as effective production enablers. 
A number of works were particularly useful in enabling a more comprehensive understanding of the dynamics of collaboration and it's key influencing factors. The first of these was Olson, Zimmerman, and Bos's theory of remote scientific collaboration (2008). This study of over 200 online collaboratories showed that even when advanced communication technologies are available, collaborations involving geographically dispersed participation have a greater chance of failure than co-located collaborations. The authors identified a number of reasons for these challenges, including difficulty in establishing and maintaining trust, lack of common ground and the nature of the work itself.

A second key reference was Diane Sonnenwald's (2007) four stages of collaboration model (foundation, formulation, sustainment and conclusion). It provided critical insight into the way effective collaboration is constructed dynamically over time. Like Olson, Zimmerman, and Bos, Sonnenwald underlines the complexity that geographical distance introduces into collaborative projects. She argues that the project set-up stage (formulation) is particularly critical to ultimate success, with key issues to be considered at this time including project vision, goals, and the use of information and communications technology (ICT).

As the research project unfolded, the theme of boundary objects emerged, a concept that Star and Griesemer (1989) introduced into the field of sociology through an examination of how artifacts such as specimens, maps, and field notes helped bring about cooperation among stakeholders in setting up a museum of zoology. Since then, a variety of artifacts, from databases to design prototypes, have been examined for their ability to bridge perceptual and practical differences, thereby building common ground and more effective collaboration.

\section{BOUNDARY OBJECTS}

Boundary objects are objects which are both plastic enough to adapt to local needs and constraints of several parties employing them, yet robust enough to maintain a common identity across sites. [...] the creation and management of boundary objects is key in developing and maintaining coherence across intersecting social worlds. (Star and Griesemer 1989: 393)

It could be argued that the capacity of team members to combine different perspectives, talents, and ideas, in a way that creates something beyond what could have been achieved individually, is linked to their ability to get beyond the boundaries or differences that divide them as individuals. These boundaries may be engendered by geographic and/or cultural distance, however study findings show that a sense of perceived 'difference' may also be experienced by co-located team members of the same age and culture, attending the same 
university. This study found that certain artifacts or 'boundary objects' can play an important role in helping bridge both perceptual and practical distance.

As Vyas and Nijholt (2010) have observed, most research into boundary objects has referred to them within the context of a collaborative work that focuses on bringing productivity and efficiency. This study explores the role of boundary objects as enablers of creative work, with three such boundary objects identified for discussion.

\section{Production Templates}

Whether radio producers are operating in analog or digital environments, running sheets and production plans are critical elements in the planning, negotiation and production phases of making radio. The study found that the templates used in this project are illustrative of what Lee (2007) calls 'boundary negotiating artifacts' - objects that are used to iteratively align perspectives and solve specific design problems that are part of a larger design project. They achieve this by providing a fundamental infrastructure and focus for critical pre-production activities where the design process is cut down into subtasks to make it more manageable, thereby creating interfaces/ boundaries and the need for making interface requirements explicit. This in turn encourages the dialogue and sharing of perspectives that results in a sense of shared ownership for final outputs.

\begin{tabular}{|l|l|l|}
\hline Segments & Talking Points & Duration \\
\hline Theme & \multicolumn{1}{|l}{$\begin{array}{l}\text { Introduction } \\
\text { Welcome to the show. Mention they are with } \\
\text { RWAV, RRR. 'Great show coming up': Men- } \\
\text { tion some artists/songs we will be airing: } \\
\text { RYAN ALICE, THE MURLOCS, BIG } \\
\text { SCARY } \\
\text { 'First up we have a Feature Documentary' } \\
\begin{array}{l}\text { Kit to provide brief outline of the documen- } \\
\text { tary. } \\
\text { Mention that Tom will be joining us in the } \\
\text { studio. Also - Later on, we'll be hearing } \\
\text { from Curt with his quirky facts of the week } \\
\text { and also from Bianca with a review of a } \\
\text { new, life changing app she has discovered. }\end{array}\end{array}$} & \\
\hline
\end{tabular}




\begin{tabular}{|c|c|c|}
\hline Segments & Talking Points & Duration \\
\hline Song & $\begin{array}{l}\text { In the Other Room-Ryan Alice } \\
\text { Singer song Writer from Ascot Vale; } 2010 \\
\text { release from album Leaking Days. }\end{array}$ & $3: 21$ \\
\hline $\begin{array}{l}\text { Introduce } \\
\text { Documentary }\end{array}$ & $\begin{array}{l}\text { Zoe and Kit to have a brief conversation } \\
\text { about their reactions to the documentary } \\
\text { while explaining what it's about. } \\
\text { - Recorded in local area of Carlton } \\
\text { - Explores the monopoly of the supermarket } \\
\text { and the demise of the Milk bar and effect on } \\
\text { society/community } \\
\text { - Nostalgia }\end{array}$ & $1: 00$ \\
\hline No Milk Today & Gets us to 15 minutes & $2: 57$ \\
\hline Toms IV & $\begin{array}{l}\text { Figure 2: Brief discussion with Tom } \\
\text { Is there a personal story behind why you } \\
\text { chose to focus on this niche in society? } \\
\text { What do you think about the 'life' of Milk } \\
\text { bars, will supermarkets and 7/11stores even- } \\
\text { tually replace them all? } \\
\text { How do you think this is affecting society } \\
\text { generally? I got a really strong sense of } \\
\text { the community involved in Milk Bars, the } \\
\text { regular customers, their quirks etc. The } \\
\text { social experience of 'shopping' is now quite } \\
\text { a sterile, impersonal experience. } \\
\text { How can the average person help struggling } \\
\text { milk bars - do you think a community kind } \\
\text { of co-op can still exist? } \\
\text { What's your ultimate milk bar snack? }\end{array}$ & $5: 00$ \\
\hline Promo & & 1:०० \\
\hline Song & $\begin{array}{l}\text { We Shall Tread Softly (from Now on) - } \\
\text { Fraser A Gorman } \\
\text { 'After spending many years plating in 6o's } \\
\text { Garage band Revolver and Sun Fraser has } \\
\text { turned his song writing abilities to country } \\
\text { music. You can really hear the influence of } \\
\text { Bob Dylan throughout this piece'. }\end{array}$ & $2: 38$ \\
\hline ID & Gets us to 24 minutes & $0: 05$ \\
\hline
\end{tabular}




\begin{tabular}{|c|c|c|}
\hline Segments & Talking Points & Duration \\
\hline $\begin{array}{l}\text { Whats } \\
\text { Coming Up }\end{array}$ & $\begin{array}{l}\text { 'ITS BEEN A GREAT SHOW SO FAR, BUT } \\
\text { DON'T } \\
\text { GO ANYWHERE' } \\
\text { Mention we have some great music still to } \\
\text { come - Big Scary, The Easy Beats. } \\
\text { Discussion about alternate ways of living } \\
\text { sustainably in Melbourne } \\
\text { Pre-recorded follow up interview with inde- } \\
\text { pendent film maker Rohan } \\
\text { Spong after his film premiere in New York. } \\
\text { BUT FOR NOW LETS HEAR FROM OUR } \\
\text { QUIRKFINDING EXTRAODINAIRE } \\
\text { CURTIS WITH HIS ODD SPOT NEWS } \\
\text { UPDATE. }\end{array}$ & 1:00 \\
\hline Curt's Quirks & & $2: 00$ \\
\hline Promo & & $0: 20$ \\
\hline $\begin{array}{l}\text { Curtis' Quirks } \\
\text { Chat }\end{array}$ & $\begin{array}{l}\text { Gets } \text { us to just under } 30 \text { minutes } \\
\text { LETS HEAR FROM THE MULOCS } \\
\text { WITH THEIR AWESOME TRACK, STEP } \\
\text { AND STAGGER, STAY WITH US GUYS, } \\
\text { YOU'RE WITH RWAV. }\end{array}$ & 2:०० \\
\hline
\end{tabular}

Table 1: RWAV - GROUP 1 - RUNNING SHEET (From ROAR)

Although these templates are not technology dependent, in this project they were available online and much of the negotiation and development occurred asynchronously through shared documents. Study findings indicate that the asynchronous nature of the process provides a useful adjunct to face-to-face production meetings.

Our extensive, three-page, running sheet was at the very heart of our entire show. It proved to be incredibly helpful and enabled us to stay on track with time and content. Having consistently edited and improved the running sheet we were very confident in the final product and we attribute the success of the show to our excellent organization and planning. (RWAV Participant) 


\section{Media Annotation}

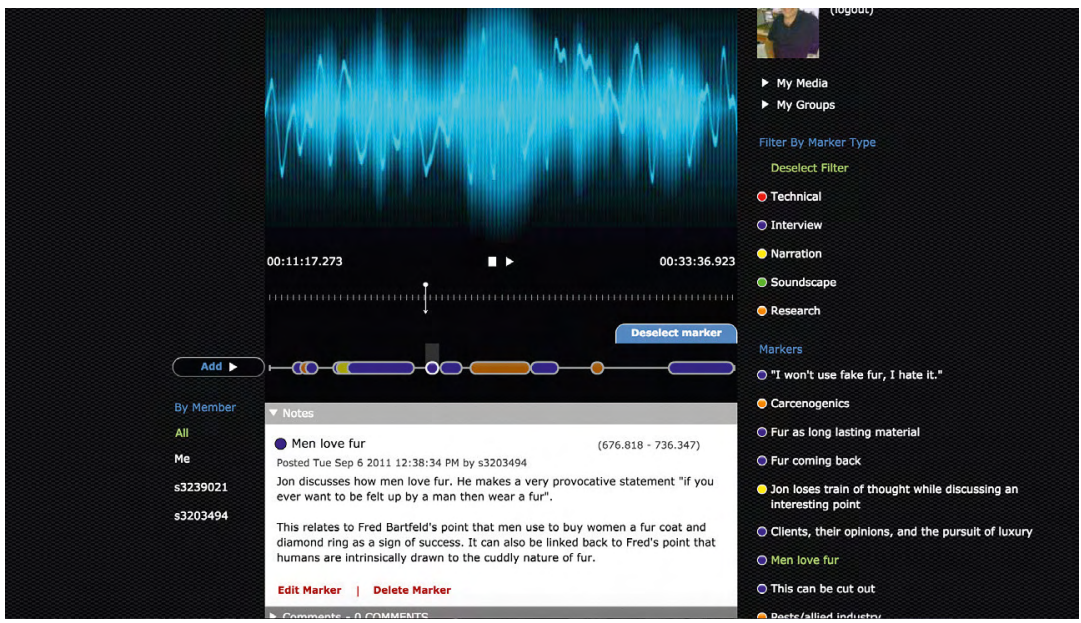

Figure 3: Screen Shot of MAT

Originally developed as a video annotation tool to assist in the evaluation and reflection process within a physical education teaching program, the Media Annotation Tool (MAT) was customised for use in radio production. Media annotation has been successfully embedded into the production processes of live to air and documentaries and in this study found to be a powerful boundary negotiating artefact. Annotation is not only an effective enabler of individual feedback and reflection on practice, but also plays a central role in supporting design exploration and creative collaboration. More specifically, study findings indicate that MAT:

- Facilitates feedback which is fact-based, specific and actionable thanks to its ability to home in on specific parts of the audio

- Opens a space for dialogue which enables team members to see new connections between fields, ideas, and concepts in a way which would not be possible through face to face discussion

- Makes the informal processes of creative collaboration traceable and visible for future cohorts of radio makers

- Supports a range of team exchange from the purely technical to the aesthetic, as well as encouraging socio-emotional exchanges that build common ground and establish and maintain shared understanding

Research suggests that the socio-emotional character of content exchanges may be particularly critical to the development of creative collaboration in an 
online environment (Aragon/Poon/Monroy-Hernandez/Aragon 2009: 10). At project outset, the communication style employed in MAT annotations was primarily neutral and task-based (technical in content, factual, objective). As participants moved further into the annotation process and gained more experience in using the tool, their annotations also increased in terms of their socio-emotional content (self-revealing, use of ' $I$ ' and 'we', references to feeling as well as thinking). This was true not only in the groups' reflections on their work but also in their feedback on the productions of others, where any criticisms or suggestions for improvement were consistently constructive, creating a strong foundation for any future work that participants might undertake together. The identification of annotation as a boundary object is also significant in terms of the creative nature of the work involved. As Vyas and Nijholt (2010) have observed, most research into boundary objects has focused on their ability to enable productivity and efficiency.

The usefulness of annotation had already been effectively demonstrated in post-production reflection, when it was introduced to bring this same form of co-creative thinking into earlier stages of the documentary and feature production process.

Annotation was used at four different phases of the production/post production process:

- Raw/unedited interview stage (group member feedback and recommendations)

- Edited interview stage (group member feedback and recommendations)

- Finished piece (group reflections)

- Finished piece (feedback from others)

Examples of annotations from each of these phases are included below.

\section{BALANCING A TASK BASED APPROACH WITH SOCIO- EMOTIONAL INPUT}

\section{Raw unedited interview stage}

Fred had a bad cough when we interviewed him. This will need to be edited out in post-production.

I like this sound-bite; I think it could be a good opening statement for Jon, as he sounds really emphatic about not wanting to use fake fur regardless of its benefits. Would be good to juxtapose with Fred Bartfeld.

This might be a good area to put a little research into so we can segue through narration to some of Tullia's thoughts on reinterpreting old materials, such as vintage fur? 


\section{Edited interview stage}

I think that although this section of the interview does supply us with context, e.g. who Fred Bartfeld is, his history in the business etc, we can cover most of this with a one-liner of narration. For example, I think it will sound cleaner and less waffly if there is a voice over saying: "We spoke to Fred Bartfeld, director of Bartfeld Textiles, who has worked in the faux fur industry for forty years" etc. That way we can save more space for the anecdotal, more interesting info he gives later on.

\section{Final Piece - Reflection on finished production}

I think this is perhaps the best part of the whole documentary. Some of the individual sounds are so wonderful, the shredder grinding, the engine whining and in particular the sound of the waste dropping into the catchment chute at the bottom of the machine. I think that it is a testament to the ZOOM as a piece of equipment, that these sections were so well recorded. I was a little bit worried that the noise of the machinery might drown out Hugh's voice, but with the microphone held quite close to his mouth, we were able to get the voice and the atmosphere without one compromising the sound of the other. I think it is one of our biggest technical achievements.

I really like the way this documentary came together, but I think that one weakness we perhaps have is the lack of music or ambient sound throughout. However, given that our interviews are quite fluid and flow into each other quite well, I think in many ways music in our documentary would have been distracting, particularly if it was simply a generic soundtrack, rather than something relevant to our topic. I also think that the soundscape at the beginning did a great job of providing some light music to grab the audience's attention.

\section{Feedback from others on finished production}

The introduction was great; the music along with the decision to get right into the interview was a really powerful technique to familiarize the audience with the interviewee. It built a connection with the voice straight away and emphasised the importance of the interviewee over the anchor. I think the sound quality is of the highest calibre of the documentaries I have heard so far, and the overall structure and editing was excellent. No complaints - Well done!

I thought this was great guys! The voice of the girl at the start was a really good way to get the audience in. Straight away I was interested in what was going to happen. One criticism was that the music got a little bit repetitive throughout the piece which made me switch off slightly as the doco continued. Obviously great interview with Pat - well done getting that! Overall top stuff- excellent mixing and recording! Well done! 


\section{Content Management System}

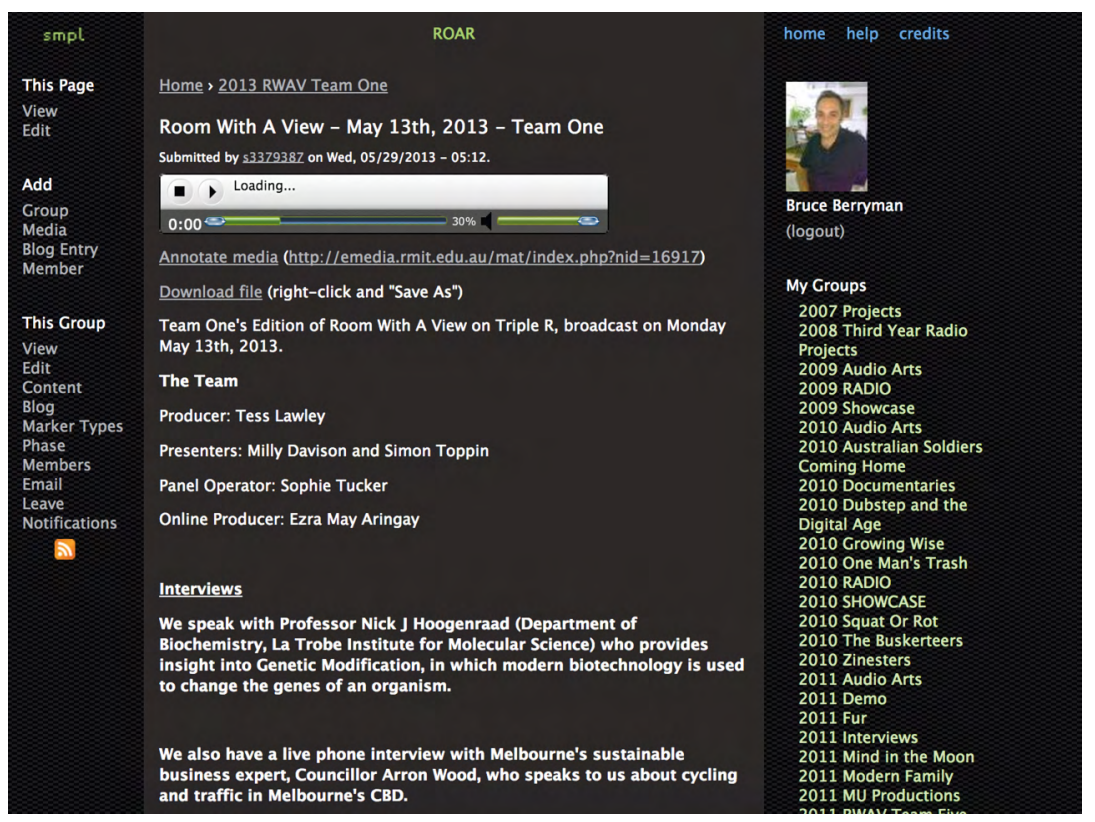

Figure 4: Screen shot of ROAR: the CMS designed, developed and implemented during this study.

In Dianne Rees's article The Challenge of Building Positive Boundary Objects (2011) she contends that although shared communication platforms and content management systems have the potential to serve as boundary objects, they often fail to do so because it is assumed that merely deploying the technology will create an impetus to use it and that this impetus will be sustainable. Rees goes on to argue that one of the keys to developing useful boundary objects lies in understanding their audience and in finding ways to adapt the boundary object to different case uses without destroying its shareability. Bechky (2006) too contends that stakeholder input is critical, arguing that all relevant actors need to actively contribute to the co-construction of meaning of a given boundary object.

Since it was first launched, ROAR evolved to become closely identified with the university's radio curriculum and a key boundary object in use. Initially envisaged as a simple archive to house material produced by students, ROAR evolved over time to integrate both a back-end collaborative production space and a publicly accessible distribution site. Study findings indicate that the CMS is particularly appreciated for its flexibility of use. There are few prescribed tools, and those that are prescribed (e.g. MAT) are recognised for their ability to 
add real value to the production process. ROAR is also appreciated for its ability to serve as a 'memory' - not only of the programs that teams have produced, which are all archived on the system, but also of the collaborative process engaged in getting there, making explicit the reflections and exchanges which resulted in particular creative decisions being made.

An action research methodology (AR) was employed in this project, motivated by two of its key characteristics - its flexible, spiral process and its collaborative, participatory approach. Implicit within AR's spiral model of planning, acting, observing and reflecting is the notion that with each action cycle there is an opportunity to integrate new learning. An AR approach therefore enables action (change and improvement) and research (understanding and knowledge) to be achieved at the same time. This methodology facilitated a process whereby productions teams and other key stakeholders (facilitator/researcher, IT designers, developers and support team) have actively engaged with the CMS over time, shaping its identity and keeping its 'plasticity' alive through an iterative process of reflective practice and informed action.

However, boundary object status is not eternal. Artifacts become (and remain) boundary objects by being used as such over time (Lee 2007: 307). This is illustrated in the case of both ROAR and MAT; boundary negotiating artifacts that were transformed significantly in response to the needs of its users. After six years of use, the interface of ROAR was somewhat 'clunky', looking tired and very 'last decade' from the users' perspective. As one participant put it, "it's like a Swiss army knife, it has a screwdriver but is it the screwdriver you want to use for the job?" Last year ROAR was archived and replaced by a simpler and cleaner looking CMS. Similarly with annotation, MAT was de-commissioned in favour of using SoundCloud. Although SoundCloud doesn't provide all of the features built into MAT the simplicity, ease of access, upload, annotation and publication enables it to be an effective boundary object within local and transnational collaborative radio production, alas to the price of dependence on a private company's future decisions.

\section{REFERENCES}

Aragon, Cecilia/Poon, Sarah/Monroy-Hernandez, Andre/Aragon, Diana (2009): “A Tale of Two Online Communities: Fostering Collaboration in Scientists and Children." In: ACM Conference on Creativity and Cognition, Berkeley, p.10.

Bechky, Beth (2006): "Gaffers, Gofers, and Grips: Role-Based Coordination in Temporary Organizations.” Organization Science 17/1, pp. 3-21.

Jenkins, Henry (2006): Convergence Culture. Where Old and New Media Collide, New York and London: New York University, p. 37. 
Lee, Charlotte (2007): "Negotiating Artifacts: Unbinding the Routine of Boundary Objects and Embracing Chaos in Collaborative Work." Journal Computer Supported Cooperative Work Archive 16/, California Institute for Telecommunications and Information Technology, Irvine: University of California Irvine, p. 307.

Olson, Gary M./Zimmerman, Ann/Bos, Nathan (Eds.) (2008): Scientific Collaboration on the Internet, Cambridge: MIT, pp. 53-72.

Rees, Diane (2011): The Challenge of Building Positive Boundary Objects, March 2, 2018 (http://instructionaldesignfusions.wordpress.com/2011/04/23/the-challengeof-building-positive-boundary-objects)

Sonnenwald, Diane H. (2007): “Scientific Collaboration.” In: B. Cronin (ed.), Annual Review of Information Science and Technology, Medford: Information Today, pp. 643-682.

Star, Susan/Griesemer, James (1989): “Institutional Ecology, 'Translations' and Boundary Objects: Amateurs and Professionals." In: Berkeley's Museum of Vertebrate Zoology, 1907-39 Social Studies of Science 19, pp. 387-420.

Vyas, Dhaval/Nijholt, Anton/van der Veer, Gerit (2010): "Supporting Cooperative Design through 'Living' Artefacts." In: Proceedings of 6th Nordic Conference on Human-Computer Interaction [NordiCHI '10], Reykjavik, pp. 541-550. 



\section{Researching Podcast Production - an Australian Podcast Study About Women and Work in Are We There Yet?}

Mia Lindgren

The \#metoo movement's viral spread across social media in October 2017 drew unprecedented global attention to the issue of sexism in the workplace. Much of the discussions focused on harassment of women, however the debate also highlighted gender equity issues more broadly, shining the light on women's experiences at work. Previously, messages about gender equality in professional life have not usually garnered such interest in the media. The podcast Are We There Yet? (AWTY), produced in Melbourne during 2016 and 2017, was a response to the lack of podcast content at the time dedicated to topics about women and work. It was decided that a podcast would be an appropriate format - simple to produce and widely accessible - to discuss gender in the workplace.

This chapter explores the audio production as a site and model for practiceresearch in podcast studies. Informed by media scholar Robert MacDougall's (2011) work, this case study examines the unprecedented opportunities podcasting affords us to reinterpret and reimagine our personal and professional lives. It looks at how a collaborative podcast production involving two gender equality and leadership consultants and a radio studies researcher in Melbourne developed into a research venture, providing a practice-informed research model for combining production with rigorous analysis. Mapping the whole chain from production to reception engendered a deeper understanding of the podcast's content and, going forward, offers one possible research model for scholars in the emerging field of podcast studies.

The two novice podcast presenters - Melbourne-based leadership consultants Linda Betts and Barbara Dalton - had run face-to-face ('f2f') leadership programs for women for over ten years. However, they had no broadcast experience. The research team wanted to examine if a podcast dedicated to the topic of women at work could provide listeners with a shared experience similar to that established in faf seminars where current gender and organisational research is discussed alongside participants' own reflections and lived expe- 
riences. Extensive research exists on the use of podcasts in educational and business settings (Drew 2017; Fernandez et al. 2015; Hatfield 2017; Moryl 2013; Popova et al. 2014; Thielst 2013) and the research team wanted to investigate how podcasting could add to the conversation about gender and work in accessible and portable ways.

\section{Storytelling Women AND Work}

An initial review identified a small number of international podcasts focussing on gender, such as Slate's long-running (since 2012) Double X Gabfest (Slate 2018). A prominent radio program which is also available via podcast is the stalwart UK-based Women's Hour, broadcast since 1946 and addressing women's perspectives on health, education, cultural, and political topics (BBC 2017). US-based podcasts focussing on women are more common, such as US entrepreneur Sophia Amoruso's Girlboss Radio, involving interviews with 'boundary-pushing women who've made their mark' (Amoruso 2018), and The Rocket Girls Podcast (Fine 2017), aimed at motivating, guiding, and supporting young women to pursue their passions in science and maths. Since the \#metoo movement in late 2017 , a number of additional podcasts focussing on women in the workplace have emerged, such as the Harvard Business Review's six-part series, Women at Work, which includes "conversations about the workplace, and women's place in it" (Harvard Business Review 2018). There is also US podcast, Women's Work, which celebrates stories of "creative women who do interesting work" (Oxenreider 2018). In Australia, the ABC launched Fierce Girls in 2018 , a podcast about Australian women "who dare to do things differently" aimed at children (ABC 2018). The closest match to the Are We There Yet? podcast is The Broad Experience, a podcast about women, work, and success (The Broad Experience n.d.) produced by US-based public radio reporter Ashley Milne-Tyte.

Despite its Australian origins, it was envisaged that the AWTY podcast could be attractive to international audiences where personal experiences and storytelling would become a lingua franca that could support and engage transnational audiences and create a shared sense of community. There is a growing body of work focused on podcasting and storytelling (Alexander 2011; Biewen/ Dilworth 2017; Dann 2014; Lindgren 2014b, 2016; McCracken 2017; McHugh 2016, 2017; Norrington 2010). Podcasting has been described as a 'pull' medium (Berry 2016; McClung/Johnson 2010), where listeners seek out content that interests them and therefore become genuinely engaged with the podcast. MacDougall argues that podcasts create a strong bond between producers and listeners, one that moves, "beyond the way readers of a novel might report sympathy for (or may empathize or identify with) various characters" (MacDougall 
2011: 722). This would support the aim of Are We There Yet? which was to produce a podcast that provided the audience with a sympathetic learning space with traits of a classroom or seminar. The production team also wanted the podcast to be solutions-oriented. Presenter Barbara Dalton said she intended Are We There Yet? to be "informative (here's the research) and also pragmatic (this is what you can do)" (Dalton 2016).

\section{Research Approach}

The team produced and analysed the podcast using a practice-research approach, building on this author's conceptual work into radio documentary forms (Lindgren 2014a) by extending it to the field of podcasting. Adams et al. (2015: 2) describe practice-led research as a "reflexive paradigmatic research structure" led by practice that acknowledges the importance of the researcher's interaction with the research material. PLR is still a novel approach in radio studies, yet one that offers myriad opportunities for rich and multi-layered scholarly analysis of audio content production providing new understandings of podcast genres and production practices. Four focus groups $(\mathrm{N}=25)$ with female listeners were undertaken with an accompanying thematic analysis of the transcripts. Women known to the consultants were invited to listen to the podcast and to then attend a focus group. The main themes identified are discussed briefly later in this chapter. Additional self-reflexive feedback was gathered from presenters Betts and Dalton, as reflective practice is a key element of PLR (Gray/Pirie 1995). The research design allowed for in-depth contribution from the production team and listeners, affording a collaborative and comprehensive approach to understanding both the production and reception of the podcast.

\section{Pilot Episode - Good Girl Syndrome}

The pilot episode, Good Girl Syndrome, was funded by Monash University in Melbourne to explore analytical models for talk-based podcast content. The 23-minute episode focused on research and societal discourse surrounding belief systems and expectations of women's behaviour in the workplace. It discussed how women often feel compelled to 'do the right thing' and to be agreeable in workplace settings. The research team used a narrative learning approach (Hatfield 2017) to effectively communicate complex issues about gender equity and the advancement of women in the workplace. Narratives can be powerful tools for making sense of the world as they "draw us into an experience at more than a cognitive level; they engage our spirit, our imagination, 
our heart, and this engagement is complex and holistic" (Clark/Rossiter 2008: 65). Stories of women's experiences in the workplace were shared with listeners as short voxpops, in the interview and by the presenters in their informal dialogue. Short audio clips were included to provide additional story examples, such as where Marge Simpson instructing Lisa on how to ignore her own feelings in order to fit in, from the US television cartoon The Simpsons (Groening/ Brooks/Simon 1990), created an audio shorthand for the 'good girl' culture. This is where women win approval by being helpful and behaving well but at a cost to their agency and leadership potential.

The episode included an interview with Melbourne-based writer and feminist Karen Pickering who shared her personal experiences of sexism in the workplace when she worked in a bar as a young woman. Ms Pickering recounted how a young male supervisor sent her home to apply makeup because she "looked tired". While this example took place in an Australian pub in the early 2000 s, the story remains relevant. Only weeks before AWTY was produced, a UK-based consultancy-firm sent home one of their female staff members because she was not wearing high-heeled shoes at work (BBC News 2016).

\section{Are We There Yet? ... Lessons Learned}

The format described above for the podcast pilot episode has clear radiogenic traits (Berry 2016) as a talk-style program incorporating talk, audio clips and music. The AWTY presenters followed a script with information about relevant gender research and links to useful readings. This dialogue between the presenters ranged from informal 'banter' to segments providing evidence-based information to accompany the personal stories. The relationship between the novice podcast presenters Barbara and Linda was noted by the focus group participants. They found that Barbara and Linda's conversational dialogue signalled a well-oiled team with expert knowledge of the subject matter and longstanding collaborations, bringing their personal - and authentic - experiences into the conversation. Barbara and Linda's lack of broadcast experience was not seen by focus group participants as an impediment.

Thematic analysis of the transcribed focus groups identified a number of key themes emerging for the listeners of the Good Girl Syndrome pilot episode. These are discussed only briefly below due to the scope of this chapter. When 
asked about the experience of listening to the episode and the use of podcasting to discuss gender in the workplace, participants noted four main themes:

1. Reflection (encouragement of reflection on self)

2. Identification (application of information to personal experience, relatability, emotional connection)

3. Education (the podcast as pedagogical tool, information tool, mentor)

4. Storytelling (the importance of personal narratives, conversational style, podcast listening as journey)

These themes relate directly to traits ascribed to podcast forms, such as its hyper-intimacy (Berry 2016), personal storytelling (Lindgren 2016; McHugh 2016) and strong listener attachment, a relationship which MacDougall (2011) suggests is specific to podcasting where it "[...] may be part of an evolution in parasocial phenomena and a fundamentally new form of mediated interpersonal communication" (716). Analysis of the focus group data suggests the pilot podcast was successful in engaging the listeners and encouraging reflection. Some listeners recognised shared experiences from the podcast stories and applied the information to their own experiences. According to one participant:

I found it really enjoyable and it's stuff that I used to do more with that I don't have time for. I found it terrifically interesting, I found it personally challenging, just to get back and start thinking more like that. And yeah, I found it to be quite motivating. (participant, focus group 4, 2016)

Another participant commented on the informative nature of AWTY and how the audio format provided an engaging form of education:

I think there's lots of ways you can potentially use it, because the stories engage and I think working again in health, if you look at things like nearly everything's in print, your clinical practice guidelines are in print, everything's in print, everyone's sick of print, it doesn't engage. (participant, focus group 2, 2016)

The solution-based approach of the podcast motivated one focus group participant to actively change her behaviour when applying for work: "it made me really think about maybe how I need to be not such a good girl in an interview potentially, so coming across a bit stronger rather than that more passive" (participant, focus group 2, 2016). 


\section{CONCLUSION}

The pilot podcast episode Good Girl Syndrome discussed in this chapter begins with the presenters Barbara and Linda explaining the ambition of the podcast as an aural space where they talk about "[...] how being a woman still impacts on our work, pay, and the opportunities we have". They continue:

Many women think what they experience in the workplace is just happening to them, but actually, it's part and parcel of being a woman at work. By connecting the dots and sharing experiences about women in the workplace, we want to give you tools to navigate the 'occupational hazards of being female' (Are We There Yet? 2016).

This introduction becomes a three-point 'manifesto' for a podcast about women and work: 1) listeners are part of a community of shared experiences; 2) those shared experiences are delivered through a narrative approach (by presenters and interviewees); and 3) informed by current research and personal experiences, the podcast will provide listeners with solutions and suggestions for actions. All of these points were noted by listeners reflecting on AWTY in the focus groups. Although the main themes noted above could be applied to some specialist radio programs, it is unlikely that you would find in mainstream radio programming schedules a series of programs dedicated to gender equality in the workplace. Furthermore, participants in the focus groups reported a high level of identification and reflection generated by listening to the podcast. This aligns with what scholars suggest is podcasting's ability to create strong communities and engagement with listeners (cf. Berry 2016; McClung/ Johnson 2010; MacDougall 2011). Although the audience focus groups only discussed the pilot episode, their feedback support the proposition that a podcast like Are We There Yet? about women and work could become an informative platform for globally shared knowledges and cultural learning where listeners are encouraged to reflect on their own gendered experiences and the strategies they can adopt in the workplace to make their working lives better.

\section{REFERENCES}

ABC Radio: “Fierce Girls”, 2018 (http://www.abc.net.au/radio/programs/fierce-girls/), accessed 9 April 2018.

Adams, Lyndall/Kueh, Christopher/Newman-Storen, Renée/Ferguson, Neil (2015): "Capturing Creative Practice." In: Australian Council of University and Design Schools Conference 2014: The Future of the Discipline, Victorian College of the Arts and RMIT University October 2-3. 
Alexander, Bryan (2011): The New Digital Storytelling - Creating Narratives with New Media, California: Praeger.

Amoruso, Sophia, “Girlboss Radio with Sophia Amoruso", 2018 (https://itunes.apple. com/us/podcast/girlboss-radio-with-sophia-amoruso/id1041122387?mt=2), accessed 9 April 2018.

BBC News, “London receptionist sent home for not wearing heels”, May 11, 2016 (http:// www.bbc.com/news/uk-england-london-36264229), accessed 9 April 2018.

Berry, Richard (2016): "Podcasting: Considering the Evolution of the Medium and its Association with the Word 'Radio'." In: The Radio Journal: International Studies in Broadcast \& Audio Media 14/1, pp. 7-22.

Betts, Linda (2016): self-reflection on production of Are We There Yet? podcast. Unpublished

Betts, Linda/Dalton, Barbara/Lindgren, Mia: "Are We There Yet? Women, Work and Equality”, 2016 (http://brdalton2.wixsite.com/arewethereyetpodcast), accessed 9 April 2018.

Biewen, John/Dilworth, Alexa (eds) (2018): Reality Radio: Telling True Stories in Sound (Second Edition), North Carolina: University of North Carolina Press.

Clark, Carolyn/Rossiter, Marsha (2008): “Narrative Learning in Adulthood”. In: New Directions for Adult and Continuing Education 119, pp. 61-70.

Dalton, Barbara (2016): self-reflection on production of Are We There Yet? podcast. Unpublished

Dann, Lance (2014): "Only Half the Story: Radio Drama, Online Audio and Transmedia Storytelling.” In: The Radio Journal - International Studies in Broadcast \& Audio Media 12/1 \& 2, pp. 141-154.

Drew, Christopher (2017): “Educational Podcasts: A Genre Analysis.” In: E-Learning and Digital Media 14/4, pp. 201-11.

Fernandez, Vicenc/Sallan, Jose/Simo, Pep (2015): "Past, Present, and Future of Podcasting in Higher Education.” In: M. Li/Y. Zhao (eds), Exploring Learning \& Teaching in Higher Education. Berlin: Springer, pp. 305-330.

Fine, Melanie, “The Rocket Girls Podcast”, 2017 (https://itunes.apple.com/us/podcast/the-rocket-girls-podcast/id1182958423?mt=2), accessed 9 April 2018.

Gray, Carole/Pirie, Ian (1995): "Artistic Research Procedure: Research at the Edge of Chaos?” In: Design Interfaces Conference 3. Salford: The European Academy of Design, University of Salford.

Groening, Matt/Brooks, James/Simon, Sam (1990): “Moaning Lisa.” The Simpsons, episode 6, season 1, February 11.

Harvard Business Review, "Women at Work”, 2018 (https://hbr.org/2018/o1/podcastwomen-at-work), accessed 9 April 2018.

Hatfield, Elizabeth Fish (2017): "Narrative Learning using Podcasts in Interpersonal Communication" In: Communication Teacher 18/1, pp. 1-7.

Lindgren, Mia (2014a): “Radio Journalism as Research -a Ph.D. Model.” In: The Radio Journal: International Studies in Broadcast and Audio Media 12/1-2, pp. 169-182. 
Lindgren, Mia (2014b): “'This Australian Life': the Americanisation of Radio Storytelling in Australia." In: Australian Journalism Review 36/2, pp. 63-75.

Lindgren, Mia (2016): “Personal Narrative Journalism and Podcasting.” In: The Radio Journal: International Studies in Broadcast and Audio Media 14/1, pp. 23-41.

Lindgren, Mia/McHugh, Siobhan (2013): "Not Dead Yet: Emerging Trends in Radio Documentary Forms in Australia and the US". In: Australian Journalism Review 35/2, pp. 101-113.

Mavenly + Co, "Women, Work and Worth", 2018 (https://itunes.apple.com/au/podcast/women-work-and-worth/id981357804?mt=2), accessed 9 April 2018.

McHugh, Siobhan (2016): "How Podcasting is Changing the Audio Storytelling Genre". In: The Radio Journal: International Studies in Broadcast and Audio Media 14/1, pp. 65-82.

McHugh, Siobhan (2017): “Memoirs for the Ears”. In: Bunty Avieson/Fiona Giles/Sue Joseph (eds.), Mediating Memory, New York: Routledge, pp. 104-122.

McClung, Steven/Johnson, Kristine (2010): "Examining the Motives of Podcast Users.” In: Journal of Radio \& Audio Media 17/1, pp. 82-95.

McCracken, Ellen (2017): The 'Serial' Podcast and Storytelling in the Digital Age, Abingdon: Routledge.

Milne-Tyte, Ashley, “The Broad Experience” (n.d.) (http://www.thebroadexperience. com/), accessed 9 April 2018.

Moryl, Rebecca (2013): “T-shirts, Moonshine, and Autopsies: Using Podcasts to Engage Undergraduate Microeconomics Students.” In: International Review of Economics Education 13, pp. 67-74.

Norrington, Alison (2010): “Harnessing 'e' in Storyworlds: Engage, Enhance, Experience, Entertain.” In: Publishing Research Quarterly 26/2, pp. 96-105.

NPR, “Women's Marches Go Global: Postcards From Protests Around The World”, January 21, 2017 (http://www.npr.org/sections/thetwo-way/2017/01/21/510940708/ womens-march-on-washington-goes-worldwide-snapshots-from-around-theglobe), accessed 9 April 2018.

Oxenreider, Tsh, “Women's Work”, 2018 (http://womensworkshow.com/), accessed 9 April 2018.

Popova, Anguelina/Kirschner,Paul A./Joiner, Richard (2014): “Effects of Primer Podcasts on Stimulating Learning from Lectures: How do Students Engage?” In: British Journal of Educational Technology 45/2, pp. 330-339.

Sawer, Marian (2013): "Misogyny and Misrepresentation: Women in Australian Parliaments." In: Political Science 65/1, pp. 105-117.

Slate, "Double X Gabfest”, 2018 (https://itunes.apple.com/au/podcast/double-x-gabfest/id317166278? mt=2), accessed 9 April 2018.

Snyder, Julie (2016): interviewed in "Download this Show", December 2, 2016, ABC Radio National, (http://www.abc.net.au/radionational/programs/downloadthisshow/serial/8085272), accessed March 5, 2018. 
Thielst, Christina Beach (2013[2010]): Social Media in Healthcare: Connect, Communicate, Collaborate, Chicago: Health Administration. 



\section{Surveying International Public Radio: Some Practical Insights}

\section{David Fernández-Quijada}

In September 2016, the Media Intelligence Service of the European Broadcasting Union (EBU) published a report on the distribution of international broadcasting services by public service media. This chapter examines the methodology of that research, only made available to EBU Members as part of the competitive advantage they obtain for their membership of the organization.

The research project provides practical insights for its recipients, broadcasters belonging to the EBU community. In the moment the survey was circulated, a total of 64 international radio services were broadcast in 31 out of the 56 countries in which the EBU has members, most of them full service and news and current affairs stations. The insights obtained during the research derive from an analysis of various sources, particularly an ad-hoc survey. Surveys are the most common way in which the Media Intelligence Service gathers information from EBU members, given their flexibility and the shared understanding they provide.

The main areas addressed in the following pages are the methodology decisions taken when defining the object of study, the survey design, and strategies to increase the response rate. Although the research included both radio and television services, and most of the design was identical for both media types, the examples provided here refer exclusively to radio.

\section{Market-oriented Research}

The origin of this research project was the need to gain a deeper understanding of the international services proposed by public broadcasters in the EBU. The focus was on the distribution networks used for international services and the strategy behind those choices. While the information on the distribution networks is more descriptive, the strategy provides the opportunity for a more analytical approach. 
In any case, the project was designed as a piece of market research, aimed at setting an international benchmark for the respondents' activities to help them understand how other broadcasters with similar characteristics and aims are tackling the same kinds of challenges. By offering best practices in tackling similar challenges, the EBU wanted to inspire other international broadcasters in their quest to expand their footprint, find better ways to distribute their content or fine-tune their strategy. In short, this was a way to serve the members of its International Broadcasting Assembly.

\section{Problems Defining the Object of Study}

Defining what international services are, and are not, is not straightforward. While our first approach relied on the public service media organizations' own declaration what their own broadcasting international services were, a closer look revealed than they did not always adhere to identical definitions. For example, two organizations declared that their international services only targeted foreigners in their country, including migrants and tourists, and did not broadcast beyond their national borders. Metaphorically, these organizations are bringing internationality to their own country. The evolution of these two previously international broadcasters in the classical sense makes them similar to national radio services that target those same audiences but which are not considered international services by their organizations. This is an example that makes it clear how difficult it is to define what international services actually are. In this sense, the option taken in this project was to highlight this evolution as a trend within international services while reporting only on those that considered themselves to be offering an international service.

Additional issues arose and decisions had to be taken. For example, when there were different signals from the same station, with specific content and often in different languages, we took the option to count them as separate services. This is why there may be several services under the umbrella of the same brand, such as in the cases of Radio Vaticana, which operates 15 different feeds worldwide, or TRT Voice of Turkey and Radio Poland, each of which operates three services with different content and in different languages.

These two examples highlight the fact that international radio is not easy to define and that researchers must seriously consider this issue when defining the scope of their projects. Certainly, our understanding of international services should not be taken for granted. In some cases, these differences also need to be taken into account when analyzing the results. For example, some broadcasters included in the project far from adhere to the traditional image of an international service, including different language desks, an editor-inchief for each language and a dedicated engineering team. While this might 
be true for some major international broadcasters, others are merely a one-man operation, or even less in the case of services that only relay programs from the national services to diaspora communities. And researchers need to accommodate all those different realities into their research project.

\section{Methodology Options}

Methodologically, the decision was taken to triangulate various sources. These included media monitoring, an ad-hoc survey and desk research. The starting point for collecting data was the list of services maintained by the Media Intelligence Service. This is an on-going monitoring exercise that identifies the various linear services offered at any one time by EBU Members and related information, including the technical networks used for distribution. Members validate it once a year, confirming or amending the data. This is a basic tool for the EBU to understand the activities of its Members, and is later used to feed various research projects and requests from EBU Members and internal departments.

An ad-hoc survey was designed to collect data not available in the list of services, as detailed in the next section. This survey was sent out to the respondents and data collected from March to May 2016.

The two previous collection methods were complemented by desk research, to cross-check the data and information gathered with third-party sources that track market developments, from press trade to academic journals and other specialized publications. The information provided in the questionnaires was systematically cross-checked with the broadcasters' own websites. Specialized websites were also used, such as Lyngsat for satellite transmissions. The 2016 edition of the World Radio TV Handbook (WRTH, 2016) was used to crosscheck data about distribution networks.

\section{SURVey Design}

The questionnaire was designed in Microsoft Excel and circulated among the previously identified contacts. Although this software tends to involve additional data processing time compared with online solutions, our experience is also that it increases both the response rate and data accuracy and reliability, probably thanks to respondents' familiarity with the format. It also dramatically reduces the number of technical problems faced by the respondents, which ultimately results in a higher response rate.

The questionnaire comprised three sections: a description of services (e.g. genres, targets, languages), information about distribution networks, and the 
distribution strategy. As more than one contact might be providing the responses, the questions for each section were included in different tabs, making internal circulation of the survey easier.

The two first sections were mainly quantitative, while the section on strategy was predominantly qualitative. All the sections included 5-year forecast questions, usually with 5-point Likert scales. This helped the researchers to quantify this forecast and make it more comparable. The qualitative insights then complemented and added granularity to the figures.

\section{Strategies to Increase Response Rate}

For radio, the survey achieved a response rate of $72.7 \%$ (24 out of 33 organizations), nearly 10 points ahead of TV, which had a response rate of $63.3 \%$. For radio, the contact rate was even higher, at $90.9 \%$, as six additional organizations replied but for various reasons did not complete the questionnaire.

As always in survey research, one of the main challenges was to maximize the response rate. To achieve a high response rate, it is essential to identify the most appropriate respondents. As previously mentioned, for this survey we took special care to find the people directly involved in distributing international services. Not only does this guarantee that the person who receives the questionnaire is the one involved in the issues we are dealing with but also enables us to presume that that person will be the most interested in answering the questionnaire, as (s)he can have a better sense of the value that can be received in return and will have more opportunities to make use of the project's findings.

At this stage, communicating with the respondents about the value they can expect in return takes center stage. This value was distilled into four key elements:

- A specific study providing an international benchmark in a field where little research is available.

- Fact-based arguments to make the case for public service media, in some cases even showing how international services contribute to fulfilling their organization's remit.

- Fact-based arguments to make the case for international radio, a worthwhile resource in the light of some recent closures (for example, Radio Vlaanderen International and RAI Radio Internazionale in 2011) or dramatic downsizing (Radio Canada International in $\mathbf{2 0 1 2}$ or Radio Netherlands Worldwide in 2012).

- A unique opportunity to highlight the position of international services within public service media organizations and within the EBU community. Unlike the two previous elements, this one is useful in house. In this sense, 
we partnered with the International Broadcasting Assembly, the group that brings together the EBU's international broadcasters. This is the EBU's newest Assembly, set up in June 2015 from the former Bruges Group, which comprised mostly EBU Members plus additional participants such as RT. This did not involve a major change but allowed international broadcasters to benefit from the permanent structure of the EBU and its corporate services, such as this research. At research level, this is undoubtedly a way to increase their profile and obtain arguments to showcase their value in a context where opposition increasingly comes from the lack of metrics for measuring their performance.

Besides highlighting the value of the research, the communication was carefully planned. The questionnaires were sent out on Monday 29 February with a deadline on Friday 18 March, i.e. three working weeks. Reminders were sent every two weeks if no response had been received. If contact had been established, the waiting time for a follow-up e-mail was extended to 3 to 4 weeks depending on the case. In the e-mail to respondents, a final hook was added: mentioning the EBU's first International Broadcasting Assembly, to be held on 19 and 20 May 2016, where the results were scheduled to be presented. As many of the respondents were their corporations' delegates at that Assembly, this was a way to showcase the value of their answers and an immediate return on the effort of completing the questionnaire. The reference to the Assembly was maintained in the reminders.

\section{Some Final Lessons}

The challenges raised in this chapter are illustrative of the difficulties in researching international radio using surveys. The first challenge arose before any methodological design. There was a clash between a purely scientific categorization of international broadcasters based on theoretical models and a practical categorization based on actual practice that would enable the recipients of the survey to recognize themselves in the study. In this sense, a compromise was needed, a typical constraint of market-oriented research. This compromise tried to combine the maximum level of rigor with the pragmatism of applied research, driven by the aim of generating immediate and useful research insights.

The second challenge was usual in survey design, notably cross-cultural issues, such as different interpretations of the questions or a different level of acquiescence depending on the country. Once again, pre-testing the survey became the better strategy to fine-tune the final questionnaire. A third major challenge was the goal to have a high response rate. The higher-than-expect- 
ed response rate shows that our strategy was quite successful. Detecting the appropriate respondents and clarifying the value they will receive thanks to their cooperation seems to work; however, this strategy obviously depends on the perception of the actual value that the survey will deliver, which may vary according to the needs of the organization and their own available research, among other things.

Despite the challenges, the results of the survey demonstrate the usefulness of the method chosen. It is a unique tool to gain insights from the inside. Otherwise, these data and information are difficult to obtain as they do not tend to be publicly available because they are often considered sensitive.

The part of the survey in which the quantity and the quality of the results was less high was the forecast, to the extent that in some cases we decided not to use the results. There may be two reasons for this: first, a possible clash between the personal opinion of the respondents as practitioners, which was what they were actually asked, and the position of their organization; second, a clear lack of previous research insights, both in-house and external, that makes it difficult for them to make informed prognoses, which might be why they refused to answer those questions. In this sense, contacts with peers in other public organizations seem to be the main sources of information for many of our respondents.

As an initial piece of research within the EBU's international radio community, this survey enabled the research team to gain an understanding of the current trends in the market but also of how to handle research in this specific field and its related community. Hopefully, this first exercise will help us to improve the procedures and streamline the processes in future research projects.

\section{References}

WRTH (2016): World Radio TV Handbook. The Directory of Global Broadcasting, Oxford: WRTH Publications. 
Outro 



\section{The Future of Radio Studies}

Michele Hilmes and Mia Lindgren

\section{INTRODUCTION}

Radio has long been an invisible medium, unseen but ever present in our lives. Despite the increased visibility and materiality conferred on radio and soundwork via emergent digital platforms, radio studies as a discipline has continued to share something of the medium's invisibility within the scholarly universe, either missing completely from media studies curricula, scattered widely among different departments - communication, journalism, music, art, literature, and more - or subsumed into more generalized explorations into sound and the sonic environment.

However, the digital revolution has affected radio studies as it has other media, not only opening up the field to new forms of soundwork - podcasts, streaming radio, digital music services, online audio - but providing new sites and sources for radio and sound scholarship, as well, including online journals, newsletters and blogs ${ }^{1}$, radio curation sites $^{2}$, research databases ${ }^{3}$, permanent web interfaces for traditional radio outlets, and last but not least, audio archives. These proliferating digital platforms with their global reach have the potential to make radio studies truly transnational for the first time since Rudolf Arnheim celebrated the medium's boundary-transcending potential in 1936 before the nationalist fervors of the twentieth-century worked to confine and control it (Arnheim 1936). Now, as radio scholar Kate Lacey has written, we can not only "listen in" but "listen out," forming new connections and potential

$\mathbf{1}$ | Such as Radio Survivor (http://www.radiosurvivor.com/), Sounding Out! (https://soundstudiesblog.com/) and Hot Pod (https://www.hotpodnews.com/).

2 | For instance, the Public Radio Exchange (PRX: http://www.prx.org/) and the Third Coast International Audio Festival (http://thirdcoastfestival.org/).

3 | These include the Media History Digital Library, a database of radio (and film and television) trade publications (http://mediahistoryproject.org/) and more recently, a searchable podcast database launched by Jeremy Morris at the University of Wisconsin-Madison, Podcastre (http://podcastre.org/). 
publics that stretch geographical and cultural limitations (Lacey 2013). While this new connectivity has undoubtedly already taken place in the realms of radio production and consumption, in this chapter we examine whether it has been translated to scholarly studies of radio. We argue that it is beginning to do so, but that such translation remains in its nascent stages.

Our chapter both marks this crucial transition and seeks to inspire further exploration, pointing to opportunities for transmedia, transnational, and transdisciplinary investigations as the way ahead for radio studies. In particular, as Golo Föllmer and Alec Badenoch write in the introduction to this book, "[f]or radio scholars it aims to provide both inspiration and concrete tools for breaking through the methodological nationalism that in many ways still structures our research." In this chapter we argue for the development of new approaches to researching and teaching radio that are as malleable and accommodating as the medium itself, encompassing radio's historical depth as well as contemporary practices. We draw upon our experience as co-editors of the Radio Journal: International Studies in Broadcast and Audio Media (Intellect Press) since 2015 , which has given us a special window onto the breadth and focus of radio research today, and as co-chairs of the closing plenary session convened at the international Transnational Radio Conference in Utrecht, Netherlands, in 2016.

The chapter begins with a brief historic overview of the field of study, highlighting the role of archives in providing important access to scholars of radio. The next part delves deeper into the interdisciplinary nature of radio studies, illustrated through a mapping of the disciplinary belonging and methodologies of five years of scholarship published from 2012 to 2016 in the Radio Journal. This analysis demonstrates the breadth of practices and disciplines intersecting with the study of radio even though most studies are done within national borders. It then considers some case studies that demonstrate new developments in the field of radio studies and how these might be extended and adapted by other scholars. Finally, the chapter looks at how practice-led research methodologies are opening up pathways into radio studies for scholars and students wanting to combine the making of radio and audio content with critical analysis. We also point out some of the continuing obstacles to transnational and transdisciplinary media research, hoping to raise awareness among future generations of scholars and inspire new directions for research and instruction.

\section{Radio's MISSING History}

As noted above, 21st century radio has escaped its former definitional boundaries as well as its national ones. The uses and meanings of radio have expanded and multiplied. Yet radio's history remains largely obscured, overshadowed for decades by the expansion of television and film studies, themselves relatively 
new fields. At the very moment that radio emerged as a dominant medium mid-century, riding on the crest of two decades of innovation and recognized as the central voice of nations and peoples during World War II and the period of reconstruction that followed, television eclipsed it in the 1950s and never looked back. Radio persevered, but as a secondary medium devoted increasingly to music, woven invisibly into everyday life. Radio research and scholarship, just beginning to flourish in the 1950s, quickly took a back seat to its more visible competitors. Not until the 1990s did scholarship on radio revive, receiving further stimulation as digital forms and practices opened up the field.

The loss of a sense of radio's history, and the subsequent failure to develop a coherent set of critical tools with which to analyse and understand its unique contributions to culture and society, is particularly acute in the United States and other countries that lack a strong central public broadcaster. Commercial broadcasters had little interest in preserving their programs or in encouraging criticism and review, especially when they held no ongoing rights in the programs they broadcast: advertisers, who both produced and owned the programs, were not in the media business and did not regard their radio efforts as any more important than last year's Ovaltine sales. It is only through illegal copying and under-the-radar circulation by organizations of amateurs that US radio programs of the 30 s through the 50 s survived at all (Patterson 2016). And many of them remain locked away still, buried in uncatalogued audio-visual collections in scattered archives, quietly decaying on long-outdated tape stock though a few recent initiatives promise to do much to correct this neglect and open up the US archive to scholars around the world, as discussed below.

Public service broadcasters typically did far more to encourage critical review of radio programs - as, for instance, in the long-running BBC publication The Listener - and made greater efforts to archive their work and preserve their history, but often found themselves faced with economizing imperatives and unfortunate administrative decisions. However, public broadcasters were also more apt to revive and re-circulate their archival programs, a practice that many have now made routine and broadly accessible via digital sites. To give just one example, besides supporting its own radio drama and documentary traditions even after the advent of television, the BBC has done more to keep historical American radio drama alive than any US broadcaster, frequently offering new interpretations of classic American soundwork and providing an internationally-accessible platform for listeners to hear them ${ }^{1}$. This points to the fact that, while research tends to concentrate on national radio traditions, transnational flows of audio influence and culture have existed since the earliest days and can be found in the archives.

1 | BBC Radio Four Extra, http://www.bbc.co.uk/radio4extra. 


\section{INTERDISCIPLINARITY}

Radio studies is by nature interdisciplinary. It attracts scholars from a range of different fields, studying radio through diverse theoretical and methodological approaches. Rather than attracting a clearly defined group of 'radio scholars' per se, radio can often be a focal point for academics who see themselves primarily as belonging in other areas. Although there are some institutional places housing a more substantial group of radio scholars, such as the Centre for Media History at Macquarie University in Sydney, in most cases studying radio can be an individual pursuit with few local colleagues.

To illustrate the interdisciplinary aspect of radio scholarship we undertook an audit of a sample of recent scholarship published in the Radio Journal, mapping the different methodological approaches used and different academic disciplines involved. The aim of this research is to measure the interdisciplinarity (in both volume and range) that characterizes current radio studies. Radio Journal's current co-editors are based in the USA and in Australia, one with a research background based in Journalism, the other in Media Studies, reflecting the journal's international and interdisciplinary aspirations. Writing in the introduction to the first issue in 2003, the founding editor Ken Garner acknowledged this agenda in choosing a title that includes nods to radio, audio, broadcast and international studies. "A mischievous reading of our full title could suggest we want to have our cake and eat it too. [...] A critic might comment that we are not so much sitting on the fence, as trying to face all four points of the compass simultaneously" (Garner 2003: 5). Radio Journal publishes two issues per year featuring approximately six new articles in each. The sample we selected for study included all 57 original articles (editorials, book reviews and conference reports were excluded) published in the journal over a five-year period (2012-2016), which covered the editorial changeover from former editor Tim Wall to the current team of Hilmes and Lindgren.

Reading articles, identifying their methodologies and nominating academic disciplines is inevitably a subjective and somewhat arbitrary process. This is further complicated by the hybrid nature of all media (especially in a digital era) and the diverse origins of media and communications as a broad topic of scholarship, which differs greatly from institution to institution and from country to country. For example, here psychoanalysis is counted as a methodology, but for some academics and institutions it is a field unto itself. Similarly, radio studies and screen studies are counted as distinct disciplines, but for some scholars they are more routinely thought of as sub-sets of media, cultural or literary studies programs. (Never mind the additional debate about what to call a field of study in the first place.)

We attempted to counter-balance the subjective nature of this approach in a number of ways. Firstly, since the premise of this audit was to assess the extent 
of radio studies' interdisciplinary nature, the articles were tagged with as many disciplines (e.g. media studies and education) or methodological approaches (e.g. psychoanalysis and focus groups) as were applicable. Secondly, we gave precedence to the methodological and disciplinary contexts explicitly self-identified by the authors themselves, in the body of the article, in their biographies and author-provided keywords, and implicitly identified in literature reviews, theoretical frameworks and list of references.

The articles primarily fell into two or more of the following broad disciplinary categories: radio studies, media studies, journalism, critical/cultural studies (including studies of popular music, gender, and race), historical studies, education and communications. Other disciplines identified included linguistics, management, economics and commerce, and psychology.

\begin{tabular}{|l|r|}
\hline DISCIPLINES & TOTALS \\
\hline RADIO STUDIES & 32 \\
MEDIA STUDIES & $3 \mathbf{I}$ \\
OTHER & II \\
HISTORICAL STUDIES & II \\
CRITICAL/CUITURAL STUDIES & IO \\
COMMUNICATIONS & 8 \\
JOURNALISM & 7 \\
EDUCATION & 4 \\
\hline GRAND TOTAL & II4 \\
\hline
\end{tabular}

Table 1: Overview of the most common disciplinary categories of articles published in the Radio Journal 2012-2016.

The methodological approaches present in the sample encompass quantitative analysis (varied); historical analysis (mostly involving new archival research); qualitative methodologies comprising one-on-one interviews, focus-groups, surveys and case studies; studies of production practices including practicebased research, participant observation and media ethnography; studies of content and aesthetics including psychoanalysis, textual analysis (close study of a radio program, podcast or their para-texts ${ }^{2}$ ), content analysis (study of phenomena across a large sample of texts); and other analytical approaches selfidentified by the authors but unique to their article including 'self-ethnography', 'cluster analysis' and 'website audit'. 'Media analysis (general)' was used to identify extensive critical analysis of radio industries, aesthetics, audiences

2 | Para-texts includes all associated extra-texts interconnected with a primary text (eg press-releases, websites, social media, fan media etc). 
and social contexts which was not based on new empirical data or close study of content.

\begin{tabular}{|l|l|}
\hline METHODOLOGIERS/APPROACHES & TOTALS \\
\hline INTERVIEWS & 29 \\
MEDIA ANALYSIS (GENERAI) & 15 \\
QUANTITATIVE ANALYSIS & 9 \\
TEXTUAL ANAIYSIS & 8 \\
CASE STUDIES & 8 \\
HISTORICAL ANAIYSIS & 7 \\
FOCUS GROUPS & 6 \\
SURVEYS & 6 \\
OTHER & 5 \\
CONTENT ANAIYSIS & 5 \\
PRACTICE-BASED RESEARCH & 5 \\
DISCOURSE ANALYSIS & 4 \\
PSYCHOANALYSIS & 4 \\
MEDIA ETHNOGRAPHY & 4 \\
PARTICIPANT OBSERVATION & 3 \\
SELF-ETHNOGRAPHY & I \\
\hline GRAND TOTAL & II \\
\hline
\end{tabular}

Table 2: list of methodological approaches identified in studies published in the Radio Journal 2012-2016.

The audit also captured authors' institutional affiliations and country location, which provide a sense of the geographic distribution of research. It clearly demonstrates the preponderance of scholarship emerging from the UK and Australia, followed by the US, Spain and Italy, as illustrated by the table below. This raises questions about where studies of radio from other countries are published, particularly those from non-English speaking countries and which strategies can be employed to support more linguistically and geographically diverse scholarship in international journals such as the Radio Journal. These are important questions for the community of radio scholars to explore further.

\begin{tabular}{l|l|}
\hline COUNTRIES & TOTAL \\
\hline UK & \multicolumn{1}{|c|}{ I9 } \\
\hline GRAND TotAL & 69 \\
\hline
\end{tabular}




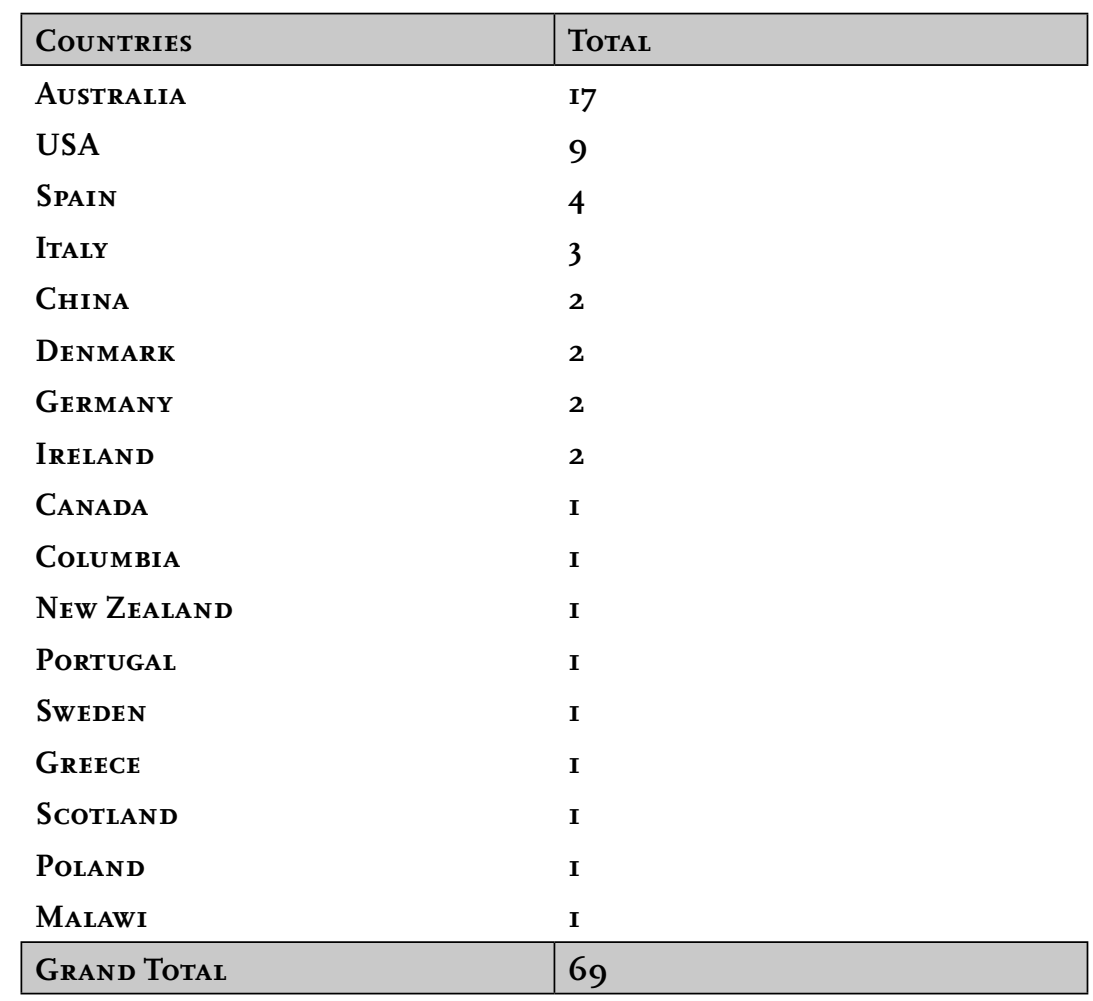

Table 3: list of authors' institutional affiliations and country location for articles published in the Radio Journal 2012-2016.

Authors and their affiliations were weighted equally, regardless of co-authorships. It is noteworthy that the majority of articles are single-authored. Only one article had more than two authors, having emerged out of a large crossEuropean research project with ten authors from ten different institutions and eight countries. This article titled "Radio formats and social media use in Europe -28 case studies of public service practice” was excluded from the final tally because it was a singular phenomenon; however, it is worth noting its significance in the context of this book identifying the relevance of transnational research of radio. The very fact that it is an outlier is perhaps indicative of the need to encourage more large-scale transnational collaborations.

Based on a selection of articles from only one English-language journal, this sample is in no way comprehensive. It does not, for example, include research being published in book form, as conference papers, in other dedicated radio and broadcast journals, in non-dedicated media and communication journals (where one might presume a high degree of interdisciplinarity) and of course, in audio form (since some researchers are also practitioners). It is, how- 
ever, a large sample of new research published in one of the very few dedicated peer-reviewed international journal platforms for radio-related scholarship. It includes 57 articles by more than 65 different authors working across more than 50 institutions and 20 countries. As such it is an indicative sample of the interdisciplinary nature of the field of study and the variety of methodological practices scholars employ in pursuing their study of radio. It also illustrates the individual nature of writing about radio, with the lion's share of articles singleauthored. Some recent European collaborations point to the potential for joint transnational research approaches; however, judging from scholarship in Radio Journal over the past five years, this has not been common practice.

\section{Transnationalizing Radio History: Methods AND TOOLS}

New digital archives are opening up the borders of radio studies like never before. Though still in their early stages, digital sound sites that not only preserve radio heritage but make transnational access an immediate, casual event (compared to arduous visits to physical archives still largely necessary) have provoked ambitious, large-scale projects that further promise to place sound on an equivalent status as visual evidence in world cultural history. The LARM Radio Research Archive in Denmark (Statsbiblioteket, n.d.), the Radio Preservation Task Force in the US (Library of Congress, n.d.), the pan-European Europeana Sounds project (Europeana Sounds, n.d.) are just a few projects aimed at preserving and making accessible sound histories formerly locked behind national and institutional walls. Other digital innovations highlight the perseverance of contemporary radio as a live, streaming medium, such as the recently-launched Radio Gardenz featuring a clickable globe that allows access to current broadcasts around the world. And taking advantage of the visual materiality that digital platforms add to sound media, Radio Atlas4 brings us something long desired by radio scholars and listeners everywhere: carefully crafted subtitled radio, translating radio programs produced in various languages into English, as their original sound plays on digital screens. As more cross-translations occur, this gives us for the first time the ability to hear an original production while being able to understand its meaning. It also begins to open up radio and soundwork to the deaf and hard-of-hearing community, an enormous social contribution.

The field of radio scholarship is clearly changing. In terms of outlets for publication, until recently only two academic journals existed that focused spe-

3 | http://radio.garden/

4 | http://www.radioatlas.org/ 
cifically on radio-centered research: the Radio Journal (founded in 2003 by the UK-based Radio Studies Network, now a part of the Media, Communications, and Cultural Studies Association of the UK [MeCCSA]) and the Journal of Radio \& Audio Media (founded in 1992 as the Journal of Radio Studies, a publication of the US-based Broadcast Education Association). Two recent online open-access journals have appeared dedicated to analyses of radio and audio forms: RadioDocReview critiquing radio documentaries/podcasts and the European Communication Research and Education Association (ECREA) publication Radio, Audio and Society. Increasing literacy about radio production is encouraged through online websites and resources dedicated to understanding radio production, eg. HowSound's (PRX, 2017) podcast about radio storytelling and website portals like Transom.org (Transom, n.d.) providing useful how-to guides to production as well as critical analyses of productions. Traditionally print-based outlets such as New York Times and other print/online publications are turning to audio to innovate and expand to new audiences. They recognise the power of hearing stories told in audio forms and the growing interest in audio as premium communication platform:

There's something about audio: a growing trend in media, it offers the distinctive intimacy of hearing journalists and others giving voice to their findings, opinions and experiences. (New York Times, 2017)

According to the British Library's Future of Radio report (2016), radio listening remains steady and has not been affected as intensely as have audiences for the digitally disrupted newspaper, television and music industries (British Library 2016: 8). Furthermore, the experts consulted for the 2016 report believe this trend will continue with no major reduction in consumption of speech and music programming in the next 20 years (British Library 2016: 8).

As outlined in the audit above, studies of a single national space have dominated recent submissions to the Radio Journal, but it is significant that in our special issue on podcasting (April 2016), a far more transnational approach applied across the majority of work published. However, there is much still to be discovered by deep focus on national audio cultures and institutions, as exhibited particularly well in Enric Castelló and Marta Montagut's 2015 article on Documentos RNE, a documentary series on Spanish National Radio that uses archival radio elements to construct - and to challenge - national memory of historical events (Castelló and Montagut 2015: 5-21). Such a meta-historical approach to radio history - critically re-examining the radio archive and rearticulating it to current concerns and interpretations - provides an example of a research method that is at once national and transnational: it reveals deep meanings in a specific national media culture while providing an example of how such an analytical approach can be used by researchers in other national 
and institutional situations. Other researchers focus on ways of analysing the persistent ephemerality of the radio experience, such as Katrine Pram-Nielsen and Jacob Kreutzfeld's interrogation of newly-accessible digital archives to provide insights into a moment of live radio experimentation in London in 1998. Combining an analysis of archival metadata itself, alongside preserved memories and recordings of never-repeated community events in sound, their research provides a model for a new way of connecting the cultural space of radio to the study of the past (Nielsen and Kreutzfeldt 2016: 159-175). Physical events can evoke transnational experience as well, as Zita Joyce explores in her article on the way that community radio stations responded to the Christchurch, New Zealand earthquakes of 2010 and 2011, illuminating radio's frequently crucial role in emergency situations around the globe (Joyce 2015: 57-73). While such articles may focus on a particular national or regional context, they highlight essential qualities of radio's cultural and social roles that apply across traditions and borders. Their chosen methodologies, shared with a transnational community of scholars, help to build a toolbox of critical methods long lacking in this neglected field. Further, by their emphasis on the processes and conditions of sound-based communication - the semiotic flexibility, ephemerality, and timebased 'live' nature of radio broadcasting that persists into the digital age - they point to the necessity of innovating new ways to understand and to study radio as it exists today.

\section{New Practice Pathways to the Study of Radio and INSTITUTIONAL OBSTACLES}

One of the most notable developments in the pedagogy of radio and soundwork is the increase of practice-led (also referred to as practice-based) research frameworks that may provide potential future pathways for the field. In Australia, practice-led PhDs in the humanities have been growing fast, with an 80 per cent increase in enrollment in Australian universities between 1997 and 2007 (Adams et al, 2015). This movement builds on a recent definition by the Australian Research Council of what constitutes research:

Research is defined as the creation of new knowledge and/or the use of existing knowledge in a new and creative way so as to generate new concepts, methodologies, inventions and understandings. This could include synthesis and analysis of previous research to the extent that it is new and creative. (Australian Research Council 2015: 3)

Along these lines, students can opt to generate research by producing indepth radio and audio pieces, accompanied by an exegesis where the practical component is critiqued and analyzed within a relevant theoretical content. 
This growing interest in practice-led Masters and PhD studies indicates that we might see the next generation of radio and sound scholars adopt more diverse forms of scholarly work. In the US, Northwestern University in Chicago has recently introduced a Masters program in Sound Arts and Industries, the first new sound-based graduate program to emerge in decades, emphasizing both practice and research. Older graduate programs, mostly in Journalism schools, have revamped their radio and audio curriculum to keep up with renewed student interest in the field.

In Australia, development of a recognized research assessment framework has opened the research door for scholars and students wanting to explore radio by combining practice and theoretical analysis, where the production of radio documentaries, for example, becomes a site for exploration as well as a nontext based platform for sharing research (Lindgren 2014). The incorporation of practice as a recognized aspect of research in Australia was strengthened and articulated in the 2015 research statement by the Journalism Education and Research Association of Australia (JERAA) stating,

Journalism practice is the process by which information is independently researched, gathered, analysed, synthesised and published, or by which innovative approaches to journalism are developed. The Excellence in Research for Australia framework (ERA) acknowledges in-depth, original journalism practice and publication as equivalent to traditional research outputs. (JERAA, 2017)

The Australian example is not, however, uncomplicated for radio studies. The above statement covers journalism but, as highlighted in the audit of 57 Radio Journal articles presented above, journalism is not one of the most common disciplinary lenses used in radio research. To complicate the situation in Australia further, the research assessment framework separates the study of journalism and creative arts on one side from communication, media and cultural studies on the other through different research codes. This type of research assessment exercise is well-known to scholars in the UK (although with a different model from Australia), where it is referred to as Research Excellence Framework (REF).

This administratively-created separation between research fields in Australia and elsewhere becomes a sorting mechanism for how research performance is assessed and ranked. The assessment is important for individual scholars and for institutional reputation, affecting the ability to attract research funding within a particular field. Furthermore, the Australian research framework splits studies and practice, locating practice-led work in journalism and creative arts with its provisions for recognizing practice as research, whereas the most relevant field for radio studies, media studies, does not commonly include practice-led research in its research assessment. These disparities clearly point 
to a need for more transnational conversation about radio's place in the evolving academic universe, particularly in post-graduate instruction and training.

\section{CONCLUSION}

Although the Australian example above is nation-based, it does highlight more generally some of the challenges faced by a field of study dispersed across disciplines and methodologies, particularly in a rapidly changing media ecology. It also reminds us of the value of creating and maintaining strong scholarly networks and publishing opportunities that encourage interdisciplinary and multi-modal studies of soundwork. It prompts us to reflect on what we understand radio studies to be and how we imagine the field of study might develop in a fast-moving media environment. How can we continue to develop the field? What mechanisms are required to support a vibrant radio studies field in a fragmented and changing environment? Rather than diminishing in popularity, radio, always the most versatile of media, continues to showcase agility in adapting to change. The podcasting boom is one example, illustrating a growing interest in forms of audio narratives from audiences, practitioners and scholars. It appears radio is holding strong, assisted by digital technologies making radio and audio content sharable to transnational listeners. This chapter has suggested that despite the obstacles, there is plenty of potential for radio scholars to utilise this changing environment to undertake innovative transnational and cross-institutional research that can extend our knowledge of this dynamic medium.

\section{REFERENCES}

Arnheim, Rudolf (1936): Radio: An Art of Sound. Boston: Da Capo.

Australian Research Council (2015): "State of Australian University Research." Volume 1, ERA National Report, March 2, 2018, http://www.arc.gov.au/sites/default/files/filedepot/Public/ERA/ERA\%202015/ERA_2015_National_Report/ ERA2015_Introduction.pdf

British Library (2016): “The Future of Radio.” March 2, 2018, https://www.bl.uk/projects/the-future-of-radio

Castelló, Enric/Montagut, Marta (2015): "Radio, memory and conflict: Reconstructing the past in Documentos RNE”. In: The Radio Journal: International Studies in Broadcast and Audio Media, 13/1-2, pp. 5-21.

Europeana Sounds (n.d.): “Europe's sound heritage at your fingertips.” March 2, 2018, http://www.europeanasounds.eu/about 
Garner, Ken (2003): “Editorial.” In: the Radio Journal: International Studies in Broadcast and Audio Media,1/1, pp. 5-7.

Journalism Education \& Research Association of Australia [JERAA], (2017): "Research.” March 2, 2018, http://jeaa.org.au/research/

Joyce, Zita (2015): "RadioQuake: Getting back 'on air' after the Christchurch earthquakes." In: The Radio Journal: International Studies in Broadcast and Audio Media, 13/1-2, pp. 57-73. Lacey, Kate (2013): Listening Publics: The Politics and Experience of Listening in the Digital Age, London: Polity.

Library of Congress (n.d.): "National Recording Preservation Plan.” March 2, 2018, https://www.loc.gov/programs/national-recording-preservation-plan/about-thisprogram/radio-preservation-task-force/

Lindgren, Mia (2014): “Radio journalism as research—a Ph.D. model.” In: The Radio Journal: International Studies in Broadcast and Audio Media, 12/1-2, pp. 169 - 182. Lyndall, Adams/Kueh, Christopher/ Newman-Storen, Renée/Ferguson, Neil (2015): "Capturing Creative Practice, study of HDR student at ECU in Perth." March 2, 2018, http://acuads.com.au/wp-content/uploads/2015/O4/Adams-Kueh-et-al.pdf

New York Times (2017): "Off the Press." a monthly newsletter for Times subscribers, February. Patterson, Eleanor (2016): "Radio Redux: The Persistence of Soundwork in the PostNetwork Era." PhD Dissertation, University of Wisconsin-Madison.

Pram-Nielsen, Katrine/Kreutzfeld, Jacob (2016): "The Resonance 107.3 FM radio art collection: Towards an archive methodology of radio as resonance.” In: The Radio Journal: International Studies in Broadcast and Audio Media, 14/2, pp. 159-175.

PRX (2017): "HowSound." March 2, 2018, https://www.prx.org/series/32401-howsound Statsbiblioteket (n.d.) LARM Audio Research Archive. https://en.statsbiblioteket.dk/ about-the-library/news/larm-audio-research-archive

Transom (n.d.): “A Showcase and Workshop for New Public Radio.” March 2, 2018, http://transom.org/ 
